\title{
Caracterização microquímica de sílicas de Stöber e de seus produtos de adsorção
}

\section{Carlos Alberto Rodrigues Costa}

\section{USP/IFSC/SBI}



8-2-001621

\begin{abstract}
Tese apresentada à Área Interunidades em Ciência e Engenharia de Materiais, da Universidade de São Paulo, para obtenção do título de Doutor em Ciências e Engenharia de Materiais.
\end{abstract}

Orientador: Prof. Dr. Fernando Galembeck 
Costa, Carlos Alberto Rodrigues

"Caracterização microquímica de sílicas de Stöber e de seus produtos de adsorção" Carlos Alberto Rodrigues Costa - São Carlos, 2004

Tese (Doutorado) - Interunidades Ciência e Engenharia de Materiais da Universidade de São Paulo, 2004 - páginas: 191

Área: Ciência e Engenharia de Materiais

Orientador: Prof. Dr. Fernando Galembeck

1. Sílicas de Stöber

1. Título 


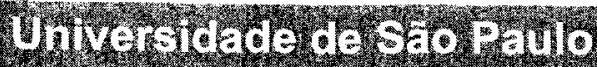

Othera e Engenhara do Marertas
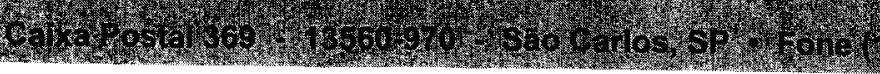

MEMBROS DA COMISSÃO JULGADORA DA TESE DE DOUTORADO DE CARLOS ALBERTO RODRIGUES COSTA APRESENTADA À ÁREA INTERUNIDADES CIÊNCIA E ENGENHARIA DE MATERIAIS, UNIVERSIDADE DE SÃO PAULO, EM 30-08-2004.

COMISSÃO JULGADORA:

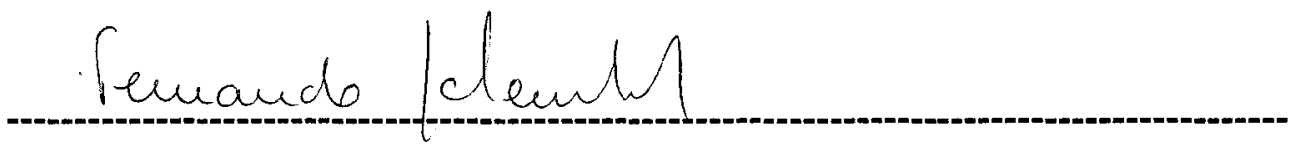

Prof. Dr. Fernando Galembeck (Orientador e Presidente) - UNICAMP
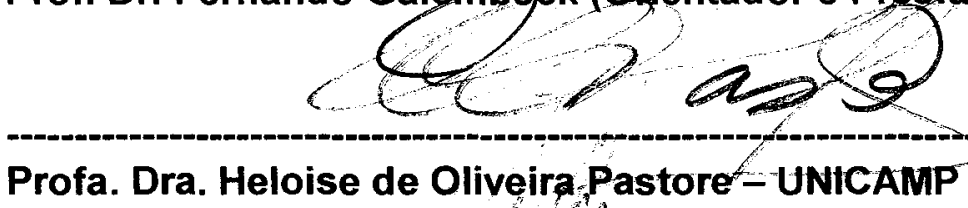

Dr. Rubens Bernardes Filho - EMBRAPA

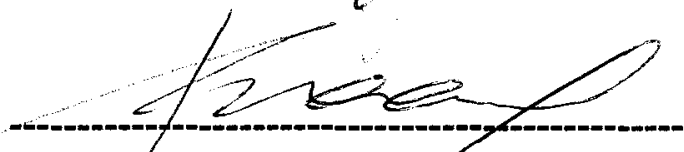

Prof. Dr. Francisco Carlos Nart - IQSCIUSP



Prof. Dr. Antonio Carlos Hernandes - IFSC/USP 
Ao meu pai, in memoriam, À minha mãe, tia, esposa e filha, que com carinho e compreensão me estimularam nesta jornada. 


\section{AGRADECIMENTOS}

Ao prof. Dr. Fernando Galembeck, pela dedicada orientação e presença constante durante a realização deste trabalho.

Aos amigos do grupo de pesquisa, pela convivência e contribuição ao projeto, em especial à Maria do Carmo, e ao Carlos Leite pelo meu aprendizado nas técnicas de microscopia eletrônica. Carlos.

À Área de Interunidades em Ciência e Engenharia de Materiais da USP - São

Ao Instituto de Química da UNICAMP, onde foram desenvolvidas as atividades experimentais.

À FAPESP, pela bolsa concedida.

À todos que de alguma maneira colaboraram na realização deste trabalho. 


\section{INTRODUÇÃO GERAL}

\section{PARTE I - SÍNTESE E CARACTERIZAÇÃO MICROQUÍMICA DE PARTÍCULAS DE SÍLICA DE STÖBER}

\section{INTRODUÇÃO}

1.1. PARTÍCULAS DE SÍLICA DE STÖBER

1.1.1. Síntese das partículas de sílica

1.1.2. Cinética

1.1.3. Efeito do solvente

1.1.4. Efeito do $\mathrm{pH}$

1.1.5. Catálise por base

1.1.6. Efeito da presença de sais

1.1.7. Mecanismo

1.2. ESPECTROSCOPIA DE CORRELAÇÃO DE FÓTONS (PCS)

1.2.1. Teoria de operação

1.2.2. Correlação

1.3. MICROSCOPIA ELETRÔNICA DE TRANSMISSÃO (TEM)

1.3.1. Preparação da amostra

1.3.2. Contraste de amplitude

3.3.3. Contraste de fase

1.3.4. Contraste de difração

1.3.5. Perda de energia

1.4. MICROSCOPIA ELETRÔNICA POR EMISSÃO DE CAMPO (FESEM)

1.4.1. Elétrons secundários

1.5. MICROSCOPIA DE VARREDURA POR SONDA (SPM)

1.5.1. Microscopia de força atômica de não-contato

1.5.2. Microscopia de força elétrica (EFM).

1.5.3. Microscopia de varredura de potencial eletrostático (SEPM)

1.5.4. Comparação entre SEPM e EFM

1.6. ENSAIOS MECÂNICOS

1.6.1. Dureza

1.6.2. Tenacidade à fratura

\section{OBJETIVOS}

\section{MATERIAIS E MÉTODOS}

3.1. DESCRIÇÃO DOS REAGENTES

3.2. EFEITO DA POTÊNCIA DO ULTRA-SOM E DA TEMPERATURA NA FORMAÇÃO DAS PARTÍCULAS DE SÍLICA

3.3. PREPARAÇÃO DAS PARTÍCULAS DE SÍLICA

3.4. CONTEÚDO DE SÓLIDOS

3.5. ESPECTROSCOPIA DE CORRELAÇÃO DE FÓTONS (PCS) 3.5.1. Preparação das amostras

3.6. MICROSCOPIA ELETRÔNICA DE TRANSMISSÃO (TEM) 3.6.1. Preparação das amostras

3.7. MICROSCOPIA ELETRÔNICA POR EMISSÃO DE CAMPO (FESEM)

3.7.1. Preparação das amostras

3.8. MICROSCOPIA DE VARREDURA POR SONDA (SPM)

3.8.1. Preparação das amostras

3.9. ESPECTROS NO INFRAVERMELHO

3.9.1. Preparação das amostras 
3.10. PREPARAÇÃO DOS MONOLITOS DE PARTÍCULAS DE SÍLICA

3.11. MICROSCOPIA ÓPTICA

3.12. DUREZA VICKERS

3.13. TENACIDADE À FRATURA

\section{RESULTADOS}

4.1. EFEITO DA POTÊNCIA DO ULTRA-SOM E DA TEMPERATURA NA FORMAÇÃO DAS PARTÍCULAS

4.2. RENDIMENTOS DAS REAÇÕES

4.3. ESPALHAMENTO DE LUZ

4.4. ESPECTROSCOPIA DE CORRELAÇÃO DE FÓTONS (PCS)

4.5. CARACTERIZAÇÃO MORFOLÓGICA POR TEM 4.5.1. Contraste de amplitude 4.5.2. Estabilidade das amostras de sílica sob o feixe de elétrons

4.6. CARACTERIZAÇÃO MORFOLÓGICA POR FESEM 4.6.1. Imagens obtidas com elétrons secundários

4.7. CARACTERIZAÇÃO TOPOGRÁFICA POR SPM. 4.7.1. Microscopia de força atômica de não-contato

4.8. DIÂMETRO DAS PARTÍCULAS

4.9. ESPECTROS DE PERDA DE ENERGIA DE ELÉTRONS (EELS)

4.10. ESPECTROS NO INFRAVERMELHO

4.11. IMAGENS ELEMENTARES (ESI-TEM)

4.12. COMPARAÇÃO ENTRE SEPM E EFM.

4.13. MICROSCOPIA DE VARREDURA DE POTENCIAL ELETROSTÁTICO (SEPM)

4.14. CARACTERIZAÇÃO DOS MONOLITOS DE PARTÍCULAS DE SÍLICA

4.14.1. Dureza Vickers

4.14.2. Tenacidade à fratura

\section{DISCUSSÃO}

5.1. INTUMESCIMENTO

5.2. PLASTICIDADE

6. CONCLUSÕES

\section{PARTE II - SORÇÃO EM SÍLICA DE STÖBER: UM ESTUDO MICROQUÍMICO}

\section{INTRODUÇÃO}

1.1. SORÇÃO

1.1.1. Sorção de ions

1.1.1.1. Sorção de $\mathrm{NaCl}$

1.1.2. Adsorção de polímeros

1.1.2.1. PNIPAM

1.1.3. Adsorção de surfactantes

1.2. INTERFACES COM CARGAS ELÉTRICAS

\section{OBJETIVOS}

\section{MATERIAIS E MÉTODOS}

3.1. PARTÍCULAS DE SÍLICA 
3.2. SORÇÃO DE CO-SOLUTOS

3.2.1. Sorção de $\mathrm{NaCl}$

3.2.2. Adsorção de PNIPAM

3.2.3. Adsorção de surfactantes

4. RESULTADOS

4.1. PARTÍCULA DE SÍLICA

4.2. SORÇÃO DE NaCl

4.3. ADSORÇÃO DE PNIPAM

4.4. ADSORÇÃO DE SURFACTANTES

4.4.1. Adsorção de SDS

4.4.2. Adsorção de CTAB

4.4.3. Adsorção de RENEX 300

5. DISCUSSÃO

5.1. PARTÍCULAS DE SÍLICA

5.2. ADSORÇÃO DE NaCl

5.3. ADSORÇÃO DE PNIPAM

5.4. ADSORÇÃO DE SURFACTANTES

5.4.1. Adsorção de SDS

5.4.2. Adsorção de CTAB

5.4.3. Adsorção de RENEX

6. CONCLUSÕES

7. CONSIDERAÇÕES FINAIS

8. REFERÊNCIAS BIBLIOGRÁFICAS 


\section{LISTA DE FIGURAS}

Figura 1. Representação das espécies químicas vizinhas ao Si. 5

Figura 2. Polimerização da sílica. (A) Em solução ácida, ou na presença de sais, as partículas agregam-se em uma rede tridimensional e formam géis (B) Em solução básica as partículas crescem em tamanho e decrescem em número. 6

Figura 3. Modelo do estágio inicial da formação de partículas a partir da condensação monomérica.

Figura 4. Microscópio eletrônico de transmissão ....................................................................... 12

Figura 5. Geometria da difração dos elétrons.

Figura 6. Ilustração esquemática dos padrões de difração de amostras com diferentes cristalinidades: (a) monocristalino, (b) policristalino, (c) não-cristalino e difratogramas reais obtidos em amostras de (d) ouro e ouro depositado sobre vidro e (e) vidro e ouro depositado sobre vidro.

Figura 7. (A) Esquema de interação de um feixe de elétrons e os átomos de uma amostra.

(B) Esquema do espectrômetro utilizado para formar imagens de perda de energia dos elétrons (ESI).

Figura 8. Excitações eletrônicas em sólidos: (a) transições intrabandas, (b) transições interbandas, (c) plasmons e (d) transições de camadas internas.

Figura 9. llustração do caminho percorrido por um elétron de um feixe normal incidente, a uma distância $x$ do centro de uma partícula de raio $r$, depositada sobre um substrato



Figura 10. Microscópio eletrônico de varredura por emissão de campo................................... 28

Figura 11. Microscopia de força atômica de não contato. ........................................................32

Figura 12. As varreduras de protuberâncias de esferas coalescidas fornecem medidas corretas no plano $x, y$, porém no eixo $z$ os valores obtidos são menores que os reais $\left(\mathrm{z}_{\mathrm{i}}<\mathrm{z}_{\mathrm{r}}\right)$

Figura 13. As varreduras de protuberâncias individuais produzem medidas maiores que as reais no plano $x, y\left(d_{r}<d_{i}\right)$, mas produzem valores corretos no eixo $z$. ....................... 33

Figura 14. (a) Imagens de AFM e EFM adquiridas em diferentes alturas da superfície. (b) As forças de van der Waals predominam em pequenas alturas ( $\cong 10 \mathrm{~nm})$, e a força

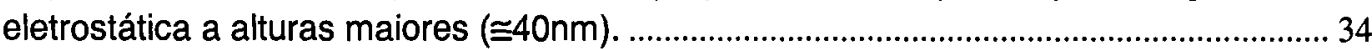

Figura 15. Microscopia de Varredura de Potencial Eletrostático............................................ 37

Figura 16. llustração de uma varredura de partículas carregadas negativamente, circundadas por cargas positivas.

Figura 17. Ilustração das diferentes alturas de varredura nas técnicas de EFM e SEPM..... 39

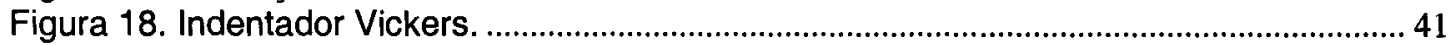

Figura 19. Relação entre a esfera e a pirâmide de indentação Brinell e Vickers.......................42

Figura 20. llustração de fissuras produzidas por uma indentação Vickers.............................45

Figura 21. Foto obtida com fundo escuro e iluminação indireta, enquadrando a região central de seis frascos, colocados lado a lado. O primeiro frasco contém água bidestilada $e$ deionizada, e os demais contêm as dispersões $A, B, C, D$ e E, respectivamente............. 53

Figura 22. Espalhamento de luz gerado pela incidência de um laser de $5 \mathrm{~mW}$ e $532 \mathrm{~nm}$, em frascos com água (bidestilada e deionizada) e as dispersões A,B,C,D e E. A fonte está à esquerda dos frascos. ................................................................................................. 54

Figura 23. Distribuição dos diâmetros das partículas da dispersão D, diâmetro efetivo, polidispersividade, taxa média de contagem, qualidade da amostra e tempo de aquisição.

Figura 24. Imagens de TEM (campo claro) dos filmes preparados com submonocamadas de partículas de sílica das dispersões $A, B, C, D$ e E.

Figura 25. Imagens de campo claro de um mesmo campo da amostra preparada com a dispersão $D$. Esquerda: após 5 minutos de exposição ao feixe de elétrons. Direita: após 120 minutos de exposição ao feixe de elétrons...

Figura 26. Imagens de FESEM (elétrons secundários) dos filmes preparados com submonocamadas de partículas de sílica das dispersões A,B,C,D e E.

Figura 27. Imagens de AFM de não contato (topografia) dos filmes preparados com multicamadas de partículas de sílica das dispersões $A, B, C, D$ e $E$. 
Figura 28. Diâmetros médios das partículas de sílica das dispersões $A, B, C, D$ e $E$, determinados em diferentes ambientes.

Figura 29. Espectro de perda de energia da borda de absorção da camada $L_{2,3}$ do silício da amostra preparada secando a dispersão E. .......................................................................6. 65

Figura 30 . Espectro de perda de energia da borda de absorção da camada $K$ do oxigênio da



Figura 31. Espectro de perda de energia da borda de absorção da camada $\mathrm{K}$ do carbono da amostra preparada secando a dispersão E. ....................................................................... 66

Figura 32. Espectro de perda de energia da borda de absorção da camada $\mathrm{K}$ do nitrogênio da amostra preparada secando a dispersão E. ...................................................................6 66

Figura 33. Espectro de perda de energia da borda de absorção da camada $\mathrm{K}$ do sódio da amostra preparada secando a dispersão $\mathrm{E}$.

Figura 34. Espectro de perda de energia da borda de absorção das camadas $L_{2}$ e $L_{3}$ do cálcio da amostra preparada secando a dispersão E.

Figura 35. Espectros de perda de energia das amostras preparadas por secagem das dispersões A,B,C,D e E. Os espectros estão normalizados em relação ao pico de 547 eV da borda de absorção da camada $K$ do oxigênio.

Figura 36. Espectros de absorção dos filmes preparados a partir da secagem das dispersões $A, B, C, D$ e E sobre janelas de $\mathrm{BaF}_{2}$, normalizados em relação ao pico de absorção das ligações Si-O-Si $\left(1100-1000 \mathrm{~cm}^{-1}\right)$.

Figura 37. Espectros da Figura 36, porém deslocando a linha de base em relação à origem no intervalo de $4000-2500 \mathrm{~cm}^{-1}$. A seta indica o pico de absorção das ligações $\mathrm{C}-\mathrm{H}$ $\left(3000-2900 \mathrm{~cm}^{-1}\right)$.

Figura 38. Imagens de campo claro e mapas elementares de $\mathrm{O}$ e Si de um filme preparado a partir da secagem da amostra $D$.

Figura 39. Imagens elementares de carbono das partículas de sílica..................................... 71

Figura 40. Imagens de EFM e SEPM de diferentes áreas da superfície de um filme de partículas de sílica, com espessura de aproximadamente $8 \mu \mathrm{m}$, preparado por secagem da dispersão C.

Figura 41. Imagens topográficas e de SEPM de filmes formados por secagem das amostras $A, B$ e $C$.

Figura 42. Imagens topográficas e de SEPM de filmes formados por secagem das amostras De E

Figura 43. Histogramas de potenciais das imagens de SEPM das amostras B e D, e perfis de topografia e SEPM adquiridos em uma mesma linha.

Figura 44. Ilustração da heterogeneidade da distribuição de cargas em função do tamanho das partículas: as partículas menores são mais heterogêneas que as maiores............. 77

Figura 45. A imagem de SEPM mostra a presença de cargas positivas entre partículas de cargas negativas, o que permite que durante a secagem as partículas se aproximem $e$ formem filmes densamente empacotados.

Figura 46. Fotos de (1) topo e (2) elevação dos monolitos preparados a partir da secagem das dispersões $A, B, C, D$ e E, respectivamente. As fotos foram obtidas com fundo escuro e iluminação indireta.

Figura 47. Micrografias das superfícies dos monolitos da Figura 46, obtidas em um microscópio óptico com luz refletida.

Figura 48. Representação esquemática de formação de ponte. .............................................90

Figura 49. Configuração de um homopolímero adsorvido: cauda, alça e trem........................90

Figura 50. Estrutura química do PNIPAM.

Figura 51. Esquema de adsorção de surfactantes em superfícies hidrofílicas e hidrofóbica, mostrando a conformação do surfactante nestas superfícies. A, B, C, D e E mostram os diferentes estágios de adsorção durante a secagem de uma solução de surfactante... 94

Figura 52. O esquema ilustra a formação de formação de uma micela na concentração crítica micelar (c.m.c.). A adsorção deve ocorrer também nas paredes do recipiente. $O$ arranjo não é mostrado pois depende da hidrofilicidade da superfície.

Figura 53. Esquema da separação de cargas em uma dispersão de partículas de sílica. Os cátions $\mathrm{NH}_{4}^{+}$são provenientes da amônia e o $\mathrm{Na}^{+}$e $\mathrm{Ca}^{2+}$ da vidraria utilizada.............. 98

Figura 54. llustração das forças entre as partículas de uma dispersão em função da força iônica do meio. A presença de contra-íons diminui a repulsão eletrostática entre as partículas negativas. 
Figura 55. Fluxograma do experimento de adsorção de $\mathrm{NaCl}$................................................. 109

Figura 56. Fluxograma dos experimentos de adsorção de PNIPAM. ....................................... 110

Figura 57. Fluxograma do experimento de adsorção de surfactantes.................................. 112

Figura 58. Probabilidade de um elétron atravessar a amostra a uma distância $x$ do centro de uma partícula com $117 \mathrm{~nm}$ de diâmetro sobre um substrato plano com $10 \mathrm{~nm}$ de espessura, sofrendo uma única perda de energia na região de baixa perda $(\lambda=50,75$,

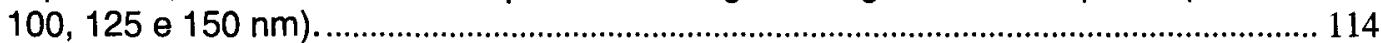

Figura 59. Probabilidade de um elétron atravessar a amostra a uma distância $x$ do centro de uma partícula com $77 \mathrm{~nm}$ de diâmetro sobre um substrato plano com $10 \mathrm{~nm}$ de espessura, sofrendo uma única perda de energia na região de baixa perda $(\lambda=50,75$, $100,125$ e $150 \mathrm{~nm})$.

Figura 60. Imagens de campo claro (CC) e de perda de energia $(\Delta E=20 \mathrm{eV})$, de uma mesma área de uma amostra de partículas de sílica com diâmetro médio de $117 \mathrm{~nm}$. Os gráficos mostram as intensidades dos níveis de cinza dos perfis com $25 \mathrm{~nm}$ de largura, indicados nas imagens.

Figura 61. Imagens de perda de energia $(\Delta \mathrm{E}=30,40 \mathrm{e} 50 \mathrm{eV}$ ) na região de baixa perda, da mesma área da amostra da Figura 60 . Os gráficos mostram as intensidades dos níveis de cinza dos perfis com $25 \mathrm{~nm}$ de largura indicados nas imagens.

Figura 62. Imagens de campo claro $(C C)$ e de perda de energia $(\triangle E=20 \mathrm{eV})$ na região de baixa perda, de uma mesma área de uma amostra de partículas de sílica com diâmetro médio de $76 \mathrm{~nm}$.

Figura 63. Imagens de campo claro de partículas de sílica da dispersão $D$, obtidas secando dispersões preparadas (A) após a diluição em água, e (B) após a diluição em $\mathrm{NaCl}$ $1 \times 10^{-5} \mathrm{~mol}^{-L^{-1}}$ seguida de nova diluição em água.

Figura 64. Imagens de campo claro de partículas de sílica da dispersão $D$, obtidas secando dispersões preparadas após a diluição em (A) $\mathrm{NaCl} 1,0 \times 10^{-3} \mathrm{~mol}^{-\mathrm{L}^{-1}}, \mathrm{e}(\mathrm{B}) \mathrm{NaCl} 0,5$ mol. $L^{-1}$ seguida de uma nova diluição em água. As imagens da direita mostram as ampliações das regiões indicadas.

Figura 65. Imagens de campo claro $(C C)$ e de perda de energia $(\Delta E=20 \mathrm{eV})$ na região de baixa perda, de uma mesma área de uma amostra das partículas de sílica preparadas a partir da dispersão $\mathrm{D}$, diluída em solução de $\mathrm{NaCl} 1,0 \times 10^{-5}$ mol.L-1 e depois novamente diluída em água..

Figura 66. Mapas elementares de sódio e cloro obtidos na mesma área da amostra da Figura 65. Os gráficos mostram as intensidades dos niveis de cinza dos perfis com 75 $\mathrm{nm}$ de largura indicados nas imagens.

Figura 67. Imagens de campo claro $(C C)$ e de perda de energia $(\Delta E=20 \mathrm{eV})$ na região de baixa perda, de uma mesma área de uma amostra das partículas de sílica preparadas a partir da dispersão $D$, diluída em solução de $\mathrm{NaCl} 1,0 \times 10^{-3} \mathrm{~mol}^{-L^{-1}}$ e depois novamente diluída em água..

Figura 68. Mapas elementares de sódio e cloro obtidos na mesma área da amostra da Figura 67. Os gráficos mostram as intensidades dos níveis de cinza dos perfis com 75 $\mathrm{nm}$ de largura indicados nas imagens.

Figura 69. Imagens de campo claro (CC) e de perda de energia $(\Delta E=20 \mathrm{eV})$ na região de baixa perda, de uma mesma área de uma amostra das partículas de sílica preparadas a partir da dispersão $\mathrm{D}$, diluída em solução de $\mathrm{NaCl} 0,5 \mathrm{~mol}^{-1} \mathrm{~L}^{-1}$ e novamente diluída em água.

Figura 70. Mapas elementares de sódio e cloro obtidos na mesma área da amostra da Figura 69. Os gráficos mostram as intensidades dos níveis de cinza dos perfis com 75 $\mathrm{nm}$ de largura indicados nas imagens.

Figura 71. Imagem de campo claro de uma amostra das partículas de sílica preparadas a partir da dispersão $D$, diluída em solução de $\mathrm{NaCl} 1,0 \times 10^{-5} \mathrm{~mol}^{-1} \mathrm{~L}^{-1}$ e novamente diluída em água. As regiões $A, B$ e $C$ identificam os campos de onde foram obtidos os espectros de perda de energia.

Figura 72. Imagem de campo claro da região A da Figura 71, obtida com a inserção da fenda seletora.

Figura 73. Espectros de perda de energia da borda de absorção da camada $\mathrm{K}$ do sódio, adquiridos nas regiōes $A, B$ e $C$ da Figura 71 . As áreas sob os picos de ionização (A) foram determinadas no intervalo de $1045 \mathrm{a} 1135 \mathrm{eV}$. 
Figura 74. Espectros de perda de energia da borda de absorção da camada $L_{2,3}$ do cloro, adquiridos nas regiōes $A, B$ e $C$ da Figura 71 . As áreas sob os picos de ionização (A) foram determinadas no intervalo de 165 a $265 \mathrm{eV}$.

Figura 75. Espectros de perda de energia da borda de absorção da camada $K$ do silício, adquiridos nas regiōes $A, B$ e $C$ da Figura 71 . As áreas sob os picos de ionização $(A)$ foram determinadas no intervalo de 1820 a $1915 \mathrm{eV}$.

Figura 76. Espectros de perda de energia da borda de absorção da camada $K$ do oxigênio, adquiridos nas regiōes $A, B$ e $C$ da Figura 71 . As áreas sob os picos de ionização (A) foram determinadas no intervalo de 520 a $590 \mathrm{eV}$.

Figura 77. Espectro de perda de energia da borda de absorção da camada $\mathrm{K}$ do oxigênio, adquirido no substrato de parlódio recoberto com um filme de $C$. A área sob o pico de ionização (A) foi determinada no intervalo de 520 a $590 \mathrm{eV}$.

Figura 78. Imagens de campo claro de partículas de sílica da dispersão $D$, obtidas secando dispersões a $20^{\circ} \mathrm{C}$ : $(A)$ após a diluição em água, e (B) após a diluição em PNIPAM $10^{-5}$ $\mathrm{g} / \mathrm{mL}$ seguida de uma nova diluição em água. As imagens da direita mostram as ampliações das regiões indicadas.

Figura 79. Imagens de campo claro de partículas de sílica da dispersão $D$, obtidas secando dispersões a $20^{\circ} \mathrm{C}$ preparadas após a diluição em (A) PNIPAM $10^{-4} \mathrm{~g} / \mathrm{mL}\left(20^{\circ} \mathrm{C}\right)$ e (B) PNIPAM $10^{-3} \mathrm{~g} / \mathrm{mL}$ seguida de uma nova diluição em água.....

Figura 80. Mapas de carbono das partículas de sílica secas a $20^{\circ} \mathrm{C}$ a partir da diluição em (A) água, e em PNIPAM a (B) $10^{-4} \mathrm{~g} / \mathrm{mL}$ e (C) $10^{-3} \mathrm{~g} / \mathrm{mL}(90 \mathrm{Kg} / \mathrm{Mol})$, seguida de uma nova diluição em água. Os esquemas $(D),(E)$ e $(F)$ ilustram o respectivo recobrimento das partículas por cadeias de PNIPAM e a dissociação dos agregados.

Figura 81. Mapas de carbono das partículas de sílica secas a $20^{\circ} \mathrm{C}$ na presença de PNIPAM com diferentes massas molares (A) $90 \mathrm{Kg} / \mathrm{Mol}$, (B) $190 \mathrm{Kg} / \mathrm{Mol}$, (C) 1050 $\mathrm{Kg} / \mathrm{Mol}$, na concentração de $10^{-3} \mathrm{~g} / \mathrm{mL}$, seguida de nova diluição em água................... 146

Figura 82. Perfis de níveis de cinza obtidos do mapa de $\mathrm{C}$ e da imagem de campo claro. $\mathrm{A}$ seta indica a espessura da camada de carbono adsorvida na partícula........................ 147

Figura 83. Imagens de campo claro (CC) e mapas elementares (C) de carbono de partículas de sílica secas a partir da diluição em PNIPAM $(90 \mathrm{Kg} / \mathrm{Mol})$ a $20^{\circ} \mathrm{C}$ e a 40 ${ }^{\circ} \mathrm{C}$, na concentração de $10^{-3} \mathrm{~g} / \mathrm{mL}$, seguida de uma nova diluição em água. Os esquemas $(A)$ e $(B)$ ilustram os respectivos recobrimentos das partículas por cadeias de PNIPAM e a dissociação dos aglomerados.

Figura 84. Ampliações das imagens de campo claro das Figuras 78 e 83 , das partículas de sílica secas após diluição em (A) água, e em PNIPAM $(90 \mathrm{Kg} / \mathrm{Mol})$ na concentração de $10^{-3} \mathrm{~g} / \mathrm{mL}$, seguida de uma nova diluição em água, a (B) $20^{\circ} \mathrm{C}$ e (C) $40^{\circ} \mathrm{C}$, respectivamente.

Figura 85. Imagens de campo claro de partículas de sílica da dispersão D, obtidas secando dispersões preparadas (A) após a diluição em água, $e(B)$ após a diluição em SDS $1,0 \times 10^{-5} \mathrm{~mol}^{-1} \mathrm{~L}^{-1}$ seguida de nova diluição em água. As imagens da direita mostram as ampliações das regiões indicadas.

Figura 86. Imagens de campo claro de partículas de sílica da dispersão $D$, obtidas secando dispersões preparadas após a diluição em (A) SDS $1,0 \times 10^{-3} \mathrm{~mol}^{-1}$, e (B) SDS $1,0 \times 10^{-1}$ mol. $L^{-1}$ seguida de uma nova diluição em água. As imagens da direita mostram as ampliações das regiões indicadas.

Figura 87. Imagens de campo claro (CC) e de perda de energia $(\Delta E=20 \mathrm{eV})$ na região de baixa perda, de uma mesma área de uma amostra das partículas de sílica ................. 152

Figura 88. Mapas elementares de carbono e sódio obtidos na mesma área da amostra da Figura 87. Os gráficos mostram as intensidades dos níveis de cinza dos perfis com 25 $\mathrm{nm}$ de largura indicados nas imagens.

Figura 89. Imagens de campo claro (CC) e de perda de energia $(\Delta E=20 \mathrm{eV}$ ) na região de baixa perda, de uma mesma área de uma amostra das partículas de sílica preparada a partir da dispersão $D$, após a diluição em SDS $1,0 \times 10^{-3} \mathrm{~mol}^{-1} \mathrm{~L}^{-1}$ seguida de nova diluição em água. 154

Figura 90. Mapas elementares de carbono e sódio obtidos na mesma área da amostra da Figura 89. Os gráficos mostram as intensidades dos níveis de cinza dos perfis com 25 $\mathrm{nm}$ de largura indicados nas imagens. 
Figura 91. Imagens de campo claro $(C C)$ e de perda de energia $(\Delta E=20 \mathrm{eV})$ na região de baixa perda, de uma mesma área de uma amostra das partículas de sílica preparada a partir da dispersão $D$, após a diluição em SDS $1,0 \times 10^{-1} \mathrm{~mol}^{-1} \mathrm{~L}^{-1}$ seguida de nova diluição em água.

Figura 92. Mapas elementares de carbono e sódio obtidos na mesma área da amostra da Figura 91 . Os gráficos mostram as intensidades dos níveis de cinza dos perfis com 25 $\mathrm{nm}$ de largura indicados nas imagens.

Figura 93. Imagens de campo claro de partículas de sílica da dispersão $D$, obtidas secando dispersões preparadas (A) após a diluição em água, $e(B)$ após a diluição em CTAB $1,0 \times 10^{-5} \mathrm{~mol}^{-L^{-1}}$ seguida de nova diluição em água.

Figura 94. Imagens de campo claro de partículas de sílica da dispersão $D$, obtidas secando

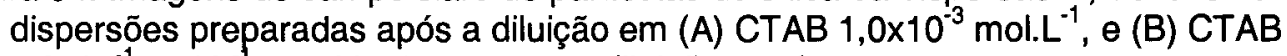
$1,0 \times 10^{-1} \mathrm{~mol}^{-1} \mathrm{~L}^{-1}$ seguida de uma nova diluição em água.

Figura 95. Imagens de campo claro (CC) e de perda de energia $(\Delta E=20 \mathrm{eV})$, de uma mesma área de uma amostra das partículas de sílica preparada a partir da dispersão $D$, após a diluição em CTAB $1,0 \times 10^{-5} \mathrm{~mol}^{-L^{-1}}$ seguida de nova diluição em água............161

Figura 96. Mapas elementares de carbono e bromo obtidos na mesma área da amostra da Figura 95. Os gráficos mostram as intensidades dos níveis de cinza dos perfis com 25 $\mathrm{nm}$ de largura indicados nas imagens.

Figura 97. Imagens de campo claro $(C C)$ e de perda de energia $(\triangle E=20 \mathrm{eV})$ na região de baixa perda, de uma mesma área de uma amostra das partículas de sílica preparada a partir da dispersão $D$, após a diluição em CTAB $1,0 \times 10^{-3} \mathrm{~mol}^{-1} \mathrm{~L}^{-1}$ seguida de nova diluição em água.

Figura 98. Mapas elementares de carbono e bromo obtidos na mesma área da amostra da Figura 97. Os gráficos mostram as intensidades dos níveis de cinza dos perfis com 25 $\mathrm{nm}$ de largura indicados nas imagens.

Figura 99. Imagens de campo claro $(C C)$ e de perda de energia $(\Delta E=20 \mathrm{eV}$ ) na região de baixa perda, de uma mesma área de uma amostra das partículas de sílica preparada a partir da dispersão $D$, após a diluição em $C T A B 1 \times 10^{-1}$ mol. $L^{-1}$ seguida de nova diluição em água......

Figura 100. Mapas elementares de carbono e bromo obtidos na mesma área da amostra da Figura 99. Os gráficos mostram as intensidades dos níveis de cinza dos perfis com 25 $\mathrm{nm}$ de largura indicados nas imagens.

Figura 101. Imagens de campo claro de partículas de sílica da dispersão D, obtidas secando dispersões preparadas (A) após a diluição em água, e (B) após a diluição em RENEX $1,0 \times 10^{-5} \mathrm{~mol}^{-L^{-1}}$ seguida de nova diluição em água. As imagens da direita mostram as ampliações das regiões indicadas.

Figura 102. Imagens de campo claro de partículas de sílica da dispersão $D$, obtidas secando dispersões após a diluição em (A) CTAB $10^{-3} \mathrm{~mol}^{-1} \mathrm{~L}^{-1}$, e (B) RENEX $1,0 \times 10^{-1} \mathrm{~mol}^{-L^{-1}}$ seguida de uma nova diluição em água.

Figura 103. Imagens de campo claro (CC), perda de energia $(\Delta E=20 \mathrm{eV})$ e mapa elementar de carbono (C) de uma mesma área de uma amostra das partículas de sílica preparada a partir da dispersão $D$, após a diluição em RENEX $1,0 \times 10^{-5} \mathrm{~mol}^{-L^{-1}}$ seguida de nova diluição em água.

Figura 104. Imagens de campo claro (CC), perda de energia $(\Delta E=20 \mathrm{eV})$ e mapa elementar de carbono $(\mathrm{C})$ de uma mesma área de uma amostra das partículas de sílica preparada a partir da dispersão $D$, após a diluição em RENEX $1,0 \times 10^{-3} \mathrm{~mol}^{-L^{-1}}$ seguida de nova diluição em água.

Figura 105. Imagens de campo claro $(C C)$, perda de energia $(\Delta E=20 \mathrm{eV})$ e mapa elementar de carbono (C) de uma mesma área de uma amostra das partículas de sílica preparada a partir da dispersão $D$, após a diluição em RENEX $1,0 \times 10^{-1} \mathrm{~mol}^{-L^{-1}}$ seguida de nova diluição em água.

Figura 106. (CC) Imagem de campo claro (Figura 71) identificando as regiões A, B e C onde foram obtidos os espectros de perda de energia e (Si) distribuição de Si nestas regiões.

Figura 107. Distribuição de $\mathrm{Na}^{+}$e $\mathrm{Cl}^{-}$nas regiões A, B e C, considerando uma proporção com razão estequiométrica na região C.....................................................................176

Figura 108. Distribuição de O nas regiões A, B, C e no substrato. ............................................ 177 


\section{LISTA DE TABELAS}

Tabela 1. Técnicas microanalíticas utilizando feixes de elétrons, íons, e fótons, com a resolução espacial estimada.

Tabela 2. Diluições das dispersões para a preparação das amostras de PCS

Tabela 3. Distribuição de diâmetros das partículas da dispersão D: $G(d)$ distribuição (\%) em função do diâmetro (d) e C(d) distribuição acumulada (\%) em função do diâmetro....... 56

Tabela 4. Valores determinados para os coeficientes de sorção em água e álcool, e dos potenciais zeta das partículas de sílica.

Tabela 5. Bordas de absorção de energia (eV) para $\mathrm{Si}, \mathrm{O}, \mathrm{C}, \mathrm{N}, \mathrm{Na}$ e $\mathrm{Ca}$.

Tabela 6. Valores médios de dureza Vickers obtidos a partir da média aritmética de 10 impressões por amostra.

Tabela 7. Valores mínimos da força aplicada $\left(P_{0}\right)$ pelo indentador Vickers para provocar fissuras nas extremidades das impressões nas superfícies dos monolitos.

Tabela 8. Diâmetros médios das partículas de sílica das diferentes dispersões, determinados por PCS (em meio aquoso) e por TEM, antes e após 18 meses de armazenamento em meio etanólico.

Tabela 9. Razão entre os números de átomos de $\mathrm{Si}, \mathrm{O}, \mathrm{Na}$ e $\mathrm{Cl}$ nas regiões $\mathrm{A}, \mathrm{B}$ e $\mathrm{C}$, subtraindo o número de átomos de $\mathrm{O}$ do substrato.

Tabela 10. Espessura da camada de polímero adsorvida determinada a partir de experimentos de TEM e PCS. 


\section{LISTA DE ABREVIATURAS E SIGLAS}

AC - corrente elétrica alternada

AFM - microscopia de força atômica

CC - campo claro

CMC - concentração crítica micelar

CTAB - brometo de cetiltrimetilamônio

DC - corrente elétrica contínua

DLVO - Derjaguin-Landau-Verwey-Overbeek

$E$ - energia

EDX - dispersão de energia de raios- $X$

EELS - espectroscopia por perda de energia de elétrons

EFM - microscopia de força elétrica

ESD - diâmetro da esfera equivalente

ESI-TEM - imageamento por espectroscopia de elétrons

E-T - Everhart-Thornley

FESEM - microscopia eletrônica de varredura por emissão de campo

FFT - transformada rápida de Fourier

HLB - balanço hidrofílico-lipofílico

$\mathrm{H}_{\mathrm{v}}$ - dureza Vickers

LCST - temperatura de solução crítica inferior

$\mathrm{M}$ - molar

$\mathrm{M}_{\mathrm{W}}$ - massa molar

PCS - espectroscopia de correlação de fótons

PNIPAM - Poli(N-isopropilacrilamida)

RENEX $300{ }^{\circledR}$ - Nonilfenilpolioxietileno (30 unidades de óxido de etileno)

SDS - dodecil sulfato de sódio

SEI - imageamento por elétrons secundários

SEM - microscopia de elétrons secundários

SEPM - microscopia de varredura de potencial eletrostático

SPM - microscopia de varredura por sonda

TEM - microscopia eletrônica de transmissão

TEOS - ortosilicato de tetraetila

UR - umidade relativa 


\section{LISTA DE SÍMBOLOS}

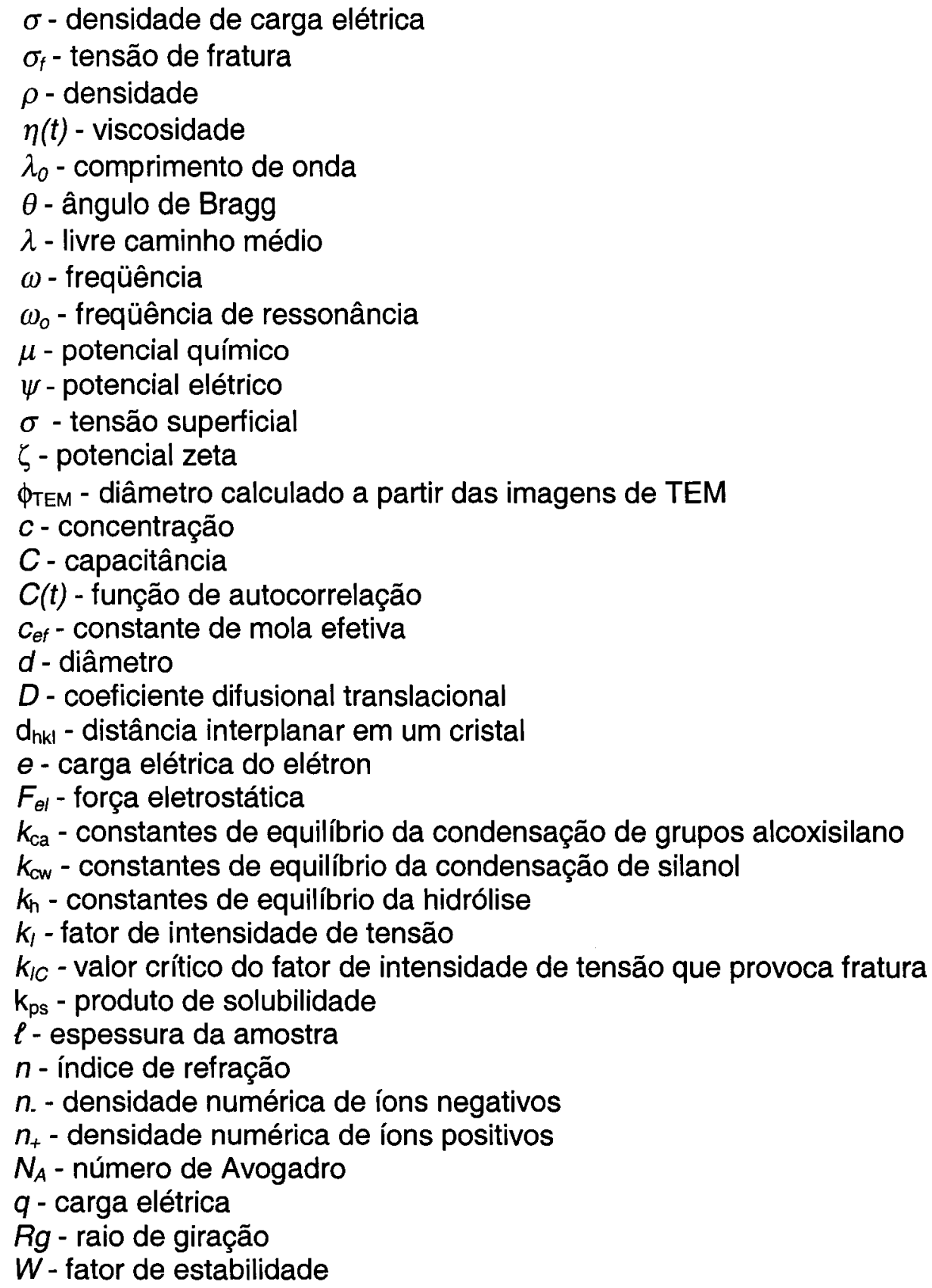




\section{RESUMO}

Partículas monodispersas formam um sistema modelo para estudos de adsorção e catálise, como também para estudos de propriedades do estado sólido dependentes do tamanho das partículas. A uniformidade destas dispersões tem sido considerada somente quanto ao tamanho e à forma das partículas, havendo pouca informação em relação à uniformidade de composição química. Nesta tese inicialmente foi examinada a uniformidade da composição química de partículas de sílica preparadas pelo método de Stöber. Foram obtidas partículas de tamanhos diferentes, em populações paucidispersas. As técnicas utilizadas são de tecnologia recente, como a microscopia de varredura por sonda (nos modos de SEPM e EFM), microscopia eletrônica de transmissão (no modo de perda de energia), microscopia eletrônica de varredura por emissão de campo (elétrons secundários e retroespalhados) e técnicas de espalhamento de luz (PCS). O intumescimento das partículas foi verificado comparando amostras expostas a diferentes ambientes: vácuo de $10^{-6} \mathrm{mbar}$ (TEM, FESEM), atmosfera ambiente a $25^{\circ} \mathrm{C}$ e $55 \%$ de umidade relativa (SPM) e dispersão em água (bidestilada e deionizada) e etanol (PCS). As partículas menores apresentaram uma grande contração ao serem submetidas ao vácuo, portanto são muito intumescidas, se comparadas às maiores. Os resultados mostraram que as partículas menores são formadas por domínios de ácido silícico de grau de hidratação variável, enquanto as partículas maiores têm uma morfologia caroço-casca, em que a casca é mais hidratada que o caroço. Na secagem das dispersões, o maior intumescimento, associado à heterogeneidade das cargas elétricas, contribuiu para a plasticidade e deformação das partículas na formação de filmes e monolitos com maior tenacidade à fratura. Evidências de variações na composição química foram obtidas por espectros de perda de energia $e$ infravermelho: as partículas menores contêm quantidades detectáveis de grupos $\mathrm{C}-\mathrm{H}$, mas estes não são detectáveis por infravermelho nas partículas maiores. A localização dos constituintes de carbono nas partículas foi determinada por mapeamento elementar no microscópio eletrônico de transmissão (ESI-TEM): o carbono está distribuído pelas partículas pequenas, mas está excluído do interior das partículas maiores. Estes resultados foram interpretados considerando o efeito da concentração de base sobre a cinética e extensão da hidrólise do TEOS e o efeito dos grupos etoxilas residuais, que é limitante da densificação da rede de sílica. ESI-TEM foi usado para examinar a localização de $\mathrm{NaCl}$, poli (isopropilacrilamida) (PNIPAM) e surfactantes (SDS, CTAB e RENEX) sorvidos em partículas de sílica $\left(\phi_{T E M}=77 \mathrm{~nm}\right.$ ), como seus efeitos na dispersão e empacotamento das partículas quando as dispersões são secas sobre um filme de carbono. No caso de $\mathrm{NaCl} 0,5 \mathrm{M}$, os espectros de EELS mostraram que as quantidades de $\mathrm{Na}^{+} \mathrm{e}$ $\mathrm{Cl}^{-}$sorvidos nas diferentes regiões estão próximas da razão estequiométrica, com um excesso de $14 \%$ de $\mathrm{Na}^{+}$nos agregados de partículas e $3 \%$ ao redor dos agregados. Os polímeros e surfactantes foram sorvidos somente na superfície das partículas, não sendo detectados no seu interior. No caso dos surfactantes iônicos, os contra-íons $\left(\mathrm{Na}^{+}, \mathrm{Br}\right)$ foram encontrados no interior das partículas negativas de sílica $(\zeta=-46 \mathrm{mV})$, independentemente do sinal de sua carga elétrica. Estes resultados mostram que a sílica de Stöber apresenta características interessantes que podem levar ao seu uso como transportadoras de moléculas e íons, devido ao pequeno tamanho da partícula, alta estabilidade coloidal e comportamento de sorção. 


\begin{abstract}
Uniform fine particles are often used as model systems in the study of adsorption, catalysis and size-dependent solid state properties. There have been significant achievements concerning the preparation of uniform colloidal dispersions, both inorganic and organic. However, uniformity has often been considered only in relationship to particle size and shape, and little information is currently available concerning the uniformity of chemical composition of particles. This thesis shows that Stöber silica particles from five different paucidisperse samples do not have uniform composition. This was done using scanning probe microscopies (atomic force, AFM, scanning electric potential, SEPM and electric force, EFM), highresolution scanning electron microscopy and transmission electron microscopy as well as photon correlation spectroscopy (PCS). Particle swelling ability was determined using particle sizes measured under different conditions at $25^{\circ} \mathrm{C}$ : under vacuum $\left(10^{-6} \mathrm{mbar}\right.$, TEM, FESEM), under $55 \%$ relative humidity (AFM), and dispersed in water and ethanol (PCS). The comparison of these results shows that the smaller particles are highly swollen in ethanol, to a greater extent than in water. The swelling coefficients are lower for the larger particles, with a preference for water. Upon drying, the smaller particles show a greater ability to form dense films that is assigned to their greater plasticity. Evidence for changes in the chemical composition were obtained by electron energy-loss and infrared absorption spectra: the smaller particles contain detectable amounts of $\mathrm{C}-\mathrm{H}$ groups, which are not detected by $I R$ in the larger ones and $O$ energy-loss spectra fine structure also changes with particle size. The location of carbon constituents in the particles was determined by electron spectroscopy imaging in the transmission electron microscope (ESI-TEM): they are dispersed throughout the finer particles, but they are excluded from the core of the larger particles. The results are interpreted considering the kinetics and extent of TEOS hydrolysis dependence on base concentration, and the limiting effect of ethoxy residual groups on the densification of the silica network. ESI-TEM was used to examine the location of sorbed $\mathrm{NaCl}$, poly (isopropylacrylamide) (PNIPAM) and surfactants (SDS, CTAB and RENEX) as well as their effect on particle dispersion and packing when silica dispersions are dried on a carbon film. In the case of $\mathrm{NaCl} 10^{-5} \mathrm{M}$, EELS spectra showed that $\mathrm{Na}^{+}$ and $\mathrm{Cl}^{-}$local concentrations are always close to stoichiometry but there is an excess $14 \% \mathrm{Na}^{+}$within the particle aggregates and $3 \%$ in the vicinity of the aggregates. Polymer and surfactants are detected only around the particles and not within them but the respective counter-ions $\left(\mathrm{Na}^{+}, \mathrm{Br}\right)$ are detected, irrespective of their charges and of the negative particle charge evidenced by the $-46 \mathrm{mV}$ zeta potential. These results show that Stöber silica has interesting features that may lead to its use as a carrier of molecules and ions due to the small particle size, high colloidal stability and sorption behavior.
\end{abstract}




\section{INTRODUÇÃO GERAL}

Partículas monodispersas formam um sistema modelo para estudos de adsorção e catálise, ${ }^{[1]}$ como também para estudos de propriedades do estado sólido dependentes do tamanho das partículas, como o confinamento quântico e a superplasticidade. ${ }^{[2]}$ Diferentes métodos têm sido propostos para a preparação de partículas esféricas monodispersas de sílica, ${ }^{[3,4,5,6,7]}$ com tamanhos cobrindo toda faixa coloidal. Destes, um método bastante prático foi descrito por Stöber et $a l^{[8]}$ através da hidrólise do ortosilicato de tetraetila, em meio alcoólico (etanol) na presença de amônia. Neste método, mudando-se as condições de preparação é possível obter-se partículas de tamanhos diferentes, em populações paucidispersas.

Houve outros avanços importantes na preparação de dispersões coloidais uniformes, tanto inorgânicas como orgânicas. ${ }^{[9]}$ Entretanto, esta uniformidade tem sido somente relativa ao tamanho e à forma das partículas, havendo pouca informação em relação à uniformidade de composição química. Isto sugere que devemos ter muita cautela ao considerarmos, mesmo em um sistema modelo, que a única diferença entre as partículas pequenas e as grandes é o seu tamanho. Em

um trabalho em nosso laboratório anterior a esta tese,$^{[10,11]}$ foi mostrado que as partículas de sílica pequenas apresentam diferenças morfológicas e estruturais importantes, se comparadas às partículas maiores. 
Nesta tese foi realizado um estudo microquímico de partículas de sílica preparadas pelo método de Stöber e de seus produtos de adsorção. Na primeira parte foi estabelecida a heterogeneidade química das partículas de sílica de mesmo tamanho, e também as diferenças entre as partículas de diferentes tamanhos. Um novo mecanismo de polimerização e crescimento das partículas foi proposto considerando estas diferenças. As técnicas utilizadas e adequadas a este tipo de caracterização são de tecnologia recente, como a Microscopia de Varredura por Sonda nos modos de não-contato e de potencial eletrostático (SEPM), e a Microscopia Eletrônica de Transmissão, no modo de perda de energia (ESI-TEM). Também foram utilizadas a Microscopia Eletrônica por Emissão de Campo (FESEM) de alta resolução (elétrons secundários), técnicas de espalhamento de luz (PCS) e espectros no infra-vermelho, buscando-se correlacionar os resultados obtidos por todas essas técnicas. Também foi verificada a contribuição destas diferenças para a plasticidade e deformação das partículas na formação de filmes e monolitos.

Na segunda parte foi escolhido um tamanho de partícula conveniente para o estudo de adsorção de co-solutos e análise por ESI-TEM. Em dispersões de partículas com este tamanho foram inseridos íons, polímeros e surfactantes, a partir de sistemas com diferentes concentrações, temperaturas, cargas iônicas e natureza dos contra-íons. A organização das partículas durante a secagem das dispersões diluídas e a distribuição dos adsorbatos foram observadas por imagens de campo claro e elementares, obtidas no microscópio eletrônico de transmissão. 


\section{PARTE I}

\section{SÍNTESE E CARACTERIZAÇÃo MICROQUÍMICA DE PARTÍCULAS DE SÍLICA DE STÖBER}

\section{INTRODUÇÃO}

\subsection{Partículas de Silica de Stöber}

1.1.1. Síntese das partículas de sílica - As partículas de sílica são sintetizadas a partir da hidrólise de um alcóxido tetrafuncional precursor. O alcóxido mais utilizado é o ortosilicato de tetraetila $\left(\mathrm{Si}\left(\mathrm{OC}_{2} \mathrm{H}_{5}\right)_{4}\right)$, abreviado na literatura como TEOS. O método tradicional de preparação de TEOS é por reação de tetraclorosilano com etanol anidro, obtendo-se ácido clorídrico como subproduto:

$$
\mathrm{SiCl}_{4}+\mathrm{EtOH} \rightarrow \mathrm{Si}(\mathrm{OEt})_{4}+4 \mathrm{HCl}
$$

A hidrólise do TEOS ${ }^{[12,13,14,15]}$ é mais rápida e efetiva quando catalisada por um ácido mineral ou uma base. Três reações reversíveis são decisivas no processo sol-gel: ${ }^{[16]}$

hidrólise

$$
\begin{gathered}
\equiv \text { Si-OR }+\mathrm{H}_{2} \mathrm{O} \rightleftarrows \text { इSi-OH }+\mathrm{ROH} \\
\text { esterificação }
\end{gathered}
$$




$$
\begin{aligned}
& \text { condensação }
\end{aligned}
$$



$$
\begin{aligned}
& \text { alcoólise } \\
& \text { condensação } \\
& \equiv \mathrm{Si}-\mathrm{OH}+\text { ISi-OH } \rightleftarrows \text { =Si-O-Si }+\mathrm{H}_{2} \mathrm{O} \\
& \text { hidrólise }
\end{aligned}
$$

onde $R$ é um grupo alquila (etila). Na reação de hidrólise os grupos alcóxidos (OR) são substituídos por grupos hidroxilas $(\mathrm{OH})$. Reações de condensação subseqüentes, dos grupos silanóis, produzem siloxanos (Si-O-Si) e subprodutos alcoólicos (ROH) ou água. As reações de condensação têm início antes de toda a hidrólise estar completa (em equilíbrio), ou seja, hidrólise e condensação são consecutivas.

A estrutura dos silicatos formados é o produto de sucessivas reações de hidrólise e condensação (e das reações inversas de esterificação, alcoólise e hidrólise). ${ }^{[17]}$ Variações estruturais são resultantes da superposição e competição entre estas três reações básicas.

1.1.2. Cinética - Os resultados apresentados nesta tese são interpretados a partir da análise dos efeitos da base sobre a cinética e a extensão da hidrólise e condensação do TEOS, não considerando a distribuição e localização dos grupos funcionais (-OR, $-\mathrm{OH}$ e -OSi) em cada átomo de Si. Desta forma, somente três reações e três constantes de equilíbrio são necessárias para descrever a cinética: $k_{\mathrm{h}}, k_{\mathrm{cw}} / 2$ e $k_{\mathrm{ca}} / 2$, onde $k_{\mathrm{h}}$ é a constante de equilíbrio da hidrólise, $k_{\mathrm{cw}} / 2$ da condensação da água e $k_{\mathrm{ca}} / 2$ da condensação do álcool:

$$
\begin{aligned}
& k_{\mathrm{h}} \\
& \equiv \mathrm{Si}-\mathrm{OR}+\mathrm{H}_{2} \mathrm{O} \rightarrow \text { ISi-OH }+\mathrm{ROH} \\
& k_{\mathrm{cW}} / 2 \\
& \equiv \mathrm{Si}-\mathrm{OH}+\equiv \mathrm{Si}-\mathrm{OH} \rightarrow \text { } \equiv \mathrm{Si}-\mathrm{O}-\mathrm{Si} \equiv+\mathrm{H}_{2} \mathrm{O}
\end{aligned}
$$




$$
\begin{gathered}
k_{\mathrm{ca}} / 2 \\
\equiv \mathrm{Si}-\mathrm{OR}+\equiv \mathrm{S}-\mathrm{OH} \rightarrow \equiv \mathrm{Si}-\mathrm{O}-\mathrm{Si} \equiv+\mathrm{ROH}
\end{gathered}
$$

Considerando os grupos funcionais ligados ao átomo de $\mathrm{Si}$, este pode apresentar até 15 diferentes combinações possíveis de números de grupos -OR, $-\mathrm{OH}$ e -OSi, ou seja, há 15 diferentes meios químicos do Si. A Figura 1 representa o número de grupos funcionais $-\mathrm{OR},-\mathrm{OH}$ e $-\mathrm{OSi}$ ligados ao átomo central de Si: $\mathrm{Si}(\mathrm{OR})_{\times}(\mathrm{OH})_{Y}(\mathrm{OSi})_{Z}$, onde $X+Y+Z=4$ (número de coordenação do $\mathrm{Si}$ ). Considerando apenas as reações diretas, as diferentes proporções possiveis dos grupos funcionais permitem que sejam definidas 165 constantes de equilíbrio.

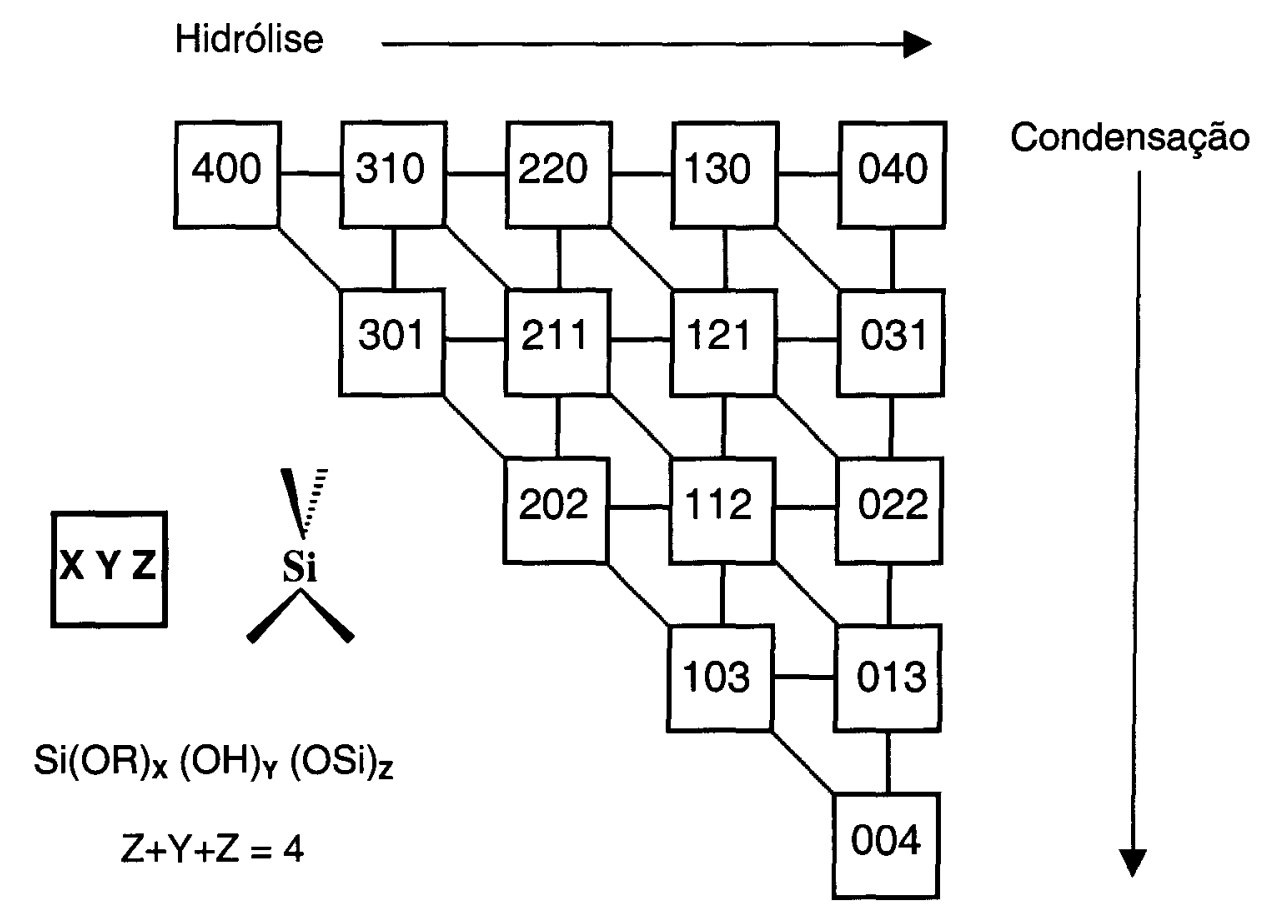

Figura 1. Representação das espécies químicas vizinhas ao $\mathrm{Si}^{[18,19]}$

1.1.3. Efeito do solvente - Como água e alcoxilano são imiscíveis, um solvente mútuo como álcool etílico é normalmente utilizado para fazer a reação em meio homogêneo. Por outro lado, o álcool não pode ser considerado apenas um solvente, já que ele participa das reações inversas de esterificação e alcoólise. 
1.1.4. Efeito do $\mathrm{pH}$ - ller ${ }^{[20]}$ divide o processo de polimerização em três diferentes domínios de $\mathrm{pH}:<2,2-7$ e $>7.0 \mathrm{pH} 2$ é uma fronteira porque tanto o ponto de carga zero, no qual a carga da partícula é zero, como o ponto isoelétrico, onde a mobilidade elétrica das partículas de sílica é zero, estão na faixa de $\mathrm{pH} 1-3 . \mathrm{O} \mathrm{pH} 7$ é outra fronteira pois acima deste $\mathrm{pH}$ as taxas de solubilidade e dissolução da sílica aumentam. Acima do pH 7 as partículas são também mais ionizadas, crescendo sem agregação ou gelatinização (Figura 2).

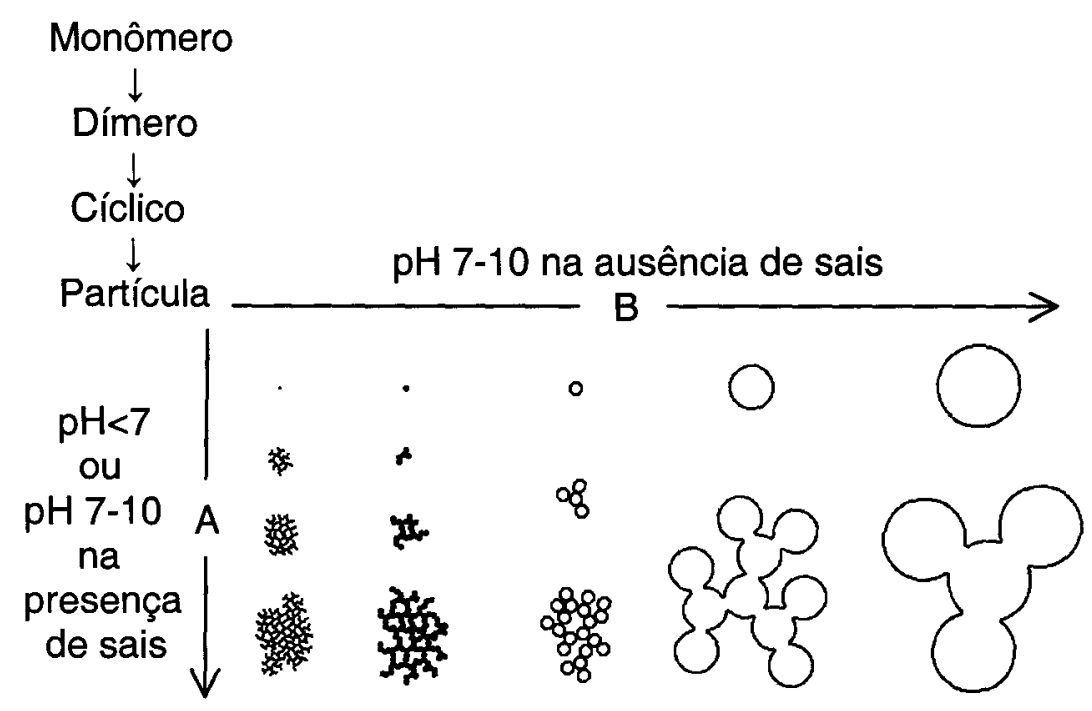

Figura 2. Polimerização da sílica. (A) Em solução ácida, ou na presença de sais, as partículas agregam-se em uma rede tridimensional e formam géis ${ }^{[21,22,23]}$ (B) $\mathrm{Em}$ solução básica as partículas crescem em tamanho e decrescem em número.

Acima do $\mathrm{pH}$ 7, a polimerização ocorre pelo mecanismo nucleofílico:

$$
\begin{aligned}
& \text { rápida } \\
& \equiv \mathrm{Si}-\mathrm{OH}+\mathrm{OH}^{-} \rightarrow \equiv \mathrm{Si}-\mathrm{O}^{-}+\mathrm{H}_{2} \mathrm{O} \\
& \text { lenta }
\end{aligned}
$$

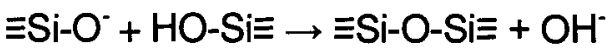

As espécies condensadas são mais ionizadas, e com uma maior repulsão mutua. Assim, o crescimento ocorre mais pela adição de monômeros, do que por agregação de partículas. Partículas de 1-2 nm de diâmetro são formadas em poucos minutos em pH 7. Devido à solubilidade da sílica, e à grande dependência 
do tamanho com a solubilidade em $\mathrm{pH}$ acima de 7, as partículas menores possuem maior solubilidade que as maiores. Assim, as partículas crescem rapidamente até um tamanho, que também depende da temperatura: altas temperaturas produzem partículas maiores devido à maior solubilidade das partículas menores. Como o crescimento ocorre pela dissolução de pequenas partículas e deposição da sílica solúvel nas partículas maiores, a taxa de crescimento depende da distribuição de tamanhos de partículas.

1.1.5. Catálise por base - As reações de hidrólise e condensação ocorrem em numerosos sítios em uma solução de TEOS e $\mathrm{H}_{2} \mathrm{O}$. Estas reações podem ser catalisadas por ácidos minerais ou bases em reações de substituição nucleofílica bimolecular. Em condições básicas, as hidroxilas ou os ânions silanolatos atacam diretamente o Si: ${ }^{[24]}$

Hidrólise catalisada por base:



Condensação catalisada por base:

$$
\begin{aligned}
& \text { rápida } \\
& \mathrm{RO}-\mathrm{Si}(\mathrm{OH})_{3}+\mathrm{OH}^{-} \rightleftarrows \mathrm{RO}-\mathrm{Si}(\mathrm{OH})_{2} \mathrm{O}^{-}+\mathrm{H}_{2} \mathrm{O} \\
& \text { lenta } \\
& \mathrm{RO}-\mathrm{Si}(\mathrm{OH})_{3}+\mathrm{RO}-\mathrm{Si}(\mathrm{OH})_{2} \mathrm{O}^{-} \rightleftharpoons \mathrm{RO}-\mathrm{Si}(\mathrm{OH})_{2}-\mathrm{O}-\mathrm{Si}(\mathrm{OH})_{2} \mathrm{OR}+\mathrm{OH}^{-}
\end{aligned}
$$

1.1.6. Efeito da presença de sais - $\mathrm{A}$ um dado $\mathrm{pH}$, a adição de sal reduz a espessura da dupla camada elétrica, reduzindo drasticamente a estabilidade da dispersão. Na ausência de sal não ocorre agregação, devido a mutua repulsão das partículas. Desta forma, sóis estáveis podem ser preparados e concentrados. 
1.1.7. Mecanismo - A cinética de condensação é responsável pela maximização do número de ligações Si-O-Si e minimização do número de grupos hidroxilas terminais (por meio de condensação interna). Assim, anéis formados a partir da adição de monômeros, geram partículas tridimensionais (Figura 3), que condensam em um arranjo espacial mais compacto, com grupos $\mathrm{OH}$ do lado externo da partícula.<smiles>[R]C12O[Si]3([R])O[Si]4([R])O[Si]([R])(O1)O[Si]1([R])O[Si]([R])(O2)O[Si]([R])(O3)O[Si]([R])(O4)O1</smiles>

Figura 3. Modelo do estágio inicial da formação de partículas a partir da condensação monomérica.

O crescimento da partícula ocorre, como descrito na literatura, ${ }^{[20]}$ através do mecanismo de Ostwald, segundo o qual as partículas crescem em tamanho e decrescem em número, quando pequenas partículas altamente solúveis dissolvemse e reprecipitam-se em maiores, menos solúveis. O crescimento termina quando a diferença na solubilidade entre a partícula menor e a maior torna-se da ordem de poucos ppm. Assim, o crescimento é acentuado em temperaturas altas, e especialmente em pH acima de 7 , onde a solubilidade da sílica é maior. 


\subsection{Espectroscopia de correlação de fótons (PCS)}

A caracterização das diferentes dispersões de sílica é bastante auxiliada pela determinação do raio hidrodinâmico, determinado pela espectroscopia de correlação de fótons, como uma forma rápida e fácil de verificação do tamanho e uniformidade das partículas formadas em cada reação.

Esta técnica é baseada na correlação das flutuações da intensidade luminosa em relação à média do espalhamento de um feixe de laser que atravessa a amostra. Esta técnica apresenta várias vantagens, como: alta velocidade de aquisição, exatidão ( $\pm 1 \%$ para amostras monodispersas), pequeno volume de amostragem (as amostras são analisadas em cubetas descartáveis de acrílico de $3 \mathrm{~mL}$ ), não requer calibração de rotina, além da versatilidade para medidas de partículas com dimensões de $2 \mathrm{~nm}$ até $1 \mu \mathrm{m}$, em diferentes dispersantes.

O diâmetro obtido é o diâmetro hidrodinâmico, isto é, o diâmetro da partícula mais a espessura da dupla camada, que é o diâmetro que uma esfera deve apresentar para difundir na mesma taxa que a partícula que está sendo medida. Este diâmetro também é chamado de diâmetro da esfera equivalente (equivalent sphere diameter - ESD).

Quando as partículas são polidispersas, o diâmetro efetivo é medido supondo distribuições lognormal, calculado a partir das intensidades de luz espalhadas por cada partícula.

Nas monodispersões de esferas rígidas diluídas, como normalmente se supõe que sejam as esferas de sílica utilizadas neste projeto, os diâmetros obtidos devem aproximar-se daqueles obtidos por técnicas de análise que permitem visualização de partículas individuais, como métodos de microscopia eletrônica e de varredura por sonda. Entretanto os resultados que serão apresentados vão mostrar que esta suposição é incorreta. 
1.2.1. Teoria de operação - Para uma melhor interpretação dos resultados obtidos, torna-se necessário compreender o princípio físico de operação. Um fotodetector é instalado a $90^{\circ}$ e a uma distância pré-fixada, em relação ao feixe de laser incidente na amostra. $\mathrm{O}$ volume de espalhamento contém um grande número de partículas, sendo que a luz espalhada por cada partícula ilumina o fotodetector. Como as partículas estão se movendo aleatoriamente no líquido (movimento Browniano), as distâncias que as ondas espalhadas pelas partículas percorrem até o fotodetector variam em função do tempo, apresentando interferências construtivas ou destrutivas. O resultado é uma média de intensidades com superposição de flutuações. Os tempos de decaimento destas flutuações são função da constante de difusão, consequentemente do tamanho das partículas. Partículas pequenas movem-se rapidamente, causando um rápido decaimento, enquanto partículas maiores movem-se mais lentamente, causando um decaimento também mais lento. O tempo de decaimento destas flutuações pode ser determinado no domínio de freqüências, utilizando um analisador de espectros, ou no domínio de tempo, utilizando um correlator. $O$ correlator oferece o modo mais eficiente para esta análise.

1.2.2. Correlação - Se duas variáveis ou sinais são altamente correlacionados, a chance de um predizer o outro é grande. Matematicamente uma função de correlação é definida como a média dos produtos de duas quantidades. Uma função de autocorrelação é a média do produto de uma variável com uma versão atrasada (no tempo) da mesma. Para determinar a função de autocorrelação em PCS, o experimento é dividido em pequenos intervalos de tempo, chamados de tempos de decaimento. Estes intervalos devem ser pequenos com relação ao tempo típico de uma flutuação. A luz espalhada em cada um destes intervalos é representada por um número de pulsos elétricos registrados, que flutuam em torno 
de um valor médio. A função de intensidade de autocorrelação $C(t)$ é formada pela média dos produtos de intensidades nestes pequenos intervalos, como uma função do tempo $t$ entre os intervalos (tempos de decaimento):

$$
C(t)=A e^{-2 \Gamma t}+B
$$

onde $A$ é uma constante óptica e $\Gamma$ é relacionado com a relaxação da flutuação por:

$$
\Gamma=D q^{2}
$$

onde $D$ é o coeficiente difusional translacional.

O valor $q$ é função do ângulo de espalhamento $\left(90^{\circ}\right)$, do comprimento de onda do laser $\left(\lambda_{0}=0,670 \mu \mathrm{m}\right)$, e do índice de refração do solvente $(n=1,5)$. A equação resultante é dada por:

$$
q=2 \pi n \lambda_{0}^{-1} 2 \operatorname{sen}(\theta / 2)
$$

Para partículas esféricas:

$$
D=k_{B} T / 3 \pi \eta(t) d
$$

onde $k_{B}$ é a constante de Boltzmann, $T$ é a temperatura, $\eta(t)$ é a viscosidade do liquido em que a partícula está se movendo e dé o diâmetro da partícula.

Em resumo, a determinação do tamanho de partícula consiste em:

- Determinar $i_{\theta}=f(t)$, com resolução temporal da ordem de $1 \mu \mathrm{s}$.

- Determinar a função de autocorrelação.

- Calcular $\Gamma$, usando a Eq. (13).

- Calcular $D$, dado $n, \theta$ e $\Gamma$, usando a Eq. (14).

- Calcular $d$, dado Te $\eta$, usando a Eq. (16).

O equipamento utilizado controla automaticamente os parâmetros para a determinação da função de autocorrelação, incluindo a escolha dos tempos de decaimento e a duração do registro de $i_{\theta}=f(t)$. Calcula $D$ e $d$, apresentando informações referentes à distribuição dos diâmetros, polidispersividade, diâmetro efetivo e qualidade da amostra. 
1.3. Microscopia eletrônica de transmissão (TEM) - Os microscópios eletrônicos de transmissão são classificados como: microscópio eletrônico de transmissão convencional (CTEM) e microscópio eletrônico de transmissão por varredura (STEM). O sistema convencional utiliza como sonda um feixe de elétrons acelerados, que percorre uma coluna, sendo focalizado por lentes eletromagnéticas sobre a amostra (Figura 4). O sistema de varredura utiliza bobinas eletromagnéticas que defletem o feixe, em um padrão de varredura focalizado no plano $x, y$ sobre a superfície da amostra. ${ }^{[25,26,27]}$



Figura 4. Microscópio eletrônico de transmissão 
O microscópio é constituído basicamente pelo sistema de iluminação, sistema formador de imagem, sistema de registro de imagem, sistema de vácuo e sistema de alimentação de corrente e alta voltagem.

O sistema de iluminação, localizado no topo da coluna, é formado pelo canhão eletrônico que é a fonte de elétrons, e um conjunto de lentes eletromagnéticas, que regula o feixe sobre a amostra. A qualidade da imagem final depende do brilho com o qual a amostra é iluminada. O canhão eletrônico consiste de um filamento (cátodo) termoiônico, usualmente um fio de tungstênio com 0,1 mm de diâmetro, na forma de $\mathrm{V}$. Quando uma corrente elétrica passa pelo filamento, este aquece até à incandescência. $\mathrm{O}$ ápice do $\mathrm{V}$ adquire a temperatura mais elevada, tornando-se a fonte efetiva de elétrons. Um bom emissor termoiônico deve ter uma baixa função de trabalho, para fornecer uma elevada quantidade de elétrons em uma temperatura razoável, e também deve ter uma longa vida de operação. Neste trabalho foi utilizado um emissor de tungstênio, que tem uma função de trabalho relativamente alta, mas também possui um ponto de fusão alto, o que minimiza a evaporação do metal. Os filamentos de tungstênio comerciais têm duração entre 40 e 80 horas de uso.

Uma capa metálica (cilindro de Wehnelt), com uma única abertura de 1 a $3 \mathrm{~mm}$ de diâmetro, centrada no ápice, blinda o filamento. Uma pequena diferença de potencial é aplicada entre o filamento e o cilindro, para o primeiro direcionamento do feixe de elétrons.

O feixe é acelerado em direção ao ânodo, que é um disco com uma abertura alinhada coaxialmente com o filamento. Este disco é aterrado eletricamente, assim como o restante do microscópio, sendo o filamento mantido em um elevado potencial negativo em relação ao ânodo: $-80.000 \mathrm{~V}$. Após deixar o ânodo, os elétrons atravessam a coluna com velocidade constante, de maneira que a sua trajetória é alterada nas lentes eletromagnéticas, mas não a sua energia. 
A lente condensadora é o primeiro conjunto de lentes, formada por duas lentes eletromagnéticas acopladas, que focalizam o feixe sobre a amostra. Este controle é realizado basicamente pela corrente elétrica nos fios da bobina, que altera o campo eletromagnético que atua sobre o feixe de elétrons. O uso de diafragmas de diâmetros variados controla a área iluminada e a divergência angular do feixe.

O sistema de formação da imagem é constituído por uma lente objetiva e lentes intermediárias e projetoras. Este sistema é responsável pela qualidade final da imagem. A lente objetiva forma a primeira imagem ampliada da amostra. Nela estão projetados os espaços para a introdução da amostra, lentes para correção de astigmatismo e um conjunto de diafragmas. A pequena distância focal permite um melhor controle sobre a aberração esférica.

Um sistema mecânico permite escolher três diferentes diafragmas. Um deles é denominado de diafragma de sete furos cujos diâmetros variam de 30 a $90 \mu \mathrm{m}$. Quanto menor o diâmetro do diafragma menor será a divergência do feixe e maior a resolução da imagem. Entretanto, a escolha dos diafragmas, seja da lente condensadora, seja da lente objetiva, é determinada pela técnica utilizada na observação, pela espessura da amostra, e pelo tipo de contraste que dá origem à imagem. Estes parâmetros devem ser otimizados durante a observação da amostra.

As imperfeições das lentes magnéticas, a repulsão mútua dos elétrons nos pontos de cruzamento e a variação da energia do feixe no instante da emissão provocam distorções na imagem. Os principais tipos de aberrações encontradas em imagens são: aberração esférica, aberração cromática, curvatura de campo, astigmatismo, cometa e distorções devido a cargas espaciais. A aberração esférica é certamente um dos fatores mais importantes que limitam a resolução da imagem: a potência da lente varia radialmente, aumentando com a distância ao centro. Um elétron que penetra no campo da lente mais próximo à sua borda sofre a ação de uma força maior do que um elétron que atravessa a lente numa trajetória paraxial. Esses elétrons 
serão portanto focalizados em pontos diferentes gerando uma imagem de um disco e não a de um ponto. Este disco é chamado disco de Airy.

1.3.1. Preparação da amostra - O material a ser observado é colocado sobre telas metálicas vazadas, com diâmetro de $3 \mathrm{~mm}$. As telas são cobertas por um filme muito fino de parlódio, e em seguida evapora-se, em vácuo, um filme de carbono. Estes filmes são finos o suficiente para serem transparentes aos elétrons do feixe, porém propiciam uma boa sustentação mecânica e facilidade para o escoamento de cargas elétricas.

A amostra tem sua espessura limitada em função da energia do feixe que irá atravessá-la. Em uma primeira aproximação pode-se estabelecer um intervalo de espessuras de 30 a $400 \mathrm{~nm}$. Os espalhamento faz com que os elétrons emergentes possuam diferentes energias, sendo focalizados em diferentes pontos pela lente objetiva, surgindo uma aberração cromática que prejudica a qualidade da imagem. No interior das amostras espessas ocorre um maior número de espalhamento múltiplo, porém, nas amostras muito finas, e compostos de elementos com pequena diferença de número atômico, ocorre pouco espalhamento, dificultando a observação devido à falta de contraste.

1.3.2. Contraste de amplitude - As imagens de campo claro apresentam contraste de amplitude, geradas pela relação entre a intensidade do feixe incidente e as diferentes seções de choque na amostra. Os elétrons do feixe sofrem espalhamento elástico quando passam muito próximos dos núcleos dos átomos da amostra analisada, sendo defletidos em ângulos relativamente grandes, sem perda de energia. Isto, porque a massa do núcleo é muito maior que a do elétron. Assim, a intensidade de espalhamento, em um dado ângulo sólido, é proporcional à espessura de massa da amostra. Um diafragma com abertura angular relativamente pequena é colocado após a amostra, removendo do feixe os elétrons espalhados. A imagem será menos intensa 
em regiões que correspondem às seções de choques maiores na amostra. O contraste da imagem pode ser aumentado ou diminuído por meio da respectiva diminuição ou aumento da abertura do diafragma localizado no plano focal posterior da lente objetiva, também conhecido como diafragma ou abertura da objetiva.

\subsubsection{Contraste de fase - Outras imagens são formadas com o contraste de fase gerado} pelo espalhamento inelástico do feixe de elétrons. Quando os elétrons do feixe chocam com elétrons dos átomos da amostra, pode ocorrer uma perda de energia dos elétrons do feixe entre 10 e $20 \mathrm{eV}$. Em amostras finas ( $\cong 60 \mathrm{~nm}$ ), um único choque do elétron do feixe, considerando que o choque é entre dois corpos de massas iguais, provocará uma deflexão em um ângulo muito pequeno ( $10^{-4}$ radianos), o que permite que ele passe pela abertura da objetiva. A pequena perda de energia corresponde a uma mudança no comprimento de onda associado ao elétron. A onda resultante da somatória das ondas dos elétrons espalhados e não espalhados revela um contraste perceptível na imagem, revelando a estrutura que deu origem ao espalhamento inelástico. Em materiais não cristalinos, o contraste nas imagens é gerado pelo contraste de amplitude devido ao espalhamento elástico, e pelo contraste de fase devido ao espalhamento inelástico. De modo geral, o contraste de amplitude é dominante nas estruturas grandes, enquanto o contraste de fase aumenta de importância em estruturas pequenas, tornando-se a única fonte de contraste para objetos muito pequenos e de baixo número atômico.

1.3.4. Contraste de difração - Outra forma de se obter uma imagem é por meio do contraste de difração, um caso particular de contraste de amplitude, onde o espalhamento elástico de elétrons ocorre em certas direções preferenciais, por planos atômicos em materiais cristalinos. A difração é governada pela relação de Bragg: $2 d_{h k l} \operatorname{sen} \theta=n \lambda$, onde $d_{h k l}$ é a distância interplanar do cristal, $\theta$ é o ângulo de incidência entre o feixe e o plano do cristal, também denominado ângulo de Bragg, $n$ é um número 
inteiro, e $\lambda$ é o comprimento de onda associado ao feixe de elétrons acelerados (Figura 5).

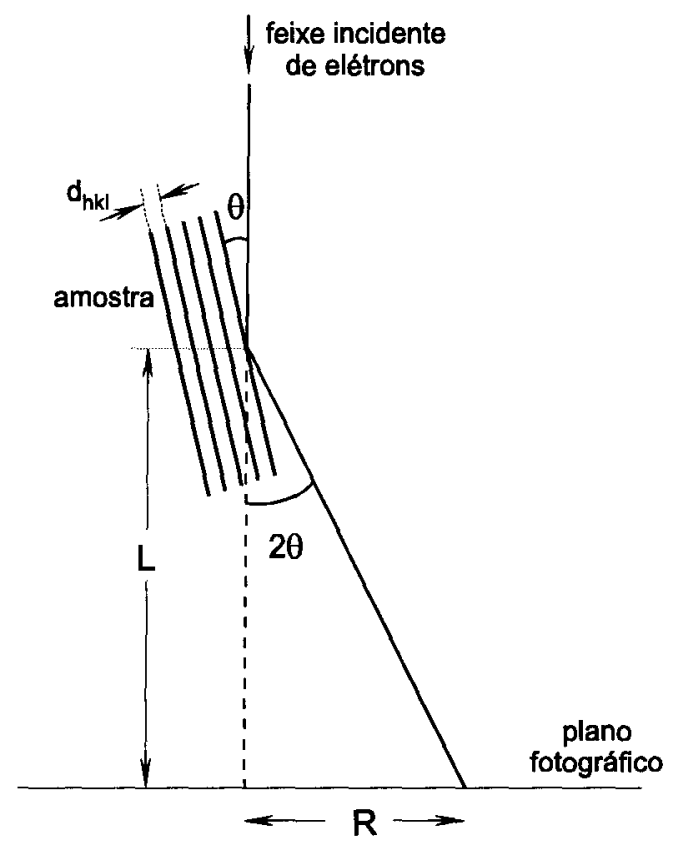

Figura 5. Geometria da difração dos elétrons.

Quando a abertura do diafragma está centrada no eixo da coluna do microscópio, a imagem de campo claro gerada será constituída pelos elétrons não espalhados menos os elétrons difratados. Os elétrons difratados formam uma imagem fora do eixo da coluna, contendo informaçōes sobre a estrutura cristalina do material analisado, e a imagem assim gerada é denominada de campo escuro. No microscópio Zeiss CEM 902, as imagens de campo escuro foram obtidas com o deslocamento da abertura do diafragma da lente objetiva até a interceptação do feixe difratado. As imagens resultantes não têm a mesma qualidade das imagens de campo claro, devido principalmente à aberração esférica. Existem microscópios onde as imagens de campo escuro são geradas com a inclinação do feixe de elétrons incidente em relação à amostra. Neste caso as imagens são geradas paraxialmente, não possuindo aberração esférica. Assim, o contraste das imagens de campo escuro é maior que o de campo 
claro, além de permitir uma identificação precisa e exata de inclusões de materiais cristalinos em amostras não cristalinas.

Em monocristais, a difração dos elétrons no arranjo atômico periódico resulta em padrões característicos de pontos (Figura 6a). Em amostras policristalinas, difrações em diferentes planos cristalinos resultam em padrões formados por anéis de Debye-Scherrer (Figura 6b). Os padrões de difração de amostras amorfas se caracterizam pela presença de largos halos (Figura 6c).



d

$\mathrm{Au}$ $\mathrm{e}$



Figura 6. llustração esquemática dos padrões de difração de amostras com diferentes cristalinidades: (a) monocristalino, (b) policristalino, (c) não-cristalino e difratogramas reais obtidos em amostras de (d) ouro e ouro depositado sobre vidro e (e) vidro e ouro depositado sobre vidro. ${ }^{[28]}$ 
1.3.5. Perda de energia - Quando um feixe de elétrons atravessa uma amostra, interações com elétrons de diferentes átomos resultam em perdas de energia características, correspondentes a determinadas energias de ligação dos elétrons nos átomos da amostra. O feixe de elétrons transmitido é dirigido para um espectrômetro de elétrons, o qual separa os elétrons de acordo com sua energia cinética, produzindo um espectro de perda de energia, mostrando a intensidade espalhada como função do decréscimo de energia cinética. A espectroscopia por perda de energia de elétrons (EELS ou ELS) permite identificar os elementos da amostra (até elementos de baixo número atômico), além de fornecer informações detalhadas sobre o estado eletrônico e das ligações químicas, permitindo também quantificá-los.

Embora o uso do EELS como técnica microanalítica tenha sido demonstrado na década de $40,{ }^{[29]}$ somente nas duas últimas décadas, com os avanços na instrumentação, esta técnica está sendo difundida. ${ }^{[30,31,32,33]}$

Um espectrômetro tipo Castaing-Henry-Ottensmeyer foi utilizado para formar as imagens de perda de energia (ESI) e elementares: os elétrons espalhados inelasticamente são filtrados em um sistema com um prisma magnético de campo uniforme e um espelho eletrostático (Figura 7). ${ }^{[34]}$ 


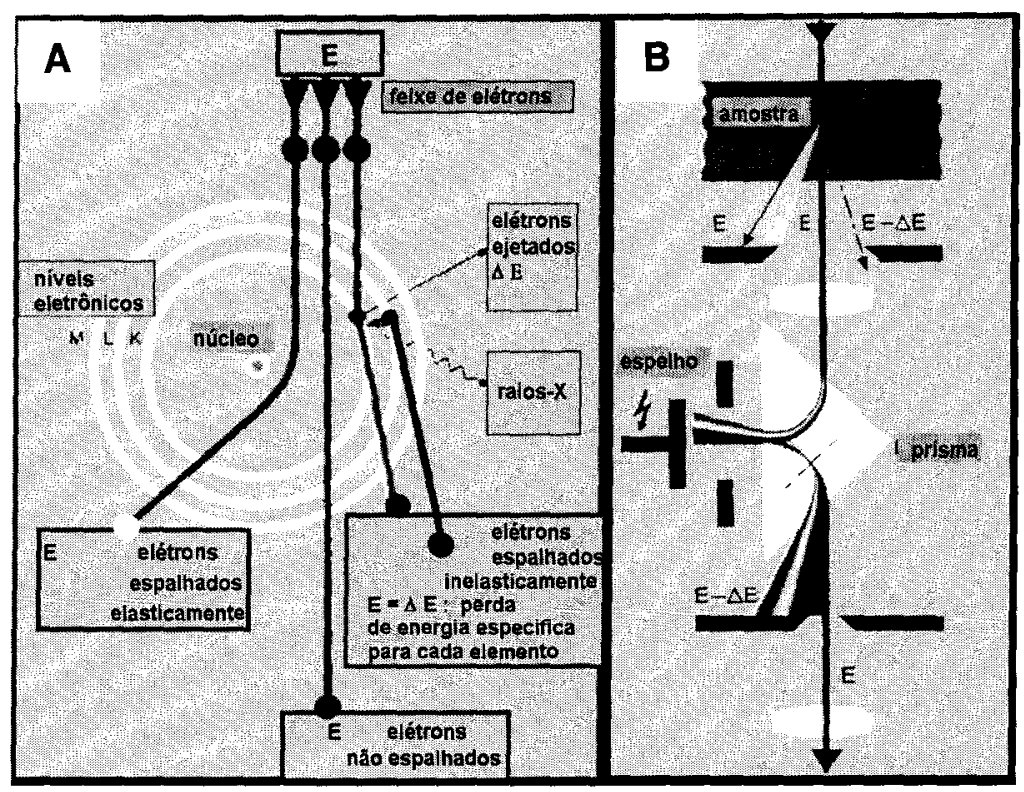

Figura 7. (A) Esquema de interação de um feixe de elétrons e os átomos de uma amostra. (B) Esquema do espectrômetro utilizado para formar imagens de perda de energia dos elétrons (ESI).

Os elétrons são defletidos a $90^{\circ}$ pelo prisma, emergem na direção horizontal, e são refletidos a $180^{\circ}$ pelo espelho, retornando para o campo do prisma. Como o sentido da velocidade é invertido, os elétrons são defletidos de volta à direção e sentido original do feixe, no eixo vertical do microscópio. Elétrons com diferentes energias descrevem raios de curvatura diferentes no prisma. $O$ espelho eletrostático consiste em um eletrodo planar e outro anular, ambos polarizados a algumas centenas de Volts negativos com relação ao potencial do feixe. A reflexão depende da polarização aplicada aos dois eletrodos, e do raio de curvatura da polarização entre os eletrodos, o que permite variar o ângulo de deflexão dos elétrons e obter uma maior faixa do espectro de perdas de energia.

O espectro é adquirido detectando-se elétrons em pequenos canais discretos de energia (tipicamente $1 \mathrm{eV}$ ). A aquisição é realizada de forma paralela, onde os elétrons com diferentes energias que emergem do espectrômetro são coletados simultaneamente em um detector sensível à posição. $O$ nível de ruído e a faixa 
dinâmica são inferiores aos obtidos em um detector de canal único, porém, como não há fenda seletora de energia, a eficiência quântica do sistema é limitada apenas pela eficiência do detector. Como resultado, os espectros podem ser adquiridos em tempos e doses de radiação menores, diminuindo os danos sofridos pela amostra.

Uma importante questão é a sensibilidade das microanálises de EELS, seja absoluta, seja em comparação com diferentes técnicas utilizadas para determinar a estrutura e/ou composição química de um sólido. As técnicas microanalíticas de alta resolução espacial mais utilizadas estão listadas na Tabela 1.

Tabela 1. Técnicas microanalíticas utilizando feixes de elétrons, íons, e fótons, com a resolução espacial estimada.

\begin{tabular}{|c|c|c|c|}
\hline $\begin{array}{c}\text { Feixe } \\
\text { incidente }\end{array}$ & $\begin{array}{c}\text { Sinal } \\
\text { detectado }\end{array}$ & Técnica microanalítica & $\begin{array}{l}\text { Resolução } \\
\text { (nm) }\end{array}$ \\
\hline \multirow{5}{*}{ elétron } & \multirow{4}{*}{ elétron } & $\begin{array}{l}\text { Microscopia eletrônica de transmissão } \\
\text { (CTEM, STEM) }\end{array}$ & 0,2 \\
\hline & & $\begin{array}{l}\text { Difração de elétrons } \\
\text { (SAD, CBD) }\end{array}$ & 10 \\
\hline & & $\begin{array}{l}\text { Espectroscopia por perda de } \\
\text { energia de elétrons (EELS) }\end{array}$ & $\sim 1$ \\
\hline & & $\begin{array}{l}\text { Espectroscopia de elétrons Auger } \\
\text { (AES) }\end{array}$ & -2 \\
\hline & fóton & $\begin{array}{l}\text { Espectroscopia por emissão de raios-X } \\
\text { (XES) }\end{array}$ & $\sim 10$ \\
\hline \multirow{3}{*}{ íon } & \multirow[t]{2}{*}{ íon } & $\begin{array}{l}\text { Espectroscopia de retroespalhamento } \\
\text { Rutherford (RBS) }\end{array}$ & \\
\hline & & $\begin{array}{l}\text { Espectroscopia de massa } \\
\text { por íons secundário (SIMS) }\end{array}$ & 50 \\
\hline & fóton & $\begin{array}{l}\text { Emissão de raios-X induzida } \\
\text { por fóton (PIXE) }\end{array}$ & 500 \\
\hline \multirow{6}{*}{ fóton } & \multirow{3}{*}{ fóton } & Difração de raios- $X$ & \multirow{3}{*}{100} \\
\hline & & $\begin{array}{c}\text { Espectroscopia de absorção } \\
\text { de raios- } X \text { (XAS) }\end{array}$ & \\
\hline & & $\begin{array}{c}\text { Espectroscopia de fluorescência } \\
\text { de raios-X (XFR) }\end{array}$ & \\
\hline & \multirow[t]{2}{*}{ elétron } & $\begin{array}{c}\text { Espectroscopia de fotoelétron } \\
\text { de raios-X (XPS) }\end{array}$ & \\
\hline & & $\begin{array}{l}\text { Espectroscopia de fotoelétron } \\
\text { de ultra-violeta (UPS) }\end{array}$ & 1000 \\
\hline & íon & $\begin{array}{c}\text { Análise de massa por microsonda } \\
\text { de laser (LAMMA) }\end{array}$ & 1000 \\
\hline
\end{tabular}


A microscopia eletrônica de transmissão (CTEM, STEM) e a espectroscopia por perda de energia de elétrons (EELS) apresentam melhor resolução espacial que as demais técnicas. Algumas destas, como a espectroscopia Auger, são sensíveis à superfície da amostra: elas caracterizam a primeira monocamada, ou algumas monocamadas de átomos. As técnicas de EELS e difração de elétrons de alta energia possuem uma sonda com maior penetração na amostra, possibilitando a obtenção de informações do interior do material, como no caso de amostras finas.

As técnicas também podem ser classificadas como destrutivas ou não destrutivas. A espectroscopia de massa de íns secundários (SIMS) e a análise de massa por microsonda de laser (LAMMA) são exemplos de técnicas que são necessariamente destrutivas, uma propriedade que muitas vezes é uma desvantagem mas que em alguns casos, como no SIMS, pode ser usado para obter informações tridimensionais, com a análise de cada camada da amostra. Os métodos de feixe de elétrons são freqüentemente não-destrutivos, mas na prática alguns choques inelásticos dos elétrons incidentes resultam em danos na amostra.

Uma técnica microanalítica bastante utilizada nos microscópios eletrônicos de varredura é o EDX ("energy-dispersive x-rays"). O EDX observa indiretamente as interações entre o feixe de elétrons incidente e a amostra, mas com o EELS estas interações podem ser estudadas diretamente, medindo as mudanças na energia, ou no momento, dos elétrons que ocorrem como resultado das colisões inelásticas. O EELS não somente é um procedimento mais eficiente, porque está sendo observado o evento primário, como também mais informativo porque uma maior faixa de interações pode ser examinada. Uma das limitações das análises por EDX é que o volume analisado tem diâmetro maior que o do feixe de elétrons incidente. Isto é causado pelo espalhamento múltiplo elástico dos elétrons e pode gerar raio- $X$ de regiões distantes da posição do feixe incidente, o que tipicamente limita a resolução espacial em centenas de Angstrons. 
No caso da microanálise por EELS este efeito não ocorre, porque somente os elétrons coletados dentro de um ângulo de aceitação do espectrômetro irão contribuir para a formação do sinal. Para um ângulo de aceitação $\beta$ e uma amostra com espessura $\tau$, a resolução será maior que $\beta \tau$. Como $\beta$ é tipicamente de poucos miliradianos, a resolução espacial definida pelo feixe de elétrons é de poucos Angstrons. Está resolução é menor considerando que um elétron pode ionizar um átomo quando passa a uma distância de até $20 \AA^{[35]}$

Na prática, a resolução espacial é determinada pelo menor tamanho da sonda que contém corrente suficiente para alcançar uma relação sinal-ruído aceitável no espectro. Usando um sistema de detecção paralelo de perda de energia de elétrons, Shuman et al. ${ }^{[36]}$ obtiveram, em um mesmo período de contagem, uma relação sinalruído com um fator 6 a 8 vezes maior que o obtido por espectroscopia EDX. Com filamentos de tungstênio convencionais, o limite de detecção do EDX em amostras de $100 \mathrm{~nm}$ é estimado em $10^{-19} \mathrm{~g} \cdot{ }^{[37,38]}$ Partículas de catalisadores metálicos com massa de $10^{-20} \mathrm{~g}$ foram analisados por EDX usando uma fonte de elétrons por emissão de campo, porém sofreram fortes danos por radiação. ${ }^{[39]}$

No EELS utilizando filamentos de tungstênio convencionais já era possível alcançar resolução de aproximadamente $100 \AA$ em $1986{ }^{[26]}$ O valor também depende da energia perdida, do pico de interesse e do tempo de aquisição. Quantidades de fósforo da ordem de $10^{-20} \mathrm{~g}$ (200 átomos) foram detectados por mapas elementares ${ }^{[40]}$ e por espectroscopia em um STEM por emissão de campo. ${ }^{[1]}$ Sob certas condições experimentais já era possível identificar átomos individuais, desde $1979 .^{[42]} \mathrm{A}$ única técnica que tem demonstrado sensibilidade comparável é a microscopia de campo iônico (FIM), onde os átomos são emitidos a partir de uma extremidade afiada de uma amostra, e individualmente analisados em um espectrômetro de massa. Entretanto, as aplicações da técnica de FIM são limitadas pela dificuldade na preparação das amostras. 
Outro importante requisito de uma técnica microanalítica é que os dados produzidos possam ser quantificáveis. Os espectros de perda de energia, tanto da região de baixa perda de energia, como na região de ionização das camadas eletrônicas mais internas, podem ser processadas para se obter uma microanálise química quantitativa.

A região de baixa perda de energia é definida como a região de perda abaixo de $100 \mathrm{eV}$. Dentro desta região, o principal mecanismo de perda de energia envolve a excitação de camadas eletrônicas externas, particularmente os elétrons de valência, ou os de condução no caso de metais, e a excitação dos fônons.

A ionização das camadas eletrônicas mais internas ocorre acima de $100 \mathrm{eV}$ (Figura 8). Cada elemento presente podem ser identificado pela ocorrência de um pico de ionização característico no espectro de perda de energia. ${ }^{[43,44]}$ A quantidade de cada elemento pode ser calculada medindo a área sob o pico de ionização, após a subtração da linha-base do sinal. O procedimento é mais exato que a medida da intensidade máxima do pico, pois a estrutura fina do pico muda consideravelmente com a estrutura e meio químico em que se encontra o átomo ionizado.



(a)

(b)

(c)

(d)

Figura 8. Excitações eletrônicas em sólidos: (a) transições intrabandas,

(b) transições interbandas, (c) plasmons e (d) transições de camadas internas. 
Embora as informações sobre a estrutura cristalográfica e a composição química da amostra estejam diretamente expressas no espectro de perda de energia, o espalhamento múltiplo altera drasticamente a intensidade e a forma do pico de ionização das camadas eletrônica internas, o que dificulta a aquisição de dados e a interpretação dos espectros. Este espalhamento resulta de uma ou mais colisões inelásticas de baixa perda de energia, com a excitação das camadas eletrônicas externas, que ocorrem em adição à ionização das camadas internas. A seção de choque das camadas eletrônicas externas, tanto para colisões elásticas como inelásticas, é da ordem de 4 ordens de grandeza maior que a seção de choque da camada $\mathrm{K}^{[45]}$ Assim, em amostras finas, onde a espessura é pequena se comparada com o livre caminho médio das camadas eletrônicas internas, a probabilidade de mais de uma ionização das camadas internas pode ser negligenciada.

A probabilidade $P_{n}$ de $n$ sucessivas colisões de um elétron do feixe incidente e uma amostra com espessura $\ell$ obedece a estatística de Poisson:

$$
P_{n}=(1 / n !) m^{n} \exp (-m)
$$

onde $m$ é o número médio de colisões com uma amostra de espessura $\ell$, que pode ser descrito como $\ell / \lambda$, onde $\lambda$ é o livre caminho médio. Substituindo na Eq. (17):

$$
P_{n}=(1 / n !)(\ell / \lambda)^{n} \exp (-\ell / \lambda)
$$

onde $\exp (-\ell / \lambda)$ é a probabilidade do elétron atravessar a espessura $\ell$ da amostra sem nenhum espalhamento. Como não é considerada a ordem das colisões, é inserido o termo $(1 / n !)$, onde $n$ ! é a permutação do número de choques. 
Para cada valor de $n$, a probabilidade máxima de espalhamento é encontrada em $\ell / \lambda=1$.

O ângulo de espalhamento aumenta com $n$. A Eq. (18) admite que todos os elétrons espalhados são detectados. Na prática, o espectrômetro detecta somente os elétrons em um ângulo menor que um valor $\beta$. Assim, esta equação é bastante adequada para as imagens de perda de energia, onde $n=1$.

Também se admite que as colisões dos elétrons são eventos independentes, e que a distância percorrida na amostra é a mesma para diferentes valores de $n$, o que é uma boa aproximação quando o ângulo de espalhamento é pequeno.

Mais de um processo de espalhamento pode ocorrer, sendo que a seção de choque efetiva $\tau$ é a soma das diferentes seções de choque:

$$
\tau=\tau_{1}+\tau_{2}+\ldots \tau_{n}
$$

ou em função de $\lambda$ :

$$
1 / \lambda=1 / \lambda_{1}+1 / \lambda_{2}+\ldots 1 / \lambda_{n}
$$

A Figura 9 ilustra uma trajetória do caminho percorrido por um elétron de um feixe normal incidente, a uma distância $x$ do centro de uma partícula de raio $r$, depositada sobre um substrato plano de espessura $\ell_{2}$ : 




Figura 9. llustração do caminho percorrido por um elétron de um feixe normal incidente, a uma distância $\mathrm{x}$ do centro de uma partícula de raio $r$, depositada sobre um substrato plano de espessura $\ell_{2}$.

Neste caso, a variação de $\ell$ em função de $x$ é determinada pelas equações (21) e (22):

$$
\begin{gathered}
\ell=\ell_{1}+\ell_{2} \\
\ell_{1}=2\left(r^{2}-x^{2}\right)^{1 / 2}
\end{gathered}
$$

para $|x| \leq r$.

Substituindo as Eqs. (21) e (22) na Eq. (18):

$$
\left.P_{1}=\left(2\left(r^{2}-x^{2}\right)^{1 / 2}+l_{2}\right) / \lambda\right) \exp \left(-\left(2\left(r^{2}-x^{2}\right)^{1 / 2}+\ell_{2}\right) / \lambda\right)
$$

para $|\mathbf{x}| \leq \mathrm{r}$.

$$
P_{1}=\ell_{2} / \lambda \exp \left(-\ell_{2} / \lambda\right)
$$

para $|x| \leq r$.

\subsection{Microscopia eletrônica de varredura por emissão de campo (FESEM) - Os} microscópios eletrônicos de varredura podem ser classificados como: microscópio 
eletrônico de varredura convencional (SEM) e microscópio eletrônico de varredura por emissão de campo (FESEM). A diferença básica é que no sistema convencional os elétrons são emitidos por um canhão termoiônico, onde o diâmetro da sonda pode variar de $10 \mathrm{~nm}$ a $1 \mu \mathrm{m}$ e as densidades de corrente de $1 \mathrm{pA}$ a $1 \mu \mathrm{A}$, enquanto no FESEM (Figura 10) a emissão dos elétrons é gerada pela aplicação de um campo elétrico de $10^{5} \mathrm{~V} / \mathrm{m}$, e o diâmetro da sonda pode variar a partir de $1 \mathrm{~nm}$.

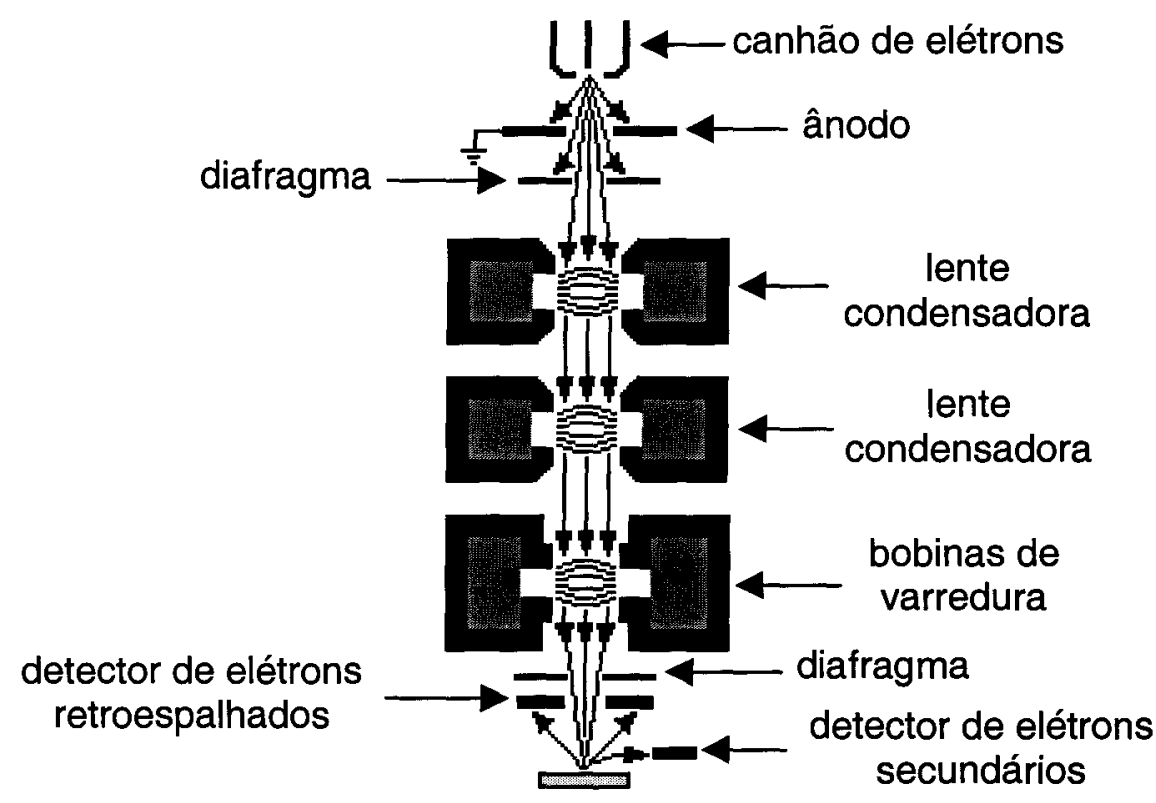

Figura 10. Microscópio eletrônico de varredura por emissão de campo.

Os elétrons emitidos pelo canhão eletrônico atravessam uma abertura com diâmetro da ordem de $50 \mu \mathrm{m}$. A seguir são acelerados com tensões que variam de 0,5 a $30 \mathrm{kV}$ em direção ao ânodo, com uma corrente de feixe de $1 \mathrm{pA}$ a $1 \mu \mathrm{A}$. Da mesma forma que no microscópio de transmissão, após atravessar a abertura central do disco anódico, a velocidade dos elétrons é constante na coluna. A sua trajetória é alterada nas lentes eletromagnéticas, mas não a sua energia. $O$ vácuo utilizado é de $10^{-7}$ torr no canhão, e de $10^{-8}$ torr no porta amostra. 
O primeiro conjunto de lentes é chamado de lentes condensadoras, que reduzem o diâmetro do feixe para cerca de $1 \mathrm{~nm}$ a $1 \mu \mathrm{m}$. A seguir, o feixe sofre a ação de um par de bobinas, que deflete o feixe periodicamente gerando um padrão de varredura $x, y$ sobre a superfície da amostra. Este padrão está sincronizado com o monitor de forma que cada ponto da varredura sobre a amostra está associado com um ponto na tela do monitor.

Antes de incidir sobre a amostra, o feixe atravessa um diafragma que limita sua divergência. A abertura vai depender da profundidade de foco e nitidez, além do tipo de sinal formador da imagem, como elétrons secundários, retroespalhados, raios $X$, etc.

Dois processos simultâneos ocorrem quando o feixe de elétrons interage com a amostra, que dão origem a diferentes sinais que podem ser coletados para formar diferentes imagens. O primeiro é o espalhamento elástico, onde a interação provoca mudanças apenas na trajetória do elétron do feixe, sem alterar sua energia cinética. Outro processo é o espalhamento inelástico, onde diferentes eventos resultam na transferência de energia dos elétrons do feixe para os átomos da amostra, podendo gerar a emissão de elétrons secundários, elétrons Auger, raios $X$ característicos e contínuos, pares de elétrons e buracos em semicondutores e isolantes, radiação eletromagnética na região do visível, ultravioleta e infravermelho (catoluminescência), vibrações de rede (fônons) e oscilações eletrônicas em metais (plasmons).

Em amostras eletricamente isolantes torna-se necessário o recobrimento da superfície com um material eletricamente condutor, geralmente ouro ou uma liga ouro-paládio ou carbono grafitizado, para aumentar a geração de elétrons secundários, o escoamento das cargas elétricas e a dissipação de energia térmica que são gerados pelo feixe de elétrons incidente. 
1.4.1. Elétrons secundários - As imagens mais usuais são as obtidas com elétrons secundários (SEI). Neste caso, a superfície da amostra tem que ser eletricamente condutora para que haja a produção de elétrons secundários. Os elétrons secundários são definidos como tendo uma energia inferior a $50 \mathrm{eV}$, sendo que $90 \%$ possuem energia inferior a $10 \mathrm{eV}$. Detectores para estes são do tipo EverhartThornley, constituídos de um cintilador, um tubo de luz e um tubo fotomultiplicador.

O detector é colocado ao lado da amostra e em um determinado ângulo, sendo isolado do restante do microscópio. Na parte frontal do detector é colocada uma grade com um potencial de cerca de $+300 \mathrm{~V}$, que atrai os elétrons secundários gerados na amostra. Os elétrons que entram no detector E-T são acelerados por uma voltagem de $+12 \mathrm{kV}$, aplicada sobre a cobertura de alumínio do cintilador. Os elétrons secundários energizados atingindo o cintilador produz luz, que penetra no tubo de luz incidindo sobre a fotomultiplicadora, que por sua vez converte o sinal luminoso em sinal elétrico amplificado. O contraste nas imagens é gerado pela variação da intensidade do sinal detectado durante uma varredura. 0 caráter tridimensional característico em imagens de microscopia eletrônica de varredura é conseqüência do ângulo de incidência do feixe primário em relação à topografia da amostra, do ângulo entre a amostra e o detector, e da contribuição de elétrons retroespalhados por superfícies frontais ao detector. Regiões varridas pelo feixe e que estão em um ângulo de visão direta do detector, produzem um sinal mais intenso (maior brilho), e as regiões que estão em um ângulo oposto produzem um sinal mais fraco. Entre estes extremos há uma variação contínua de intensidades, gerando o contraste observado nas imagens. 


\subsection{Microscopia de Varredura por Sonda (SPM)}

1.5.1. Microscopia de força atômica de não-contato (AFM non-contact) - A microscopia de força atômica de não-contato é um método de operação onde através de piezoelementos, o conjunto sonda/armação é colocado a oscilar livremente, na vertical, em sua freqüência natural de ressonância. ${ }^{[46]} A$ seguir a sonda é aproximada da superfície da amostra, onde o gradiente de forças $F^{\prime}=\partial F_{z} / \partial z$ entre a sonda e a superfície modifica a constante de mola efetiva da sonda:

$$
c_{e f}=c-F
$$

onde cé a constante de mola na ausência de forças de interação sonda-amostra.

Forças atrativas $F>0$ resultam na diminuição da constante de mola efetiva $c_{e f}<c$, e forças repulsivas $F^{\prime}<0$ resultam no aumento da constante de mola efetiva $c_{e f}>c$. Estas variações resultam mudanças na freqüência de ressonância da sonda:

$$
\omega=\left(C_{e f} / m\right)^{1 / 2}=\left[\left(c-F^{\prime}\right) / m\right]^{1 / 2}=(c / m)^{1 / 2}\left(1-F^{\prime} / c\right)^{1 / 2}=\omega_{o}\left(1-F^{\prime} / c\right)^{1 / 2}
$$

onde $m$ é a massa efetiva e $\omega_{\circ}$ é a freqüência de ressonância da sonda na ausência do gradiente de forças. Se $F$ 'é relativamente pequeno em relação a $c$, a equação pode ser aproximada:

$$
\omega \approx \omega_{o}\left(1-F^{\prime} / 2 c\right)
$$

então:

$$
\Delta \omega=\omega-\omega_{o} \approx-F^{\prime} / 2 c
$$


Forças atrativas ( $F>0$ ) resultam no decréscimo da freqüência de ressonância $\left(\omega<\omega_{0}\right)$, e forças repulsivas $\left(F^{\prime}<0\right)$ resultam no acréscimo da freqüência de ressonância $\left(\omega>\omega_{0}\right)$. Diferentes métodos são comumente usados para analisar o deslocamento da freqüência de ressonância. Mudanças na amplitude ou fase da oscilação são resultantes das interações sonda-amostra, que são adquiridas através de um feixe do laser refletido pela sonda em um fotodetector. Estas variações são utilizadas em uma malha fechada de realimentação para controlar o deslocamento do piezo z, mantendo constante o gradiente de forças. Percorrendo o plano de varredura $x, y$ paralelo à superfície, a voltagem aplicada ao piezo z, devidamente calibrada, é plotada como imagem topográfica (Figura 11).

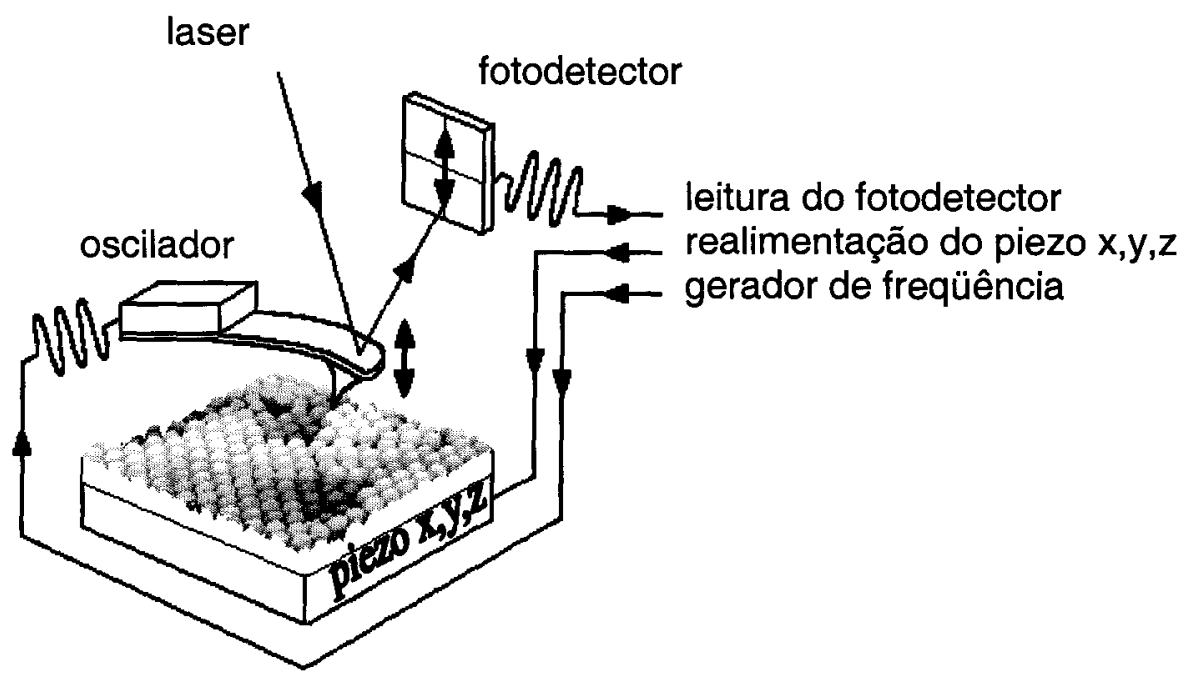

Figura 11. Microscopia de força atômica de não contato.

Estas imagens são geradas pela convolução da sonda, com extremidade de raio $-20 \mathrm{~nm}$, com a geometria da superfície da amostra. No caso de partículas coalescidas (Figura 12), os valores de x e y são verdadeiros, porém os valores de $z$ são inferiores aos reais, devido à penetração incompleta da sonda entre as partículas. Isto dificulta bastante a resolução de partículas com diâmetros da ordem de $40 \mathrm{~nm}$ ou menores. 




Figura 12. As varreduras de protuberâncias de esferas coalescidas fornecem medidas corretas no plano $x, y$, porém no eixo $z$ os valores obtidos são menores que os reais $\left(z_{i}<z_{r}\right)$.

Imagens de varreduras de partículas individuais (Figura 13) apresentam diâmetros no plano $x, y$ maiores que os reais.
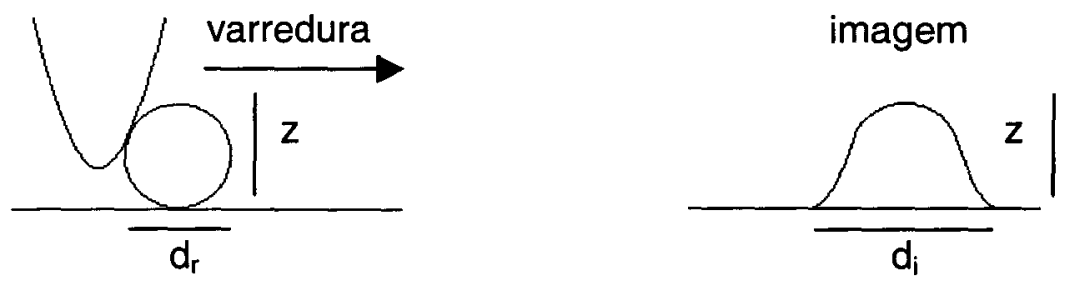

Figura 13. As varreduras de protuberâncias individuais produzem medidas maiores que as reais no plano $x, y\left(d_{r}<d_{i}\right)$, mas produzem valores corretos no eixo $z$.

1.5.2. Microscopia de Força Elétrica (EFM) - A força eletrostática $F_{\mathrm{el}}$ entre uma sonda condutora e uma superfície é dado por ${ }^{[47]}$ :

$$
F_{e l}=-\left(V^{2} / 2\right) \cdot(\partial C / \partial z)
$$

onde $\mathrm{V}$ é a diferença de potencial, $\mathrm{C}$ é a capacitância e zé a distância entre a sonda e a amostra.

A microscopia de Força Elétrica é um modo de aquisição onde o gradiente elétrico sobre a superfície de uma amostra é mapeado através de uma sonda de Si recoberta com Pt ${ }^{[48]}$. Como as interações elétricas são de longo alcance, as 
informações de topografia e força elétrica são adquiridas em duas etapas em cada ponto da amostra: primeiramente próximo da superfície, a aproximadamente $10 \mathrm{~nm}$, onde as forças de van der Waals são predominantes, são adquiridas as informações topográficas, de modo análogo à microscopia de força atômica de não contato. A seguir a sonda é afastada da superfície a uma distância entre 40 a $60 \mathrm{~nm}$. Nesta distância a força elétrica é predominante e as informações elétricas são obtidas ${ }^{[49]}$ (Figura 14).

(a)

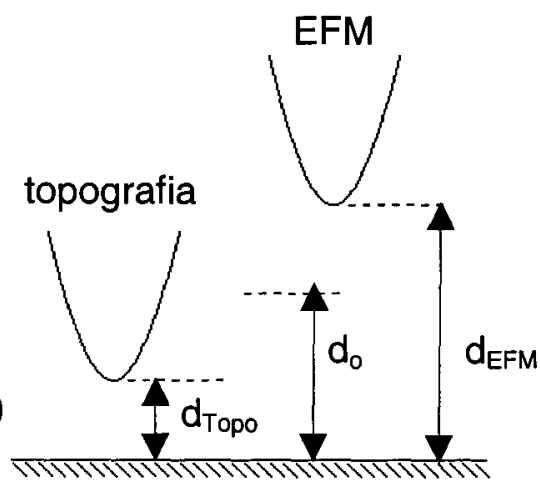

força

(b)

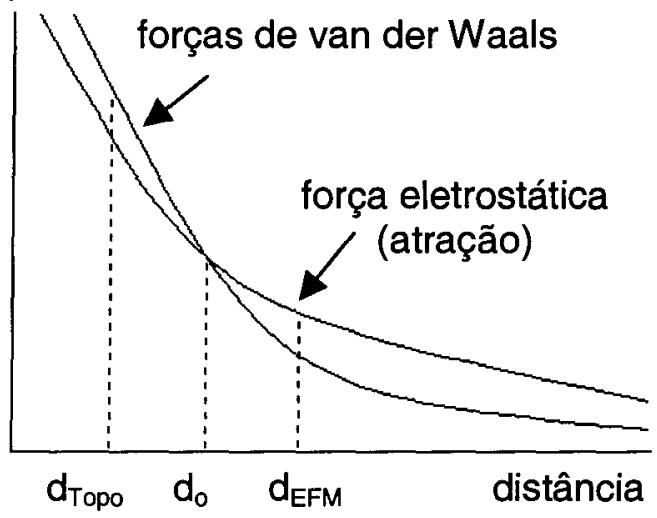

Figura 14. (a) Imagens de AFM e EFM adquiridas em diferentes alturas da superfície. (b) As forças de van der Waals predominam em pequenas alturas ( $10 \mathrm{~nm})$, e a força eletrostática a alturas maiores $(\cong 40 \mathrm{~nm})$.

A imagem topográfica é obtida pela monitoração da voltagem, devidamente linearizada, aplicada pela malha de realimentação ao piezo z para manter constante a amplitude de oscilação da sonda durante a varredura.

A imagem elétrica é gerada pela defasagem do sinal de oscilação da sonda a uma distância pré-determinada, em torno de $60 \mathrm{~nm}$ da superfície da amostra. Para maximizar a separação dos sinais elétricos e topográficos, é usado um amplificador tipo lock-in, as variações devido ao sinal elétrico são monitoradas em um ângulo de $90^{\circ}$ adiantadas com a monitoração topográfica. (Em um gráfico polar, podemos representar o eixo x (real) como a amplitude, e o eixo y (imaginário) como a fase, o vetor representa a oscilação da sonda: o tamanho é o módulo, e o ângulo com o eixo 
x representa o ângulo de fase. Devemos ajustar os parâmetros iniciais de aquisição para que este ângulo seja aproximadamente zero, assim qualquer variação na amplitude provoca variação equivalente no eixo $x$, assim como qualquer variação no ângulo de defasagem provocará maior variação no eixo y, maximizando o desacoplamento destes sinais).

O contraste observado nas imagens de EFM mostra o quanto as cargas da amostra estão perturbando o sinal de oscilação da sonda a uma altura onde a força eletrostática é muito maior que as forças de van der Waals. Se a sonda está carregada negativamente, o sinal de fase pode adiantar ou atrasar quando a varredura é realizada sobre domínios negativos ou positivos respectivamente. 0 inverso é válido quando a sonda estiver carregada positivamente. Se a sonda não estiver aterrada, nem polarizada externamente, cargas positivas ou negativas na amostra sempre irão induzir cargas de sinal contrário na sonda, surgindo sempre uma força de atração eletrostática, que irá atrasar o sinal de fase.

1.5.3. Microscopia de varredura de potencial eletrostático (SEPM) - A força eletrostática $F_{e l}$ entre uma sonda e a superfície de uma amostra, sem aplicação de potencial externo, é dada por:

$$
F_{e l}(d)=1 / 4 \pi \varepsilon_{o} \sum_{\mathrm{j}=1}^{\mathrm{N}} \sum_{\mathrm{i}=1}^{\mathrm{N}}-q_{i} q_{j} /\left|r_{i}+r_{j}\right|^{2}
$$

sendo $q_{i}$ e $q_{j}$ as cargas elétricas na sonda e na amostra, e $r_{i}$ e $r_{j}$ a separação entre as cargas.

A expressão para o cálculo do campo elétrico $E$ gerado pela amostra na sonda é dada por:

$$
E=1 / 4 \pi \varepsilon_{o} \sum_{j=1}^{N}-q_{j} / r_{j}^{2}
$$


O valor do potencial elétrico em um ponto $P$, localizado a uma distância $r_{j}$ da carga $q_{j}$ geradora do campo em $P$, é dado por:

$$
V=1 / 4 \pi \varepsilon_{o} \quad \sum_{j=1}^{N} q_{j} / r_{j}
$$

A microscopia de varredura de potencial eletrostático (SEPM) mede o potencial eletrostático presente sobre a superfície da amostra com resolução espacial de $\approx 20 \mathrm{~nm}$. O princípio utilizado para medir a diferença de potencial entre a sonda e a amostra é análogo ao método do capacitor vibrante, ou método de Kelvin, no qual a oscilação da distância entre duas placas paralelas, na freqüência $\omega$, resulta em uma corrente $i(t)$ dado por :

$$
i(t)=V_{p c} \omega \Delta C \cos \omega t
$$

onde $V_{p c}$ é a diferença de potencial de contato entre as duas placas, e $\Delta C$ é a mudança na capacitância.

Para determinar o valor de $V_{p c}$, é aplicado um potencial adicional até anular o campo elétrico entre as placas e anular a corrente $i(t)$. No SEPM a força eletrostática é a grandeza analisada, ao invés da corrente: para cada ponto da imagem, uma tensão elétrica adicional é aplicada entre a sonda e a amostra até que o campo elétrico entre elas se anule, anulando a força eletrostática. Esta tensão corresponde ao potencial de superfície. ${ }^{[50]}$

Um sistema padrão de aquisição de imagens por força atômica sem contato é utilizado para a aquisição da imagem topográfica da superfície. Simultaneamente um segundo oscilador insere um sinal elétrico $A C$ na sonda, em uma freqüência cerca de $10 \mathrm{kHz}$ abaixo da freqüência do primeiro oscilador, que esta ajustado na freqüência de oscilação natural da sonda (entre 40 e $70 \mathrm{kHz}$ ). As sondas de Si, recobertas por um material condutor (geralmente platina), durante uma oscilação 
livre vibram mecanicamente na freqüência do primeiro oscilador e possuem um sinal elétrico $A C$ na freqüência do segundo oscilador.

O sinal de leitura do fotodetector com as informações das interações sonda/amostra é desacoplado nas freqüências originais através de dois amplificadores tipo "lock-in". Na realimentação do segundo oscilador, as cargas presentes na superfície da amostra defasam o sinal de leitura na freqüência do sinal elétrico $A C$, e a eletrônica soma um potencial $D C$ ao sinal $A C$ aplicado à sonda, para anular a diferença de potencial entre a ponteira e a amostra, mantendo a fase constante. A monitoração do nível DC durante uma varredura fornece a imagem do potencial na superfície (Figura 15).

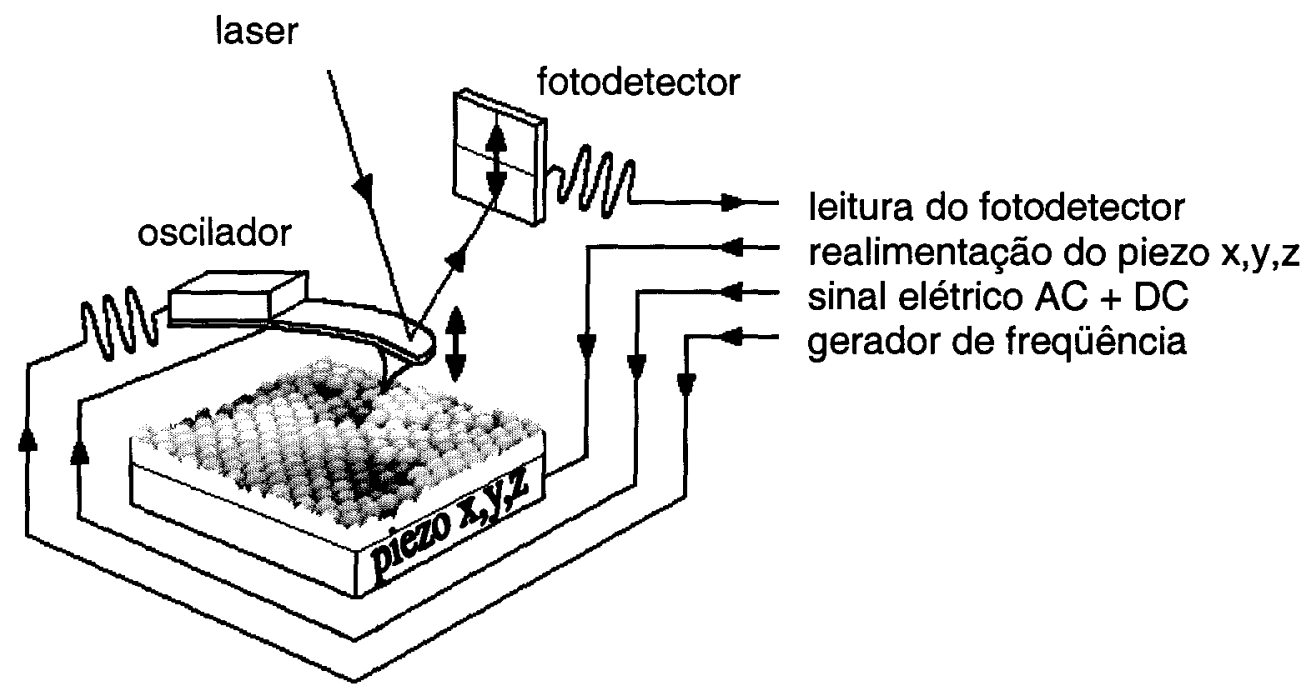

Figura 15. Microscopia de Varredura de Potencial Eletrostático.

Esta técnica pode ser usada para obter o mapeamento elétrico da superfície de filmes formados por partículas de sílica. Um modelo para a distribuição dos íons e contra-íons nesses filme é apresentado na Figura 16: as partículas de sílica são predominantemente negativas e encontram-se circundadas por contra-íons de carga positiva. 


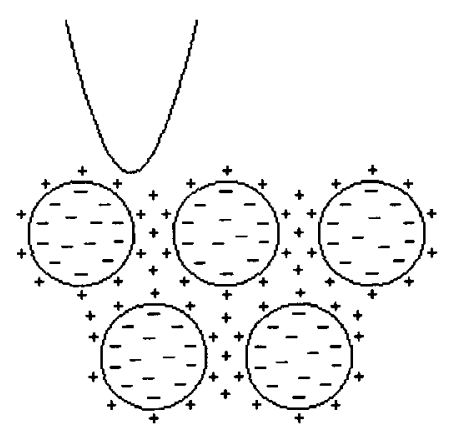

Figura 16. Ilustração de uma varredura de partículas carregadas negativamente, circundadas por cargas positivas.

O potencial resultante em cada ponto varrido pela sonda é a soma de todos os potenciais elétricos gerados pelas cargas presentes na amostra, como íons e cargas estáticas. Cada potencial é diretamente proporcional à carga elétrica, e inversamente proporcional à sua distância à sonda. A partir da Eq. (32) podemos verificar que um pequeno desbalanço iônico de 10 íons monovalentes, entre regiões contíguas $(\approx 20 \mathrm{~nm})$, gera diferenças de potencial da ordem de $1 \mathrm{~V}$ em pontos contíguos ( $\approx 20 \mathrm{~nm})$ a $10 \mathrm{~nm}$ de distância da superfície da amostra.

Os potenciais eletrostáticos podem ser positivos ou negativos, dependendo da preparação da amostra. São gerados por uma somatória de fatores como: (a) clivagem da mica utilizada como substrato, (b) aplicação de fita adesiva dupla face para aderir a mica ao porta amostra: a remoção do papel protetor provoca carregamento elétrico do adesivo e (c) manipulação com instrumentos que podem estar carregados eletricamente. Para diminuir o potencial eletrostático, a superfície da amostra deve ser colocada por alguns segundos em contato com um condutor metálico aterrado. Também é possível aplicar um potencial de mesmo módulo e sinal inverso ao porta amostra. 
1.5.4. Comparação entre SEPM e EFM - Os valores de tensão encontrados nas imagens de SEPM correspondem aos valores dos potenciais elétricos na superfície da amostra. No EFM estes valores são apenas um sinal de saída do lock-in, indicativo da defasagem observada devido a força eletrostática, não correspondem diretamente ao valor do potencial na superfície da amostra.

O SEPM também possui maior resolução espacial das cargas, devido a maior proximidade da sonda em relação à superfície da amostra durante uma varredura (Figura 17). Por outro lado apresenta um maior grau de dificuldade nos ajustes dos parâmetros e tempo de aquisição.

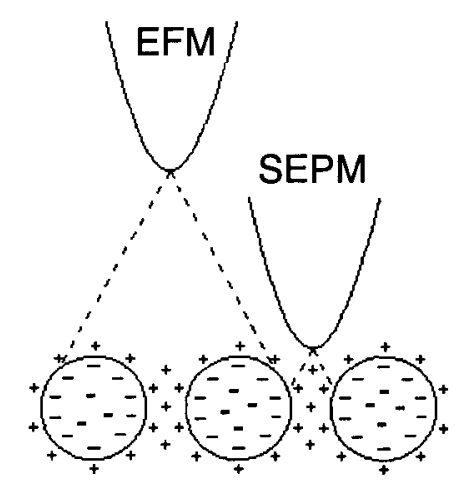

Figura 17. Ilustração das diferentes alturas de varredura nas técnicas de EFM e SEPM.

Na seção 4.12. são comparadas as imagens obtidas por SEPM e EFM de um filme de partículas de sílica, com $57 \mathrm{~nm}$ de diâmetro. 


\subsection{Ensaios mecânicos}

1.6.1. Dureza - A resistência de um material a uma indentação é uma indicação de sua resistência mecânica à compressão, desgaste e tensão de escoamento. Os ensaios de dureza medem a resistência de penetração da superfície de um material por um objeto duro. Diferentes ensaios são utilizados, os mais usuais são os ensaios Brinell, Rockwell e Vickers. ${ }^{[51]}$

Dureza Brinell - O material é submetido à ação de uma esfera de aço duro de diâmetro $D$ (tipicamente $10 \mathrm{~mm}$ ), comprimida por uma força $F$. Isto produz uma cavidade de diâmetro $d$ no material. A dureza Brinell (HB) é dada por: ${ }^{[52]}$

$$
H B=F /(\pi / 2) D\left(D-\sqrt{ } D^{2}-d^{2}\right)
$$

O número de dureza Brinell é relacionado com a tensão de escoamento pela relação:

$$
\text { Tensão de escoamento }(p s i)=500 \mathrm{HB}
$$

Dureza Rockwell - A profundidade de penetração de um indentador em uma superfície é convertida em um número de dureza (HR). Diferentes indentadores são utilizados em várias escalas de dureza, dependendo dos materiais avaliados. Para materiais duros, o indentador é um cone de diamante com ângulo de vértice de $120^{\circ}$. Esta escala é denominada Rockwell C (HRC). Para materiais semi-duros ou

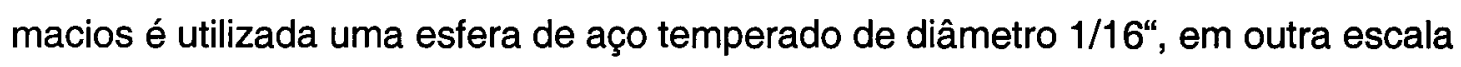
denominada Rockwell B (HRB). ${ }^{[53]}$ Isto representa uma vantagem em relação ao ensaio Brinell, que pode ser realizado em apenas uma pequena escala. Entretanto, as escalas Rockwell não têm continuidade, e a dureza de materiais nas duas escalas não podem ser comparadas entre si. A dureza Rockwell também não 
apresenta relação com o valor de resistência à tração, como acontece na dureza Brinell.

Dureza Vickers - O valor de dureza Vickers (HV) é baseado na resistência que um material oferece à indentação de uma pirâmide de base quadrada e ângulo entre faces de $136^{\circ}$, submetida a uma carga aplicada $F$ (kgf) (Figura18):

$$
H V=F / A
$$

onde A é a área de impressão deixada no corpo de prova ensaiado.



Figura 18. Indentador Vickers.

O equipamento não oferece o valor da área de impressão da pirâmide, mas por meio de um microscópio acoplado, permite obter as medidas das diagonais $\left(d_{1}\right.$ e $\mathrm{d}_{2}$ ) formados pelos vértices opostos da base da pirâmide. A área pode ser calculada pela Eq. (37): ${ }^{[53]}$

$$
A=d^{2} / 2 \operatorname{sen}(136 \% / 2)
$$

onde $\mathrm{d}$ corresponde à diagonal média $(\mathrm{mm})$ : 


$$
d=\left(d_{1}+d_{2}\right) / 2
$$

Das equações 36 e 37 temos:

$$
H V=F / d^{2} / 2 \operatorname{sen} 68^{\circ}=1,8544 F / d^{2}
$$

O ensaio Vickers foi desenvolvido considerando a relação ideal de 0,375 entre o diâmetro da calota esférica (d) e o diâmetro da esfera do indentador Brinell (D). O ângulo de $136^{\circ}$ da ponta de diamante produz uma impressão que mantém esta relação (Figura 19). Existe uma proporcionalidade entre a força aplicada e a área de impressão, portanto, o resultado não depende da força aplicada. Isto é conveniente para indentações micrométricas e determinações de durezas superfíciais em filmes finos, amostras tratadas superficialmente (nitretação, carbonetação, têmpera), ou para a determinação de dureza de microconstituintes individuais.

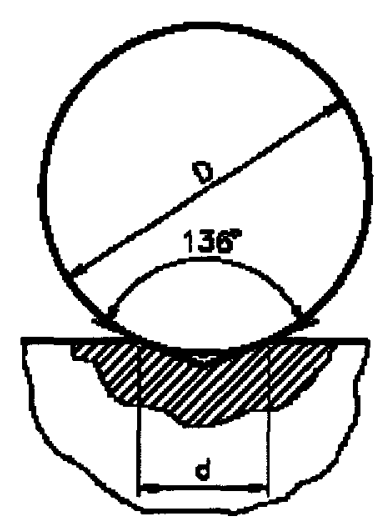

Figura 19. Relação entre a esfera e a pirâmide de indentação Brinell e Vickers.

Na prática, os valores de dureza Brinell e Vickers são iguais até o valor de $300\left(\mathrm{kgf} / \mathrm{mm}^{2}\right)$. O ensaio Vickers fornece uma escala contínua de dureza, medindo uma ampla faixa de valores em uma única escala. ${ }^{[53]}$ 
Defeitos de impressão - No ensaio Vickers a impressão do indentador na superfície da amostra deve apresentar os lados retos, as medidas das diagonais iguais e não apresentar fissuras nas extremidades. Defeitos de impressão podem ocorrer devido ao afundamento, formação de fissuras ou aderência da amostra nas faces do indentador.

Como o cálculo do valor de dureza Vickers utiliza a média das duas diagonais da impressão, os valores obtidos com defeitos de impressão devem ser desconsiderados.

É possivel corrigir esses defeitos aumentando ou diminuindo o valor da carga do ensaio, dependendo do tipo de defeito apresentado e do material.

1.6.2. Tenacidade a fratura - ${ }^{[54]}$ A tenacidade é uma medida da quantidade de energia que um material pode absorver antes de fraturar. Várias características como resistência mecânica, resistência ao choque térmico e susceptibilidade ao desgaste erosivo são controladas por esta propriedade.

Um dos métodos mais usuais para medir a tenacidade é o ensaio de resistência ao impacto. Neste método um pêndulo choca-se com uma amostra, fraturando-a. A energia absorvida pela fratura corresponde à diminuição da energia do pêndulo. Este método permite obter valores comparativos muito úteis. Contudo, estes ensaios não permitem obter valores de propriedades que possam ser utilizados em projetos de peças com fissuras ou fendas.

A fratura de um material inicia-se em um local em que a concentração de tensões é mais elevada, como por exemplo a extremidade de uma fenda. A intensidade da tensão na extremidade de uma fenda depende da tensão aplicada e do comprimento da fenda. A combinação dos efeitos da tensão aplicada na extremidade e do comprimento da fenda é expressa pelo fator de intensidade de tensão $k_{l}$ : 


$$
k_{l}=Y \sigma \sqrt{ } \pi a
$$

onde $k_{l}$ é o fator de intensidade de tensão, $Y$ é uma constante geométrica adimensional, $\sigma$ é a tensão nominal aplicada e a é o comprimento da fenda superficial ou metade do comprimento da fenda interna.

O valor crítico do fator de intensidade de tensão que provoca a fratura do material é definida como $k_{\mathcal{~}}$ do material.

$$
k_{i C}=Y \sigma_{f} \sqrt{ } \pi a
$$

onde $\sigma_{f}$ é a tensão de fratura.

Experimentalmente estes valores podem ser obtidos em ensaios onde a amostra é submetida a uma tração variável uniaxial até sua ruptura. Também são utilizados ensaios de flexão em três ou quatro pontos, onde a amostra é fletida com uma tensão variável até sua ruptura. Estes métodos requerem amostras com dimensões padronizadas. As amostras das partículas de sílica, preparadas a partir da secagem das diferentes dispersões diluídas, apresentam diferentes contrações volumétricas em relação ao molde utilizado (seção 4.14), o que dificulta a preparação das amostras para a utilização destes métodos.

Outro método usado na obtenção da tenacidade à fratura é a técnica da indentação, proposta primeiramente por Parmqvist. ${ }^{[55]}$ A tenacidade a fratura é calculada a partir das medidas de fissuras obtidas do centro da indentação Vickers em direção às extremidades (Figura 20). 


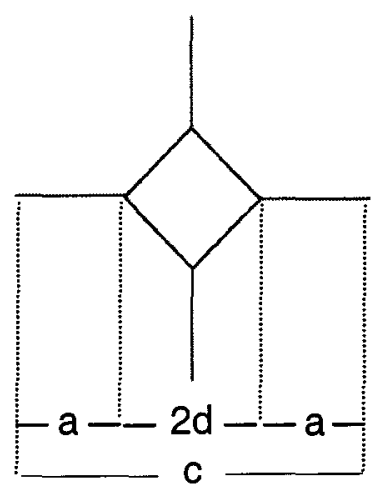

Figura 20. llustração de fissuras produzidas por uma indentação Vickers.

Baseada em observações experimentais, a relação entre o comprimento da fissura (c) e a carga de indentação $(P)$ é dada por:

$$
c=k P^{2 / 3}
$$

onde $k$ é uma função da geometria de indentação, módulo de Young, dureza e tenacidade à fratura do material.

O cálculo do valor de $k_{1 C}$ encontrado na literatura ${ }^{[56]}$ é freqüentemente classificado em dois grupos principais:

Regime de fissuras radiais "Palmqvist" - usado para c/d $\leq 2,5$.

$$
k_{1 C}=0,0193\left(H_{v} d\right)\left(E / H_{v}\right)^{2 / 5}(a)^{-1 / 2}
$$

Regime de fissuras "half-penny", usado para c/d $\geq 2,5$.

$$
k_{I C}=0,0711\left(H_{v} d^{1 / 2}\right)\left(E / H_{v}\right)^{2 / 5}(c / d)^{-3 / 2}
$$

O valor de $k_{1 C}$ pode ser relacionado com a diferença entre a força aplicada na indentação $(P)$ e força mínima de indentação necessária para iniciar uma fissura $\left(P_{0}\right)$ :

$$
k_{I C}=\beta\left[\mathrm{H}_{\mathrm{v}}\left(\mathrm{P}-\mathrm{P}_{0}\right) / 4 \mathrm{a}\right]^{1 / 2}
$$

onde a é o comprimento médio da fissura radial e $\beta$ é uma constante adimensional para o material utilizado. 


\section{OBJETIVOS}

O objetivo desta primeira parte da tese foi estabelecer a heterogeneidade das distribuições química e de potencial elétrico, entre partículas de sílica de mesmo tamanho e também entre partículas de diferentes tamanhos. Os efeitos destas heterogeneidades também foram analisados sobre as propriedades de sorção de água, etanol, coalescência de partículas, dureza e tenacidade à fratura de monolitos formados por secagem de dispersões. Estas heterogeneidades foram caracterizadas de forma microscópica, microanalítica e topoquimicamente, a fim de se obter uma melhor compreensão do mecanismo de polimerização, crescimento das partículas e tendência à formação de filmes e monolitos. 


\section{MATERIAIS E MÉTODOS}

3.1. Descrição dos reagentes - As diferentes preparaçōes foram usando-se sempre solução de com $50 \mathrm{~mL}$ de etanol (MERCK PA), 4mL de TEOS (MERCK PA), e diferentes quantidades de amônia saturada (SYNTH PA).

3.2. Efeito da potência do ultra-som e da temperatura na formação das partículas de sílica - Os efeitos da potência do ultra-som e da temperatura na formação das partículas de sílica foram observados usando-se solução de $50 \mathrm{~mL}$ de etanol $(0,857$ mols $), 4 \mathrm{~mL}$ de TEOS $(0,018 \mathrm{mols})$ e $2 \mathrm{~mL}$ de amônia $(0,017$ mols $)$ em temperaturas de $25^{\circ} \mathrm{C}$ e $36^{\circ} \mathrm{C}$, sonificação de $25 \mathrm{kHz}$ - 200 Watts (Thornton GA 200) e $40 \mathrm{kHz}$ - 80 Watts (Thornton T1440), por 2 horas.

3.3. Preparação das partículas de sílica - Cinco diferentes dispersões de nanopartículas de sílica ( $A, B, C, D$ e E) foram preparadas pela hidrólise do TEOS (4mL - 0,018 mols), em meio alcoólico (etanol) $(50 \mathrm{~mL}-0,857$ mols), na presença de diferentes volumes de $\mathrm{NH}_{4} \mathrm{OH}$ (saturado) (2 - 0,017 mols; 2,5 - 0,021 mols; 3 0,025 mols; 3,5 - 0,030 mols e $4 \mathrm{~mL}$ - 0,034 mols, respectivamente), em um banho termostatizado a $(36,0 \pm 0,1)^{\circ} \mathrm{C}$, sob sonificação contínua $(25 \mathrm{kHz}-200 \mathrm{~W})$ por 2 horas. 
3.4. Conteúdo de sólidos - O conteúdo de sólidos foi determinado por gravimetria da amostra seca a $80^{\circ} \mathrm{C}$ até peso constante $( \pm 0,2 \mathrm{mg})$.

3.5. Espectroscopia de correlação de fótons (PCS) - Foi utilizado um instrumento modelo ZetaPlus (Brookhaven Instruments) com software Bi-MAS e laser de estado sólido $(15 \mathrm{~mW}, \lambda=670)$, projetado para análises de tamanhos de partículas entre $2 \mathrm{~nm}$ e $3 \mu \mathrm{m}$, em suspensões ou soluções de macromoléculas.

3.5.1. Preparação das amostras - Como a técnica de fotocorrelação é baseada no espalhamento de um feixe de laser que atravessa a amostra, a dispersão deve estar suficientemente diluída para evitar os efeitos de espalhamento múltiplo. Durante cada análise, uma avaliação da amostra pelo equipamento é realizada. Um valor entre 0 e 10 é apresentado como indicativo da diferença entre os valores medidos e calculados para a linha de base da função de correlação. O fabricante sugere que as amostras concentradas sejam diluídas até apresentarem avaliações maiores que 8.

3.6. Microscopia eletrônica e transmissão (TEM) - O equipamento utilizado foi um microscópio de transmissão convencional Carl Zeiss, modelo CEM 902, 80 kV, equipado com um filtro de energia espectrométrico tipo Castaing-HenryOttensmeyer na coluna.

3.6.1. Preparação das amostras - As partículas foram observadas em submonocamadas, em que é possivel examinar partículas sem incorrer nos problemas causados pela sua superposição. Para a preparação de submonocamadas de partículas de sílica, a amostra de cada dispersão foi preparada diluindo $20 \mu \mathrm{l}$ da dispersão em $4 \mathrm{~mL}$ de água bidestilada e deionizada. 
$10 \mu \mathrm{l}$ de cada solução diluída foram aplicados sobre telas de cobre vazadas de 400 mesh (Ted Pella), recobertas com filmes muito finos de parlódio $(\approx 10 \mathrm{~nm}$ ) e de carbono evaporado $(\approx 3 \mathrm{~nm})$. A seguir, foram secas à temperatura de $25^{\circ} \mathrm{C}$ e $55 \%$ de umidade relativa.

As imagens foram registradas em áreas contendo poucas partículas, pois as partículas absorvem energia do feixe de elétrons, e o aumento de temperatura rompe o filme de parlódio utilizado como suporte.

3.7. Microscopia eletrônica por emissão de campo (FESEM) - . O equipamento utilizado foi um microscópio de emissão de campo JEOL J5M-6340F, operando a $15 \mathrm{KV}$, o que corresponde a uma resolução nominal de $1,2 \mathrm{~nm}$

3.7.1. Preparação das amostras - Foram analisados filmes com submonocamadas de partículas de sílica, preparados a partir da secagem de $10 \mu \mathrm{l}$ das dispersões diluídas (20 $\mu \mathrm{l}$ da dispersão em $4 \mathrm{~mL}$ de água bidestilada e deionizada). As gotas foram aplicadas sobre lâminas de mica recém-clivadas. Após a secagem a $25^{\circ} \mathrm{C}$ e $55 \%$ de umidade relativa, foi evaporado um fino filme de carbono. Este fino filme de carbono sobre o filme de sílica tem como função o aumento da condutividade elétrica, necessária para a geração dos elétrons secundários, e evitar o carregamento elétrico em bordas. Outra função é o aumento da condutividade térmica, diminuindo o deslocamento e a degradação da amostra.

\subsection{Microscopia de varredura por sonda (SPM) - Foi utilizado um microscópio de} varredura por sonda modelo Discoverer TMX 2010 (TopoMetrix). O sistema é constituído de uma eletrônica de controle e um chassi básico, e módulos adicionais para os modos de microscopia de força atômica de não-contato, e de potenciais elétricos (EFM e SEPM). 
3.8.1. Preparação das amostras - Para a formação de filmes com multicamadas de partículas, as amostras foram preparadas dispensando $10 \mu \mathrm{l}$ de dispersão sobre lâminas de mica recém clivadas, aderidas aos porta amostras padrão de SPM. A seguir, as gotas foram secas sob condições ambientais $\left(25^{\circ} \mathrm{C}\right.$ e umidade relativa de $55 \%$ ), formando filmes com espessura de aproximadamente $8 \mu \mathrm{m}$.

Para melhor comparação entre as imagens das amostras das dispersões $A, B, C, D$ e $E$, foram varridas áreas de $2 \mu \mathrm{m} \times 2 \mu \mathrm{m}$, com resolução de $300 \times 300$ pontos. A velocidade de varredura da sonda foi fixada em $1 \mu \mathrm{m} / \mathrm{s}$, com parâmetros de realimentação PID iguais a $1,0,5$ e 0 respectivamente. Foi utilizado uma cerâmica piezoelétrica com curso máximo de $70 \mu \mathrm{m}$, linearizada por resistências elétricas proporcionais ao deslocamento, e por software de linearização. As cargas estáticas adquiridas nas preparações das amostras foram neutralizadas pela aplicação durante os experimentos de diferentes potenciais DC nos porta amostras.

3.9. Espectros no infravermelho - Foi utilizado um espectrômetro Bomem B-100.

3.9.1 Preparação das amostras - Os espectros no infravermelho foram adquiridos a partir dos filmes preparados das dispersões em janelas de $\mathrm{BaF}_{2}$, e secos por 20 minutos sob umidade relativa de $47.5 \%$, a $19^{\circ} \mathrm{C}$.

3.10. Preparação dos monolitos de partículas de sílica - Os monolitos foram preparados a partir da secagem de $4 \mathrm{~mL}$ de cada dispersão, por 7 dias sob umidade relativa de $55 \%$, a $25^{\circ} \mathrm{C}$, em moldes com $1 \mathrm{~cm} \times 1 \mathrm{~cm}$ de base e $4,3 \mathrm{~cm}$ de altura. 
3.11. Microscopia óptica - Foi utilizado um microscópio óptico modelo Orthoplan (Leitz Wetzlar), no modo de luz refletida, acoplado a um sistema de aquisição de imagem com uma câmara CCD modelo KP-C550 (Hitachi) e software de aquisição Aver TV Phone 1.10A (AVerMedia).

3.12. Dureza Vickers - Foi utilizado um microdurômetro Vickers modelo 1600-6300 (Buekler), com força mínima de indentação de $0,1 \mathrm{~N}$, do Departamento de Materiais da Faculdade de Engenharia Mecânica da UNICAMP.

3.13. Tenacidade à fratura - Foi utilizado o método de indentação de Parmqvist. ${ }^{[55]}$ A comparação da tenacidade à fratura entre as diferentes amostras foi realizada a partir dos valores da força mínima aplicada pelo indentador Vickers para provocar fissuras nas extremidades das impressões. 


\section{RESULTADOS}

\subsection{Efeito da potência do ultra-som e da temperatura na formação das} partículas de sílica - Inicialmente foram verificadas as condições de temperatura e sonificação para a obtenção de altos rendimentos. Fixadas estas condições, partículas com diferentes diâmetros foram preparadas, variando a concentração inicial de amônia.

Para a temperatura de $25^{\circ} \mathrm{C}$ e sonificação a $40 \mathrm{kHz}$ - 80 Watts, o rendimento das reações, calculados em função dos teores de sólidos determinados por gravimetria a peso constante, foi inferior a $20 \%$. O aumento da temperatura para $36^{\circ} \mathrm{C}$, e sonificação a $25 \mathrm{kHz}$ - 200 Watts, resultaram em um rendimento maior que $95 \%$. Neste caso foi verificado um aumento no diâmetro médio das partículas de 6 $\mathrm{nm}$ para $15 \mathrm{~nm}$ com o aumento da temperatura e potência de sonificação.

Para manter altos os rendimentos das reações, os valores de temperatura e da sonificação foram fixados em $36^{\circ} \mathrm{C}$ e $25 \mathrm{kHz}$ - 200 Watts respectivamente.

4.3. Rendimentos das reações - Os conteúdos de sólidos foram determinados gravimetricamente pela secagem das dispersões até peso constante $( \pm 0.2 \mathrm{mg})$. Os rendimentos das reações foram maiores que $95 \%$ em todas as preparações. 
4.4. Espalhamento de luz - A Figura 21 mostra uma foto dos frascos com água bidestilada e deionizada, e com as dispersões $A, B, C, D$ e $E$, respectivamente. A foto foi obtida com fundo escuro e iluminação indireta, enquadrando a região central dos frascos, colocados lado a lado.

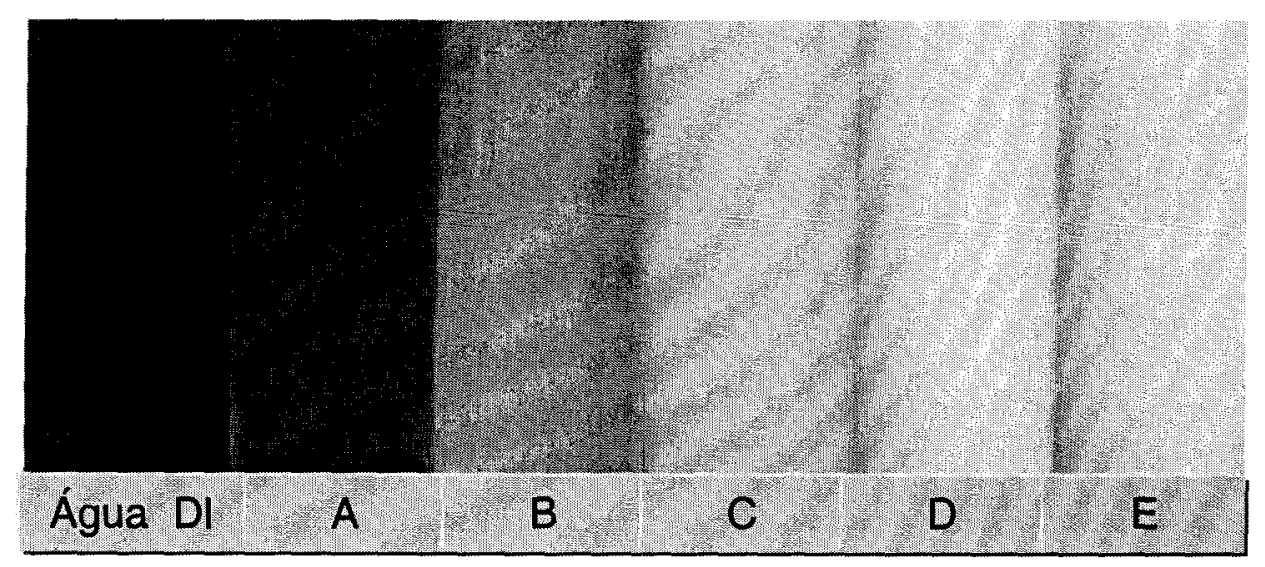

Figura 21. Foto obtida com fundo escuro e iluminação indireta, enquadrando a região central de seis frascos, colocados lado a lado. O primeiro frasco contém água bidestilada e deionizada, e os demais contêm as dispersões $A, B, C, D$ e $E$, respectivamente.

A água bidestilada e deionizada não apresenta espalhamento de luz, pela ausência de partículas dispersas. O espalhamento aumenta com o aumento do tamanho das partículas, o que justifica a crescente opacidade das dispersōes, de A até $\mathrm{E}$.

A incidência de um feixe de laser de $5 \mathrm{~mW}$ e $532 \mathrm{~nm}$ nas dispersões evidencia ainda mais as diferenças no espalhamento de luz pelas diferentes dispersões. (Figura 22). 

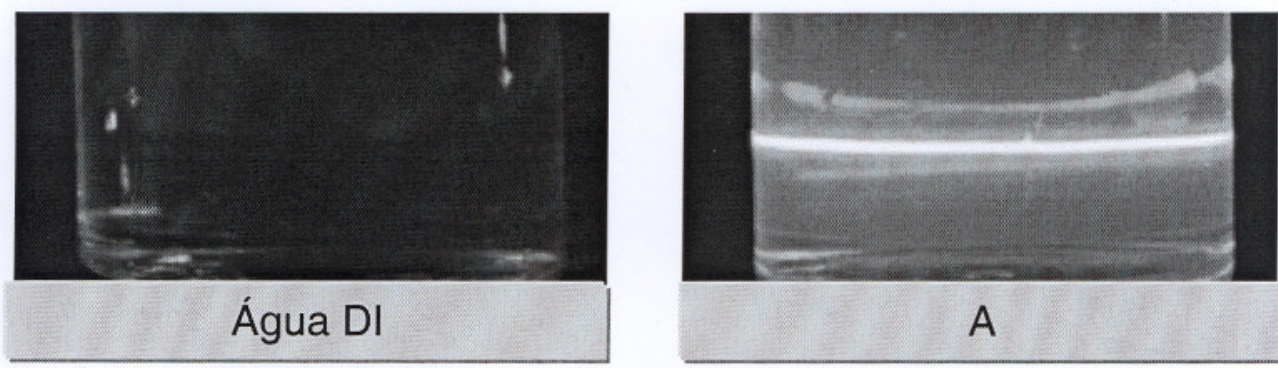

A
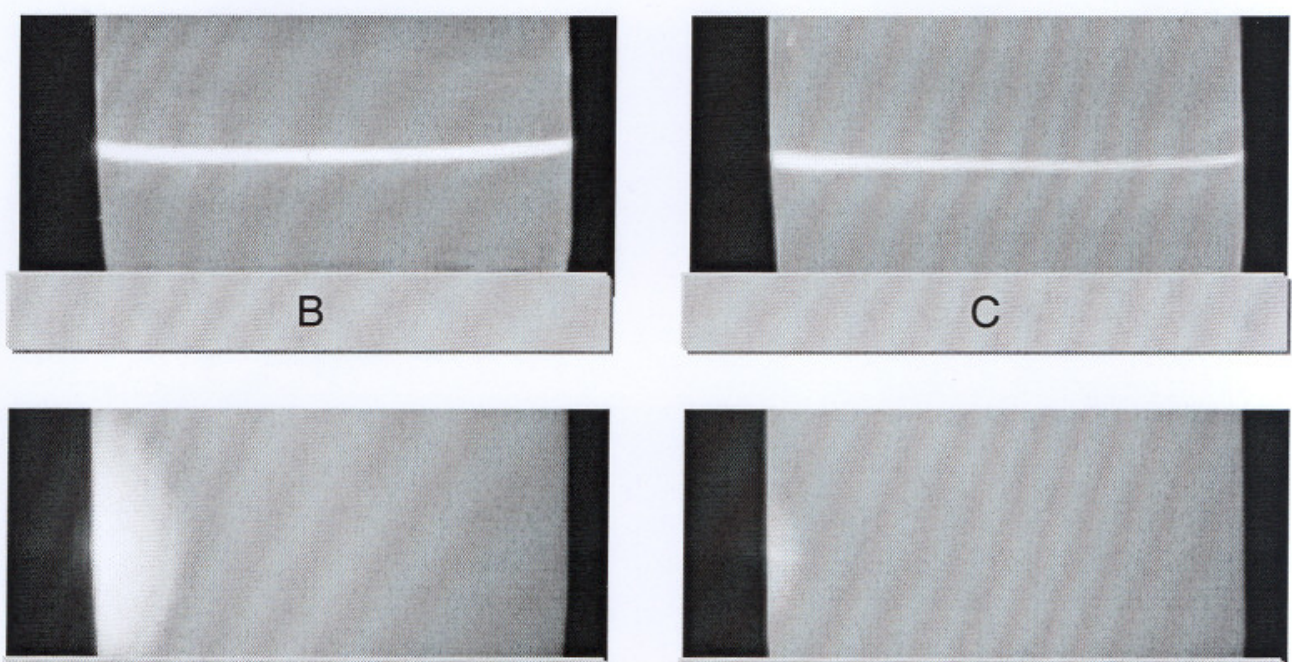

D

$\mathrm{E}$

Figura 22. Espalhamento de luz gerado pela incidência de um laser de $5 \mathrm{~mW}$ e 532 $\mathrm{nm}$, em frascos com água (bidestilada e deionizada) e as dispersões A,B,C,D e E. A fonte está à esquerda dos frascos.

A água bidestilada e deionizada não espalha a luz com intensidade detectável pela câmara usada. O aumento da intensidade de espalhamento é verificado com o aumento do tamanho das partículas entre as dispersões $\mathrm{A}$ e E: no frasco com a dispersão A, podemos observar um feixe estreito do laser, gerado pelo espalhamento de luz pelas partículas presentes na dispersão. A largura deste feixe aumenta na dispersão B. Na dispersão C observa-se um estreitamento do feixe no lado oposto à fonte, ocasionado pela diminuição da intensidade devido ao maior espalhamento. Nas dispersões $\mathrm{D}$ e E, o espalhamento é grande o suficiente 
para impedir a passagem do feixe de laser pelos frascos, e apenas se observa 0 espalhamento junto ao ponto de incidência do laser.

Como as reações apresentaram o mesmo rendimento, o produto da reação A, com menor tamanho de partícula, deve possuir um número maior de partículas, ao contrário de $\mathrm{E}$, que tem partículas de maior tamanho mas em menor número.

4.4. Espectroscopia de correlação de fótons - Nesta técnica, as dispersões devem estar suficientemente diluídas para evitar os efeitos de espalhamento múltiplo. A Tabela 2 apresenta as diluições realizadas nas diferentes dispersões, para a obtenção de uma amostra com índice maior que 8.

Tabela 2. Diluições das dispersões para a preparação das amostras de PCS.

\begin{tabular}{|c|c|c|c|c|c|}
\hline & A & B & C & D & E \\
\hline $\begin{array}{c}\text { Volume de diluente } \\
\text { (água DI ou etanol, } \mathrm{mL})\end{array}$ & 2 & 2 & 2 & 2 & 2 \\
\hline $\begin{array}{c}\text { Volume da dispersão } \\
(\mu \mathrm{L})\end{array}$ & 800 & 400 & 200 & 75 & 50 \\
\hline
\end{tabular}

As determinações foram realizadas um dia após a reação, e novamente após uma semana. Os valores dos diâmetros obtidos não apresentaram mudança significativa $(<1 \%)$, o que indica que a reação já havia atingido seu final, e os diâmetros das partículas em cada dispersão atingiram valores estáveis.

O gráfico da Figura 23 e a Tabela 3 , mostram um exemplo da distribuição dos diâmetros das partículas obtido na dispersão D. 


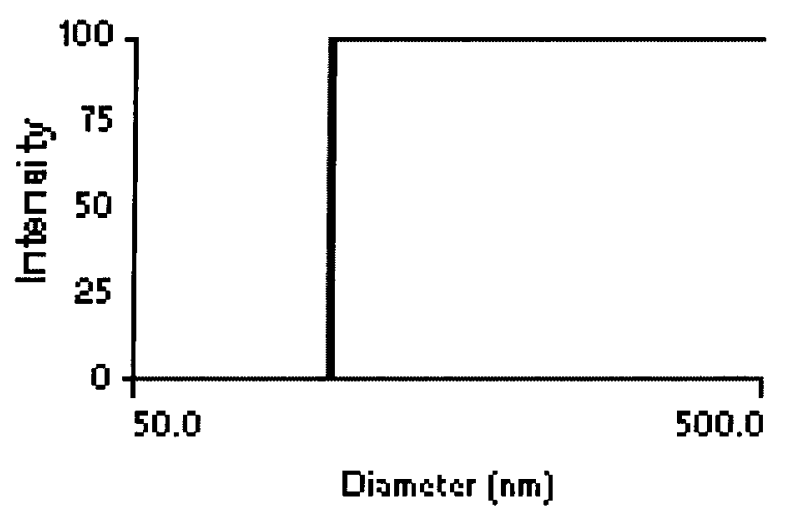

AMOSTRA D

Effective Diameter: $102.7 \mathrm{~nm}$

Polydispersity:

0.004

Avg. Count Rate: $\quad 399.7 \mathrm{kcps}$

Sample Quality:

9.9

Elapsed Time:

00:06:00

Figura 23. Distribuição dos diâmetros das partículas da dispersão $D$, diâmetro efetivo, polidispersividade, taxa média de contagem, qualidade da amostra e tempo de aquisição.

Tabela 3. Distribuição de diâmetros das partículas da dispersão $D: G(d)$ distribuição (\%) em função do diâmetro (d) e C(d) distribuição acumulada (\%) em função do diâmetro.

\begin{tabular}{rrr|rrr|rrr}
$\mathrm{d}(\mathrm{nm})$ & $\mathrm{G}(\mathrm{d})$ & $\mathrm{C}(\mathrm{d})$ & $\mathrm{d}(\mathrm{nm})$ & $\mathrm{G}(\mathrm{d})$ & $\mathrm{C}(\mathrm{d})$ & $\mathrm{d}(\mathrm{nm})$ & $\mathrm{G}(\mathrm{d})$ & $\mathrm{C}(\mathrm{d})$ \\
\hline 99.7 & 0 & 0 & 101.8 & 5 & 1 & 103.8 & 0 & 100 \\
99.9 & 0 & 0 & 102.0 & 14 & 4 & 104.2 & 0 & 100 \\
100.1 & 0 & 0 & 102.2 & 34 & 10 & 104.4 & 0 & 100 \\
100.2 & 0 & 0 & 102.3 & 62 & 23 & 104.6 & 0 & 100 \\
100.4 & 0 & 0 & 102.5 & 89 & 40 & 104.8 & 0 & 100 \\
100.6 & 0 & 0 & 102.7 & 100 & 60 & 105.0 & 0 & 100 \\
100.8 & 0 & 0 & 102.9 & 89 & 77 & 105.2 & 0 & 100 \\
101.0 & 0 & 0 & 103.1 & 62 & 90 & 105.4 & 0 & 100
\end{tabular}

Os valores obtidos para as diferentes dispersões são apresentados e correlacionados com os valores obtidos pelas outras técnicas utilizadas na Tabela 4 da seção 4.8 . 


\subsection{Caracterização morfológica por TEM}

4.5.1. Contraste de amplitude - A Figura 24 mostra as imagens de campo claro, geradas com o contraste de amplitude no feixe de elétrons emergente. As áreas das imagens apresentadas possuem as mesmas dimensões, a fim de facilitar a visualização e comparação dos diâmetros das partículas entre as diferentes dispersões.



Figura 24. Imagens de TEM (campo claro) dos filmes preparados com submonocamadas de partículas de sílica das dispersões A,B,C,D e E.

Os diâmetros médios das partículas foram calculados utilizando o software AnalySis Pro 3.1 (Soft Imaging System $\mathrm{GmbH}$ ): em cada imagem, o diâmetro médio foi calculado como a média aritmética dos diâmetros das partículas. Nos casos em que as partículas aglomeraram, os diâmetros foram medidos em direções em que não havia partículas conectadas. Estes valores são apresentados na Tabela 4 da seção 4.8. 
4.5.2. Estabilidade das amostras de sílica sob o feixe de elétrons - Quando uma área é exposta ao feixe de elétrons por muito tempo, como nas análises mais demoradas, as partículas começam apresentar deformações, e em alguns casos ocorre até mesmo a ruptura do filme de parlódio.

A Figura 25 mostra duas imagens de uma mesma área da amostra D, obtidas após 5 minutos e 120 minutos de exposição ao feixe de elétrons utilizado nas condições normais de operação. Podemos verificar que a exposição prolongada ao feixe provoca sinterização das partículas de sílica, com a típica formação de "pescoços" entre partículas vizinhas.
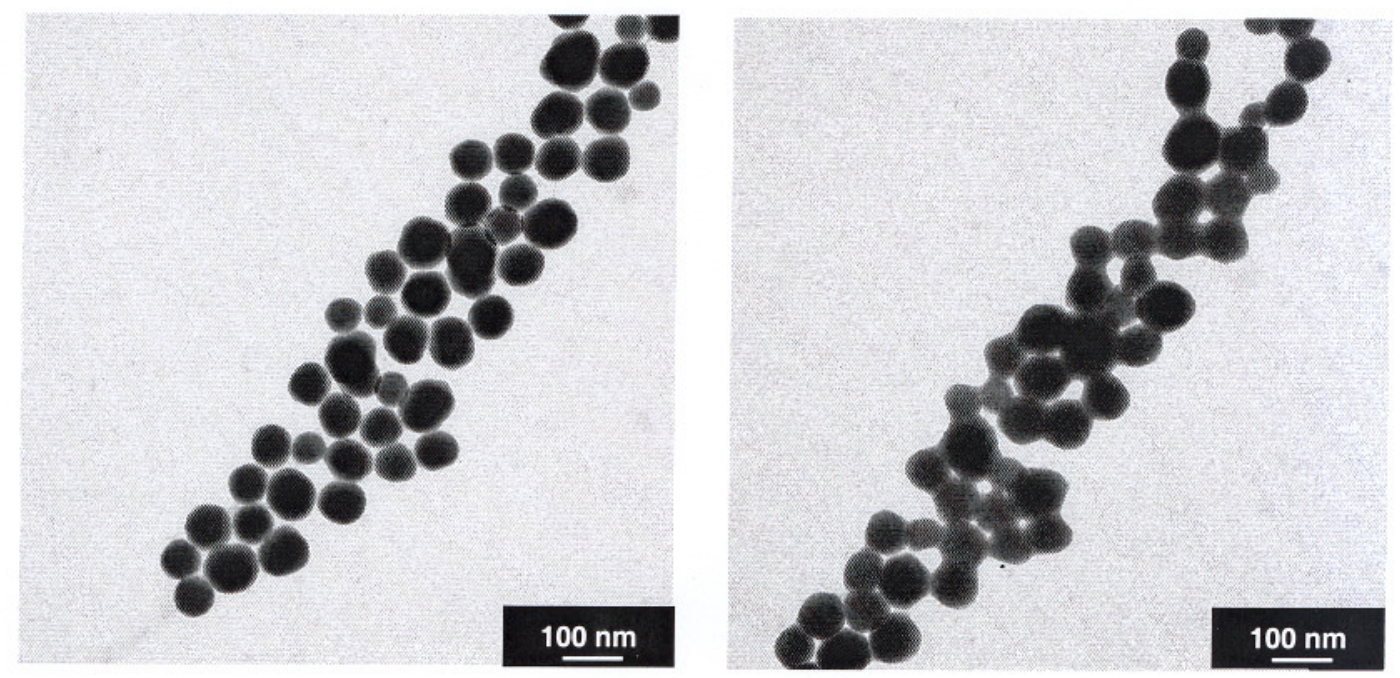

Figura 25. Imagens de campo claro de um mesmo campo da amostra preparada com a dispersão D. Esquerda: após 5 minutos de exposição ao feixe de elétrons. Direita: após 120 minutos de exposição ao feixe de elétrons. 


\subsection{Caracterização morfológica por FESEM}

4.6.1. Imagens obtidas com elétrons secundários - A Figura 26 mostra as imagens formadas pelos elétrons secundários, gerados pela varredura de um feixe de elétrons acelerados entre 3 e $10 \mathrm{kV}$, sobre as diferentes amostras. As energias usadas em cada caso estão indicadas nas legendas das fotos

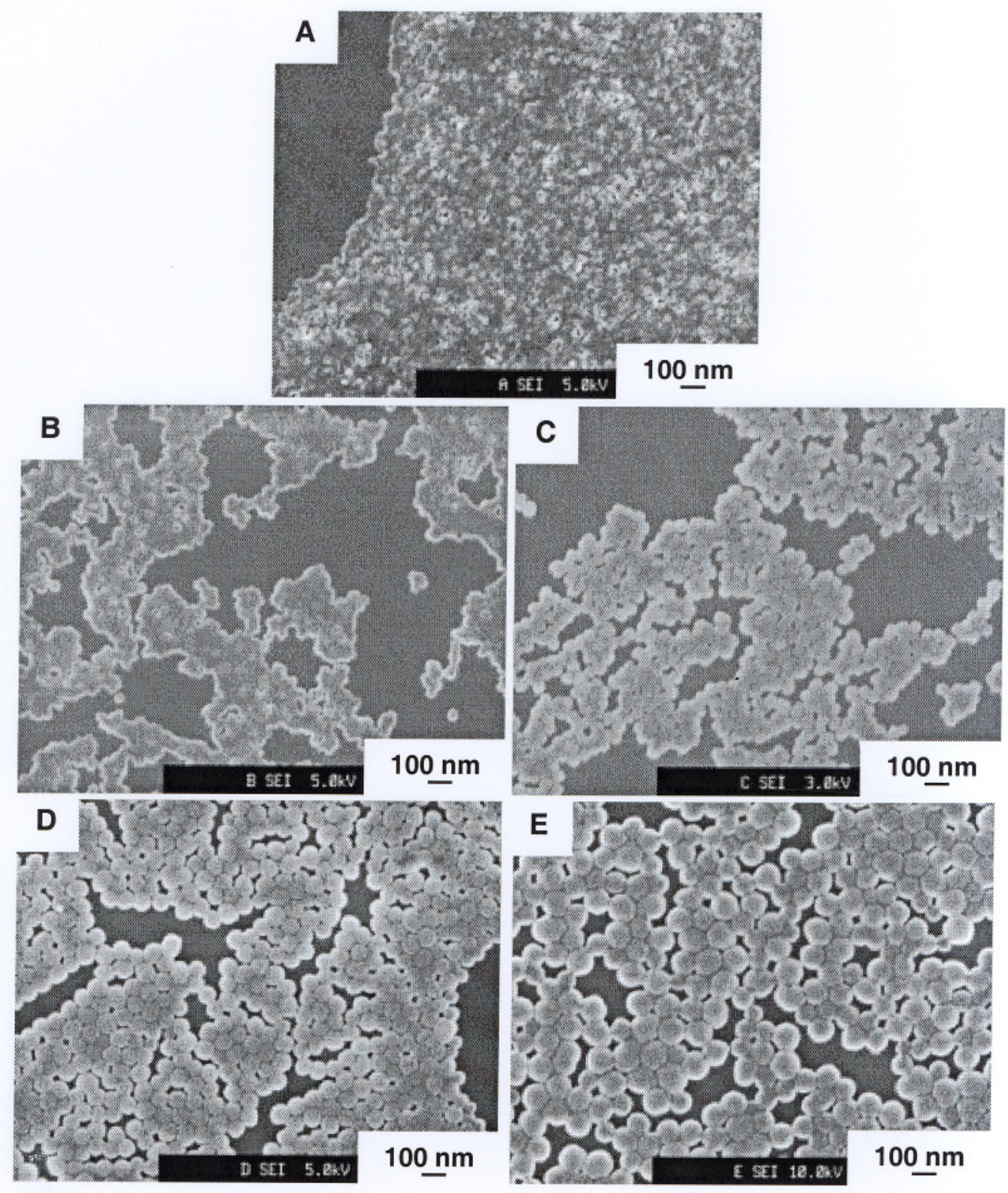

Figura 26. Imagens de FESEM (elétrons secundários) dos filmes preparados com submonocamadas de partículas de sílica das dispersões A,B,C,D e E. 
Os diâmetros médios das partículas foram determinados utilizando o software Image-Pro Plus 4.0 (Media Cybernetics): diferentes perfis foram traçados nas imagens e pela análise dos níveis de cinza, foram determinados os diâmetros de um número representativo de partículas (tipicamente entre 50 e 70). Os diâmetros médios são as médias aritméticas destes diâmetros. As partículas individuais e as bordas dos agregados apresentaram alargamento devido ao filme de carbono depositado sobre as partículas de sílica. A espessura deste filme de carbono é da ordem de $10 \mathrm{~nm}$, que é um valor bastante significativo perante o diâmetro das partículas menores. Por outro lado, o diâmetro medido nas direções onde as partículas estavam conectadas às vizinhas apresentou encolhimento, devido às deformações plásticas por adesão capilar. Estes valores são apresentados e correlacionados com os valores obtidos nas outras técnicas na Tabela 4 da seção 4.8. 


\subsection{Caracterização topográfica por SPM}

4.7.1. Microscopia de força atômica de não contato - Na Figura 27 são apresentadas as imagens topográficas dos filmes preparados a partir das diferentes dispersões:


Figura 27. Imagens de AFM de não contato (topografia) dos filmes preparados com multicamadas de partículas de sílica das dispersões A,B,C,D e E. 
A microscopia de força atômica de não contato fornece como imagem um gráfico $x, y, z$ que pode ser apresentado na forma tridimensional. Para a determinação do diâmetro médio das partículas, a partir destas coordenadas foram traçados diferentes perfis da superfície da amostra. Nestes perfis foram determinados os diâmetros de um número representativo de partículas (tipicamente entre 50 e 70). O diâmetro médio é a média aritmética destes diâmetros.

Outro método utilizado para determinar o valor do diâmetro médio das partículas foi a análise FFT (transformada rápida de Fourier). Pela análise bidimensional FFT podemos verificar como a coordenada $z$ se repete no plano $x, y$. As repetições terão freqüência de até $1 /$ diâmetro médio das partículas. Repetições com comprimentos maiores que o diâmetro das partículas referem-se à topografia de fundo, que é pequena em relação às protuberâncias das partículas. Os diâmetros médios determinados a partir da análise FFT e a partir da análise dos perfis apresentaram os mesmos valores, e são apresentados e correlacionados com os valores obtidos nas outras técnicas na Tabela 4 da próxima seção.

4.8. Diâmetro das partículas - Os valores determinados para os diâmetros médios são apresentados na Figura 28 e na Tabela 4. Nas técnicas microscópicas os diâmetros médios são as médias numéricas dos diâmetros individuais. Em PCS, são medidos os diâmetros hidrodinâmicos efetivos, supondo distribuições lognormal. Os coeficientes de sorção foram calculados a partir da variação volumétrica apresentada devido à desolvatação da amostra nos diferentes ambientes, comparando-se as medidas de PCS em meios alcoólico e aquoso com as medidas por TEM em vácuo de $10^{-6} \mathrm{mbar}$. Os valores dos diâmetros médios determinados por FESEM são ligeiramente maiores que os determinados por TEM. Nas amostras de FESEM, um filme de carbono de aproximadamente $10 \mathrm{~nm}$ é depositado sobre as partículas de sílica, o que provoca um aumento no diâmetro 
das partículas localizadas nas bordas dos agregados, mas não nas partículas que estão no meio dos agregados.



Figura 28. Diâmetros médios das partículas de sílica das dispersões $A, B, C, D$ e $E$, determinados em diferentes ambientes.

Tabela 4. Valores determinados para os coeficientes de sorção em água e álcool, e dos potenciais zeta das partículas de sílica.

\begin{tabular}{|c|c|c|c|c|c|c|}
\hline \multicolumn{2}{|c|}{ AMOSTRA } & $A$ & B & C & D & $E$ \\
\hline água , $25^{\circ} \mathrm{C}$ & $\operatorname{PCS}(\mathrm{nm})$ & $54 \pm 5$ & $66 \pm 6$ & $77 \pm 2$ & $103 \pm 1$ & $136 \pm 1$ \\
\hline etanol, $25^{\circ} \mathrm{C}$ & $\operatorname{PCS}(\mathrm{nm})$ & $72 \pm 2$ & $74 \pm 2$ & $67 \pm 6$ & $99 \pm 1$ & $131 \pm 1$ \\
\hline ar, $55 \%$ UR, $25^{\circ} \mathrm{C}$ & AFM (nm) & $33 \pm 2$ & $45 \pm 4$ & $57 \pm 5$ & $81 \pm 8$ & $125 \pm 11$ \\
\hline $10^{-6} \mathrm{mbar}$ & FESEM (nm) & $22 \pm 2$ & $39 \pm 3$ & $51 \pm 4$ & $79 \pm 7$ & $118 \pm 10$ \\
\hline $10^{-6} \mathrm{mbar}$ & TEM (nm) & $15 \pm 2$ & $33 \pm 3$ & $47 \pm 4$ & $76 \pm 7$ & $115 \pm 10$ \\
\hline \multicolumn{2}{|c|}{$\begin{array}{l}\text { Coeficiente de sorção de água } \\
\text { (\% em volume })\end{array}$} & 4600 & 700 & 340 & 149 & 65 \\
\hline \multicolumn{2}{|c|}{$\begin{array}{c}\text { Coeficiente de sorção de etanol } \\
(\% \text { em volume) }\end{array}$} & 11000 & 1028 & 190 & 121 & 48 \\
\hline \multicolumn{2}{|c|}{ Sólidos (\% em massa) } & 2,7 & 2,7 & 2,6 & 2,5 & 2,5 \\
\hline \multicolumn{2}{|c|}{$\begin{array}{c}\text { Potencial Zeta } \\
\left.\text { (meio de } \mathrm{KCl} 10^{-3} \mathrm{~mol}^{-1} \mathrm{~L}^{-1}\right)(\mathrm{mV})\end{array}$} & -27 & -38 & -36 & -46 & -49 \\
\hline
\end{tabular}


4.9. Espectros de perda de energia de elétrons (EELS) - Para identificar os principais elementos químicos presentes nas amostras, foram obtidos diferentes espectros de perdas de energia, mostrando a intensidade espalhada como função da perda de energia cinética pelos elétrons do feixe que atravessa a amostra. ${ }^{[26]}$ Os elementos foram determinados em função da borda de absorção de energia característica para cada elemento. Além do silício e oxigênio, presentes na sílica, e este último também na água de hidratação, outros elementos foram encontrados, como carbono (dos grupos etilas), nitrogênio (da amônia utilizada como catalisador), e traços de sódio e cálcio (provenientes da vidraria).

Os valores típicos para as bordas de absorção de energia para estes elementos $^{[57,58]}$ são apresentados na Tabela 5 . Os valores medidos podem apresentar deslocamento de até $8 \mathrm{eV}$ em relação a estes valores tabelados devido as mudanças na vizinhança química.

Tabela 5. Bordas de absorção de energia (eV) para Si, O, C, N, Na e Ca.

\begin{tabular}{|c|c|c|c|c|c|c||}
\hline & Silício & Oxigênio & Carbono & Nitrogênio & Sódio & Cálcio \\
\hline camada & $\mathrm{L}_{2,3}$ & $\mathrm{~K}$ & $\mathrm{~K}$ & $\mathrm{~K}$ & $\mathrm{~K}$ & $\mathrm{~L}_{2} ; \mathrm{L}_{3}$ \\
\hline $\begin{array}{c}\text { borda de } \\
\text { absorção de } \\
\text { energia (eV) }\end{array}$ & 99 & 532 & 284 & 401 & 1072 & $350 ; 346$ \\
\hline
\end{tabular}

As Figuras 29 a 34 mostram os espectros típicos obtidos para os diferentes elementos na amostra preparada a partir da dispersão E. Os espectros adquiridos tiveram a linha de base subtraída de uma exponencial determinada usando as intensidades do feixe medidas em energias menores que a de cada borda de absorção. Os espectros foram tratados para minimizar o ruído de $1,5 \mathrm{eV}$ proveniente das variações características do feixe incidente. Foi utilizado um filtro digital que apresenta o valor médio das intensidades medidas em intervalos de 1,5 eV. 


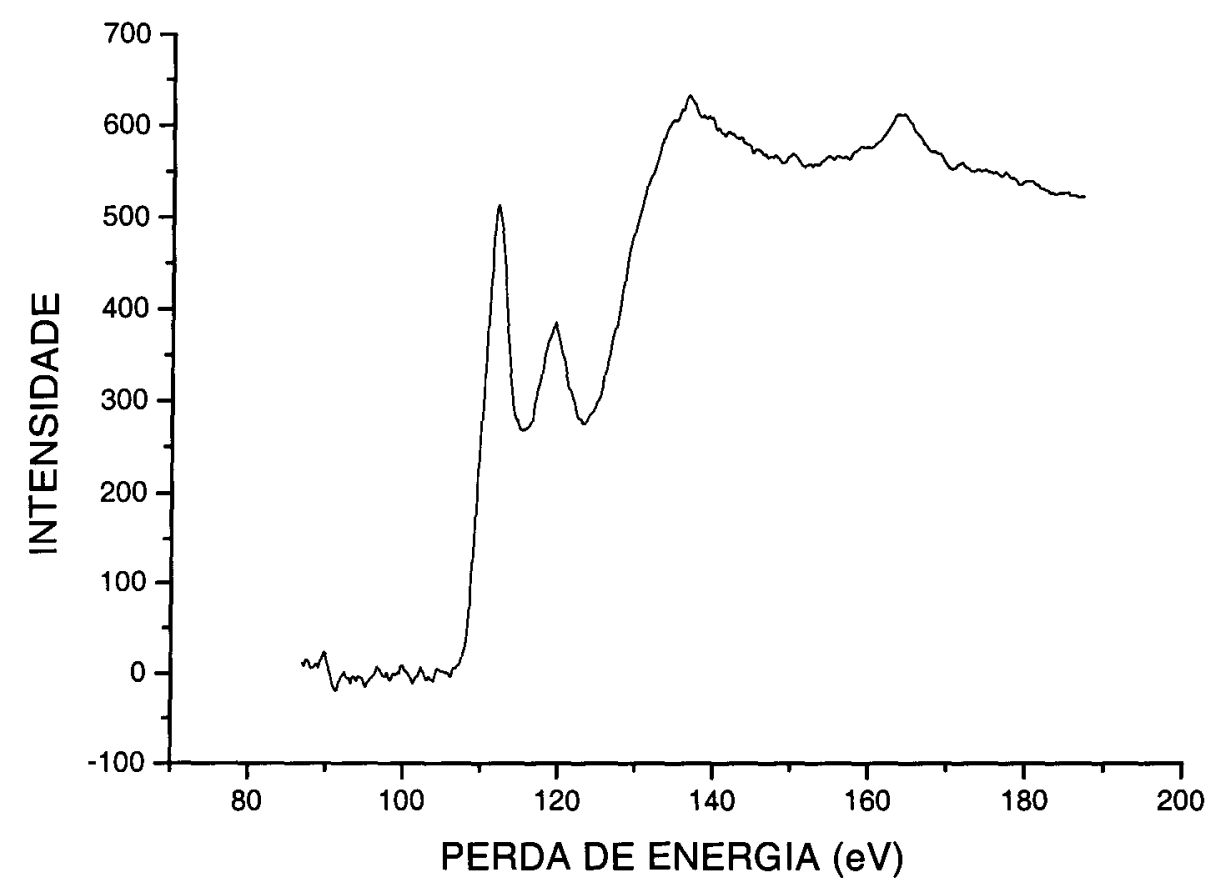

Figura 29. Espectro de perda de energia da borda de absorção da camada $L_{2,3}$ do silício da amostra preparada secando a dispersão $E$.

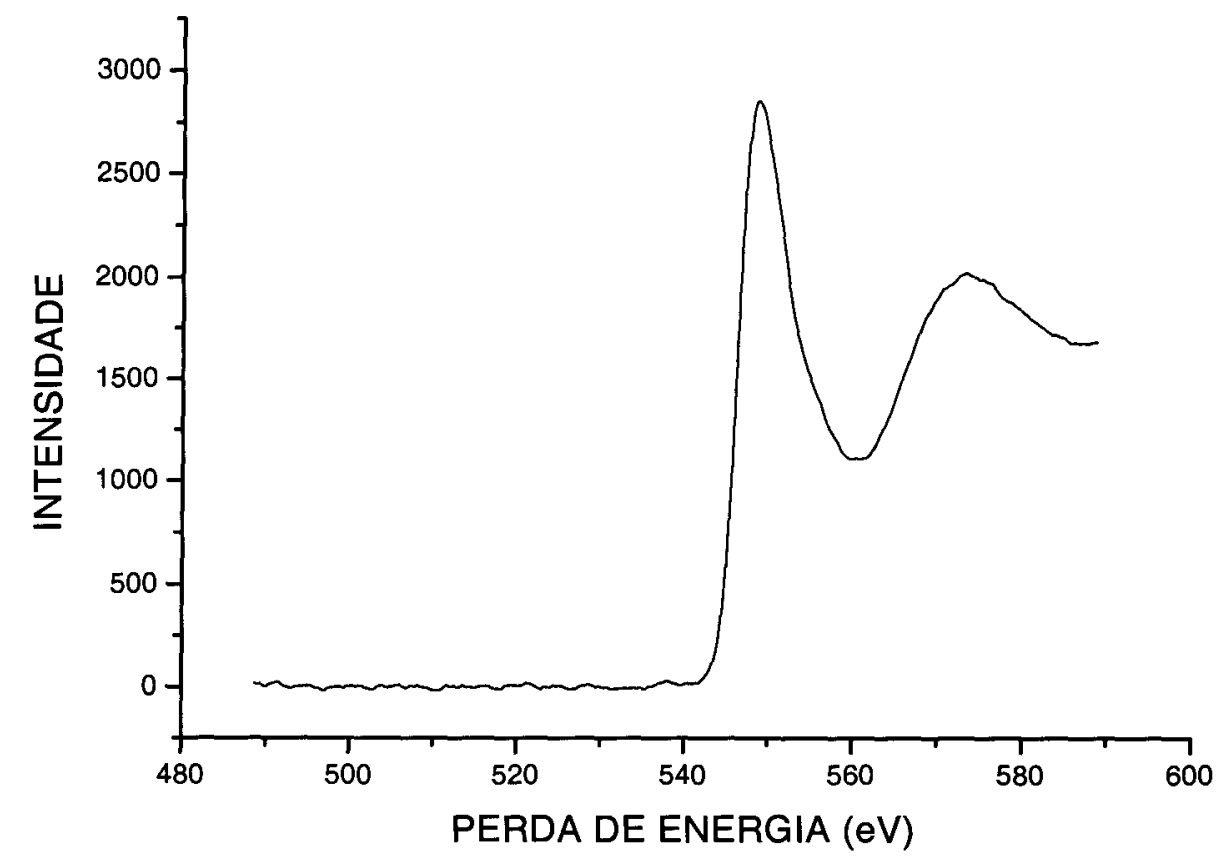

Figura 30. Espectro de perda de energia da borda de absorção da camada $K$ do oxigênio da amostra preparada secando a dispersão $E$. 


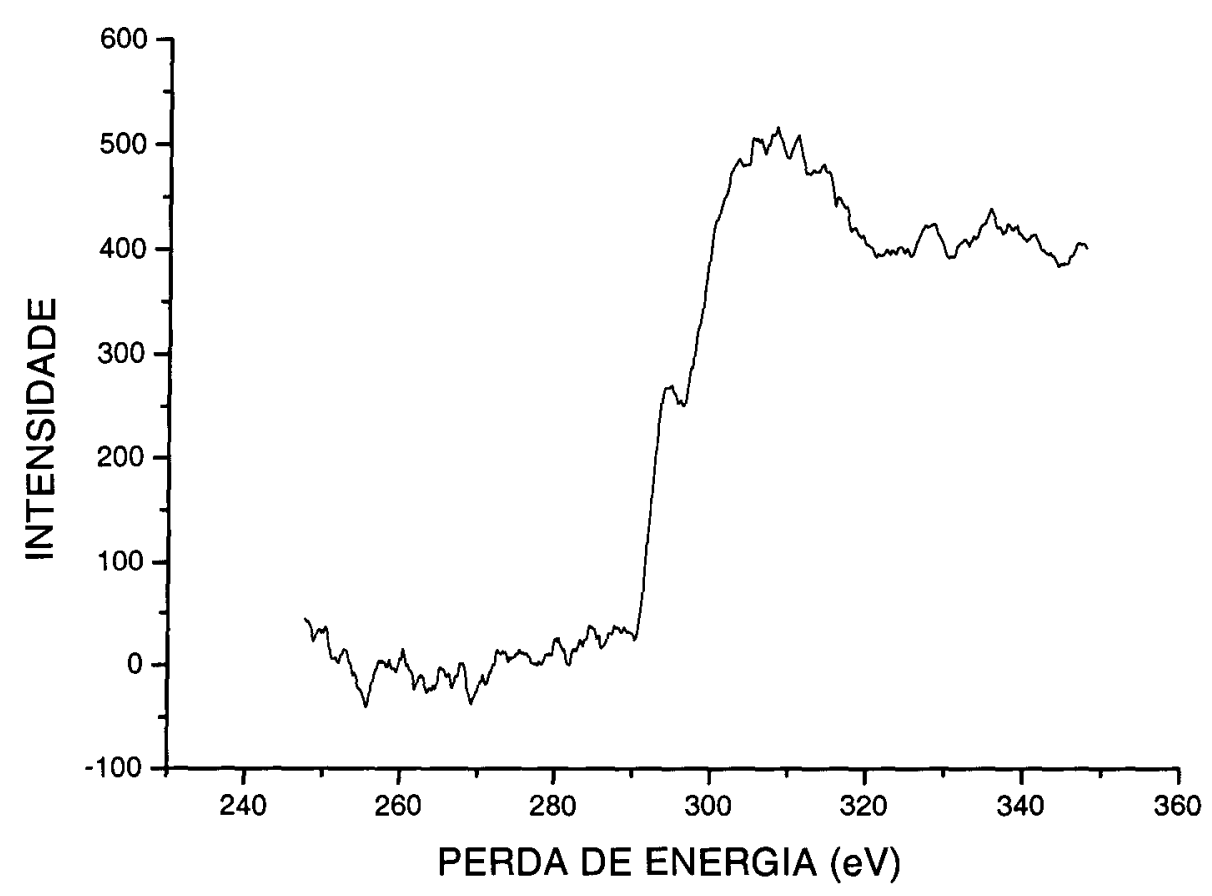

Figura 31. Espectro de perda de energia da borda de absorção da camada $\mathrm{K}$ do carbono da amostra preparada secando a dispersão $\mathrm{E}$.

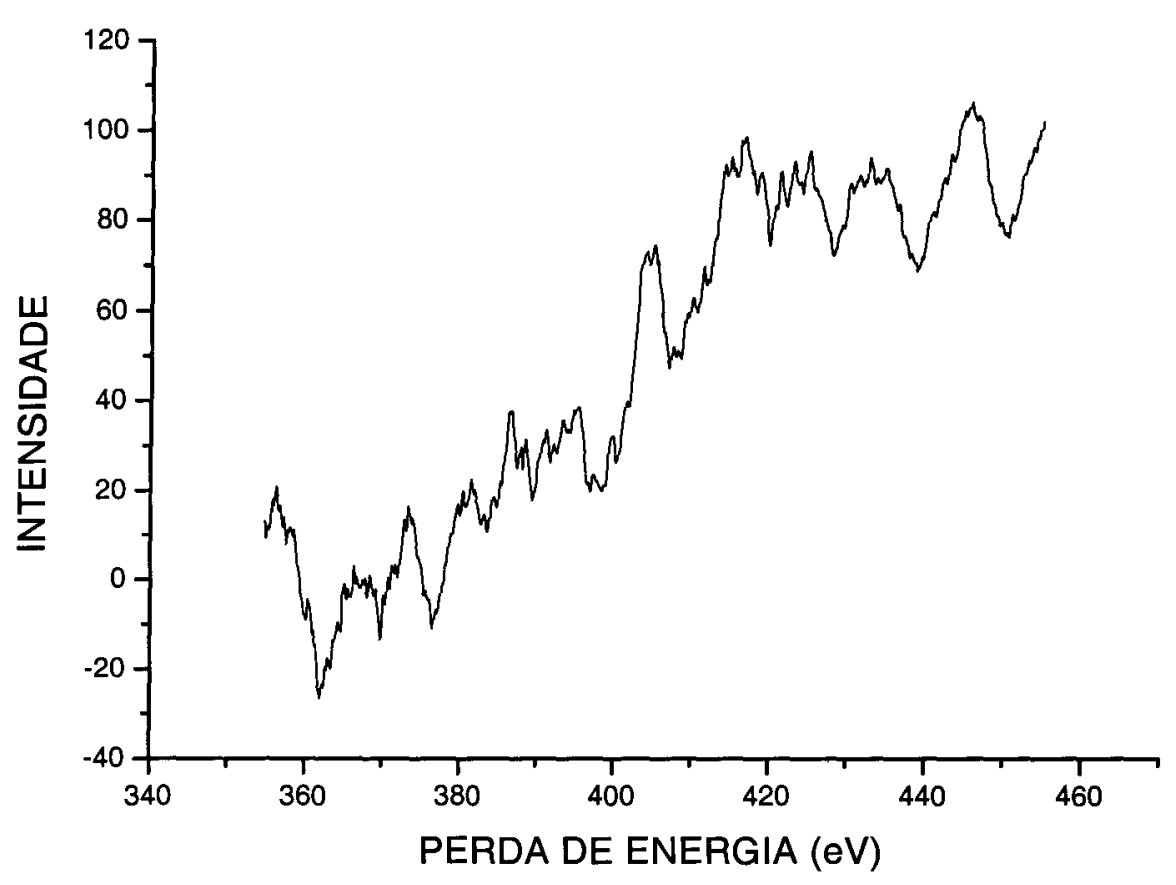

Figura 32. Espectro de perda de energia da borda de absorção da camada $K$ do nitrogênio da amostra preparada secando a dispersão $E$. 


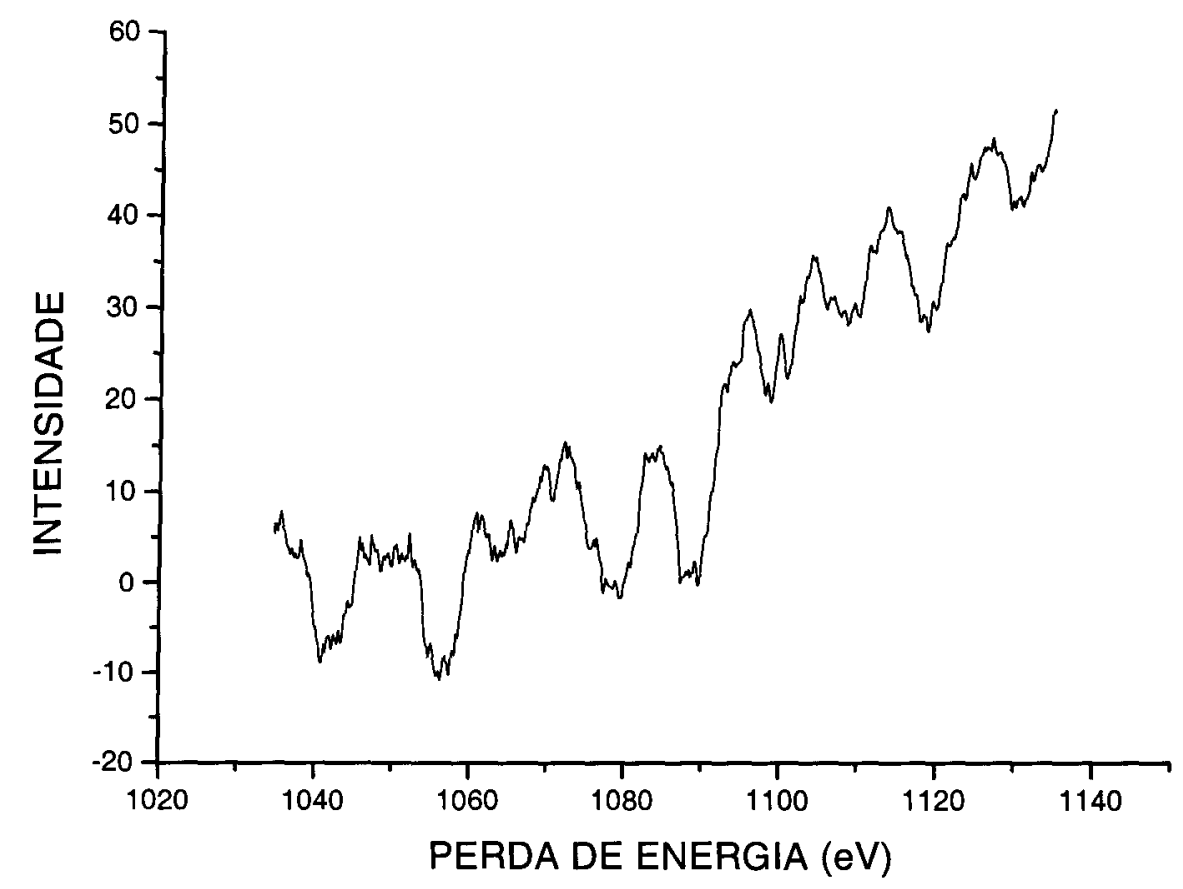

Figura 33. Espectro de perda de energia da borda de absorção da camada $\mathrm{K}$ do sódio da amostra preparada secando a dispersão E.

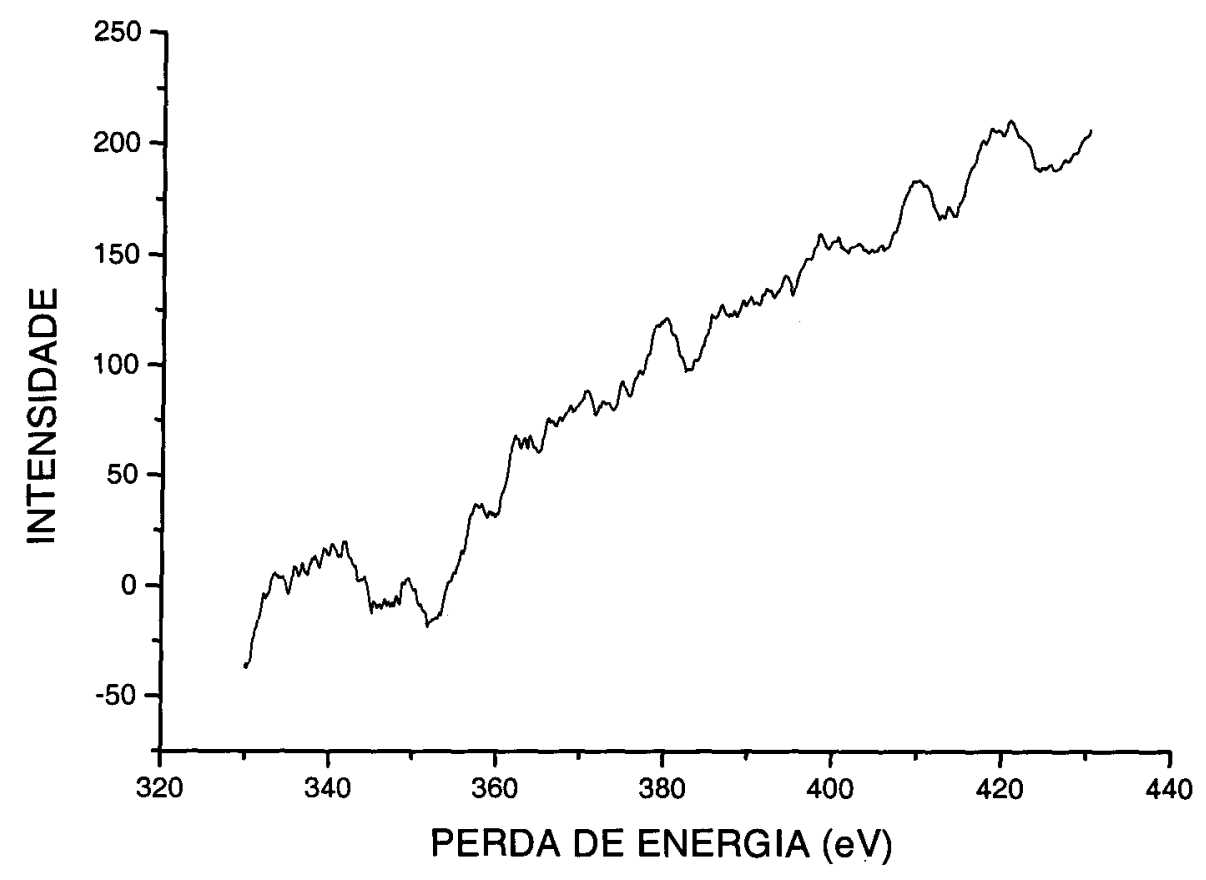

Figura 34. Espectro de perda de energia da borda de absorção das camadas $L_{2}$ e $L_{3}$ do cálcio da amostra preparada secando a dispersão E. 
A intensidade espalhada é proporcional à quantidade de átomos do elemento presente na região analisada da amostra, porém a quantificação não é obtida de forma direta, pois depende também da seção de choque e do livre caminho médio dos elétrons, além da espessura da amostra. A intensidade também é proporcional aos parâmetros utilizados, como tempo de aquisição e aberturas das fendas. A intensidade espalhada também varia de acordo com a área analisada, em função da variação da quantidade de material analisado.

A identificação de diferenças entre os ambientes químicos dos principais elementos presentes nas amostras foi feita pelos espectros de perda de energia (EELS). A Figura 35 mostra os espectros de perda de energia da borda de absorção da camada $\mathrm{K}$ do oxigênio, das amostras preparadas a partir das diferentes dispersões de sílica. As intensidades foram normalizadas em relação ao pico de maior intensidade (547 eV), para comparação dos espectros das diferentes amostras.

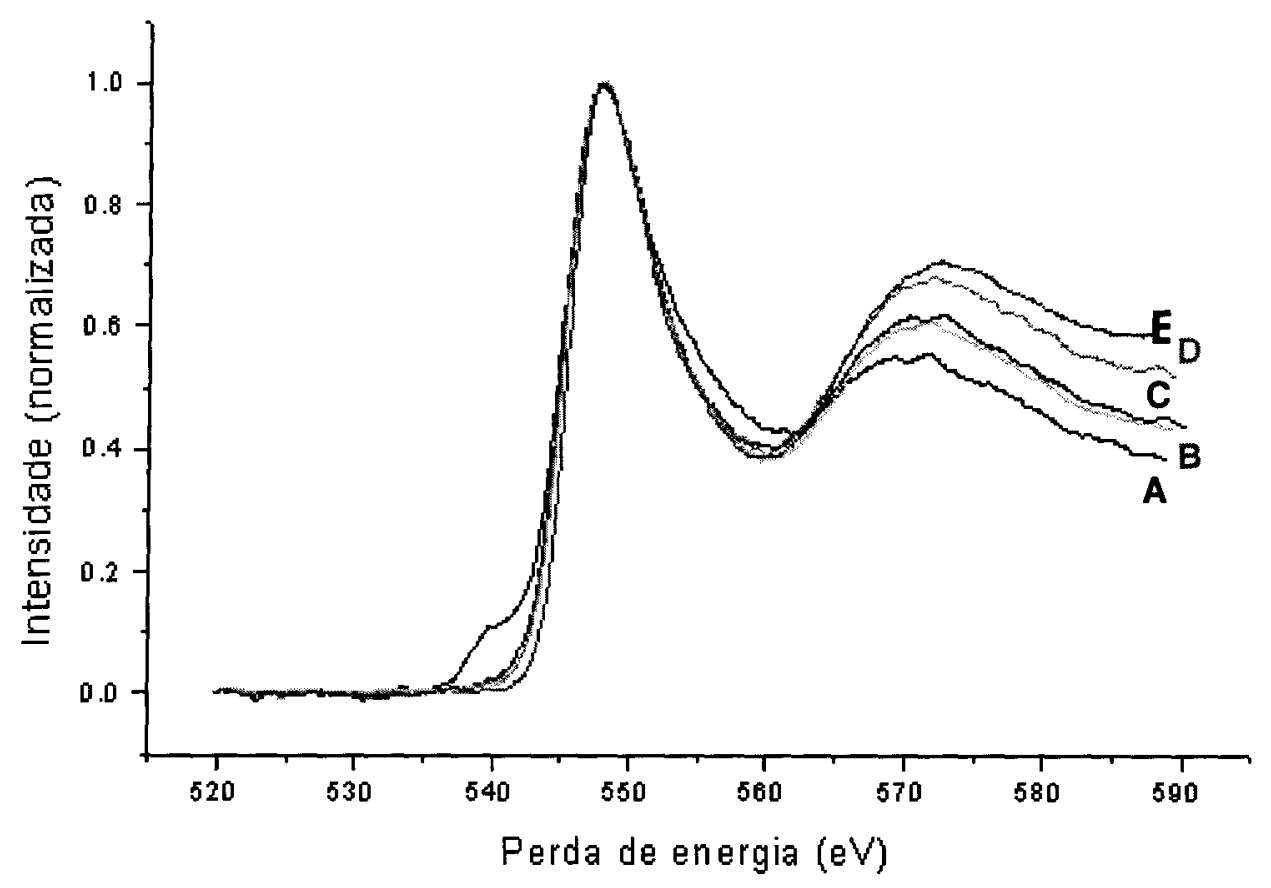

Figura 35. Espectros de perda de energia das amostras preparadas por secagem das dispersões $A, B, C, D$ e $E$. Os espectros estão normalizados em relação ao pico de 547 eV da borda de absorção da camada $K$ do oxigênio. 
Podemos observar uma variação entre as intensidades máximas dos dois picos de perda de energia da camada $K$ do oxigênio com a variação do diâmetro das partículas de sílica analisadas. A estrutura fina da borda de absorção da camada $\mathrm{K}$ do oxigênio, observada na Figura 35 , sugere que há mudanças no ambiente químico (médio) do O nas partículas de diferentes diâmetros.

4.10. Espectros no infravermelho - Outra evidência da diferença na composição química das partículas das diferentes dispersões pode ser observada nos espectros de absorção na região do infravermelho. As Figuras 36 e 37 mostram os espectros normalizados em relação ao pico de absorção das ligações Si-O-Si (1100-1000 $\left.\mathrm{cm}^{-1}\right)$, sendo que na Figura 37 a linha de base é deslocada em relação à origem para melhor visualização do pico de absorção das ligações C-H.

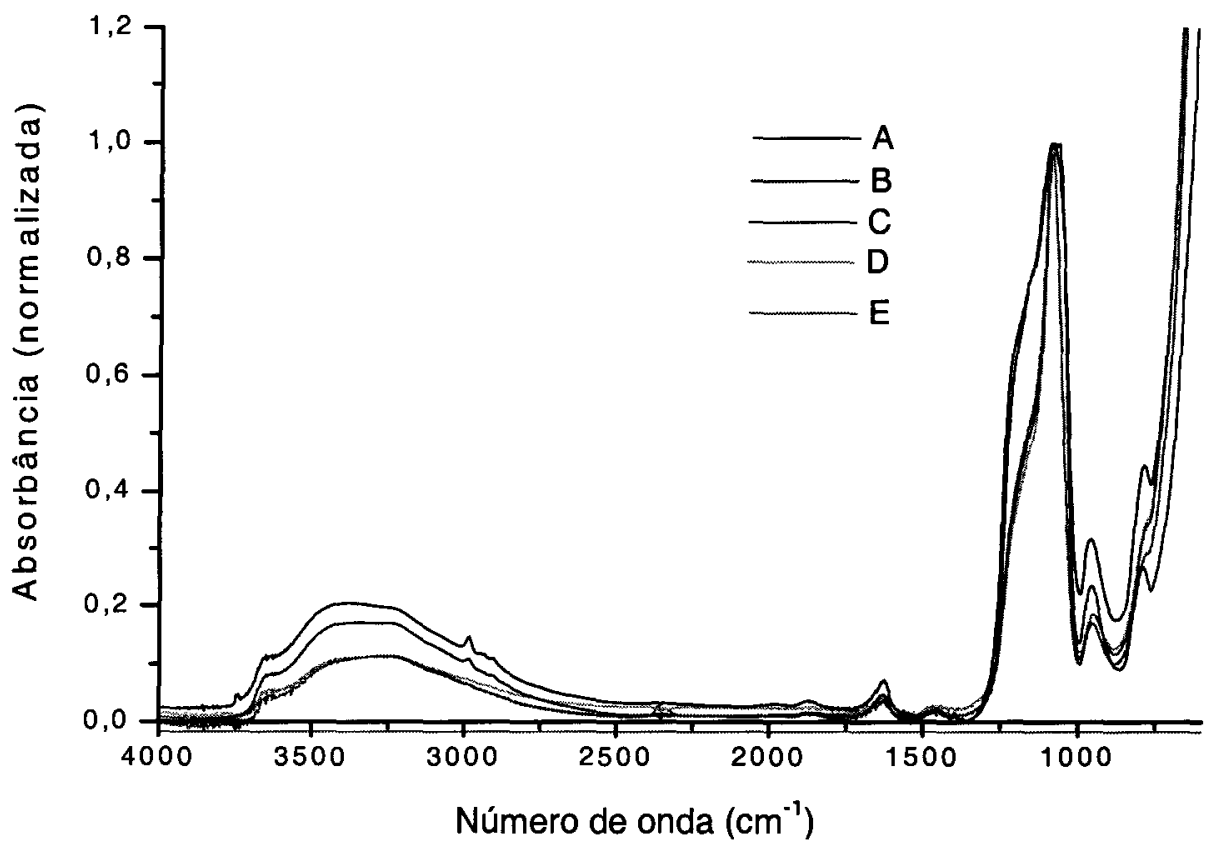

Figura 36. Espectros de absorção dos filmes preparados a partir da secagem das dispersões A,B,C,D e E sobre janelas de $\mathrm{BaF}_{2}$, normalizados em relação ao pico de absorção das ligações Si-O-Si (1100-1000 $\left.\mathrm{cm}^{-1}\right)$. 


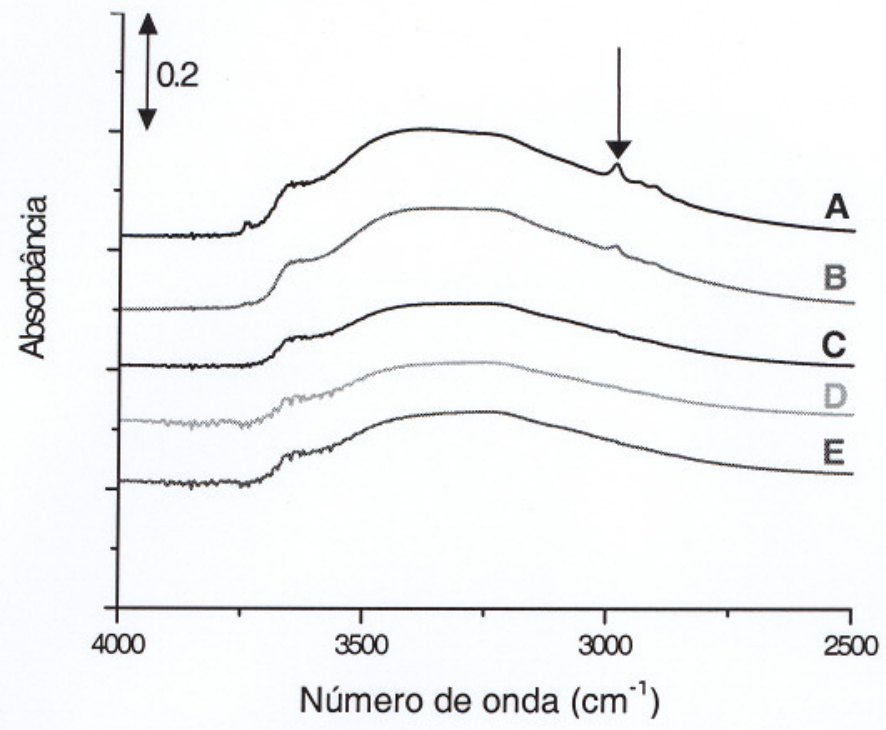

Figura 37. Espectros da Figura 36, porém deslocando a linha de base em relação à origem no intervalo de $4000-2500 \mathrm{~cm}^{-1}$. A seta indica o pico de absorção das ligações C-H (3000-2900 $\left.\mathrm{cm}^{-1}\right)$.

Os filmes preparados com as partículas menores apresentam um pequeno mas claro pico em $3000-2900 \mathrm{~cm}^{-1}$, mostrando que eles contêm quantidades detectáveis de grupos $\mathrm{C}-\mathrm{H}$. Este pico não é visto nos filmes preparados com as partículas maiores.

\subsection{Imagens elementares (ESI-TEM) - A Figura 38 mostra os mapas} elementares de $\mathrm{O}$ e Si adquiridos de um filme preparado a partir da dispersão D:
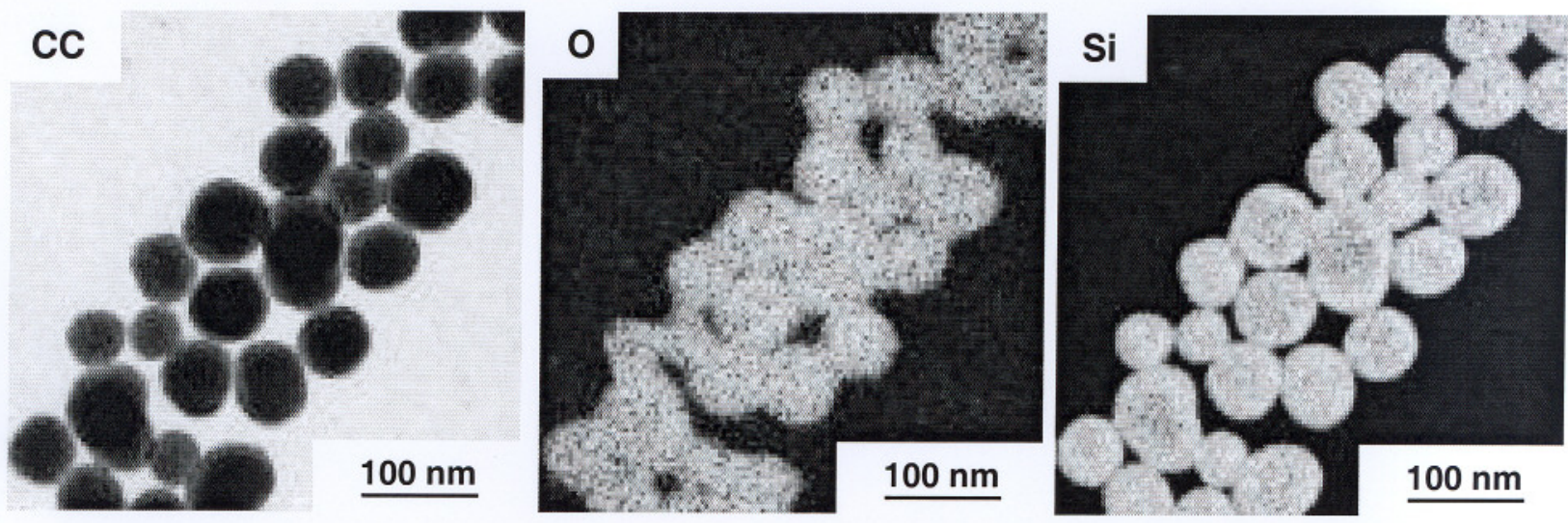

Figura 38. Imagens de campo claro e mapas elementares de O e Si de um filme preparado a partir da secagem da amostra D. 
Podemos observar que as partículas parecem maiores no mapa de $\mathrm{O}$ do que no mapa de $\mathrm{Si}$, sugerindo uma maior quantidade de $\mathrm{O}$ na superfície.

A distribuição do carbono nas diferentes amostras pode ser observada na Figura 39:

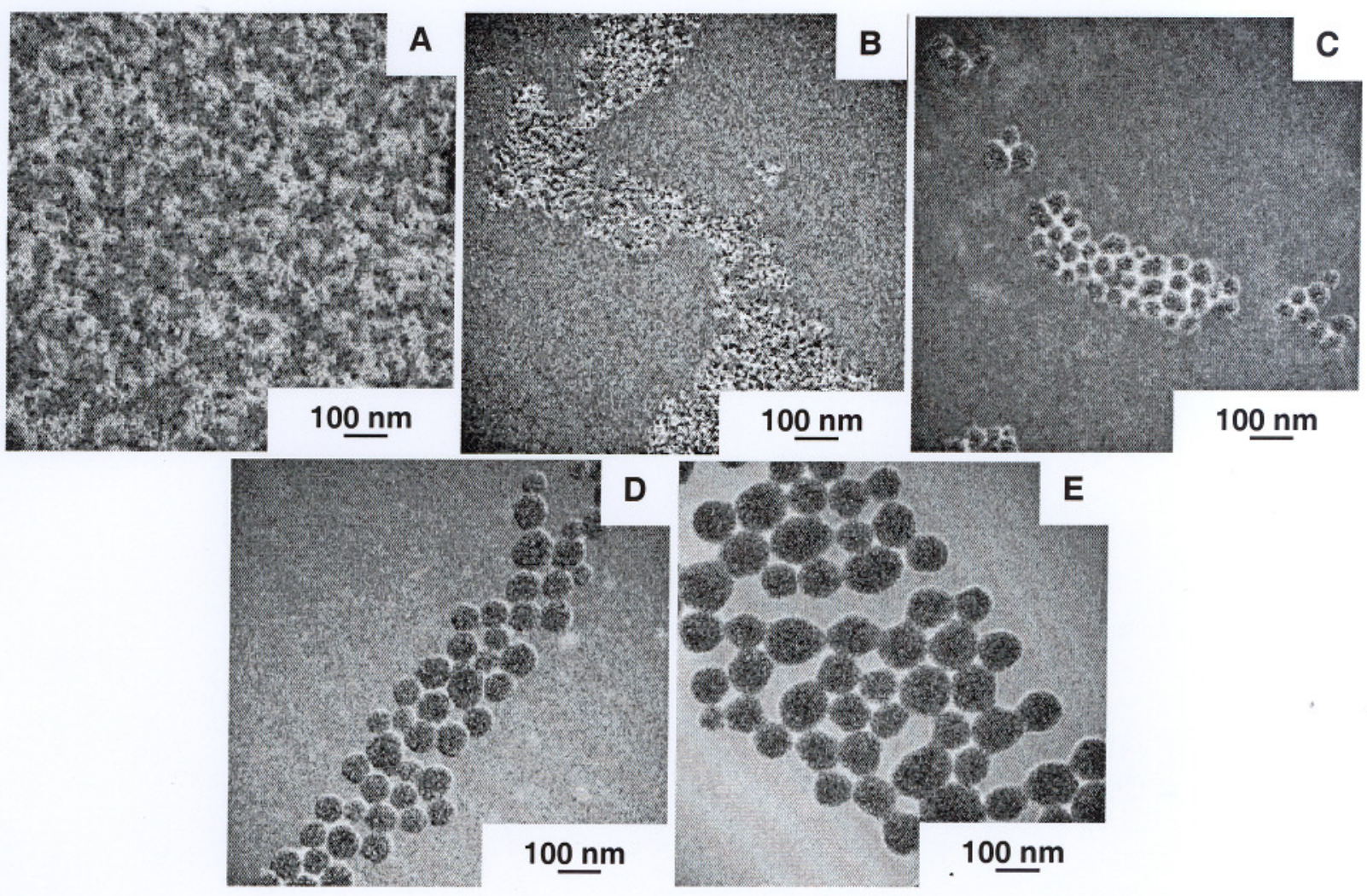

Figura 39. Imagens elementares de carbono das partículas de sílica.

As imagens elementares de carbono mostram que as partículas pequenas (amostra A) contêm pontos mais brilhantes que o substrato, o que revela a presença do carbono. As partículas maiores (amostras $\mathrm{D}$ e E) são menos brilhantes que o substrato, o que evidencia uma quantidade menor de carbono em relação às partículas pequenas, mas as bordas contêm pontos brilhantes. Nas amostras B e C, os interstícios entre as partículas são muito brilhantes, o que evidencia o acúmulo de carbono nestes interstícios.

A presença de grupos etoxilas distribuídos nas partículas pequenas, como foi verificado pelos espectros de IR e EELS, explicam o grande intumescimento 
destas em álcool. Estes grupos diminuem a conectividade das cadeias de ácido polisilícico, prevenindo assim a densificação da rede de sílica, e devem ainda provocar um aumento na quantidade de grupos silanóis não condensados, que contribuem para seu intumescimento em água.

Em alta concentração de amônia, a hidrólise dos grupos etoxilas é mais completa, permitindo que a reação de condensação do silanol seja mais extensa, decrescendo o intumescimento das partículas tanto em água como etanol. As partículas maiores apresentam baixos coeficientes de intumescimento e intumescem mais em água que em etanol, porque os principais grupos disponíveis para interação com o solvente são agora os grupos siloxano e silanol, ao invés dos grupos etoxila.

4.12. Comparação entre SEPM E EFM - para determinar qual das técnicas é a mais apropriada para a aquisição de informações sobre a distribuição de cargas elétricas em filmes de partículas de sílica, foram adquiridas imagens por EFM e SEPM de diferentes áreas de um mesmo filme de partículas de sílica, obtido a partir da secagem da dispersão C (Figura 40).
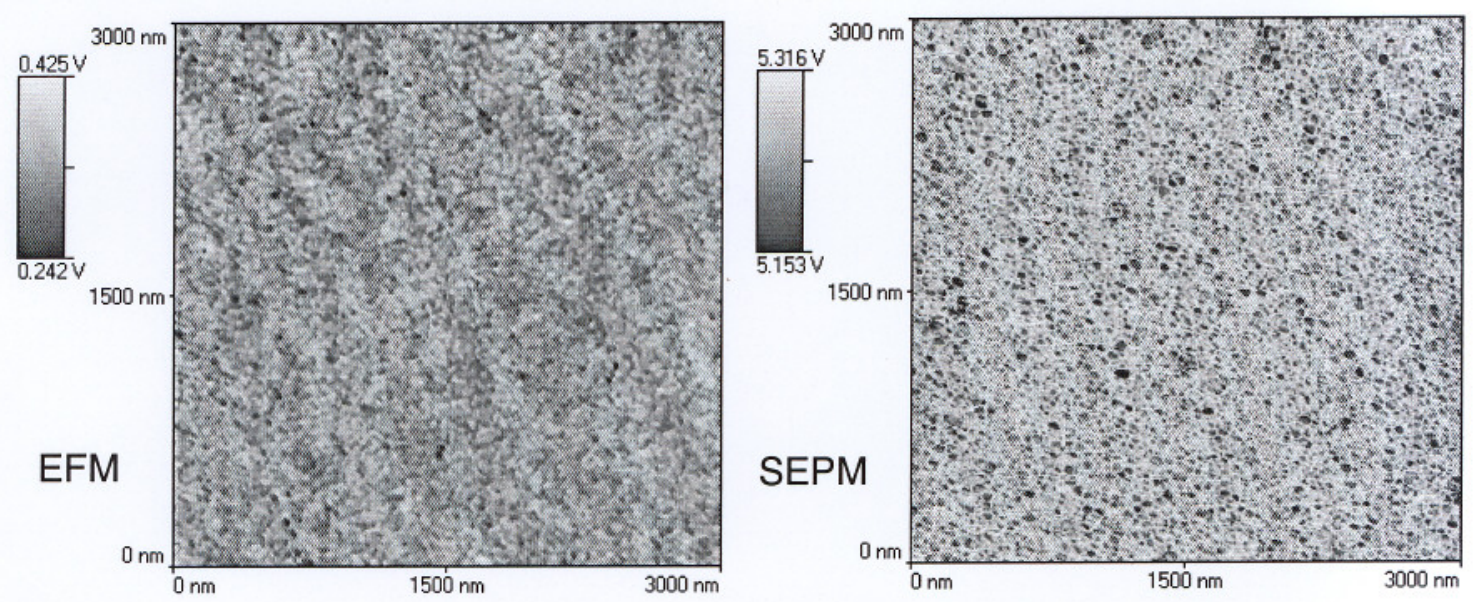

Figura 40. Imagens de EFM e SEPM de diferentes áreas da superfície de um filme de partículas de sílica, com espessura de aproximadamente $8 \mu \mathrm{m}$, preparado por secagem da dispersão C. 
Na Figura 40, os valores de tensão $(5,153$ - 5,316 V) da imagem de SEPM correspondem aos valores dos potenciais elétricos na superfície da amostra. Podemos verificar que estes potenciais estão deslocados em relação à terra devido a presença de cargas eletrostáticas, porém são mensuráveis as diferenças de potenciais entre os diferentes pontos de uma mesma imagem. Os valores de tensão da imagem de EFM $(0,242$ - 0,425V) são obtidos na saída de um amplificador tipo lock-in, são apenas sinais indicativos da defasagem da oscilação da sonda devido a força eletrostática.

A maior proximidade da sonda à superfície da amostra na varredura de SEPM $(\approx 10 \mathrm{~nm})$, em relação ao EFM $(\approx 40 \mathrm{~nm})$, permite uma maior resolução espacial das cargas. A imagem de SEPM da Figura 40 mostra maior contraste: domínios (negativos) discretos estão dispersos em uma matriz contínua, que é positiva com relação aos domínios discretos.

Por outro lado, a imagem de SEPM apresenta maior grau de dificuldade nos ajustes dos parâmetros, e um maior tempo de aquisição $(\approx 40$ minutos) que a imagem de $E F M(\approx 10$ minutos).

Em razão das vantagens apresentadas pela técnica de SEPM, as imagens de distribuição de cargas elétricas dos filmes de partículas de sílica das demais dispersões serão obtidas por esta técnica.

\subsection{Microscopia de varredura de potencial eletrostático (SEPM) - As imagens} das Figuras. 41 e 42 mostram as imagens topográficas, e também os respectivos mapas elétricos obtido por SEPM, dos filmes com espessura de aproximadamente $8 \mu \mathrm{m}$, preparados a partir da secagem das diferentes dispersões sobre as lâminas de mica recém clivadas. 



Figura 41. Imagens topográficas e de SEPM de filmes formados por secagem das amostras A, B e C. 

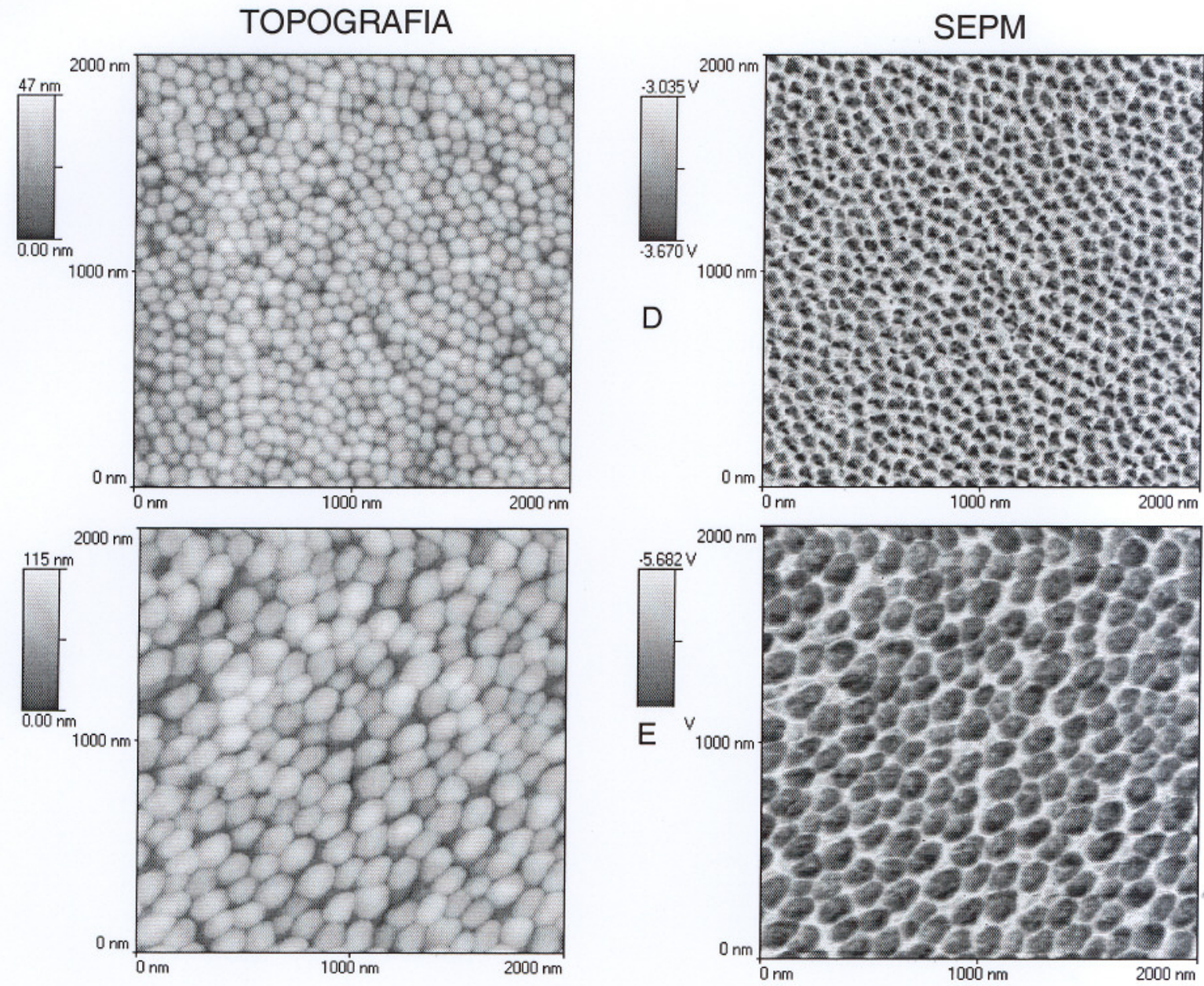

Figura 42. Imagens topográficas e de SEPM de filmes formados por secagem das amostras D e E.

As imagens de SEPM das Figuras 41 e 42 mostram que o potencial nas partículas é menor que o potencial nos interstícios, e que as partículas menores (amostras A,B e C) apresentam uma maior heterogeneidade na distribuição de cargas que as partículas maiores (amostras D e E). A Figura 43 mostra os histogramas de potenciais das imagens de SEPM das amostras B e D e os perfis de topografia e SEPM adquiridos em uma mesma linha: 


\section{AMOSTRA B}



Histograma de potenciais

\section{AMOSTRA D}

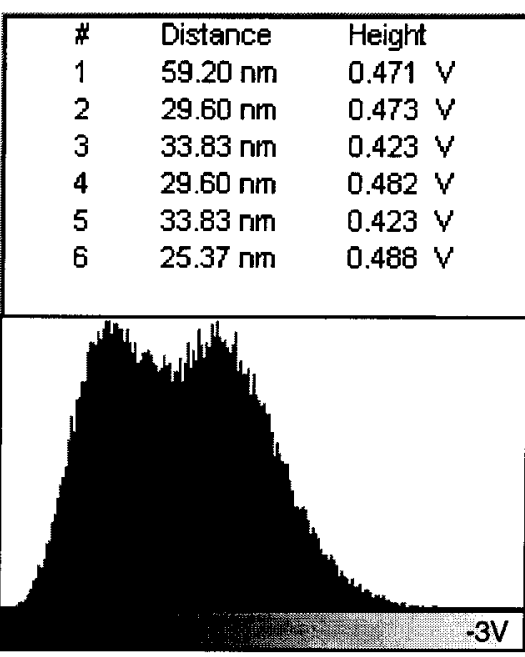

Histograma de potenciais
TOPOGRAFIA
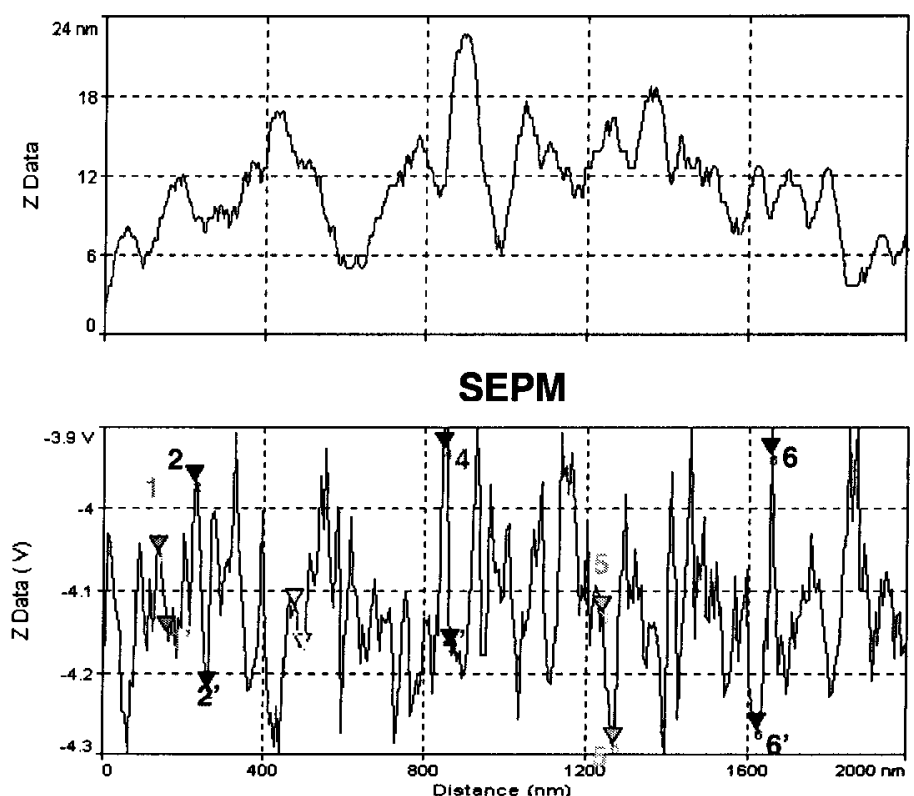

TOPOGRAFIA
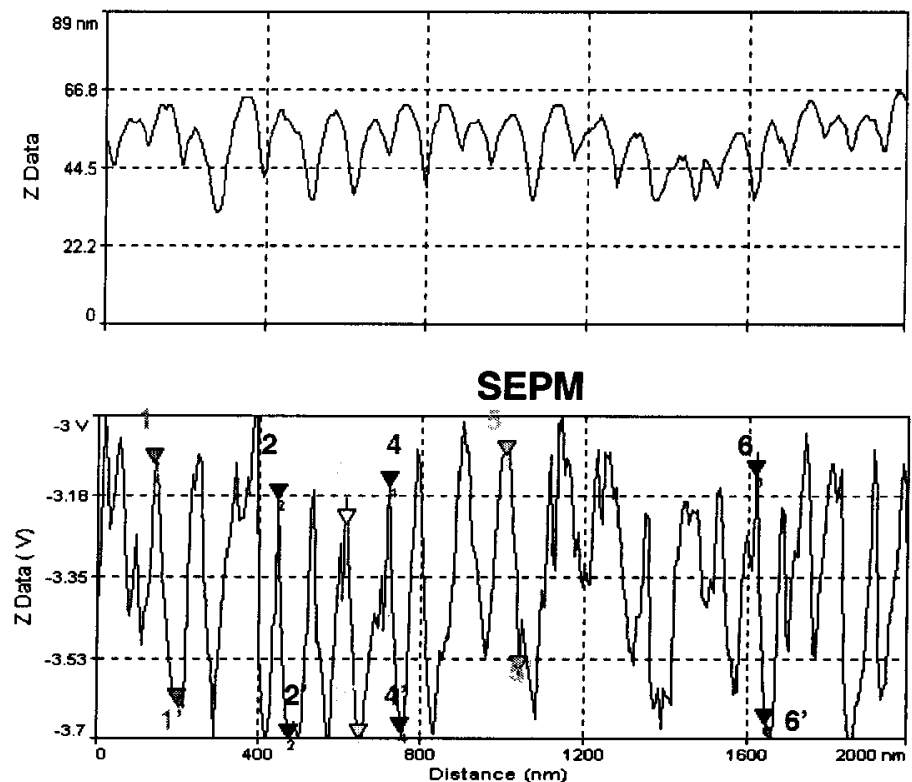

Figura 43. Histogramas de potenciais das imagens de SEPM das amostras B e D, e perfis de topografia e SEPM adquiridos em uma mesma linha.

O perfil de topografia da amostra $B$ mostra depressões e elevações na superfície da amostra maiores que o diâmetro das partículas. Não há correlação entre estas variações topográficas e o sinal de SEPM. Como mostrado na Figura 41B, o sinal de SEPM tende a valores máximos nos interstícios das partículas e a 
valores mínimos sobre as partícuals, com diferenças médias de potenciais entre valores consecutivos de picos de máximo e mínimo de 0,09 e 0,32 V.

Os perfis de topografia e SEPM da amostra D mostram que nas depressões, que correspondem aos interstícios entre as partículas, o potencial tende a um pico de máximo, e nas elevações, que correspondem as partículas, a um pico de mínimo. As diferenças médias de potenciais entre valores consecutivos de picos de máximo e mínimo variam entre 0,42 e 0,49 V.

A amostra B apresenta uma maior variação de potenciais entre os valores consecutivos de picos de máximo e mínimo que a amostra $\mathrm{D}$. Isto também pode ser verificado pelos histogramas de potenciais das imagens de SEPM: o histograma da amostra B apresenta uma distribuição monomodal, ou seja, os valores dos picos dos potenciais possuem uma distribuição ao redor de um valor médio, enquanto que o histograma da amostra D apresenta uma distribuição bimodal, com valores de pico de potenciais tendendo a um determinado valor de máximo ou mínimo.

A Figura 44 ilustra a heterogeneidade da distribuição de cargas em função do tamanho das partículas, observadas nas Figuras 41 a 43 :
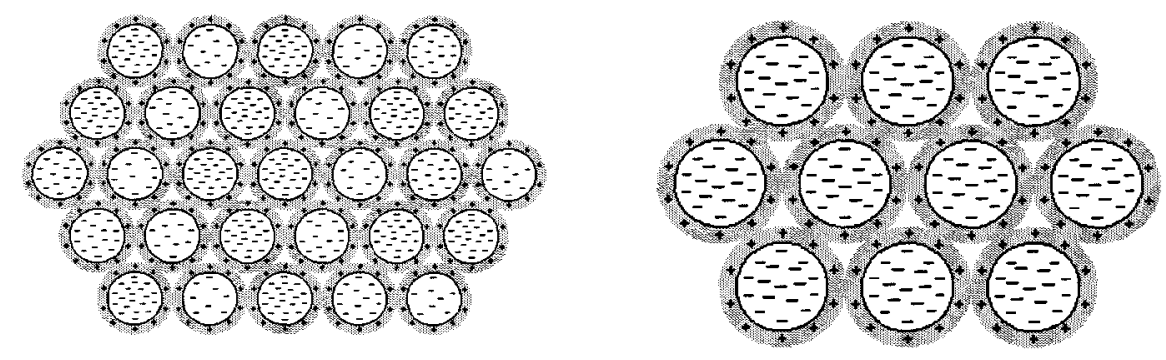

Figura 44. llustração da heterogeneidade da distribuição de cargas em função do tamanho das partículas: as partículas menores são mais heterogêneas que as maiores.

A presença de cargas positivas, entre as partículas de sílica com cargas negativas, permite que durante a secagem de dispersões concentradas e não- 
dialisadas, as partículas se aproximem e formem filmes densamente empacotados. (Figura 45).
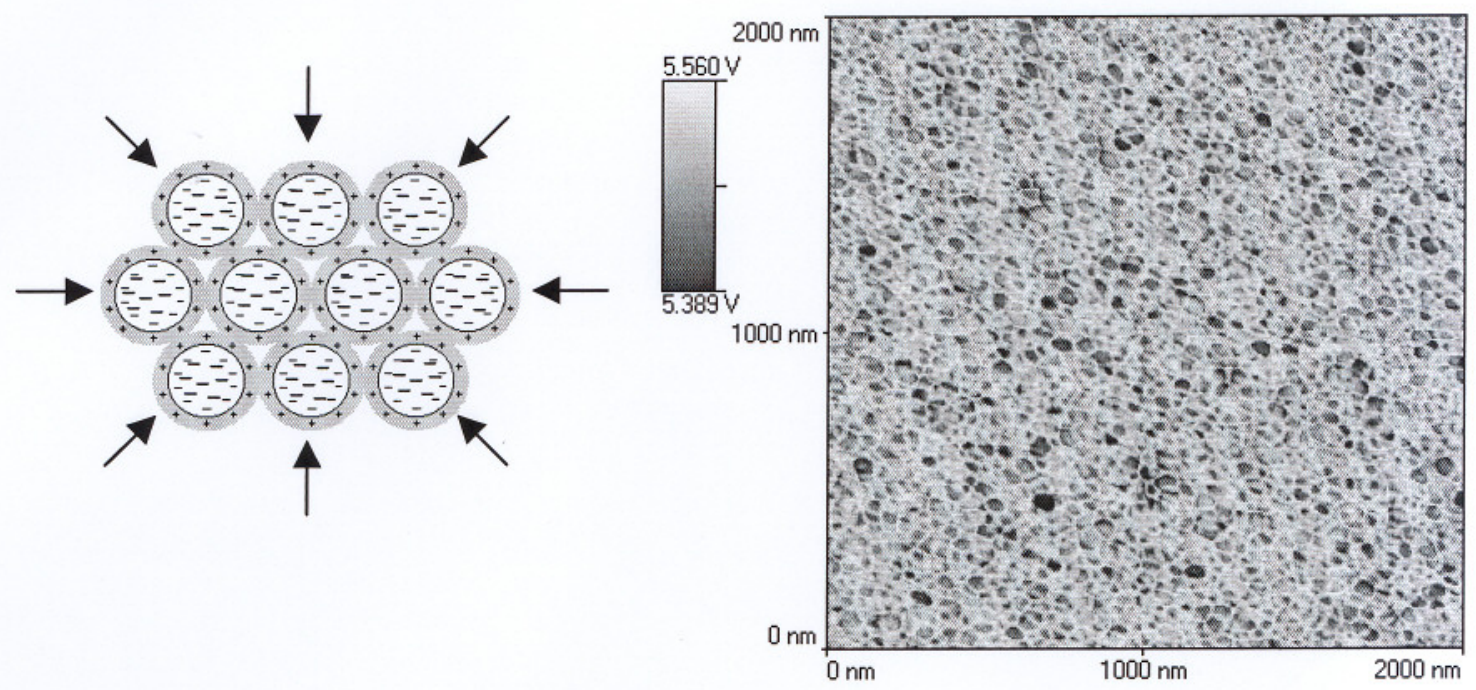

Figura 45. A imagem de SEPM mostra a presença de cargas positivas entre partículas de cargas negativas, o que permite que durante a secagem as partículas se aproximem e formem filmes densamente empacotados. 
4.14. Caracterização dos monolitos de partículas de sílica - As Figuras 46.1 e 46.2 mostram fotos de topo e elevação dos monolitos preparados a partir da secagem das dispersões $A, B, C, D$ e $E$, respectivamente. As fotos foram obtidas com fundo escuro e iluminação indireta por uma câmera fotográfica digital modelo Coolpix 4300 (Nikon).
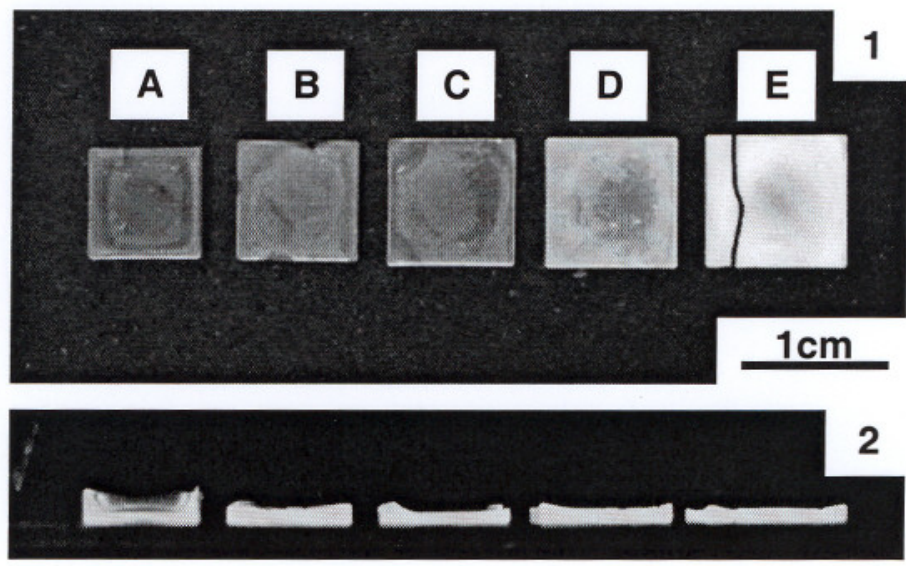

Figura 46. Fotos de (1) topo e (2) elevação dos monolitos preparados a partir da secagem das dispersões $A, B, C, D$ e E, respectivamente. As fotos foram obtidas com fundo escuro e iluminação indireta.

Os monolitos preparados a partir da secagem das dispersões com partículas maiores (C, D e E) são menos espessos, mais opacos e com dimensões mais próximas às da base do molde, apresentando contração linear de 12\%, 10\% e 9\% respectivamente. $\mathrm{O}$ monolito preparado a partir da dispersão $\mathrm{E}$ trincou durante $\mathrm{o}$ processo de secagem. Os monolitos preparados a partir da secagem das partículas menores ( $\mathrm{A}$ e B) são mais espessos, mais transparentes e apresentam maior contração durante a secagem: $24 \%$ e $17 \%$ em relação às dimensões da base do molde, respectivamente. 
A Figura 47 mostra as micrografias das superfícies dos monolitos da Figura 46, obtidas em um microscópio óptico com luz refletida.


Figura 47. Micrografias das superfícies dos monolitos da Figura 46, obtidas em um microscópio óptico com luz refletida.

As superfícies dos monolitos preparados por secagem das dispersões com partículas maiores (C, D e E) apresentam rachaduras microscópicas, com profundidade de aproximadamente $20 \mu \mathrm{m}$. Na superfície do monolito preparado a partir da dispersão B são observadas somente algumas trincas e uma superfície bastante homogênea é observada no monolito preparado a partir da dispersão A. 
4.14.1. Dureza Vickers - A Tabela 6 mostra os valores médios de dureza Vickers obtidos a partir da média aritmética de 10 impressões por amostra, aplicando-se uma força de indentação de $0,1 \mathrm{~N}$.

Tabela 6. Valores médios de dureza Vickers obtidos a partir da média aritmética de 10 impressões por amostra.

\begin{tabular}{|c|c|c|c|c|c|}
\hline Amostra & A & B & C & D & E \\
\hline Dureza Vickers & $19 \pm 3$ & $22 \pm 3$ & $34 \pm 5$ & $\cdots--^{*}$ & -.--* $^{*}$ \\
\hline
\end{tabular}

* As impressões do indentador nas superfícies das amostras D e E apresentam fissuras nas extremidades, mesmo aplicando a força mínima de indentação do equipamento $(0,1 \mathrm{~N})$. A presença destas fissuras invalida os valores de dureza Vickers obtidos.

Portanto, as amostras preparadas a partir da secagem das dispersões de partículas menores apresentaram uma menor dureza.

4.14.2. Tenacidade à fratura - A Tabela 7 mostra os valores mínimos da força aplicada pelo indentador Vickers para provocar fissuras nas extremidades das impressões nas superfícies dos monolitos.

Tabela 7. Valores mínimos da força aplicada $\left(P_{0}\right)$ pelo indentador Vickers para provocar fissuras nas extremidades das impressões nas superfícies dos monolitos.

\begin{tabular}{|c|c|c|c|c|c|}
\hline Amostra & A & B & C & D & E \\
\hline$P_{0}(N)$ & $0,75 \pm 0,25$ & $0,43 \pm 0,17$ & $0,18 \pm 0,7$ & $<0,1^{*}$ & $<0,1^{*}$ \\
\hline
\end{tabular}

* $0,1 \mathrm{~N}$ é a força mínima aplicada pelo equipamento utilizado.

As amostras preparadas a partir da secagem das dispersões de partículas menores apresentaram um maior valor de $\mathrm{P}_{0}$, o que indica uma maior tenacidade a fratura. 


\section{DISCUSSÃO}

5.1. Intumescimento - Comparando-se os diâmetros determinados em diferentes condições, observa-se que as partículas de sílica pequenas apresentam uma grande contração ao serem submetidas ao vácuo, portanto são facilmente intumescidas em etanol e água, com um maior coeficiente de intumescimento no etanol. Por outro lado, as partículas maiores são pouco intumescidas, e com preferência por água. Isto revela que as nanopartículas de sílica de diferentes tamanhos, que são freqüentemente admitidas como idênticas em muitos aspectos exceto o tamanho, são diferentes em sua afinidade por solvente e assim, na sua composição química.

Os diferentes graus de intumescimento em função dos diâmetros podem ser explicados pelos diferentes mecanismos de formação das partículas: de acordo com ller, ${ }^{[20]}$ o interior das partículas de sílica é constituído por sílica anidra $\left(\mathrm{SiO}_{2}\right)$, com densidade de $2,2 \mathrm{~g} \cdot \mathrm{cm}^{2}$. Ainda segundo ller, os átomos de silício localizados na superfície estão ligados nos grupos $\mathrm{OH}$, que não são removidos quando a sílica é desidratada.

Resultados topoquímicos obtidos anteriormente neste laboratório [10,11] mostraram a natureza caroço-casca das partículas maiores de sílica, e que a espessura da casca se estendia por muitos nanômetros. A formação desta estrutura pode ser explicada pelo mecanismo proposto por El Aasser ${ }^{[59]}$ para a formação de partículas poliméricas tipo caroço-casca: as cadeias mais hidrofilicas movem-se para a superfície das partículas, guiadas pela minimização da tensão 
interfacial entre as partículas e o meio de reação. Outro mecanismo de formação de partículas tipo caroço-casca pode ser proposto, baseado em um argumento de Kramarenko: ${ }^{[60]}$ o colapso de géis de polieletrólitos diminui a constante dielétrica efetiva do meio, diminui o grau de ionização, aumentando as vantagens termodinâmicas do estado colapsado, e pelo mecanismo de sinerese, a água movese para a superfície das partículas.

Nas partículas menores o alto coeficiente de sorção de água sugere que as cadeias de siloxano formadas são agregadas com baixo grau de reticulação, formando pequenos domínios de gel de ácido silícico altamente hidratado.

5.2. Plasticidade - Em partículas com dimensões nanométricas, partes apreciáveis de suas superfícies podem aproximar-se a distâncias muito pequenas, permitindo que as forças de van der Waals atinjam valores significativos assim permitindo a sua auto-adesão. ${ }^{[61]}$ Uma fração significativa do número de átomos na partícula se encontra na superfície, onde a difusão é mais rápida porque o volume livre é maior do que no interior do sólido. De fato, átomos da superfície sempre podem migrar, se tiverem energia suficiente para reduzir o número de contatos com seus vizinhos. ${ }^{[22]}$

Analisando as micrografias dos filmes obtidas pelas diferentes técnicas (Figuras 24, 26, 41 e 42), podemos verificar que, após a secagem das dispersões, as partículas maiores apresentaram formato quase-esférico, mostrando-se um pouco deformadas por adesão capilar. Por outro lado, as partículas menores produzem filmes densamente empacotados, o que é uma evidência de sua grande plasticidade. Estas partículas são formadas por ácido silícico esterificado com cadeias alcoxisilano, que são cadeias flexíveis e com alto grau de hidrofilicidade. Tratando-se de cadeias pouco reticuladas e flexíveis, justifica-se a grande plasticidade das partículas, alcançada pela retenção do solvente. 
Esta plasticidade também é verificada pela maior contração, durante a secagem, dos monolitos formados pelas partículas menores. Estes monolitos apresentam uma superfície mais lisa (Figura 47), são menos duros e mais tenazes à fratura.

O menor módulo do potencial zeta das partículas menores também contribui durante a formação dos filmes e monolitos, facilitando a aproximação, deformação e empacotamento mais acentuado das partículas menores em relação às maiores. 


\section{CONCLUSÕES}

Nanopartículas de sílica de diferentes diâmetros, preparadas pelo método de Stöber, apresentam grandes diferenças em sua composição química e no grau de intumescimento em presença de água e etanol: as partículas menores preparadas na presença de baixa concentração de base contém grupos etoxilas residuais que limitam a extensão e a reticulação das cadeias do ácido silícico, limitando assim o crescimento das partículas na dispersão. Sendo ricas em grupos etoxila e pouco reticuladas, as partículas menores são mais fortemente intumescidas em etanol e água do que as partículas maiores. Este intumescimento, associado à heterogeneidade na distribuição das cargas elétricas e o baixo grau de reticulação, contribui para a plasticidade e deformação das partículas na formação de filmes e monolitos preparados por secagem das dispersões. Isso justifica os filmes densamente empacotados, observados nas imagens microscópicas, e a menor dureza e maior tenacidade à fratura dos monolitos preparados com partículas menores. 


\section{PARTE II}

\section{SORÇÃO EM SÍLICA DE STÖBER: UM ESTUDO MICROQUÍMICO}

\section{INTRODUÇÃO}

1.1. Sorção - Em um sólido, a sorção de um componente, a partir de uma solução, pode ocorrer tanto pela absorção da solução em poros, ou em uma estrutura aberta, bem como pela adsorção na superfície. A quantidade adsorvida de um componente em uma superfície, a partir de uma solução, é correlacionada com a concentração deste componente no interior da solução por uma expressão analítica denominada isoterma de adsorção. ${ }^{[62]}$ As forças anisotrópicas que predominam na superfície fazem com que a concentração da espécie adsorvida seja diferente daquela no interior da solução. Assim, estas duas regiões podem ser consideradas como fases distintas e a condição de equilíbrio requer, para uma espécie qualquer $i$, que seus potenciais químicos sejam iguais:

$$
\mu_{i}^{a}=\mu_{i}^{s}
$$

onde $\mu_{i}^{a}$ e $\mu_{i}^{s}$ são os potenciais químicos da espécie $i$ na interface e no interior da solução, respectivamente. Desta equação resulta:

$$
\mu_{i}^{0, a}+R \pi n a_{i}^{a}=\mu_{i}^{0, s}+R 7 n a_{i}^{s}
$$

que rearranjada fornece a expressão termodinâmica da isoterma de adsorção: 


$$
a_{i}^{a}=a_{i}^{s} \exp \left(-\Delta G_{a d s}{ }^{0} / R T\right)=a_{i}^{s} \beta
$$

onde

$$
\beta=\exp \left(-\Delta G_{a d s}{ }^{0} / R T\right)
$$

sendo

$$
\Delta G_{a d s}{ }^{0}=\mu_{i}^{0, a}-\mu_{i}^{0, s}
$$

denominado energia livre padrão de adsorção.

Devido às diferentes interações que governam a adsorção de diferentes espécies, não existe uma única isoterma aplicável a todas as situações. Diferentes isotermas resultam de considerar $\beta$ constante e diferentes expressões para o termo.

1.1.1. Sorção de íons - Considerando um soluto iônico dissolvido na água, observase que o comportamento de um íon presente no interior da solução é governado por forças isotrópicas, enquanto que o comportamento perto da superfície é governado por forças anisotrópicas. ${ }^{[62]}$ A concentração de um íon no interior da solução é constante; por outro lado, dependendo da componente total das forças anisotrópicas superficiais, nas regiões próximas à superfície haverá um aumento ou uma diminuição da concentração do ín. Tratando-se de espécies carregadas eletricamente, o resultado será uma distribuição desigual de cargas elétricas da qual resulta uma diferença de potencial entre a superfície e o interior da solução. A região fronteiriça é denominada de dupla camada elétrica. $\mathrm{Na}$ ausência de fatores externos, a anisotropia de forças resulta em acúmulo ou carência de determinadas espécies sobre a superfície, com relação ao meio da solução.

A descrição quantitativa da adsorção na superfície, em condições $P, T$ pode ser feita termodinamicamente por meio da equação de Gibbs, ou seja,

$$
d \sigma=-\Sigma \Gamma_{i} \mu_{i} \quad(P, T=\text { constantes })
$$


onde $\sigma$ é a tensão superficial, ou seja, o trabalho superficial reversível necessário para aumentar a área interfacial de uma unidade; $\mu_{i}$ é o potencial químico do componente $i$, e $\Gamma_{i}$ é o excesso de concentração superficial do componente $i$.

Em termos das concentrações:

$$
\Gamma_{i}={ }_{0}{ }^{x 0} c_{i} d x-c_{i}^{0} x_{0}
$$

onde $c_{i}$ é a concentração volumétrica do componente adsorvido, e $c_{i}^{0}$ é a concentração do mesmo componente no interior da solução.

Nesta tese foram utilizadas nanopartículas de sílica preparadas pelo método de Stöber (seção 1-3.3). Quando estas partículas são colocadas em água apresentam um potencial zeta negativo, isto é, migram em direção a um eletrodo positivo devido ao excesso de cargas negativas. Podemos entender este fato considerando a dissociação dos grupos silanóis na superfície exposta ao meio aquoso. ${ }^{[63]}$ Assim, muitos dos cátions $\mathrm{H}^{+}$, além de outros em menor quantidade como $\mathrm{NH}_{4}^{+}$(proveniente da amônia que catalisa a hidróise do TEOS), $\mathrm{Ca}^{2+}$ e $\mathrm{Na}^{+}$ (provenientes da dissolução do vidro), dissociam-se das partículas de sílica, dissolvendo-se na água e conferindo ao meio um excesso de cargas positivas sobre as negativas e mantendo a eletroneutralidade do sistema. Assim, a interface pode ser considerada como um capacitor de placas paralelas. Utilizando-se um modelo simples de capacitor, o trabalho pode ser expresso pelo produto da carga pelo diferencial da diferença de potencial entre as placas, ou seja, $-q^{M} d(\Delta \varphi)$. Introduzindo este termo na equação de Gibbs, obtém-se:

$$
d \sigma=-q^{M} d(\Delta \varphi)-\Sigma \Gamma_{i} \mu_{i} \quad(P, T=\text { constantes })
$$


1.1.1.1. Sorção de $\mathrm{NaCl}$ - A sorção de $\mathrm{NaCl}$ pelas partículas de sílica pode ocorrer tanto pela absorção da solução de $\mathrm{NaCl}$ pela estrutura aberta das partículas, que em meio líquido encontram-se bastante intumescidas, bem como pela adsorção na superfície.

A interação entre um eletrólito e um adsorvente pode ocorrer de diferentes formas: o eletrólito pode ser adsorvido in toto, ou seja, de forma similar à adsorção molecular. Entretanto, é mais freqüente que íons de um mesmo sinal se liguem mais fortemente com os íons de sinal contrário presentes na camada difusa da partícula. Também pode ocorrer troca iônica: os íons ligados quimicamente nas partículas podem ser trocados pelos íons $\mathrm{Na}^{+}$e $\mathrm{Cl}^{-}$da solução.

1.1.2. Adsorção de polímeros - Quando um polímero é adsorvido nas superfícies das partículas de uma dispersão coloidal, a estabilidade da dispersão é afetada, às vezes drasticamente. ${ }^{[64,65]}$ Não somente a repulsão eletrostática e a atração de van der Waals são influenciadas diretamente, como também há importantes contribuições adicionais para a energia livre de interação das partículas. Sob diferentes condições, uma dispersão pode ser estabilizada ou desestabilizada por um polímero, por meio de uma variedade de mecanismos. ${ }^{[6]]}$ Freqüentemente estes dois efeitos podem ocorrer em um mesmo sistema: em baixas concentrações de polímeros a dispersão pode flocular, por outro lado, em altas concentrações o sistema pode ser fortemente estabilizado.

Os efeitos na estabilidade das dispersões são uma das principais causas de interesse na adsorção de polímeros, em função da grande aplicação tecnológica. Os polímeros são freqüentemente usados como estabilizadores de emulsões. A maioria das aplicações são na área de tecnologia de alimentos e nas indústrias farmacêutica e química. ${ }^{[67,68]}$

Outra importante aplicação da adsorção de polímeros é a desestabilização de suspensões. ${ }^{[69,70]} \mathrm{Na}$ produção industrial de muitos metais, como a produção de 
alumínio a partir do processamento da bauxita, há um problema de separação das fases sólida e líquida. Com a adição de aditivos poliméricos, flocos grandes são formados e sedimentam rapidamente. A purificação de água é outro exemplo de aplicação da floculação por polimeros. Rejeitos industriais líquidos são usualmente clarificados desta forma. A floculação por pontes é classicamente definida como resultado da associação entre partículas, que ocorre quando uma cadeia polimérica se adsorve simultaneamente em duas partículas (Figura 48).



Figura 48. Representação esquemática de formação de ponte.

Geralmente, as pontes são esperadas quando pequenas quantidades de polímeros de alto peso molecular são adicionados a uma dispersão de partículas, adsorvendo nas interfaces com grau de cobertura da ordem de $50 \% .{ }^{[7]}$

A adsorção de homopolímeros em uma interface simples envolve uma configuração como a descrita na Figura 49. A seção da cadeia que toca a superfície e se estende na solução é chamada de cauda, as secções que iniciam na superfície, fazem voltas na solução, mas retornam para a superfície são chamadas de alças, e as secções completamente aderentes à superfície são os trens.

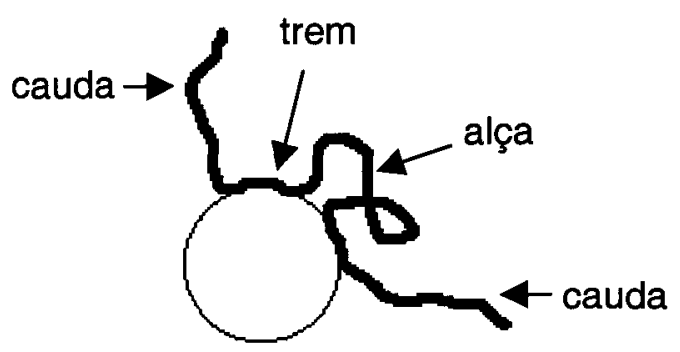

Figura 49. Configuração de um homopolímero adsorvido: cauda, alça e trem. 
A região de cauda se estende da superfície até uma distância $\mathrm{Rg}$, onde $\mathrm{Rg}$ é o raio de giração da partícula. ${ }^{[72]}$ As caudas não são detectáveis pela maioria das técnicas experimentais, como a elipsometria, ${ }^{[73]}$ espalhamento de neutrôns, ${ }^{[7]}$ e reflectividade de neutrôns, ${ }^{[75]}$ mas dominam as propriedades hidrodinâmicas ${ }^{[76]}$ das partículas e as interações de longa distância. Para as distâncias da ordem de Rg, as alças e trens dominam as interações partícula-partícula. ${ }^{[7]} \mathrm{O}$ perfil de concentração das alças decai exponencialmente com o aumento da distância da superfície, enquanto que o perfil de concentração das caudas atinge um máximo próximo de $\mathrm{Rg}$, e decai exponencialmente com distâncias maiores. ${ }^{[74]}$

Homopolímeros com altos pesos moleculares relativos, excedendo 1000 segmentos, possuem aproximadamente $10-20 \%$ de sua massa nas caudas quando a superfície das partículas está totalmente recoberta. ${ }^{[7]}$ Quando o recobrimento da superfície é baixo, as cadeias tendem a se assentar na superfície, o que diminui as caudas e loops. $\mathrm{Na}$ adsorção de polímeros com baixo peso molecular relativo, somente uma pequena fração de massa contribui para as caudas, independente da taxa de recobrimento da superfície da partícula. ${ }^{[74]}$

1.1.2.1. PNIPAM - Poli(N-isopropilacrilamida) (PNIPAM) (Figura 50) é um polímero solúvel em água com uma baixa temperatura crítica de solução (LCST), entre 30 e $35^{\circ} \mathrm{C}$, dependendo dos detalhes da estrutura da macromolécula. ${ }^{[8,79]}$ Abaixo de LCST, as cadeias de PNIPAM formam novelos expandidos e portanto solúveis em meio aquoso, e acima de LCST, ocorre o colapso das espiras, levando à precipitação. 


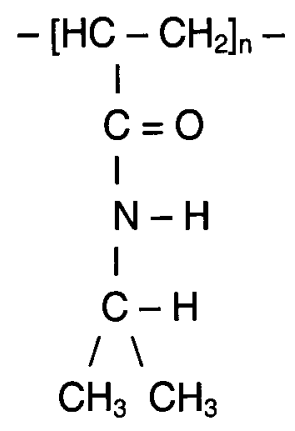

Figura 50. Estrutura química do PNIPAM.

Esta transição presumivelmente resulta de mudanças em vários tipos de interações (especialmente pontes de hidrogênio e interações hidrofóbicas) que ocorrem entre as cadeias de PNIPAM e as moléculas de água. ${ }^{[80,81]}$ O PNIPAM demonstra um complexo comportamento de intumescimento e colapso em resposta a pequenas mudanças na composição do solvente, a uma dada temperatura. ${ }^{\left[{ }^{82]}\right.}$ Devido à proximidade de sua temperatura crítica de solução da temperatura corporal, muitas aplicações para o PNIPAM têm sido propostas, incluindo métodos para a preparação de conjugados com proteínas, ${ }^{[83]}$ sistemas de liberação controlada de drogas, ${ }^{[84,85]}$ e reatores de enzima imobilizada. ${ }^{[86]}$

As amostras de PNIPAM usadas neste estudo foram sintetizadas usando o método descrito por Schild and Tirrell ${ }^{[87]}$ e foram descritas em estudos anteriores, ${ }^{[8]}$ tendo sido cedidas pela Dra. L-T Lee.

1.1.3. Adsorção de surfactantes - Surfactantes iônicos ou não iônicos influenciam fortemente as propriedades coloidais que dependem das interações partículapartícula. Como exercem seus efeitos mesmo em concentrações bastante baixas, são usados em uma variedade de aplicações industriais e na agricultura, para modificar e controlar a estabilidade, flotabilidade e reologia de sistemas coloidais. 0 papel usual de um surfactante é modificar as propriedades das interfaces líquidolíquido, sólido-líquido ou gás-líquido. Para ser efetivo em qualquer destas 
aplicações, o surfactante precisa adsorver fortemente na interface. Além da concentração na interface, a conformação do surfactante é um fator importante..$^{[89,90,91]}$

A porção hidrofóbica de um surfactante adsorve em uma superfície hidrofóbica, e a porção hidrofílica é voltada para a fase aquosa. Para uma superfície hidrofílica, a orientação da adsorção é oposta.

Variações na polaridade das superfícies exercem uma grande influência na adsorção. Como as partículas também possuem cargas elétricas, as interações eletrostáticas entre a superfície e as moléculas do surfactante possuem uma influência significativa na quantidade e conformação do material adsorvido. A adsorção dos contra-ions dos surfactantes iônicos, freqüentemente ignorada na literatura, também modifica a interação eletrostática entre a superfície-surfactante.

Nos surfactantes iônicos o grupo iônico é a parte hidrofílica. Os íons apresentam uma forte afinidade com a água, por causa da atração eletrostática entre os íons e os dipolos da água, e são capazes por isso de carregar consigo cadeias carbônicas bastante longas, provocando sua dissolução em água.

No nonilfenilpolioxietileno que é um surfactante não-iônico, a parte hidrofílica é o grupo polioxietileno, que adsorve nos sítios de adsorção hidrofílicos, e a parte hidrofóbica é o grupo nonilfenil que adsorvem nos sítios hidrofóbicos. ${ }^{\left[{ }^{[2]}\right.}$ Com o aumento do grau de etoxilação da parte hidrofílica da molécula (medida pelo balanço hidrofílico-lipofílico - HLB), altera-se sua solubilidade em água, seu poder espumante, molhabilidade e detergência, permitindo que tais produtos sejam utilizados como emulsionantes, detergentes, solubilizantes, umectantes e desengraxantes.

Em concentrações baixas $\left(<1,0 \times 10^{-4} \mathrm{~mol}^{-1} \mathrm{~L}^{-1}\right)$ os surfactantes iônicos são solúveis em água e se dissociam como eletrólitos, formando soluções eletrolíticas simples. Algumas moléculas são preferencialmente adsorvidas nas superfícies da 
solução: além das superfícies das partículas de sílica, adsorvem também na interface ar-solução e nas paredes do recipiente.

Aumentando a concentração do surfactante, o número de moléculas adsorvidas aumenta e o empacotamento das cadeias é mais compacto, o que resulta em uma forte interação entre as cadeias hidrofóbicas, que tendem a se esticar na direção normal à superfície hidrofílica (Figura 51).



Figura 51. Esquema de adsorção de surfactantes em superfícies hidrofilicas e hidrofóbica, mostrando a conformação do surfactante nestas superfícies. A, B, C, D e E mostram os diferentes estágios de adsorção durante a secagem de uma solução de surfactante. 
Outro processo que ocorre nesta mesma concentração é a formação de micelas (Figura 52). Nestas estruturas, as porções hidrofóbicas das moléculas do surfactante se associam para formar regiões em que o solvente, no caso a água, é excluída. Os grupos hidrofílicos permanecem do lado de fora da superfície das micelas, maximizando as interações com a água e contra-íons. Uma fração significativa dos contra-íons permanece ligada aos grupos hidrofílicos, diminuindo a força lateral repulsiva entre estes grupos.

A concentração na qual as micelas se formam em solução é chamada concentração crítica micelar (c.m.c.). Mudanças abruptas nas propriedades de equilíbrio e transporte são verificadas nesta concentração.

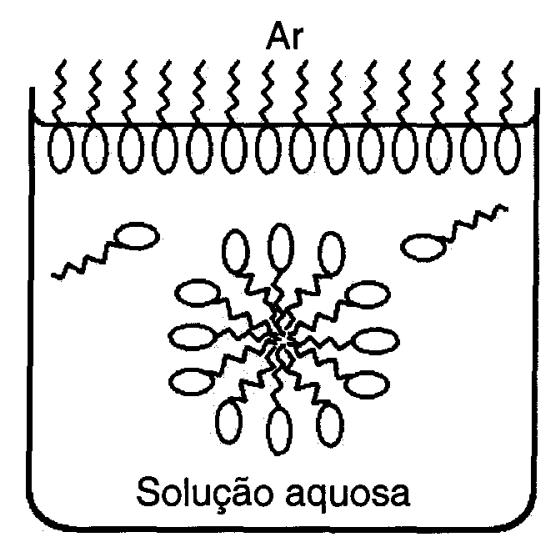

$0 \longrightarrow$ grupo hidrofílico

$\xi \rightarrow$ grupo hidrofóbico

Figura 52. O esquema ilustra a formação de formação de uma micela na concentração crítica micelar (c.m.c.). A adsorção deve ocorrer também nas paredes do recipiente. $O$ arranjo não é mostrado pois depende da hidrofilicidade da superfície.

As micelas formadas em baixas concentrações são esféricas e possuem um número bem definido de unidades de agregação. Um exemplo é o dodecil sulfato de sódio (SDS) que forma micelas esféricas, monodispersas, com 50 unidades de sulfito de sódio. Aumentando a concentração, o formato esférico é distorcido, formando cilindros, discos planos e cristais líquidos, também chamados de fases mesomórficas. ${ }^{[93]}$ 
1.2. Interfaces com cargas elétricas - As propriedades elétricas de sistemas coloidais representam um dos tópicos mais complexos na ciência de colóides e interfaces. ${ }^{[94]}$ Do ponto de vista elétrico, as partículas coloidais possuem muitas cargas, como os polieletrólitos, estando imersas em soluções eletrolíticas e sendo circundadas por uma interface carregada.

As partículas geram fortes campos elétricos: as cargas que geram esse campo são fixas nos meios que são os seus portadores, portanto não geram correntes elétricas. Correntes elétricas somente surgem quando as partículas carregadas se deslocam sob a ação do campo elétrico.

Diferentes mecanismos podem levar à separação de cargas em diferentes domínios:

Eletrização devido à diferença de funções trabalho - A transferência de cargas elétricas entre dois diferentes domínios é determinada pela diferença da função trabalho entre os dois materiais, isto é, pela diferença de energia para remover um elétron de cada um dos materiais. Este mecanismo é efetivo em metais e semicondutores.

lonização de grupos superficiais - Ocorre em uma superfície com grupos ionizáveis. A carga da superfície depende do $\mathrm{pH}$.

Adsorção diferencial de ions - ĺons adsorvem em superfícies; se as partículas em uma solução aquosa adsorvem cátions em maior escala do que ânions, as partículas adquirirão carga elétrica positiva. A adsorção pode ser tão intensa e específica que termina por vencer a contribuição eletrostática. Um caso bem conhecido é o de íons $\mathrm{Ba}^{2+}$ em hematita: mesmo em um $\mathrm{pH}$ tal que as partículas tenham carga positiva, ocorre adsorção de íons $\mathrm{Ba}^{2+}$, evidenciando a existência de 
uma interação específica que supera a repulsão eletrostática. Esse efeito é muito pronunciado, e quase universal: partículas de óleo (hidrocarboneto) em água são negativas, porque a adsorção de íons hidroxila é mais acentuada que a adsorção de ions $\mathrm{H}^{+}$. Por outro lado, borbulhando gases inertes em água puríssima, em uma célula potenciométrica, observa-se uma aparente mudança de $\mathrm{pH}$. Análises de EELS das partículas de sílica mostram uma grande adsorção de cátions $\mathrm{Ca}^{2+}$ e $\mathrm{Na}^{+}$ provenientes da vidraria utilizada, além de $\mathrm{NH}_{4}{ }^{+}$da solução de amônia catalisadora da reação.

Dissolução diferencial de íons - Quando se dissolve iodeto de prata em água até a saturação, as partículas de iodeto de prata remanescentes apresentam carga negativa, devido à retenção de ânions iodeto ser mais intensa que a de cátions prata. $O \mathrm{~K}_{\mathrm{ps}}$ do iodeto de prata é $10^{-16}$ e as partículas só são neutras quando pAg = 5,5 (e pl = 10,5), isto é, quando há um excesso de prata sobre iodeto, em solução.

Indução por ação mecânica - Operações como a moagem de sólidos geram alterações químicas locais. A relaxação térmica elimina as espécies transientes mais violentamente reativas, mas deixa espécies reativas inexistentes no material antes da moagem. Por exemplo, a moagem de quartzo provoca rupturas nas cadeias de O-Si-O, formando radicais livres e íons que contribuem para separação de cargas nas superfícies das partículas.

No caso de partículas secas de sílica, podemos supor que: os íons silício e oxigênio, estão preferencialmente no interior da partícula, enquanto os contra-íons de $\mathrm{H}^{+}, \mathrm{NH}_{4}{ }^{+}, \mathrm{Na}^{+}$e $\mathrm{Ca}^{2+}$ predominam na sua superfície (Figura 53). 

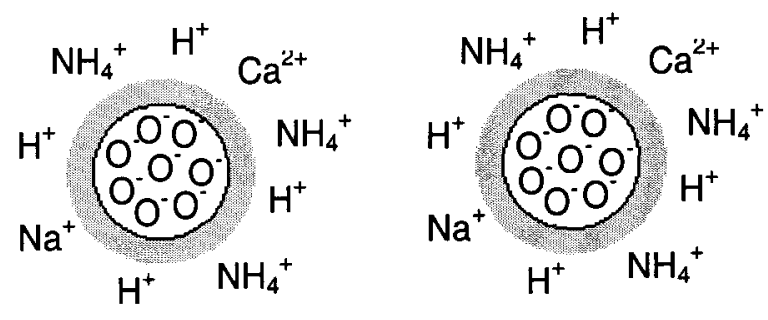

Figura 53. Esquema da separação de cargas em uma dispersão de partículas de sílica. Os cátions $\mathrm{NH}_{4}^{+}$são provenientes da amônia e $\circ \mathrm{Na}^{+}$e $\mathrm{Ca}^{2+}$ da vidraria utilizada.

Por outro lado, quando estas partículas de sílica são colocadas em água, migram em direção a um eletrodo positivo, isto é, elas apresentam uma carga global negativa. Podemos entender este fato admitindo que muitos dos cátions dissociam-se da partícula, dissolvendo-se na água e conferindo ao meio líquido uma carga positiva ou melhor, um excesso de cargas positivas sobre as negativas.

Por outro lado, temos evidências de que ocorre o seguinte, na superfície da sílica (e de outras partículas coloidais):

a) uma parte dos contra-íons se encontra fortemente ligada à superfície;

b) há moléculas de água imobilizadas junto à superfície, orientadas segundo seus dipolos;

c) moléculas de outros solutos, iônicos ou não, podem estar também fortemente adsorvidas, seja devido a interações dipolares, seja devido a ligações covalentes;

d) à medida em que nos afastamos da superfície, encontramos água e íons mais livres. O excesso de concentração dos cátions, no caso da sílica, diminui à medida em que nos afastamos da superfície, até atingir a concentração média no líquido. Se houver ânions, como cloreto, em presença de partículas negativas, sua concentração será muito pequena junto à superfície, aumentando gradativamente até atingir a concentração média. 
Portanto, cada partícula será circundada por uma região muito diferente do resto do líquido, e caracterizada por duas camadas de cargas elétricas (totais) opostas, denominada dupla camada elétrica. Dela depende grande parte das interações entre partículas e superfícies em geral.

A dupla camada elétrica é formada pelos íons e dipolos orientados que fazem parte da superfície ou do interior da partícula, e pelos íons e dipolos orientados que fazem parte do meio, mas se encontram fortemente ligados à superfície, de tal maneira que migram juntamente com a partícula. Esta parte da dupla camada elétrica é chamada de camada de Stern e tem uma espessura da ordem de raios moleculares ou atômicos. Outra parte da dupla camada elétrica é difusa, e é chamada de camada de Gouy-Chapman. Possui uma espessura bem maior. É formada por solvente, outras moléculas neutras e por íons, com predominância dos contra-íons e depleção dos co-íons. Os íons e moléculas desta camada têm uma grande liberdade de movimento, semelhante à dos íons e moléculas que estão no interior do líquido e afastados das partículas.

A principal característica da camada difusa é a concentração variável de íons, segundo a equação de Poisson: há no seu interior uma variação do campo elétrico, portanto a densidade de carga deve ser não-nula. Como o sistema todo é eletroneutro, isso significa que o líquido em que a partícula se encontra tem carga oposta à da partícula. Esta situação deve respeitar duas relações fundamentais: a equação de Poisson, da Eletrostática, e a equação de Boltzmann, da Mecânica Estatística. Supondo um eletrólito de carga $z, \psi_{0}$ o potencial elétrico em uma superfície plana e $\psi$ o potencial elétrico a uma distância $x$ da superfície, no seio da solução do eletrólito. Considerando-se uma superfície carregada positivamente, e aplicando a distribuição de Boltzmann: 


$$
\begin{aligned}
& n_{+}=n_{0} \exp [-z e \psi / k T] \\
& n_{.}=n_{0} \exp [+z e \psi / k T]
\end{aligned}
$$

onde $n_{+}$e $n$. são os números de íons positivos e negativos por unidade de volume, respectivamente, em pontos nos quais o potencial é $\psi$ (isto é, onde a energia

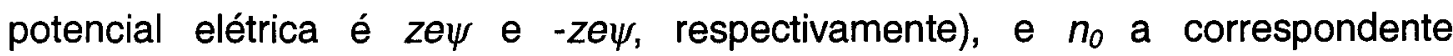
concentração de cada espécie iônica na solução.

A densidade de carga total $\rho$ em pontos de potencial $\psi$ é dada por:

$$
\begin{gathered}
\rho=z e\left(n_{+}-n_{-}\right) \\
\rho=z e n_{0}(\exp [-z e \psi / k T]-\exp [+z e \psi / k T]) \\
\rho=-2 z e n_{0} \operatorname{senh} z e \psi / k T
\end{gathered}
$$

A relação entre $\rho$ e $\psi$ é dada pela equação de Poisson, que para uma dupla camada plana assume a forma:

$$
d^{2} \psi / d x^{2}=-\rho / \varepsilon
$$

onde $\varepsilon$ é a permissividade do meio.

Aplicando-se a equação de Boltzmann ao cálculo de potencial elétrico nas vizinhanças de uma superfície dotada de carga elétrica, obtemos a equação de Poisson-Boltzmann, que tem um papel central na química coloidal. Assim, combinando as Eqs. (58) e (59), tem-se:

$$
d^{2} \psi / d x^{2}=(2 z e n d \varepsilon) \text { senh } z e \psi / k T
$$

Esta é uma equação diferencial não-linear, que não tem solução analítica geral. Isto cria enormes problemas, porque nos obriga a fazer simplificações para tratar de problemas concretos e estas são muitas vezes drásticas e irrealísticas. Uma das soluções dessa equação, considerando as condições limitantes $\left(\psi=\psi_{0}\right.$ quando $x=0$; e $\psi=0, d \psi / d x=0$ quando $x=\infty$ ) pode ser escrita como: 


$$
\psi=(2 k T / z e) \ln (1+\gamma \exp [-k x]) /(1-\gamma \exp [-k x])
$$

onde

$$
\begin{gathered}
\gamma=\left(\exp \left[z e \psi_{0} / 2 k T\right]-1\right) /\left(\exp \left[z e \psi_{0} / 2 k T\right]+1\right) \\
k=\left(2 e^{2} n_{0} Z^{2} / \varepsilon k T\right)^{1 / 2}=\left(2 e^{2} N_{A} c Z / \varepsilon k T\right)^{1 / 2}
\end{gathered}
$$

sendo $N_{A}$ a constante de Avogadro e $c$ a concentração do eletrólito.

Se ze $\psi_{0} / 2 k T \ll 1\left(k T / e=25,6 \mathrm{mV}\right.$ a $\left.25^{\circ} \mathrm{C}\right)$, é possível fazer a aproximação de Debye-Hünckel:

$$
\left(\exp \left[z e \psi_{d} / 2 k T\right] \approx 1+z e \psi_{d} / 2 k T\right)
$$

Simplificando as Eqs. (64) e (61):

$$
\psi=\psi_{0} \exp (-k x)
$$

o que mostra que em potenciais baixos, o potencial decresce exponencialmente à medida que aumenta a distância a uma superfície carregada. Nas proximidades da superfície, onde o potencial deve ser relativamente alto e é inaplicável a equação de Debye-Hückel, o potencial deve decrescer mais rapidamente do que 0 decréscimo exponencial acima.

Podemos relacionar o potencial $\psi_{0}$ com a densidade de carga na superfície $\sigma_{0}$, equacionando a carga superficial com a carga total na parte difusa da dupla camada $\left(\sigma_{0}=\int_{0}^{\infty} \rho d x\right)$, e aplicando a distribuição de Poisson-Boltzmann a expressão resultante é:

$$
\sigma_{o}=\left(8 n_{o} \varepsilon k T\right)^{1 / 2} \operatorname{senh} z e \psi_{0} / 2 k T
$$

Para potenciais baixos, esta expressão pode ser simplificada:

$$
\sigma_{0}=\varepsilon k \psi_{0}
$$


O potencial superficial $\psi_{0}$, depende, portanto da densidade de carga superficial $\sigma_{0}$ e por intermédio de $k$, da composição iônica do meio. Se a dupla camada for comprimida, ou se $k$ for aumentado, teremos ou aumento de $\sigma_{0}$, ou diminuição de $\psi_{0}$, ou ambos simultaneamente.

Da Eq. (67) poderemos concluir que, em potenciais baixos, uma dupla camada difusa apresenta a mesma capacidade de um capacitor de placas paralelas, separadas por uma distância $1 / k$. A grandeza $1 / \mathrm{k}$ é chamada de espessura da dupla camada difusa.

Para uma solução aquosa de um eletrólito simétrico a $25^{\circ} \mathrm{C}$, a Eq. (63) se transforma em:

$$
\left.\mathrm{k}=0,328 \times 10^{10}\left(\mathrm{cz}^{2} / \mathrm{mol} \mathrm{dm}\right)^{-3}\right)^{1 / 2} \mathrm{~m}^{-1}
$$

Para um eletrólito 1:1 a espessura da dupla camada será, portanto, de cerca de $1 \mathrm{~nm}$, para uma solução de concentração $1,0 \times 10^{-1}$ mol.L $\mathrm{L}^{-1}$, e de cerca de $10 \mathrm{~nm}$ para uma solução de concentração $1,0 \times 10^{-1} \mathrm{~mol}^{-L^{-1}}$. Para eletrólitos assimétricos, a espessura da dupla camada pode ser calculada se considerarmos $z$ como a carga do contra-íon.

Entre as partes fixa e difusa da dupla camada elétrica há uma região de separação, que é modelada como uma superfície de cisalhamento entre a partícula e o restante do líquido. Tudo que estiver entre o interior da partícula e esta superfície move-se com a mesma velocidade que a partícula; tudo que estiver além da superfície de cisalhamento move-se independentemente da partícula, exceto por estar sujeito ao campo elétrico gerado por esta.

Forças de van der Waals fazem com que moléculas ou átomos neutros sejam sempre atraídos devido a interações do tipo dipolar. Uma verificação imediata desta afirmação é a tendência de uma partícula de sílica aderir a outra 
com a qual está em contato. Porém, as forças de van der Waals são de muito curto alcance. Por exemplo, as forças de atração entre duas partículas esféricas de pequeno raio, por exemplo dois átomos de argônio, diminuem com a sexta potência da distância entre as esferas. Assim, as partículas de sílica coloidal tendem a se unirem, formando um agregado. Entretanto, só o farão a partir de um momento em que a distância entre elas se torne muito pequena, de ordem de grandeza de um nanômetro. Acima disto, a energia de interação torna-se menor que $k T$, não ocorrendo a agregação.

As partículas de sílica apresentam um potencial zeta negativo, isto é, têm um excesso de cargas negativas. Se as partículas forem todas homogêneas, as cargas provocarão a repulsão entre elas, segundo a lei de Coulomb. Nesse caso, a força repulsiva é função do inverso do quadrado da distância entre as partículas.

Pela teoria DLVO (Derjaguin-Landau-Verwey-Overbeek), ${ }^{[89]}$ a soma das energias de repulsão e de atração resulta em curvas com as seguintes características:

i) energia zero, quando a distância entre as partículas é elevada;

ii) quando a força iônica é elevada, a energia de um par de partículas diminui monotonicamente quando a distância entre as partículas diminui, tendendo a valores muito baixos (o mínimo primário, quando as distâncias entre os átomos da superfície começam a se tornar menores que a soma dos seus raios, e a energia começa a aumentar de novo);

iii) quando a força iônica é pequena ou tende a zero, à medida que a distância entre as partículas diminui há primeiro uma diminuição da energia até atingir um mínimo pouco profundo (o mínimo secundário), a partir do qual a energia aumenta até um máximo. Então, volta a diminuir rumo ao mínimo primário. 
Se a força iônica for baixa, há uma barreira de ativação causada pela repulsão eletrostática, para que as partículas se aproximem até se tocarem. Isso cria uma estabilidade cinética, que desaparece se a força iônica for elevada (Figura 54).
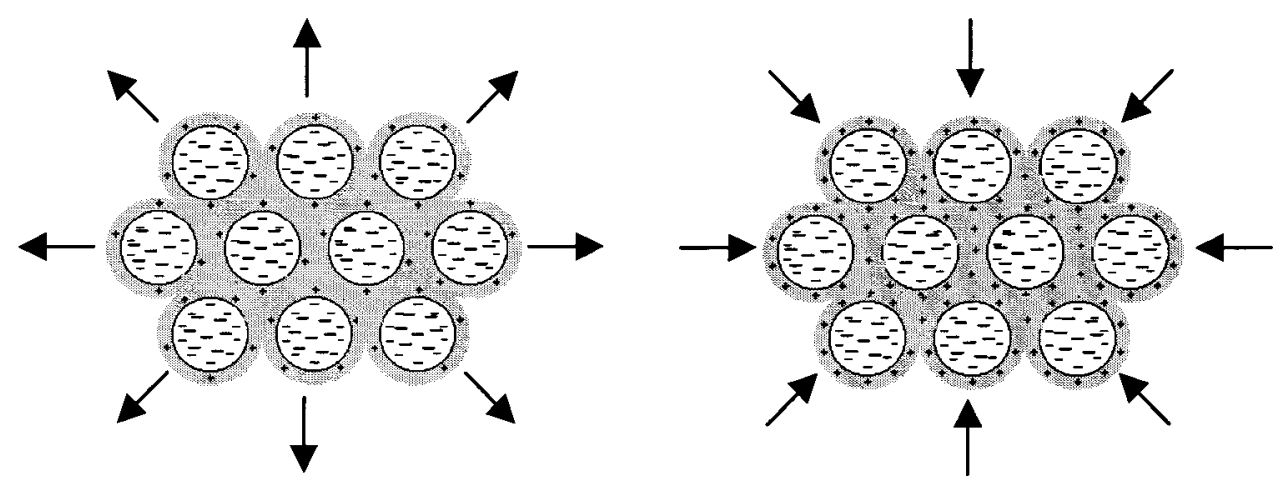

Figura 54. Ilustração das forças entre as partículas de uma dispersão em função da força iônica do meio. A presença de contra-íons diminui a repulsão eletrostática entre as partículas negativas.

Uma dispersão de sílica de Stöber apresenta desvios do comportamento predito pela teoria DLVO, pois há outros fatores importantes na interação entre partículas, além da atração de van der Waals e a repulsão Coulombiana, como a repulsão eletrostérica, hidratação da superfície, além das interações hidrodinâmicas.

A repulsão eletrostérica ocorre quando as partículas em dispersão têm sua superfície recoberta com íons. Há uma repulsão entre as cargas elétricas dos íons e, consequentemente, entre as partículas de sílica. A forte hidratação da superfície das partículas leva a formação de camadas de água ordenadas, o que também muda a força necessária para a aproximação de duas partículas. As taxas de cisalhamento do líquido contíguo a superfícies sólidas são sempre muito baixas. Isto introduz um importante fator de retardamento da aproximação da partículas. 
Quando a barreira energética à aproximação de partículas é muito pequena, a agregação é muito rápida e limitada apenas pela difusão das partículas. Em alguns casos a barreira é tão grande que o sistema é estável indefinidamente, em outros a agregação ocorre gradualmente. A relação entre uma taxa de agregação (medida experimentalmente) e a taxa no limite de difusão é chamada de fator de estabilidade, W. O sol é muito estável quando a barreira à aproximação das partículas é de ordem de $25 \mathrm{kT}$, o que resulta em $\mathrm{W}=10^{9}$. 


\section{OBJETIVOS}

O objetivo desta parte da tese é a determinação microquímica dos padrões de distribuição espacial de co-solutos adsorvidos e absorvidos em partículas de sílica. Os co-solutos usados são: um sal, um polímero solúvel em água e três tensoativos, um aniônico, um catiônico e um não-iônico. A metodologia usada é a microscopia eletrônica de transmissão associada à espectroscopia de perda de energia de elétrons, sendo observados efeitos de concentração, temperatura e de natureza de íons sorvidos. 


\section{MATERIAIS E MÉTODOS}

3.1. Partículas de sílica - Foram usadas as amostras de sílica preparadas na Parte I. Entre estas, foi escolhida a dispersão com um tamanho de partícula mais apropriado para o estudo da adsorção de substâncias e análise por ESI-TEM. As partículas das dispersões $D$ e $E$ são maiores e precisam de um aumento menor que as partículas das dispersões $\mathrm{A}, \mathrm{B}$ e $\mathrm{C}$, gerando imagens de melhor qualidade. Por outro lado, a quantificação analítica por EELS admite que não ocorre espalhamento múltiplo quando um elétron atravessa a amostra. Isto requer que a espessura da amostra analisada seja menor que o livre caminho médio entre duas colisões sucessivas.

No item 4.1. foi verificado que as partículas da dispersão $E$ não são as mais apropriadas para estes experimentos, pois ocorre espalhamento múltiplo de elétrons em uma escala que dificulta os procedimentos de análises das imagens de ESI-TEM. Assim, a melhor opção é a dispersão D ( $\left.\phi_{\text {TEM }}=77 \mathrm{~nm}\right)$, na qual a escala de efeitos do espalhamento múltiplo verificados é pequena e pode ser minimizada por métodos de deconvolução.

\subsection{Sorção de co-solutos}

A adsorção de co-solutos nas partículas de sílica não é um processo instantâneo, mas é governada pela velocidade de difusão dos co-solutos através da solução, em direção à interface. Pode decorrer um tempo até que a solução atinja seu equilíbrio, especialmente se a solução for diluída. Estudos de adsorção de 
metais, ${ }^{[95]}$ surfactantes $^{[96]}$ e proteínas $^{[97]}$ em partículas mostraram que as quantidades adsorvidas em 30 minutos não apresentaram variações significativas após duas horas de exposição a solução.

A preparação de amostras para microscopia de transmissão requer a secagem da dispersão final sobre o porta amostra. A quantidade de co-solutos na solução, principalmente das soluções mais concentradas, pode ser suficiente para que após a secagem forme agregados de tamanho que prejudique o exame microscópico. Para evitar isto foi realizado uma diluição final da dispersão em água. As taxas de dessorção dos co-solutos são muito menores que as taxas de adsorção. ${ }^{[97,98]}$ A cinética de dessorção somente é significativa em experimentos com maiores taxas de agitação e temperatura. ${ }^{[99]}$

3.2.1. Sorção de $\mathrm{NaCl}$ - Foram adicionados $200 \mu \mathrm{L}$ de dispersão-estoque (alcoólica) de sílica $\left(\phi_{\text {TEM }}=77 \mathrm{~nm}\right.$ ) em 1,8 $\mathrm{mL}$ de soluções de $\mathrm{NaCl}$ (MERCK PA) 0,5 mol. $\mathrm{L}^{-1}$, $1,0 \times 10^{-3}$ mol.L $\mathrm{L}^{-1}$ e $1,0 \times 10^{-5}$ mol.L $\mathrm{L}^{-1}$. A mistura foi sonicada por 2 minutos em $40 \mathrm{kHz}$ 80 Watts, a $25^{\circ} \mathrm{C}$ e as dispersões ficaram em repouso por 30 minutos.

Para a preparação de amostras para microscopia de transmissão analítica, uma segunda diluição foi realizada: $200 \mu \mathrm{L}$ das dispersões em $\mathrm{NaCl}$ foram diluídos em $4 \mathrm{~mL}$ de água destilada e deionizada, agitados mecanicamente por $5 \mathrm{~s}$ e $15 \mu \mathrm{L}$ colocados sobre telas metálicas vazadas com diâmetro de $3 \mathrm{~mm}$, cobertas por um filme fino de parlódio e um filme de carbono. Esta diluição permite que a secagem da dispersão sobre o porta amostra forme subcamadas de partículas, e os íons se depositem nas partículas e no substrato sem formar cristais de $\mathrm{NaCl}$ de tamanho suficiente para prejudicar o exame microscópico. Um cálculo aproximado, considerando uma deposição homogênea dos íons sobre o substrato, determina que partindo das concentrações iniciais de 0,5 mol.L $\mathrm{L}^{-1}, 1,0 \times 10^{-3} \mathrm{~mol}^{-L^{-1}}$ e $1,0 \times 10^{-5}$ mol.L.-1, o $\mathrm{NaCl}$ forma sobre o substrato uma camada de $4 \mathrm{~nm}$ de espessura média, 
uma monocamada, ou recobre apenas $1 \%$ da superfície, respectivamente. A Figura 55 mostra o fluxograma do experimento de adsorção de $\mathrm{NaCl}$ em partículas de sílica, e a preparação das amostras para a microscopia de transmissão analítica.



Figura 55. Fluxograma do experimento de adsorção de $\mathrm{NaCl}$.

3.2.2. Adsorção de PNIPAM - A dispersão-estoque (alcoólica) de sílica ( $\phi_{T E M}=77 \mathrm{~nm}$ ) foi diluída, adicionando $200 \mu \mathrm{L}$ de dispersão a $1,8 \mathrm{~mL}$ de água destilada e deionizada. A dispersão diluída foi sonicada por 2 minutos em $40 \mathrm{kHz}$ - 80 Watts, a $25^{\circ}$ C. Soluções de PNIPAM (Polymer Science, $90 \mathrm{Kg} / \mathrm{Mol}$ ) foram então adicionadas até as concentrações finais de $10^{-5} \mathrm{~g} / \mathrm{mL}, 10^{-4} \mathrm{~g} / \mathrm{mL}, 10^{-3} \mathrm{~g} / \mathrm{mL}$. As dispersões foram colocadas em repouso por 30 minutos, a $20^{\circ} \mathrm{C}$. A adsorção do PNIPAM nas partículas de sílica não é um processo instantâneo, mas é governada pela velocidade de difusão das moléculas do polímero através da solução, em direção à interface. Pode decorrer um tempo até o equilíbrio, especialmente se a solução for diluída e se as moléculas do soluto forem grandes e assimétricas.

Para a preparação das amostras de microscopia de transmissão analítica, uma segunda diluição foi realizada para cada amostra: $200 \mu \mathrm{L}$ das dispersões 
foram diluídos em $4 \mathrm{~mL}$ de água destilada e deionizada, agitados mecanicamente por $5 \mathrm{~s}$ e $15 \mu \mathrm{L}$ colocados sobre telas metálicas vazadas com diâmetro de $3 \mathrm{~mm}$, cobertas por um filme fino de parlódio e um filme de carbono. Esta diluição permitiu que a secagem da dispersão sobre o porta amostra formasse subcamadas de partículas, e as cadeias se depositassem nas partículas e no substrato sem formar agregados de PNIPAM. As secagens foram realizadas a 20 e $40^{\circ} \mathrm{C}$, ou seja, abaixo e acima da LCST do PNIPAM.

A Figura 56 mostra o fluxograma do experimento de adsorção de PNIPAM em sílica, e a preparação das amostras para a microscopia de transmissão analítica (ESI-TEM):

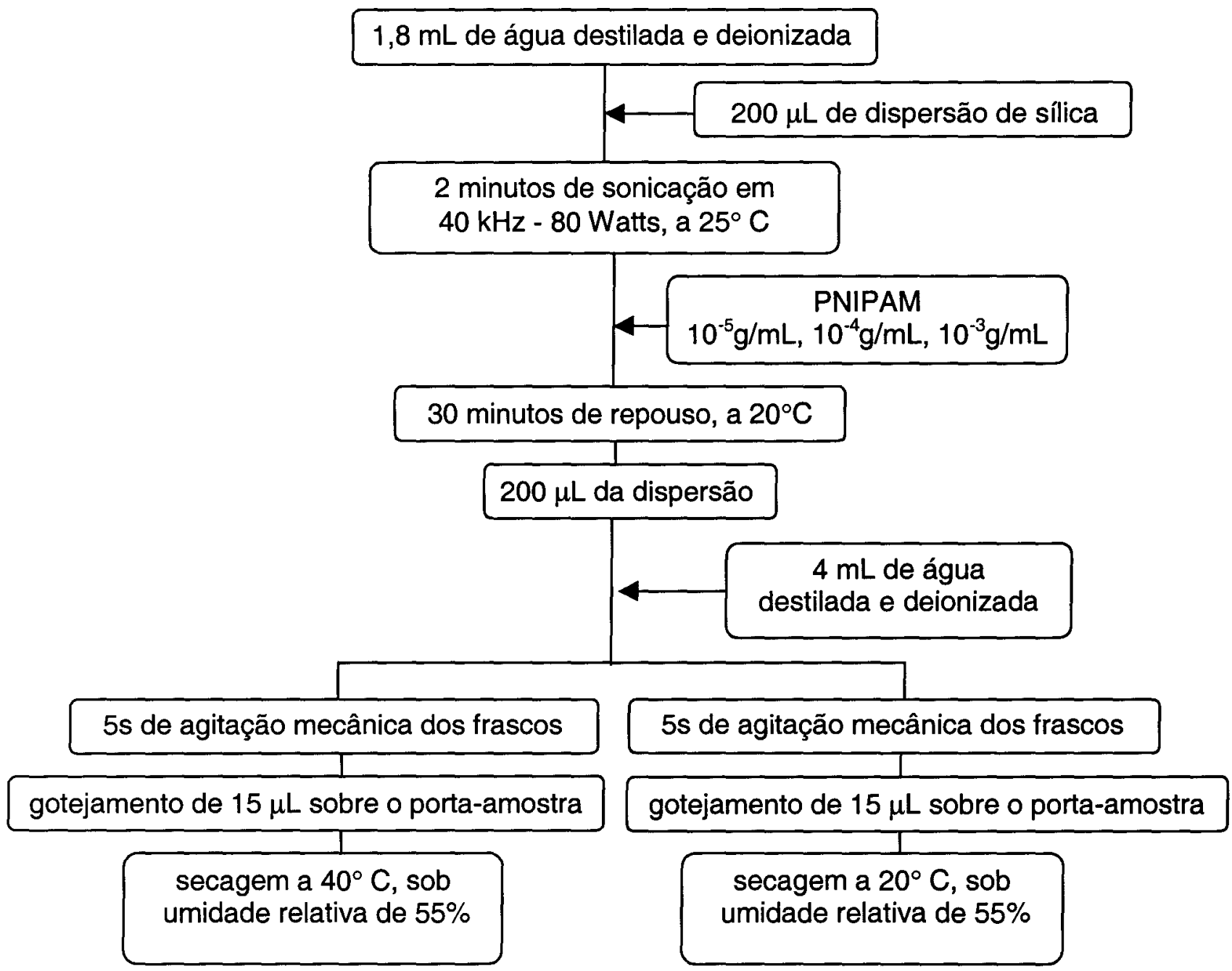

Figura 56. Fluxograma dos experimentos de adsorção de PNIPAM. 
3.2.3. Adsorção de surfactantes - A adsorção de surfactantes nas partículas de sílica foi estudada em experimentos utilizando três diferentes agentes tenso-ativos:

- Surfactante aniônico.

SDS - Dodecil sulfato de sódio (Aldrich)

$\mathrm{CH}_{3}\left(\mathrm{CH}_{2}\right)_{11} \mathrm{SO}_{4}^{-} \mathrm{Na}^{+}$

Massa molar: $288,4 \mathrm{~g} / \mathrm{Mol}$

c.m.c. $=8 \times 10^{-3} \mathrm{M}$

- Surfactante catiônico.

CTAB - Brometo de cetiltrimetilamônio (Sigma)

$\mathrm{CH}_{3}\left(\mathrm{CH}_{2}\right)_{15} \mathrm{~N}\left(\mathrm{CH}_{3}\right)_{3}{ }^{+} \mathrm{Br}$

Massa molar: $364 \mathrm{~g} / \mathrm{Mol}$

c.m.c. $=9 \times 10^{-4} \mathrm{M}$

- Surfactante não-iônico.

RENEX $300^{\circledR}$ - Nonilfenilpolioxietileno (Oxiteno)

$\mathrm{HO}\left(\mathrm{C}_{2} \mathrm{H}_{4} \mathrm{O}\right)_{30} \mathrm{C}_{15} \mathrm{H}_{23} \mathrm{O}$

Massa molar: $1556 \mathrm{~g} / \mathrm{Mol}$

c.m.c. $=5 \times 10^{-4} \mathrm{M}$

Foram adicionados $200 \mu \mathrm{L}$ de dispersão-estoque (alcoólica) de sílica $\left(\phi_{\text {TEM }}=77 \mathrm{~nm}\right)$ em $1,8 \mathrm{~mL}$ de soluções de SDS; CTAB; RENEX $\left(1,0 \times 10^{-1} \mathrm{~mol} . \mathrm{L}^{-1}\right.$, $1,0 \times 10^{-3}$ mol.L $L^{-1}$ e $1,0 \times 10^{-5} \mathrm{~mol}^{-L^{-1}}$ ). Para uma melhor dispersão das partículas na solução salina, a mistura foi sonicada por 2 minutos em $40 \mathrm{kHz}$ - 80 Watts, a $25^{\circ} \mathrm{C}$. As dispersões ficaram em repouso por 30 minutos, para que a solução de surfactante atinja sua tensão superficial de equilíbrio.

Para a preparação de amostras para microscopia de transmissão analítica, uma segunda diluição foi realizada: $200 \mu \mathrm{L}$ das dispersões nos diferentes surfactantes foram diluídos em $4 \mathrm{~mL}$ de água destilada e deionizada, agitados 
mecanicamente por $5 \mathrm{~s}$ e $15 \mu \mathrm{L}$ colocados sobre telas metálicas vazadas com diâmetro de $3 \mathrm{~mm}$, cobertas por um filme fino de parlódio e um filme de carbono. Esta diluição permitiu que a secagem da dispersão sobre o porta amostra formasse subcamadas de partículas, e as cadeias de surfactantes se depositem nas partículas e no substrato sem formar agregados de micelas de tamanho suficiente para prejudicar o exame microscópico.

A Figura 57 mostra o fluxograma do experimento da adsorção dos surfactantes nas partículas de sílica, e a preparação das amostras para a microscopia de transmissão analítica (ESI-TEM).

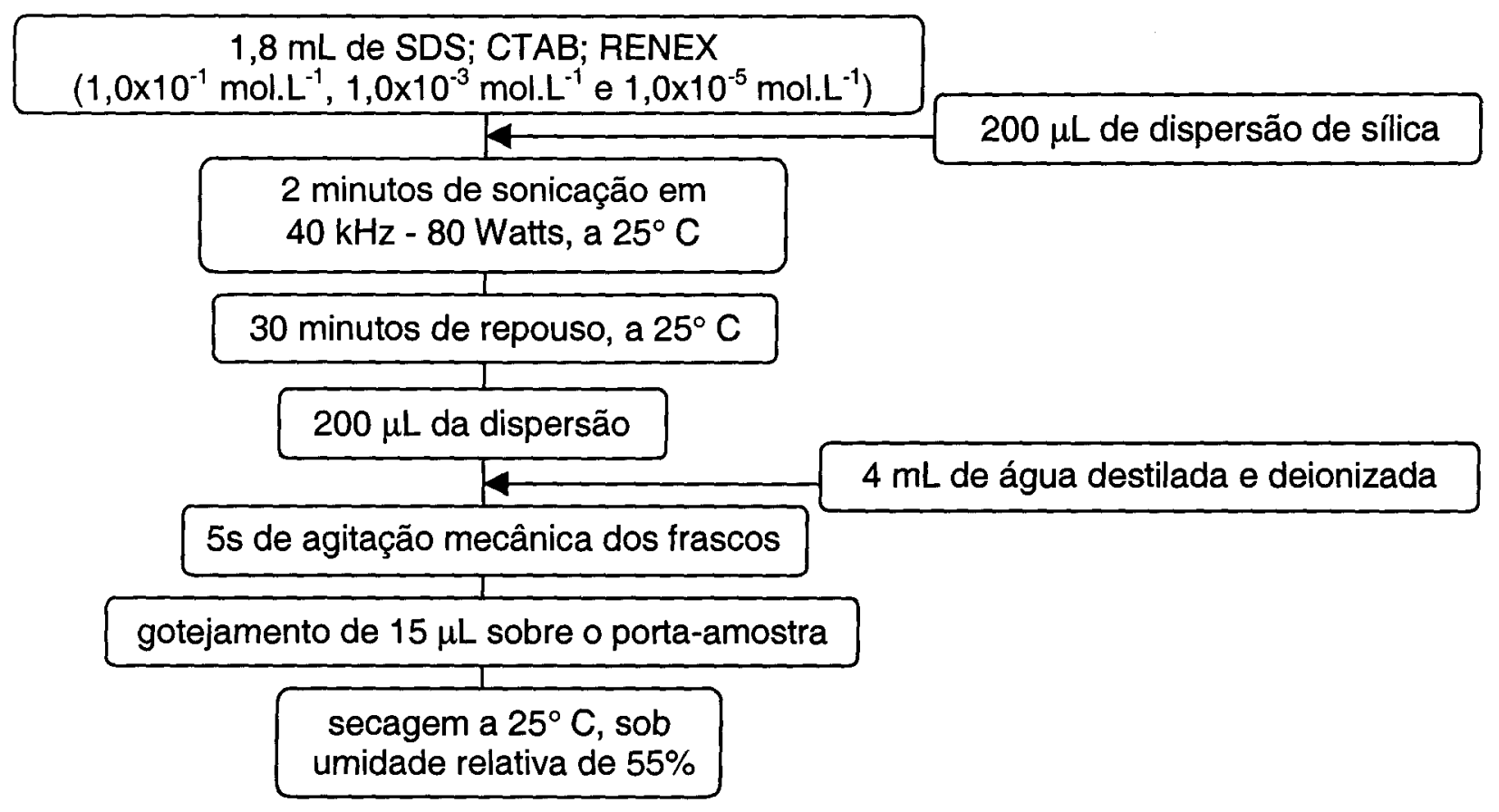

Figura 57. Fluxograma do experimento de adsorção de surfactantes. 


\section{RESULTADOS}

4.1. Partículas de sílica - A Tabela 8 mostra os valores dos diâmetros médios das partículas de sílica das diferentes dispersões, obtidos por PCS (em meio aquoso) e por TEM, antes e após um período de 18 meses em que as partículas estiveram armazenadas em meio etanólico. Estes valores não apresentaram variações dentro do erro experimental, o que mostra a excelente estabilidade dessas partículas em meio etanólico.

Tabela 8. Diâmetros médios das partículas de sílica das diferentes dispersões, determinados por PCS (em meio aquoso) e por TEM, antes e após 18 meses de armazenamento em meio etanólico.

\begin{tabular}{|c|c|c|c|c|c|c|c|}
\hline \multicolumn{3}{|c|}{ AMOSTRA } & $A$ & $\mathrm{~B}$ & $C$ & $D$ & E \\
\hline \multirow{2}{*}{$\begin{array}{l}\text { água } \\
25^{\circ} \mathrm{C}\end{array}$} & \multirow{2}{*}{$\begin{array}{l}\text { PCS } \\
(\mathrm{nm})\end{array}$} & inicial & $54 \pm 5$ & $66 \pm 6$ & $77 \pm 2$ & $103 \pm 1$ & $136 \pm 1$ \\
\hline & & $\begin{array}{c}\text { após } 18 \\
\text { meses }\end{array}$ & $58 \pm 5$ & $68 \pm 6$ & $77 \pm 2$ & $104 \pm 1$ & $138 \pm 1$ \\
\hline \multirow{2}{*}{$\begin{array}{l}10^{-6} \\
\text { mbar }\end{array}$} & \multirow{2}{*}{$\begin{array}{l}\text { TEM } \\
(\mathrm{nm})\end{array}$} & inicial & $15 \pm 2$ & $33 \pm 3$ & $47 \pm 4$ & $76 \pm 7$ & $115 \pm 10$ \\
\hline & & $\begin{array}{c}\text { após } 18 \\
\text { meses }\end{array}$ & $15 \pm 2$ & $34 \pm 3$ & $48 \pm 4$ & $77 \pm 7$ & $117 \pm 10$ \\
\hline
\end{tabular}

Os diâmetros médios não apresentaram variações significativas dentro do erro experimental dos valores da Tabela 8. Isto indica a excelente estabilidade destas dispersões. ${ }^{[100]}$ 
A escolha da dispersão com um tamanho de partícula mais apropriado para o estudo da adsorção de substâncias e análise por ESI-TEM requer uma análise mais detalhada. As partículas maiores precisam de um aumento menor, gerando imagens de melhor resolução. Por outro lado, nestas partículas ocorre um número maior de colisões quando um elétron atravessa a amostra, o que dificulta as análises por ESI-TEM.

Foram analisadas as probabilidades de um elétron sofrer uma única colisão ao atravessar as partículas da dispersão E e D sobre o porta amostra de TEM. As Figuras 58 e 59 mostram os gráficos de probabilidade de uma colisão calculada a partir das Eqs. (23) e (24), na região de baixa perda de energia ( $\Delta \mathrm{E}<50 \mathrm{eV}$ e $\lambda$ entre 50 e $150 \mathrm{~nm}$ ), para partículas com diâmetros de $117 \mathrm{~nm}$ e 77 $\mathrm{nm}$ sobre substratos planos com $10 \mathrm{~nm}$ de espessura.

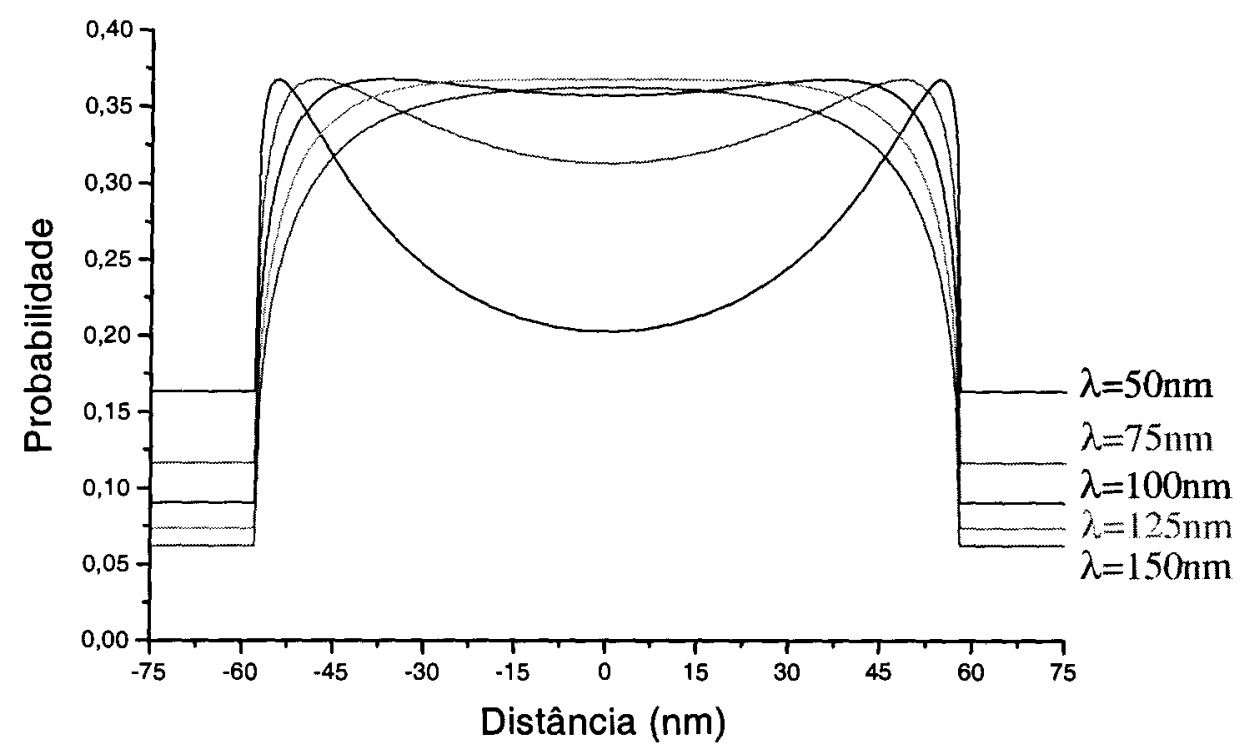

Figura 58. Probabilidade de um elétron atravessar a amostra a uma distância $x$ do centro de uma partícula com $117 \mathrm{~nm}$ de diâmetro sobre um substrato plano com 10 $\mathrm{nm}$ de espessura, sofrendo uma única perda de energia na região de baixa perda $(\lambda=50,75,100,125$ e $150 \mathrm{~nm})$. 




Figura 59. Probabilidade de um elétron atravessar a amostra a uma distância $x$ do centro de uma partícula com $77 \mathrm{~nm}$ de diâmetro sobre um substrato plano com 10 $\mathrm{nm}$ de espessura, sofrendo uma única perda de energia na região de baixa perda $(\lambda=50,75,100,125$ e $150 \mathrm{~nm})$.

A partir das Eqs. (23) e (24) podemos verificar que para $\lambda$ menor que a espessura máxima das amostras (127 nm e $87 \mathrm{~nm}$, respectivamente) ocorre uma diminuição da probabilidade de um elétron sofrer uma única colisão no centro das partículas. Assim, esta probabilidade atinge um máximo de 0,37 próximo da borda da partícula e decai a um mínimo no centro, como mostrado nas Figuras 58 e 59. Para $\lambda$ maior que a espessura máxima da amostra, a probabilidade aumenta da borda até um valor máximo, menor que 0,37 , no centro da partícula.

A partir das Eqs. (18) e (23) e das Figuras 58 e 59, e da análise dos perfis dos níveis de cinza das imagens de perda de energia, podemos calcular a diminuição da probabilidade de um único espalhamento no centro das partículas. A Figura 60 mostra as imagens de campo claro e de baixa perda de energia ( $\Delta E=20$ eV) das partículas com diâmetro médio de $117 \mathrm{~nm}$, preparadas a partir da dispersão $E$. 

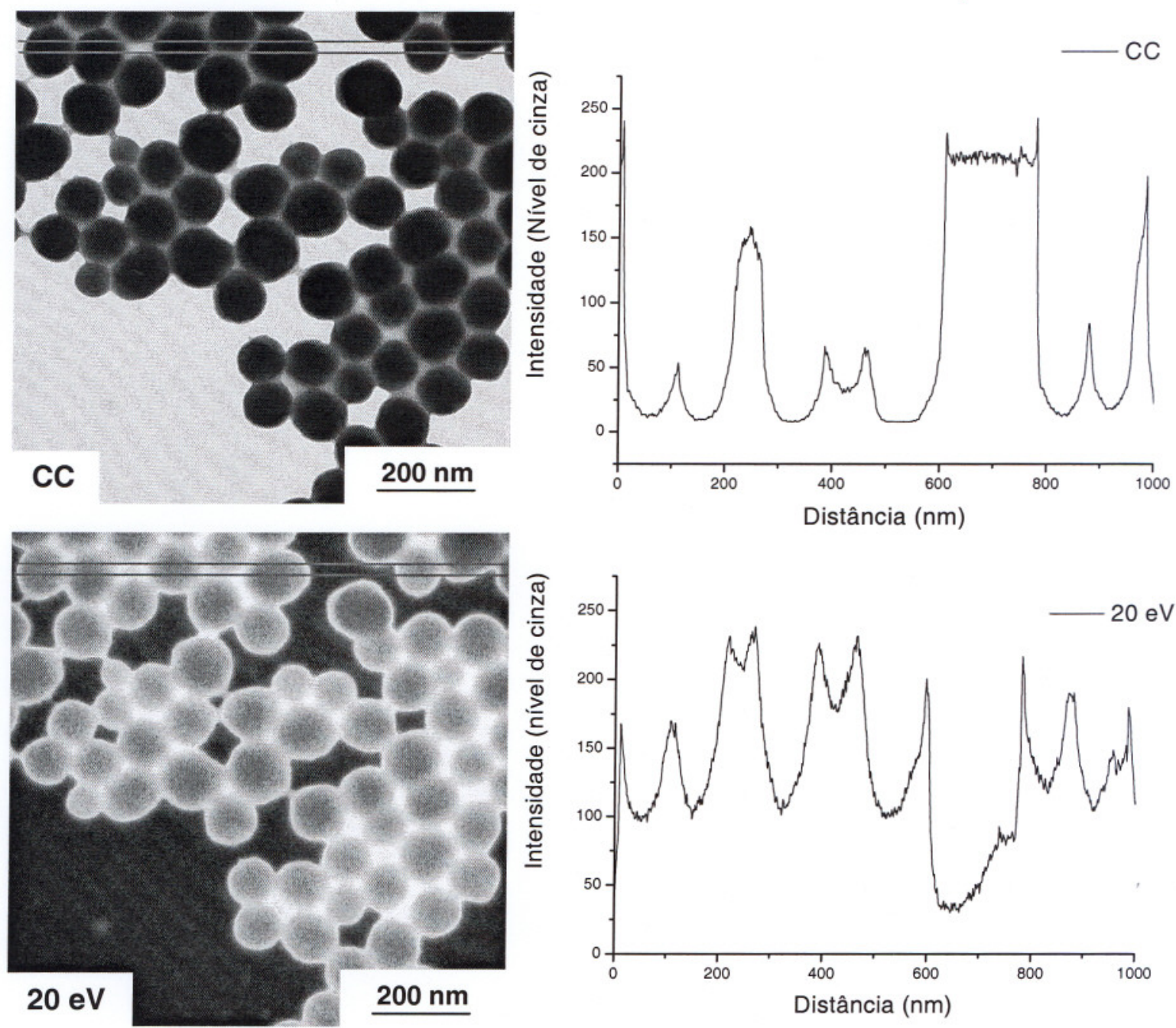

Figura 60. Imagens de campo claro (CC) e de perda de energia ( $\Delta \mathrm{E}=20 \mathrm{eV}$ ), de uma mesma área de uma amostra de partículas de sílica com diâmetro médio de $117 \mathrm{~nm}$. Os gráficos mostram as intensidades dos níveis de cinza dos perfis com 25 $\mathrm{nm}$ de largura, indicados nas imagens.

A imagem de perda de energia $(\Delta E=20 \mathrm{eV})$ apresentou um contraste bastante diferente do inverso da imagem de campo claro no centro das partículas, onde a espessura é maior. Isto indica a ocorrência significativa de espalhamento múltiplo nesta perda de energia. ${ }^{[101]}$ De acordo com a Eq. (18), a probabilidade máxima $\left(P_{n}\right)$ para um único espalhamento $(n=1)$ é de 0,37 , para qualquer valor de 
$\lambda$. Assim, a partir dos perfis das intensidades dos níveis de cinza da imagem de perda de energia da Figura 60, a probabilidade $\left(P_{1}\right)$ calculada para um único espalhamento nos centros das partículas é de 0,23 , considerando que o máximo de intensidade dos perfis corresponde a 0,37 . Substituindo $P_{1}$ na Eq. (23), foi calculado o livre caminho médio $\lambda=54 \mathrm{~nm}$.

A Figura 61 mostra as imagens de perda de energia com $\Delta \mathrm{E}=30,40$ e 50 eV na mesma área da amostra da Figura anterior. 

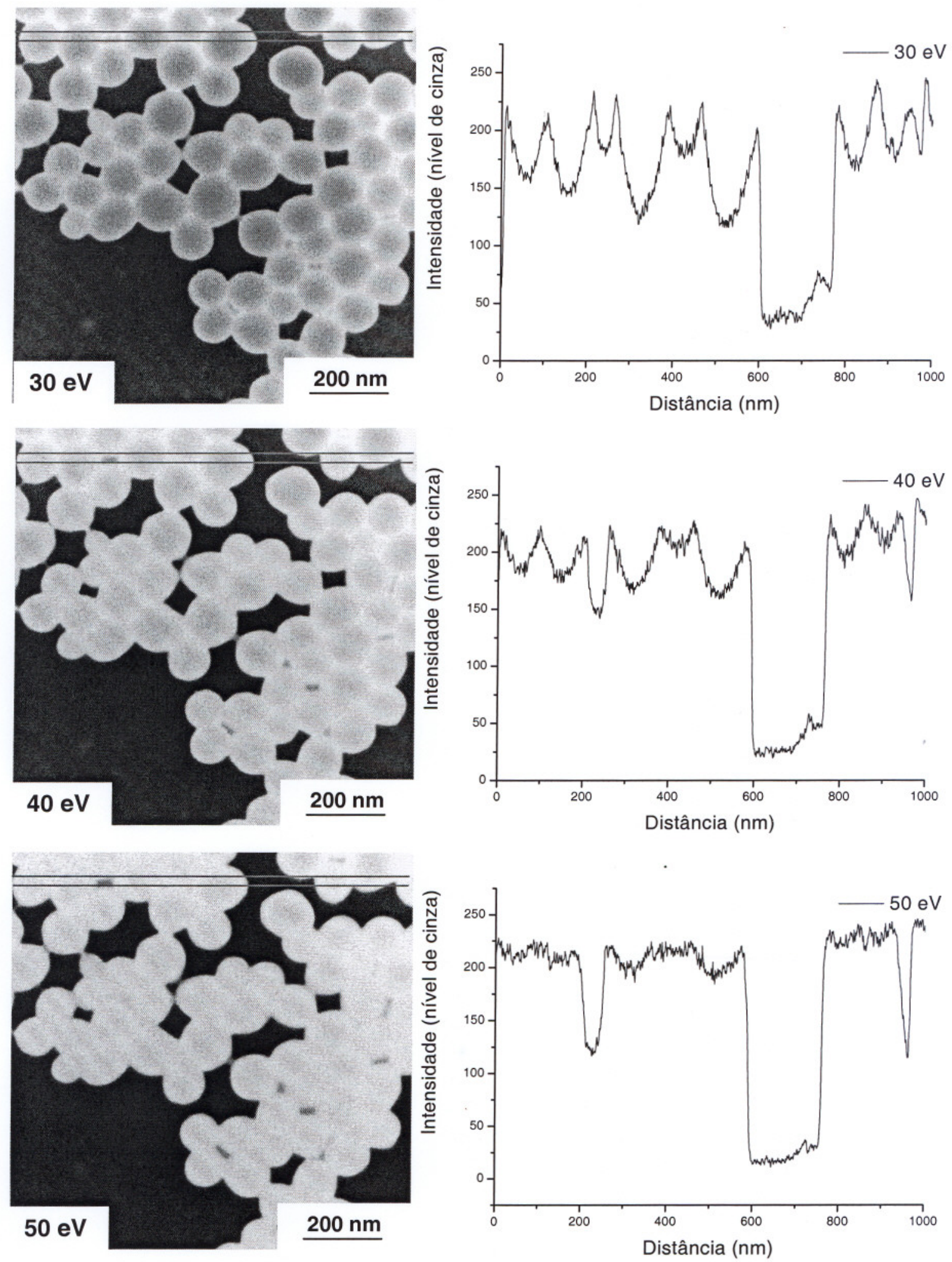

Figura 61. Imagens de perda de energia $(\Delta \mathrm{E}=30,40$ e $50 \mathrm{eV})$ na região de baixa perda, da mesma área da amostra da Figura 60. Os gráficos mostram as intensidades dos níveis de cinza dos perfis com $25 \mathrm{~nm}$ de largura indicados nas imagens. 
A medida que as perdas de energia aumentam $(\Delta E=30,40$ e $50 \mathrm{eV})$, aumenta a probabilidade de uma única colisão no centro das partículas: $P_{1}=0,25$, 0,31 e 0,34 respectivamente.

As partículas da dispersão $E$ não são as mais apropriadas para os experimentos, pois ocorre espalhamento múltiplo de elétrons com perda de energia $(\Delta \mathrm{E}=20 \mathrm{eV})$ em uma escala suficiente para dificultar os procedimentos de análises das imagens de ESI-TEM.

A próxima melhor opção é a dispersão D. A Figura 62 mostra as imagens de campo claro e de perda de energia $(\Delta E=20 \mathrm{eV})$, na região de baixa perda, de uma mesma área de uma amostra das partículas de sílica com 77 nm de diâmetro, preparadas a partir desta dispersão. 

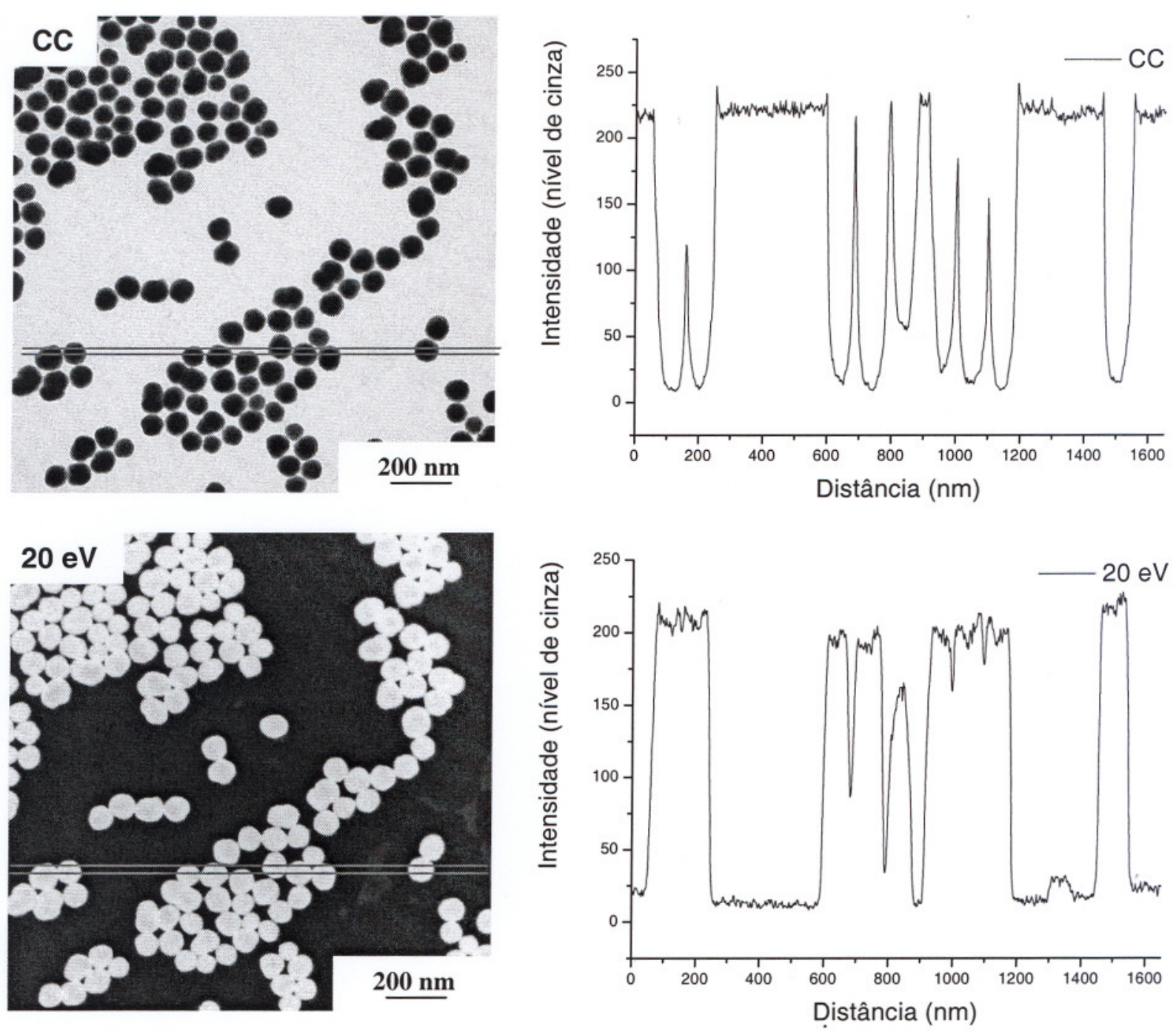

Figura 62. Imagens de campo claro $(\mathrm{CC})$ e de perda de energia $(\Delta \mathrm{E}=20 \mathrm{eV})$ na região de baixa perda, de uma mesma área de uma amostra de partículas de sílica com diâmetro médio de $76 \mathrm{~nm}$. Os gráficos mostram as intensidades dos níveis de cinza dos perfis com $25 \mathrm{~nm}$ de largura indicados nas imagens.

A imagem de baixa perda de energia $(\Delta \mathrm{E}=20 \mathrm{eV})$ apresenta um contraste mais próximo do inverso da imagem de campo claro do que no caso da dispersão E. Isto pode ser melhor verificado pela análise dos perfis traçados da mesma região da amostra nas diferentes imagens. A partir dos perfis dos níveis de cinza da imagem de perda de energia da Figura 62, a probabilidade $\left(P_{1}\right)$ calculada para um 
único espalhamento nos centros das partículas é de 0,36 e o livre caminho médio (ג) é de $65 \mathrm{~nm}$.

Para uma mesma perda de energia $(\Delta \mathrm{E}=20 \mathrm{eV})$, as partículas de sílica com diâmetros maiores apresentaram, no seu centro, um menor $\lambda$. Isto ocorre devido aos diferentes graus de intumescimento das partículas, e consequente composição química, e da natureza caroço-casca das partículas maiores, com casca mais hidrofílica.

De acordo com a Eq. (18), a probabilidade máxima para um único espalhamento é de 0,37. Para perdas de energia de $20 \mathrm{eV}$ a probabilidade de um único espalhamento, nos centros das partículas da amostra $D$, é apenas $1 \%$ menor que a probabilidade máxima próxima das bordas das partículas. Assim, estas partículas possuem diâmetro adequado para a aquisição de imagens em maiores perdas de energia.

Porém, há muitos eventos de espalhamento múltiplo (fônons, plasmons, baixa e alta perda) e é desejável remover do espectro seus efeitos, ou ao menos reduzi-lo para permitir o procedimento de análise. 0 método de deconvolução padrão, que na maioria dos casos produz bons resultados, consiste em subtrair do sinal adquirido a linha-base representada por uma função exponencial.

Para a deconvolução na aquisição de mapas elementares é utilizado o método das três janelas: ${ }^{[102]}$ o sinal adquirido em duas das janelas, com largura de energia de $15 \mathrm{eV}$ cada e energias menores que a da borda de absorção do elemento, permite determinar uma função exponencial, que é utilizada como linhabase do sinal adquirido na janela do pico de absorção.

Os mapas elementares possuem maior resolução espacial que os espectros de perda de energia, pois o tempo de aquisição é utilizado em uma única perda de energia. 
4.2. Sorção de $\mathrm{NaCl}$ - As Figuras 63 e 64 mostram as imagens de campo claro de submonocamadas de partículas de sílica da dispersão $D$, obtidas secando dispersões sem adição de adsorbatos e também após a adição de $\mathrm{NaCl}$ em diferentes concentrações.
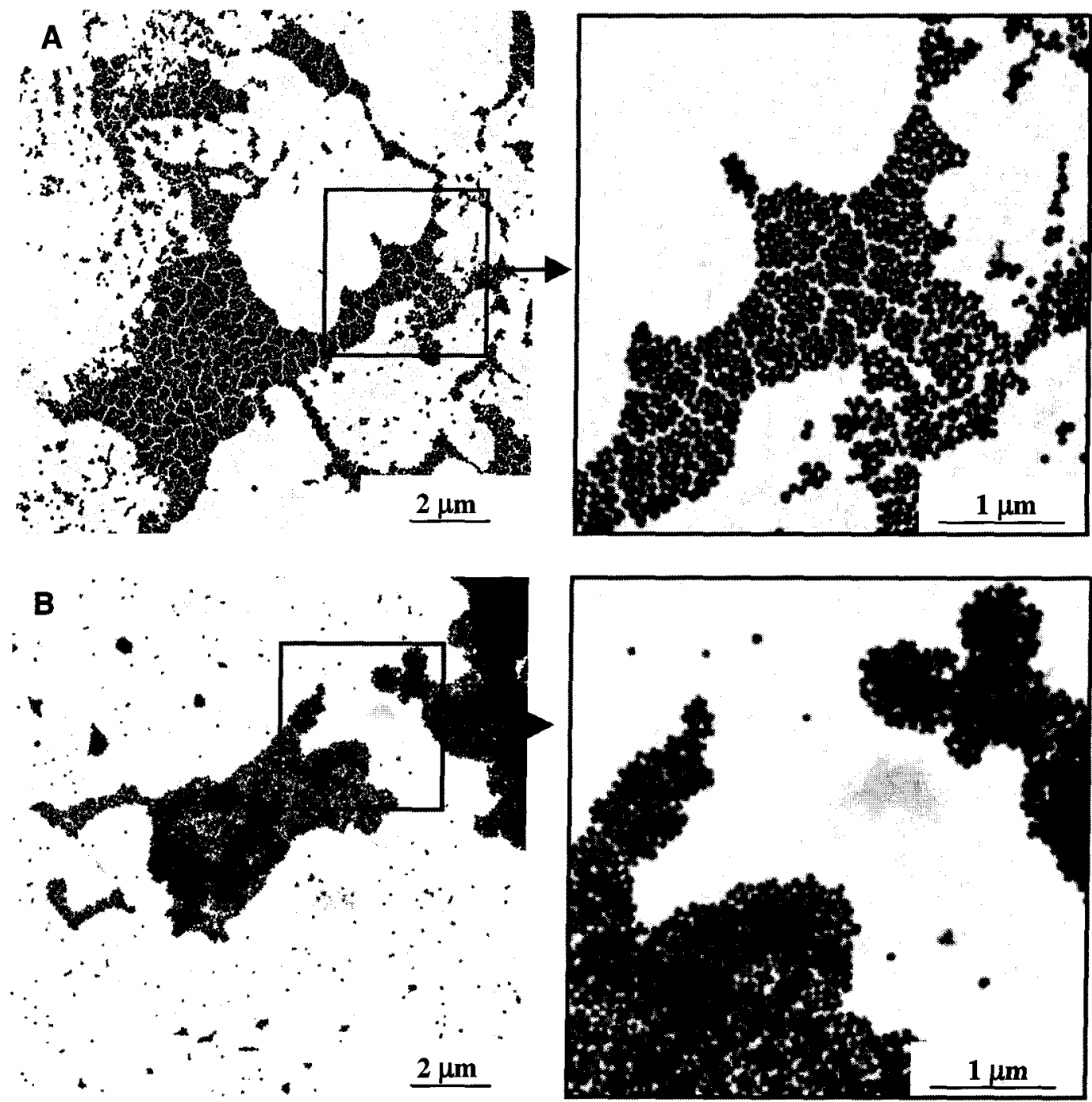

Figura 63. Imagens de campo claro de partículas de sílica da dispersão D, obtidas secando dispersões preparadas (A) após a diluição em água, e (B) após a diluição em $\mathrm{NaCl} 10^{-5} \mathrm{~mol}^{-1}$ seguida de nova diluição em água. As imagens da direita mostram as ampliações das regiões indicadas. 



Figura 64. Imagens de campo claro de partículas de sílica da dispersão D, obtidas secando dispersões preparadas após a diluição em (A) $\mathrm{NaCl} 10^{-3} \mathrm{~mol}^{-1} \mathrm{~L}^{-1}$ e (B) $\mathrm{NaCl}$ 0,5 mol. $\mathrm{L}^{-1}$, seguida de uma nova diluição em água. As imagens da direita mostram as ampliações das regiões indicadas.

A Figura 63A mostra uma submonocamada de partículas que não foram expostas a $\mathrm{NaCl}$ e se depositaram sobre toda extensão do porta-amostra, formando agregados bidimensionais descontínuos e com diferentes quantidades de partículas. 
As partículas que foram expostas a $\mathrm{NaCl} 10^{-5}$ mol.L $\mathrm{L}^{-1}$ e $10^{-3} \mathrm{~mol} . \mathrm{L}^{-1}$ (Figura 63B e 64A), se depositaram superpondo-se em algumas regiões dos agregados descontínuos, sobre toda extensão do porta-amostra.

Aumentando a concentração de $\mathrm{NaCl}$ para $0,5 \mathrm{~mol} \cdot \mathrm{L}^{-1}$ (Figura 64B), as partículas se depositaram em poucas regiões do porta-amostra, como densos agregados, com partículas superpostas em algumas regiões.

Para determinar a localização de $\mathrm{Na}^{+}$e $\mathrm{Cl}^{-}$nos diferentes domínios da amostra, foram adquiridas imagens de campo claro e de perda de energia de elétrons obtidas com maior resolução. As Figuras 65 e 66 mostram as imagens de campo claro, perda de energia $(\Delta \mathrm{E}=20 \mathrm{eV})$, e mapas elementares de sódio e cloro de uma mesma área de uma amostra das partículas de sílica preparadas a partir da dispersão $D$, diluída em solução de $\mathrm{NaCl} 1,0 \times 10^{-5}$ mol. $\mathrm{L}^{-1}$ e depois novamente diluída em água. 


\section{$\mathrm{NaCl} 1,0 \times 10^{-5} \mathrm{~mol}^{-\mathrm{L}^{-1}}$}
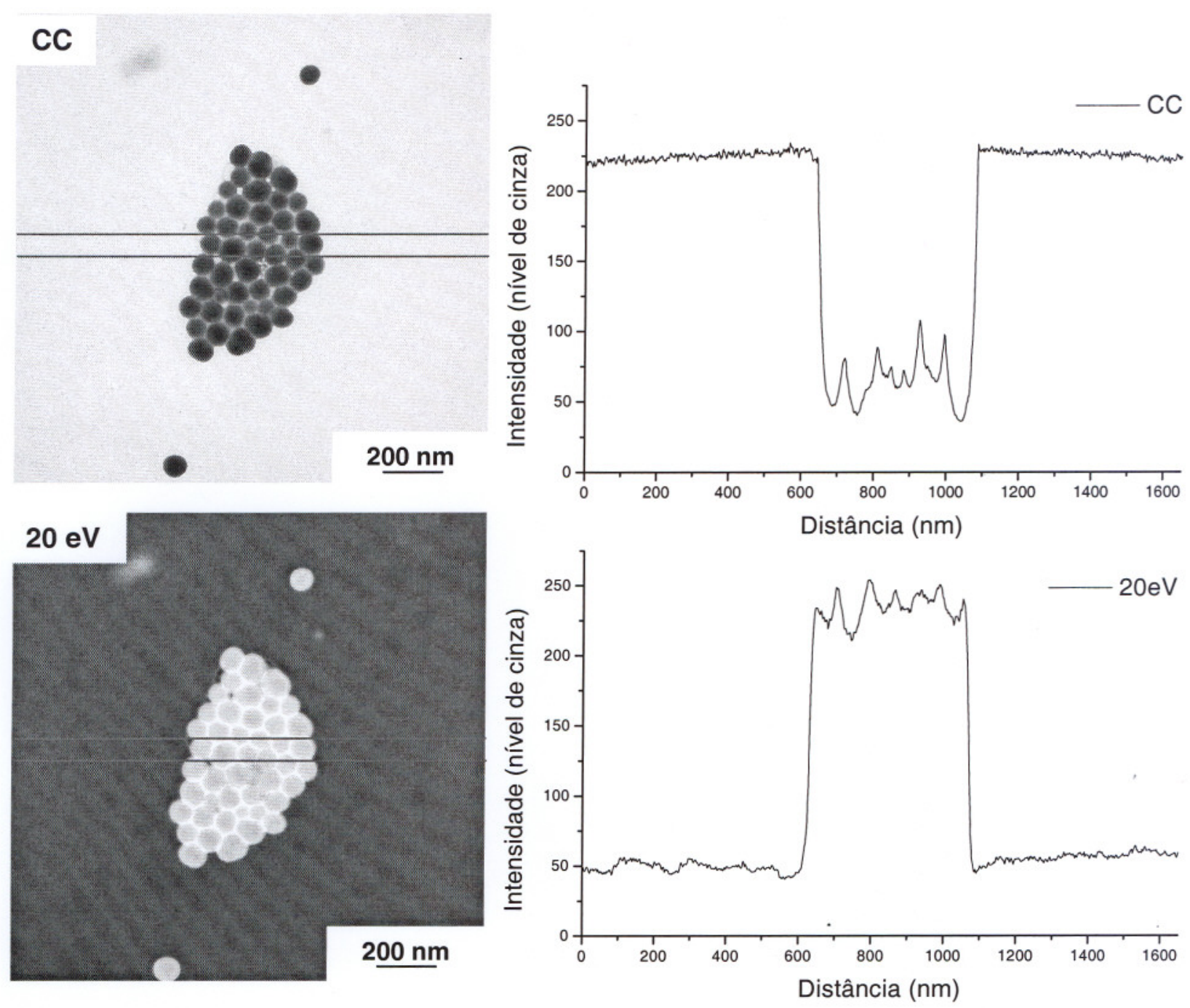

Figura 65. Imagens de campo claro $(\mathrm{CC})$ e de perda de energia $(\Delta \mathrm{E}=20 \mathrm{eV})$ na região de baixa perda, de uma mesma área de uma amostra das partículas de sílica preparadas a partir da dispersão $\mathrm{D}$, diluída em solução de $\mathrm{NaCl} 1,0 \times 10^{-5} \mathrm{~mol}^{-L^{-1}} \mathrm{e}$ depois novamente diluída em água. Os gráficos mostram as intensidades dos níveis de cinza dos perfis com $75 \mathrm{~nm}$ de largura indicados na imagem.

O perfil da imagem de campo claro da Figura 65 mostra um pequeno aumento de brilho ao redor dos agregados das partículas que diminui gradativamente com a distância da superfície dos agregados. Na imagem de perda de energia ocorreu uma diminuição do brilho na mesma região. Isto indica que 
existe material depositado sobre o substrato, e que este material sofre depleção de forma gradativa ao redor dos agregados.
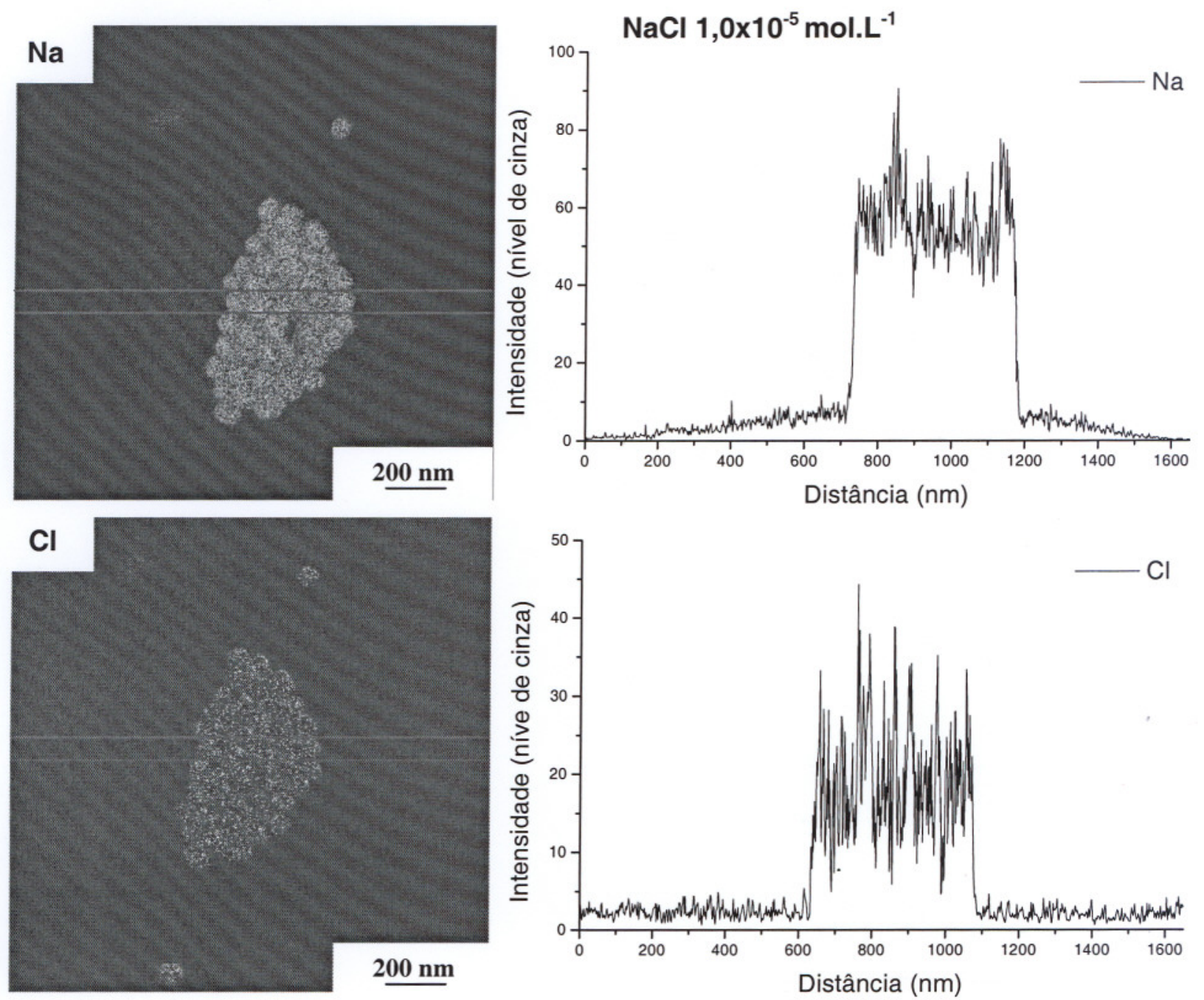

Figura 66. Mapas elementares de sódio e cloro obtidos na mesma área da amostra da Figura 65. Os gráficos mostram as intensidades dos níveis de cinza dos perfis com $75 \mathrm{~nm}$ de largura indicados nas imagens.

O mapa de sódio da Figura 66 mostra a incorporação de sódio às partículas, e a deposição de cerca de $15 \%$ no substrato ao redor dos agregados de partículas, em relação a quantidade depositada nas partículas. Esta deposição diminui gradativamente até $500 \mathrm{~nm}$ de distância da superfície das partículas dos agregados. O mapa de cloro mostra a incorporação de cloro às partículas, porém com distribuição mais heterogênea. 
As Figuras 67 e 68 mostram as imagens de campo claro, perda de energia $(\Delta \mathrm{E}=20 \mathrm{eV})$, e mapas elementares de sódio e cloro de uma mesma área de uma amostra das partículas de sílica preparadas a partir da dispersão $D$, diluída em solução de $\mathrm{NaCl} 1,0 \times 10^{-3}$ mol.L-1 e depois novamente diluída em água.

\section{$\mathrm{NaCl} 1,0 \times 10^{-3} \mathrm{~mol}^{-\mathrm{L}^{-1}}$}

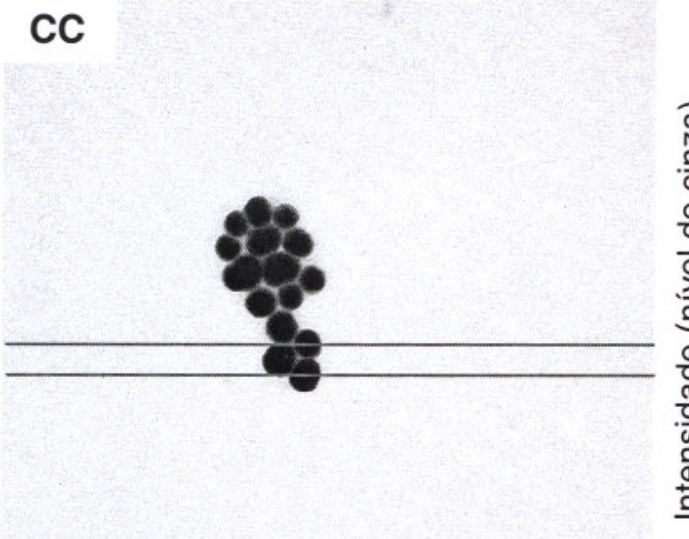

$200 \mathrm{~nm}$

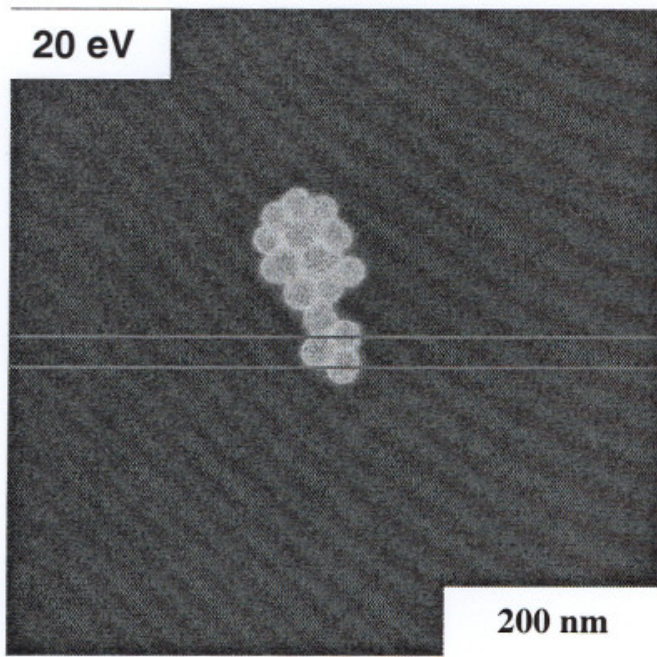

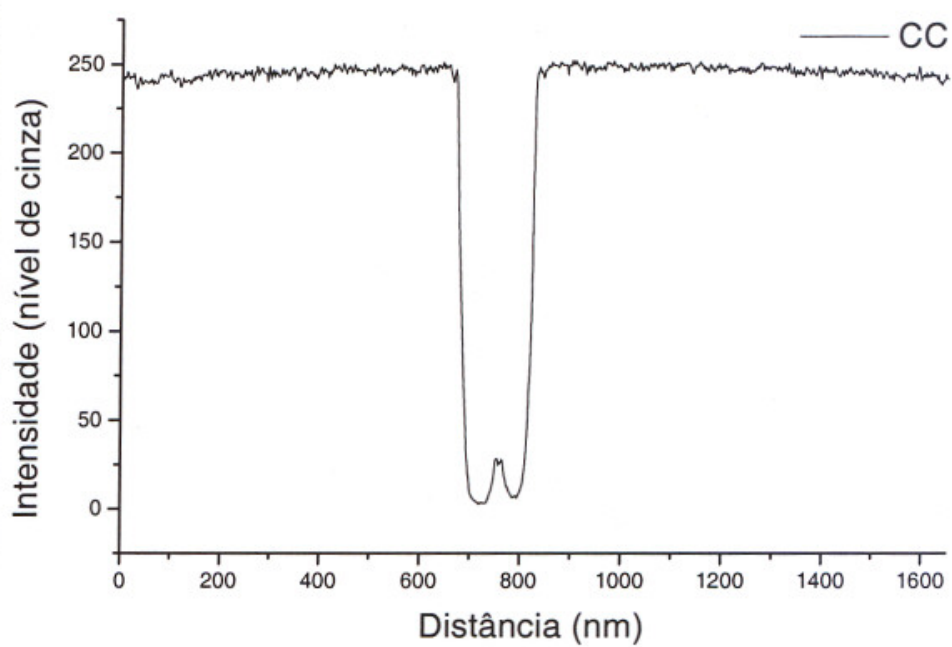



Figura 67. Imagens de campo claro $(C C)$ e de perda de energia $(\Delta E=20 \mathrm{eV})$ na região de baixa perda, de uma mesma área de uma amostra das partículas de sílica preparadas a partir da dispersão $\mathrm{D}$, diluída em solução de $\mathrm{NaCl} 1,0 \times 10^{-3} \mathrm{~mol}^{-\mathrm{L}^{-1} \mathrm{e}}$ depois novamente diluída em água. Os gráficos mostram as intensidades dos níveis de cinza dos perfis com $75 \mathrm{~nm}$ de largura indicados na imagem. 


\section{$\mathrm{NaCl} 1,0 \times 10^{-3} \mathrm{~mol}^{-\mathrm{L}^{-1}}$}
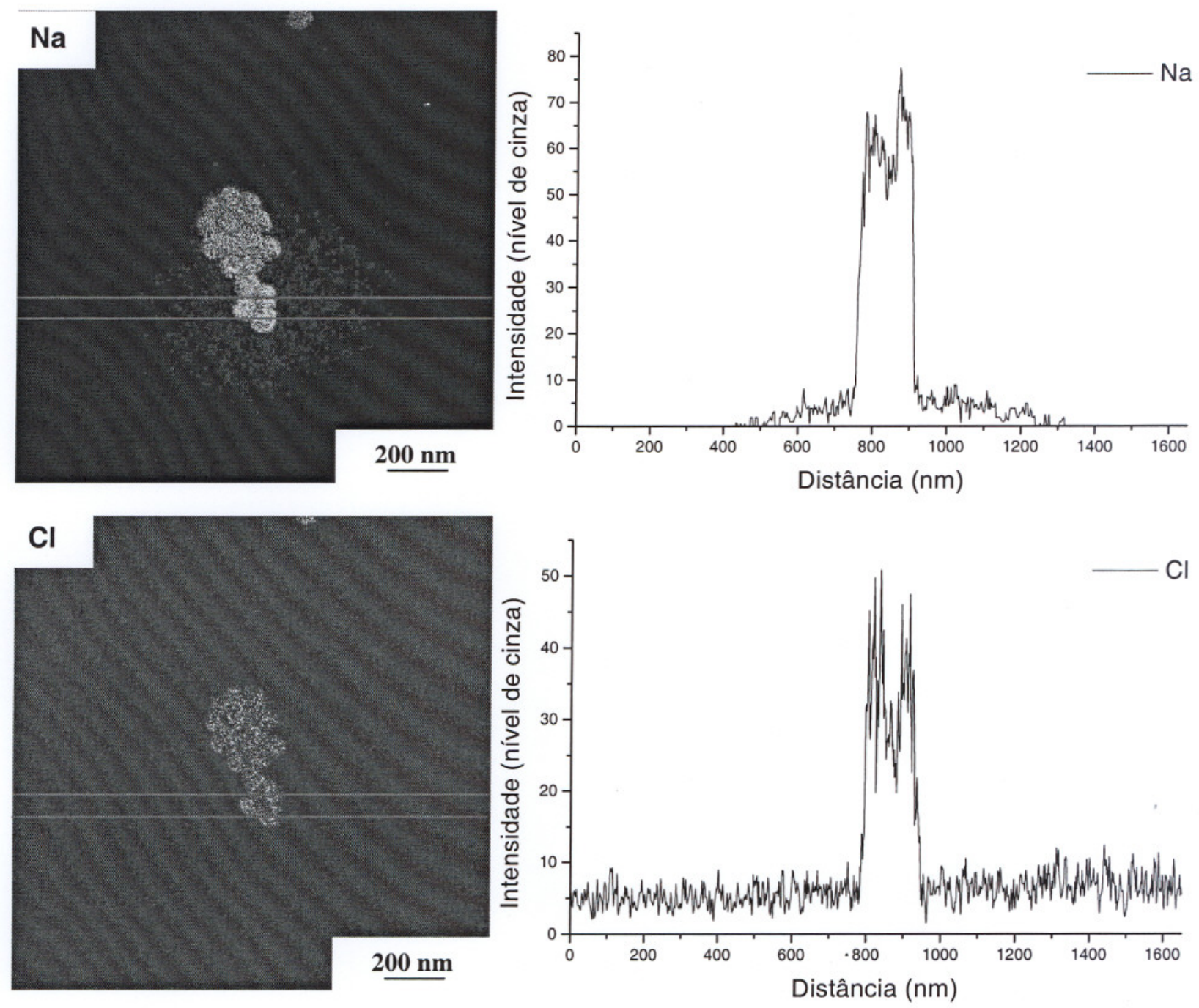

Figura 68. Mapas elementares de sódio e cloro obtidos na mesma área da amostra da Figura 67. Os gráficos mostram as intensidades dos níveis de cinza dos perfis com $75 \mathrm{~nm}$ de largura indicados nas imagens.

O mapa de sódio da Figura 68 mostra a incorporação de sódio às partículas, e a deposição de cerca de $10 \%$ no substrato ao redor dos agregados de partículas, em relação à quantidade depositada nas partículas. Esta deposição diminui gradativamente até $300 \mathrm{~nm}$ de distância da superfície das partículas dos agregados. O mapa de cloro mostra a incorporação de cloreto às partículas, porém com distribuição mais heterogênea. 
As Figuras 69 e 70 mostram as imagens de campo claro, perda de energia $(\Delta \mathrm{E}=20 \mathrm{eV})$, e mapas elementares de sódio e cloro de uma mesma área de uma amostra das partículas de sílica preparadas a partir da dispersão $D$, diluída em solução de $\mathrm{NaCl}$ 0,5 mol.L-1 e depois novamente diluída em água.

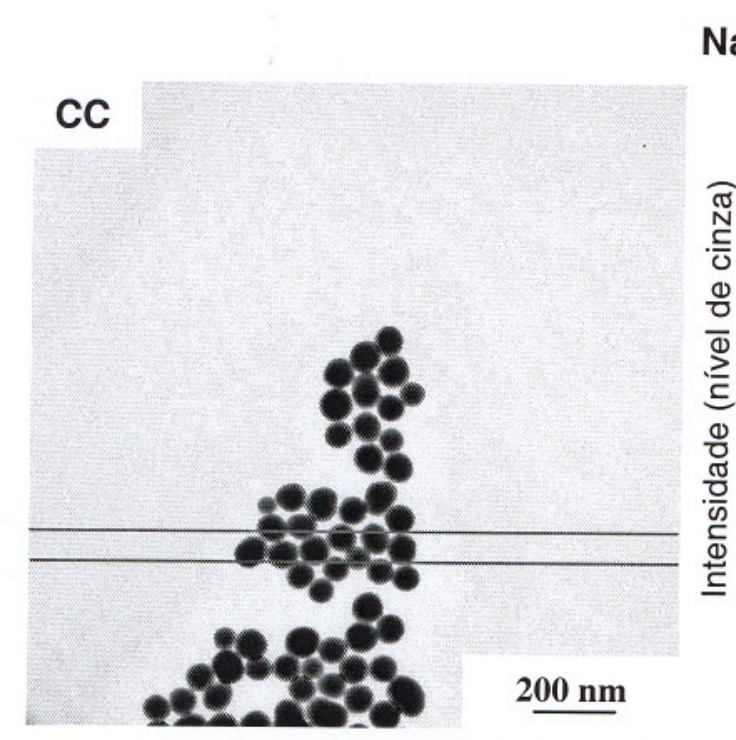

\section{$\mathrm{NaCl} 0,5 \mathrm{~mol}^{-\mathrm{L}^{-1}}$}
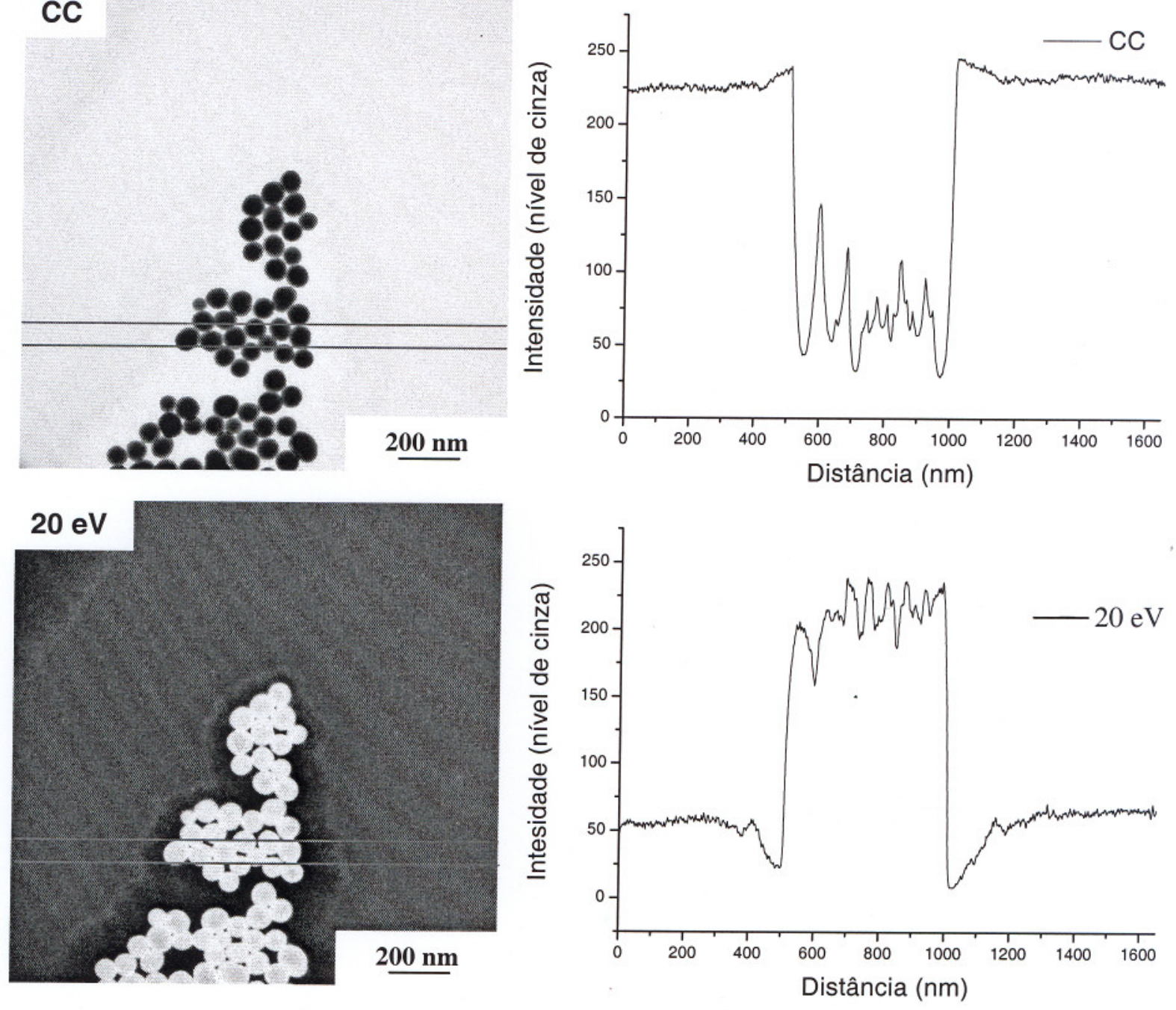

Figura 69. Imagens de campo claro $(C C)$ e de perda de energia $(\Delta E=20 \mathrm{eV})$ na região de baixa perda, de uma mesma área de uma amostra das partículas de sílica preparadas a partir da dispersão $\mathrm{D}$, diluída em solução de $\mathrm{NaCl} 0,5 \mathrm{~mol}^{-L^{-1}} \mathrm{e}$ novamente diluída em água. Os gráficos mostram as intensidades dos níveis de cinza dos perfis com $75 \mathrm{~nm}$ de largura indicados na imagem. 
O perfil da imagem de campo claro da Figura 69 mostra um pequeno aumento de intensidade de sinal ao redor dos agregados das partículas, que diminui gradativamente até $100 \mathrm{~nm}$ dos agregados, atingindo um valor constante sobre o substrato. $\mathrm{Na}$ imagem de perda de energia $(\Delta \mathrm{E}=20 \mathrm{eV})$ ocorre uma diminuição do sinal na mesma região. Isto indica que existe material depositado sobre o substrato, e que este material sofre depleção de forma gradativa, da borda das partículas até uma faixa de aproximadamente $100 \mathrm{~nm}$ dos agregados.

\section{$\mathrm{NaCl} 0,5$ mol. $\mathrm{L}^{-1}$}
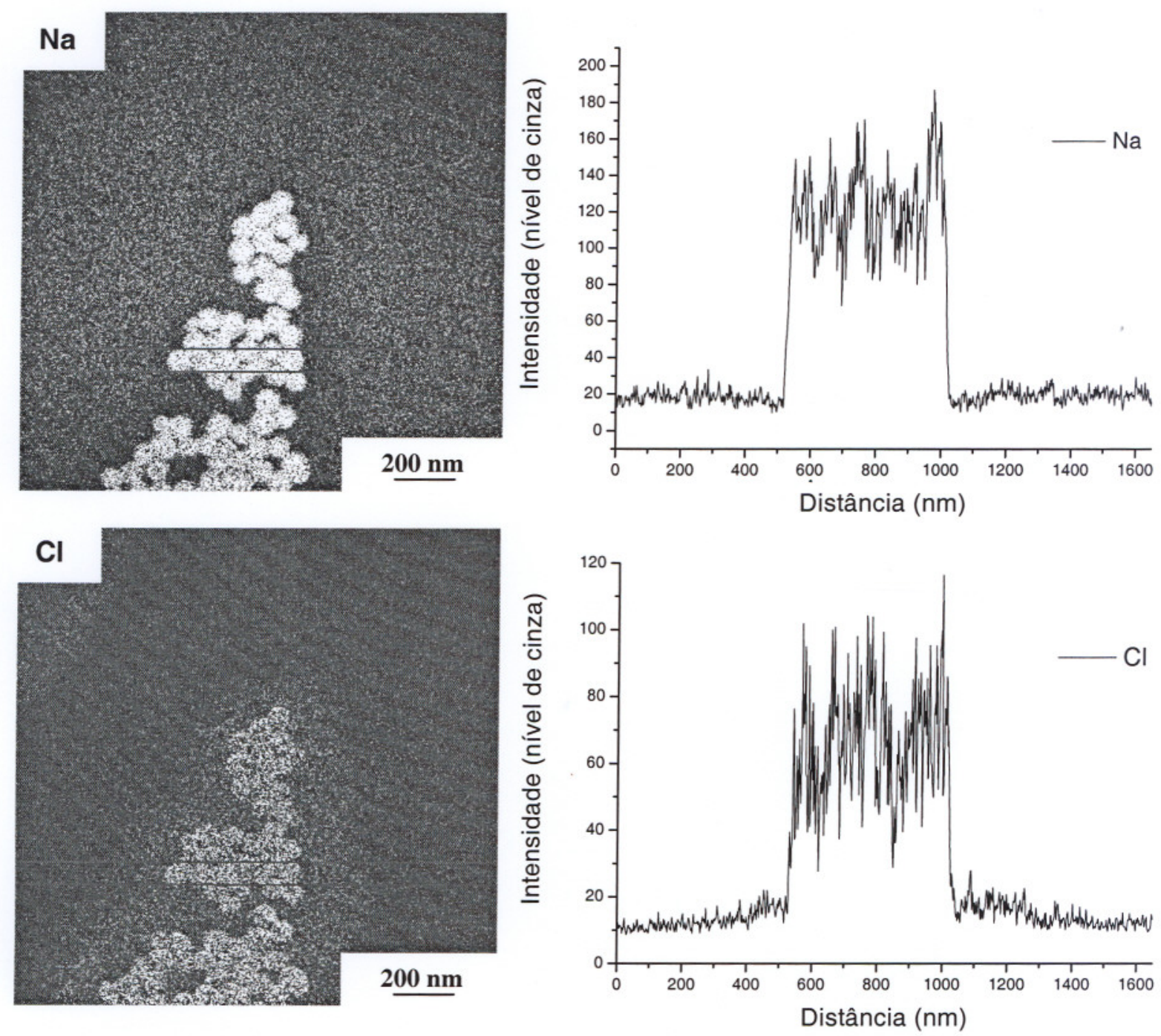

Figura 70. Mapas elementares de sódio e cloro obtidos na mesma área da amostra da Figura 69. Os gráficos mostram as intensidades dos níveis de cinza dos perfis com $75 \mathrm{~nm}$ de largura indicados nas imagens. 
No mapa de sódio da Figura 70 podemos observar que ocorre uma acentuada incorporação de sódio às partículas. Podemos observar também que ao redor dos agregados de partículas ocorreu uma diminuição de $40 \%$ na intensidade dos níveis de cinza em relação ao substrato, o que representa uma depleção de cerca de $40 \%$ de sódio em relação à quantidade depositada sobre o substrato. Esta depleção diminui gradativamente até $100 \mathrm{~nm}$ de distância da superfície das partículas dos agregados.

No mapa de cloro também podemos observar a incorporação de cloreto às partículas, porém com distribuição muito mais heterogênea sobre as partículas. Podemos observar também que ao redor dos agregados de partículas ocorreu um aumento de $40 \%$ na intensidade dos níveis de cinza em relação ao substrato, o que representa um acúmulo de cerca de $40 \%$ de cloro em relação à quantidade depositada sobre o substrato. Este acúmulo diminui gradativamente até cerca de $250 \mathrm{~nm}$ da superfície dos agregados.

A inversão do contraste entre as imagens de campo claro e de perda de energia das Figuras 65, 67 e 69 é suficiente para concluirmos que não há espalhamento múltiplo importante para perdas de energia de $20 \mathrm{eV}$. Nas imagens de perda de energia $(20 \mathrm{eV}) \circ$ contraste da casca para o centro diminui com o aumento da concentração de $\mathrm{NaCl}$, e o aumento da incorporação de sódio e cloro às partículas, mostrado nas imagens elementares das Figura 66, 68 e 70.

A Figura 71 mostra uma imagem de campo claro das partículas de sílica que foram expostas a $\mathrm{NaCl} 0,5 \mathrm{~mol} . \mathrm{L}^{-1}$. Foram comparados os espectros de três diferentes regiões: (A) em um agregado de partículas, (B) no substrato sem partículas entre agregados, e (C) no substrato sem partículas, a uma distância média de $1 \mu \mathrm{m}$ dos agregados. 


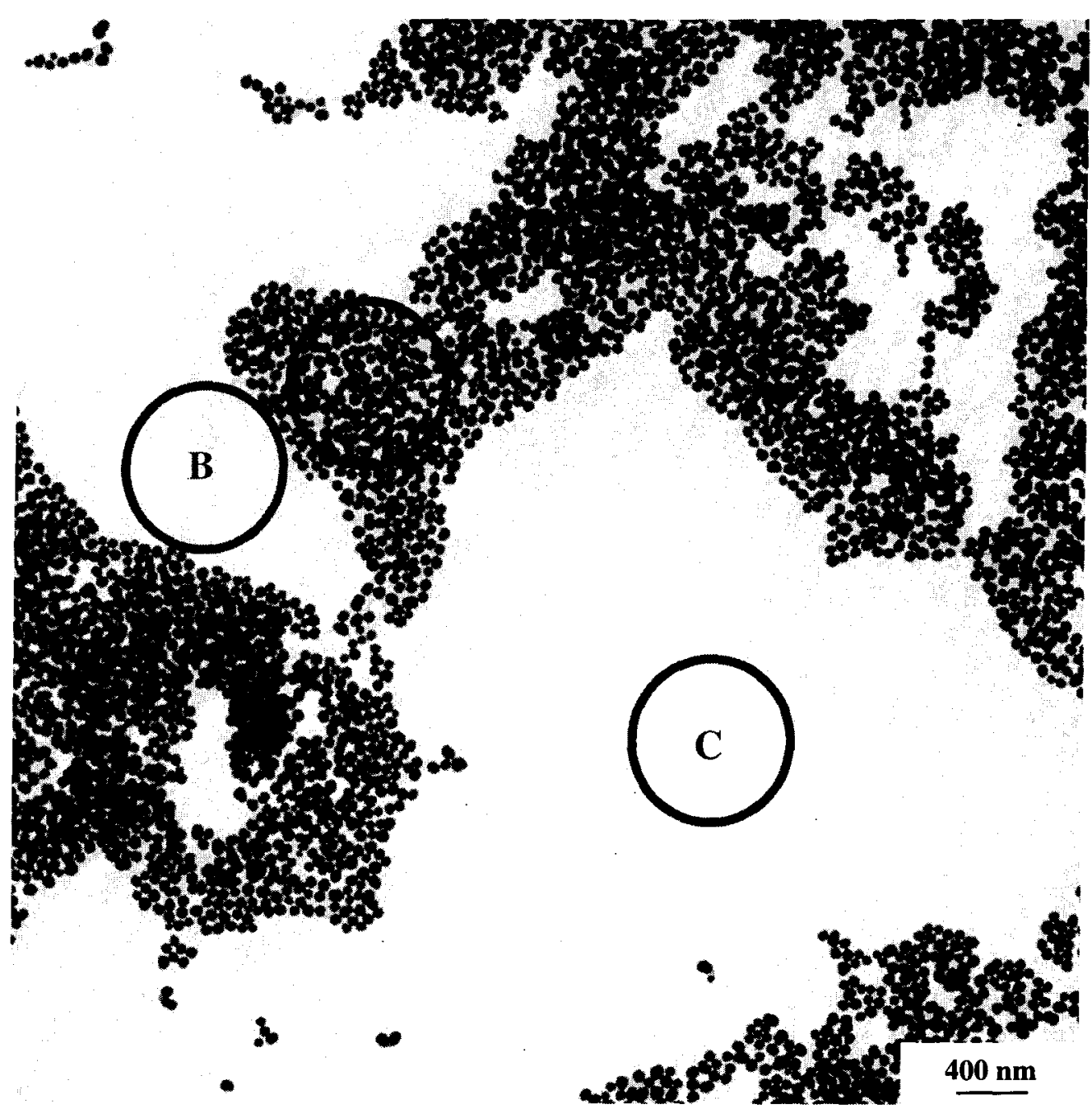

Figura 71. Imagem de campo claro de uma amostra das partículas de sílica preparadas a partir da dispersão $\mathrm{D}$, diluída em solução de $\mathrm{NaCl} 1,0 \times 10^{-5} \mathrm{~mol} . \mathrm{L}^{-1} \mathrm{e}$ novamente diluída em água. As regiōes $A, B$ e $C$ identificam os campos de onde foram obtidos os espectros de perda de energia.

A Figura 72 mostra a imagem de campo claro da região $A$, obtida com a inserção da fenda seletora. 




Figura 72. Imagem de campo claro da região A da Figura 71, obtida com a inserção da fenda seletora.

Os espectros nesta região foram obtidos de uma área de 0,60 $\mu \mathrm{m}^{2}$, coberta em $81 \%$ com partículas de sílica, sendo que em $15 \%$ desta área há partículas superpostas.

Os espectros nas outras regiões foram obtidas com a mesma abertura da fenda seletora, posicionando a amostra nos campos indicados. As Figuras 73 a 76 mostram os espectros de $\mathrm{Na}, \mathrm{Cl}, \mathrm{Si}$ e $\mathrm{O}$ obtidos nas diferentes regiões. Há poucos exemplos da obtenção de espectros de perda de energia em situação análoga à deste trabalho: Naji et al. ${ }^{[103,104]}$ caracterizaram qualitativamente os elementos $\mathrm{Na}$, $\mathrm{Cl}, \mathrm{C}$ e $\mathrm{O}$ eletroquimicamente intercalado em eletrodos de grafite. Scheneider et al. ${ }^{[105]}$ caracterizaram qualitativamente os elementos $\mathrm{Si}$, O e C em compósitos de fibra de $\mathrm{C}$ e SiC. Não foram encontradas citações sobre a caracterização quantitativa por EELS da sorção de $\mathrm{Na}$ e $\mathrm{Cl}$ em $\mathrm{SiO}_{2}$. 



Figura 73. Espectros de perda de energia da borda de absorção da camada $\mathrm{K}$ do sódio, adquiridos nas regiões $\mathrm{A}, \mathrm{B}$ e $\mathrm{C}$ da Figura 71 . As áreas sob os picos de ionização (A) foram determinadas no intervalo de 1045 a $1135 \mathrm{eV}$. 

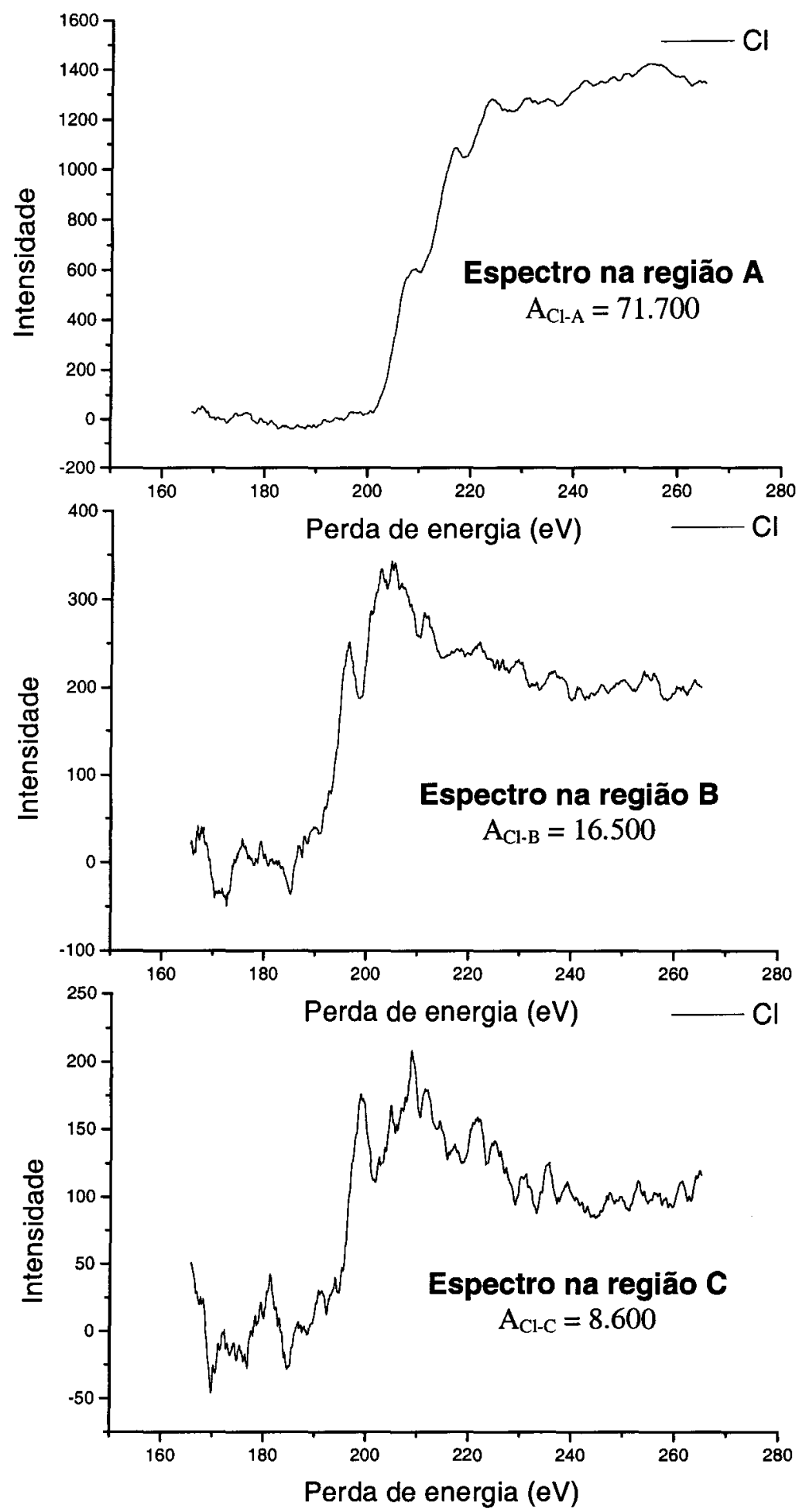

Figura 74. Espectros de perda de energia da borda de absorção da camada $L_{2,3}$ do cloro, adquiridos nas regiões $\mathrm{A}, \mathrm{B}$ e $\mathrm{C}$ da Figura 71. As áreas sob os picos de ionização (A) foram determinadas no intervalo de 165 a $265 \mathrm{eV}$. 



Figura 75. Espectros de perda de energia da borda de absorção da camada K do silício, adquiridos nas regiões $A, B$ e $C$ da Figura 71. As áreas sob os picos de ionização (A) foram determinadas no intervalo de 1820 a $1915 \mathrm{eV}$. 

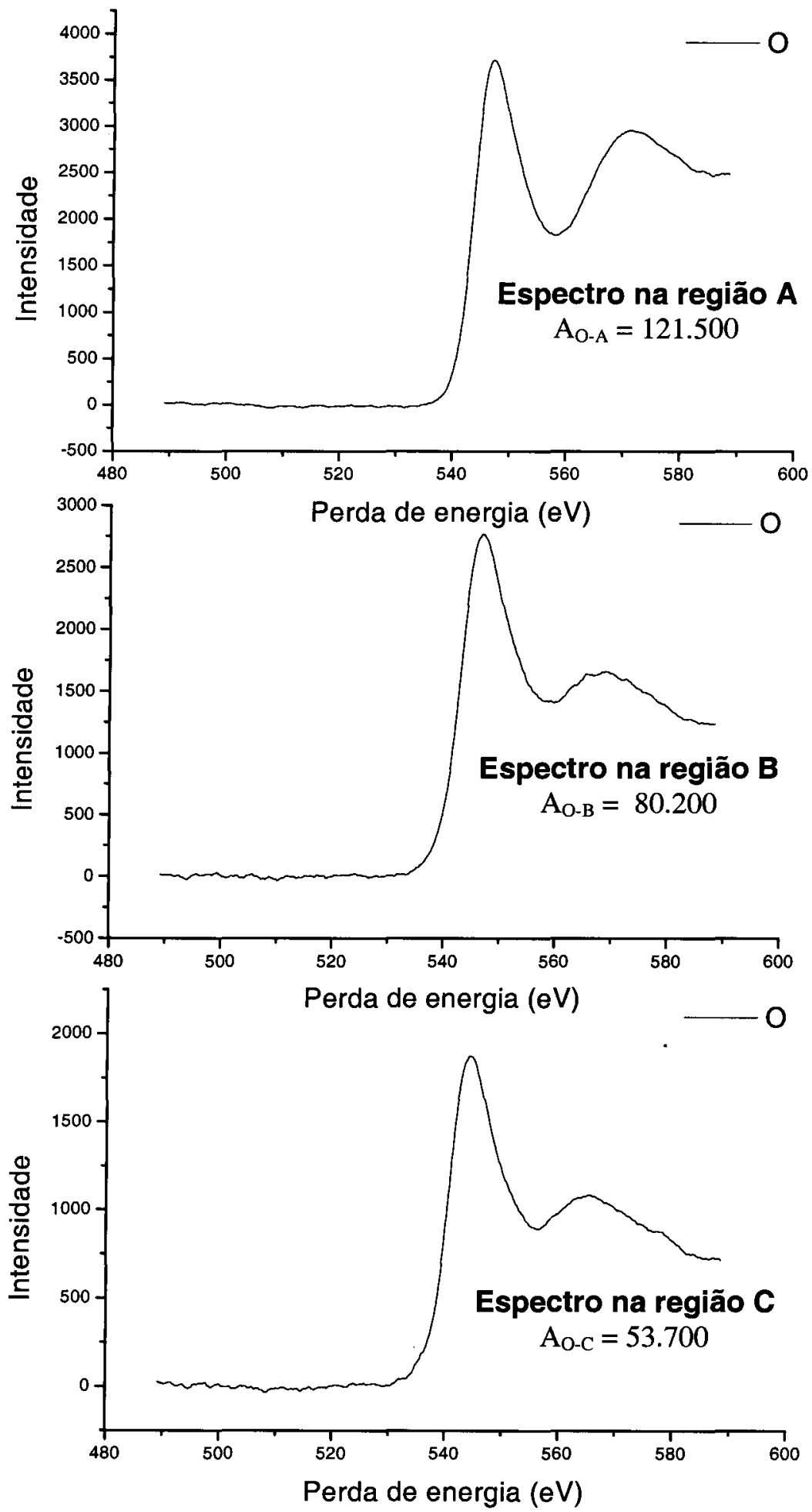

Figura 76. Espectros de perda de energia da borda de absorção da camada $\mathrm{K}$ do oxigênio, adquiridos nas regiōes $A, B$ e $C$ da Figura 71. As áreas sob os picos de ionização (A) foram determinadas no intervalo de 520 a 590 eV. 
Como o substrato contém O proveniente do filme de parlódio, e da oxidação de parte do filme de carbono, foi realizado um espectro de perda de energia da borda de absorção do oxigênio somente do filme de parlódio coberto com $C$, que é o substrato (Figura 77).

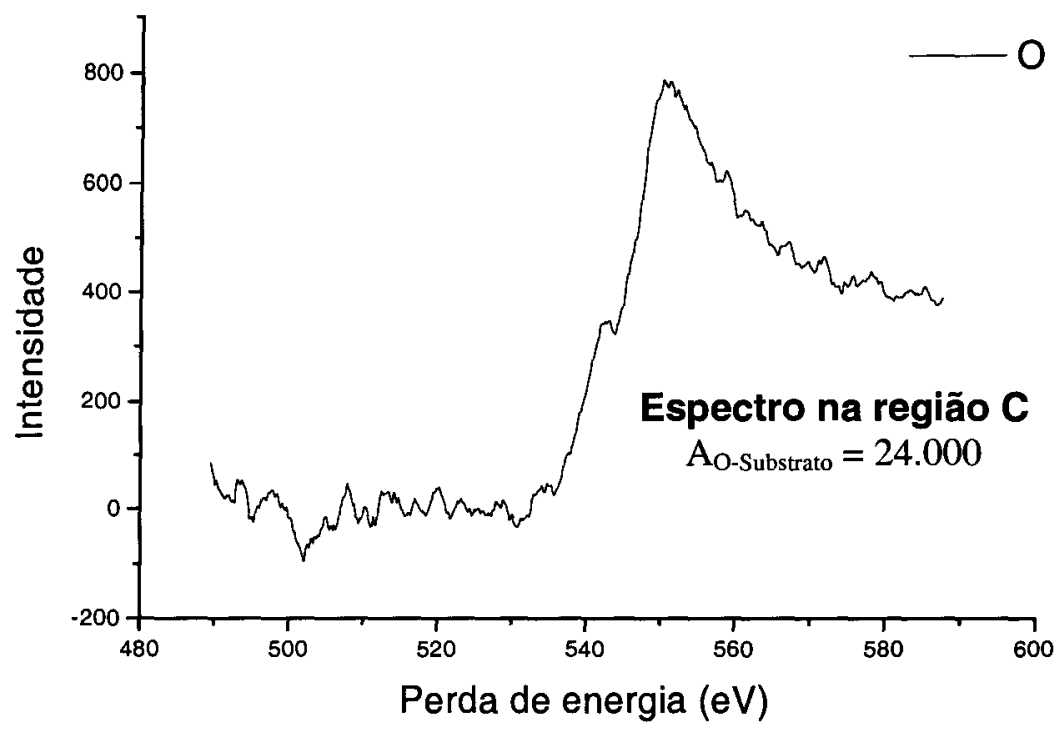

Figura 77. Espectro de perda de energia da borda de absorção da camada $\mathrm{K}$ do oxigênio, adquirido no substrato de parlódio recoberto com um filme de C. A área sob o pico de ionização (A) foi determinada no intervalo de 520 a $590 \mathrm{eV}$.

Os espectros das Figuras 73 a 76 mostram que para cada elemento analisado, além da variação da área sob o pico de ionização, as estruturas finas dos espectros obtidos nos agregados de partículas (região A), apresentam diferenças qualitativas com os espectros obtidos no substrato sem partículas (regiões B e C). Mudanças na estrutura fina nos espectros de Si e O, mostrando variações no ambiente químico, foram estudadas por Lichtenberger et al. ${ }^{[106]} \mathrm{em}$ sistemas biológicos. A estrutura fina dos espectros apresenta um pico secundário, com maior perda de energia que o da borda de absorção, e com intensidade maior na região $A$ que nas regiões $B$ e $C$. No espectro do cloro da região $A$ a intensidade 
deste pico é maior que a do pico da borda de absorção, e as energias estão deslocadas $13 \mathrm{~V}$ para a região de maior perda, em relação aos espectros das regiões $\mathrm{B}$ e $\mathrm{C}$.

O espectro de oxigênio adquirido no substrato (Figura 77), sem adição das amostras, não apresenta um acentuado pico secundário com maior perda de energia, como mostram nos espectros das regiões A, B e C. Entretanto, apresenta um pico com energia aproximadamente $100 \mathrm{eV}$ menor que a borda de absorção que não está presente nos demais espectros. Além disso, todo o espectro está deslocado em $8 \mathrm{eV}$ para a região de maior perda de energia. Este deslocamento pode ser associado às variações locais de carga na superfície do filme.

As variações qualitativas observadas nos espectros de perda de energia mostram uma variação significativa no ambiente químico dos elementos.

Os elementos podem ser quantificados a partir da Eq. (69), que mostra a relação entre a área $A_{i}$ sob o pico de ionização do espectro e o número $N_{i}$ de átomos do elemento i na área amostrada:

$$
A_{i}=c_{i} \cdot N_{i}
$$

onde $c_{i}$ é uma constante, para um dado elemento sob condições de aquisição constantes.

A quantidade relativa de um mesmo elemento em diferentes regiões ( 1 e 2) pode ser calculada a partir da Eq. (69):

$$
\begin{gathered}
A_{i 1}=c_{i 1} \cdot N_{i 1} \\
A_{i 2}=c_{i 2} \cdot N_{i 2} \\
N_{i 2} / N_{i 1}=A_{i 2} c_{i 1} / A_{i 1} c_{i 2}
\end{gathered}
$$

Adquirindo sob condições constantes: 


$$
c_{i 1}=c_{i 2}
$$

Substituindo a Eq. (73) na Eq. (72):

$$
N_{i 2} / N_{i 1}=A_{i 2} / A_{i 1}
$$

A quantidade relativa de diferentes elementos ( $i$ e $k$ ) em uma região (1) é dada por:

$$
\begin{aligned}
A_{i 1} & =c_{i 1} \cdot N_{i 1} \\
A_{k 1} & =c_{k 1} \cdot N_{k 1} \\
c_{i 1} & \neq c_{k 1} \\
N_{k 1} / N_{i 1} & =A_{k 1} c_{i 1} / A_{i 1} c_{k 1}
\end{aligned}
$$

A quantidade relativa entre diferentes elementos (i e $k$ ) em uma região (2) é dada por:

$$
\begin{gathered}
A_{i 2}=c_{i 2} \cdot N_{i 2} \\
A_{k 2}=c_{k 2} \cdot N_{k 2} \\
c_{i 2} \neq c_{k 2} \\
N_{k 2} / N_{i 2}=A_{k 2} c_{i 2} / A_{i 2} c_{k 2}
\end{gathered}
$$

A relação entre as quantidades relativas de diferentes elementos ( $i$ e $k$ ), em diferentes regiões ( 1 e 2 ) pode ser calculada a partir das Eqs. (78) e (82). Adquirindo sob condições constantes:

$$
\begin{aligned}
c_{i 1} & =c_{i 2} \\
c_{k 1} & =c_{k 2} \\
N_{k 2} / N_{i 2} & =\left(N_{k 1} / N_{i 1}\right) \cdot\left(A_{k 2} / A_{i 2}\right) \cdot\left(A_{i 1} / A_{k 1}\right)
\end{aligned}
$$


A Tabela 9 mostra a razão entre as quantidades relativas de $\mathrm{Si}, \mathrm{O}, \mathrm{Na}$ e $\mathrm{Cl}$ entre as regiões $A, B$ e $C$ da Figura 71, após a subtração do número de átomos de O do substrato, calculada a partir das Eqs. (74) e (85) e dos espectros das Figuras 73 a $76:$

Tabela 9. Razão entre os números de átomos de $\mathrm{Si}, \mathrm{O}, \mathrm{Na}$ e $\mathrm{Cl}$ nas regiões $\mathrm{A}, \mathrm{B}$ e C, subtraindo o número de átomos de $\mathrm{O}$ do substrato.

\begin{tabular}{|c|c|c|c|c|c|c|c|c|c|c|c|c|c|}
\hline & \multicolumn{4}{|c|}{$\bar{A}$} & \multicolumn{4}{|c|}{$\bar{B}$} & \multicolumn{4}{|c|}{$C$} \\
\hline & & $\mathrm{Si}$ & 0 & $\mathrm{Na}$ & $\mathrm{Cl}$ & $\mathrm{Si}$ & 0 & $\mathrm{Na}$ & $\mathrm{Cl}$ & Si & 0 & $\mathrm{Na}$ & $\mathrm{Cl}$ \\
\hline & $\mathrm{Si}$ & 1 & a & b & C & 0,11 & & & & 0,03 & & & \\
\hline & 0 & $1 / a$ & 1 & d & e & & 0,58 & & & & 0,30 & & \\
\hline$\varangle$ & $\mathrm{Na}$ & $1 / \mathrm{b}$ & $1 / d$ & 1 & $f$ & & & 0,21 & & & & 0,11 & \\
\hline & $\mathrm{Cl}$ & $1 / \mathrm{c}$ & $1 / \mathrm{e}$ & $1 / f$ & 1 & & & & 0,23 & & & & 0,12 \\
\hline & $\mathrm{Si}$ & 9,00 & & & & 1 & $5,22 a$ & $1,89 b$ & $2,07 c$ & 0,29 & 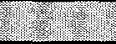 & &  \\
\hline & 0 & & 1,73 & & & $0,19 / a$ & 1 & $0,36 \mathrm{~d}$ & $0,40 \mathrm{e}$ & 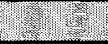 & 0,52 & 8 & 5 \\
\hline$\infty$ & $\mathrm{Na}$ & & & 4,79 & & $0,52 / \mathrm{b}$ & $2,78 / d$ & 1 & $1,10 \mathrm{f}$ & 38 & 8 & 0,51 & TE \\
\hline & $\mathrm{Cl}$ & & & & 4,35 & $0,48 / \mathrm{c}$ & $2,52 / e$ & $0,91 / f$ & 1 & & 28 & 2 & 0,52 \\
\hline & $\mathrm{Si}$ & 30,76 & & & & 3,42 & 20 & 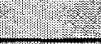 & $8=$ & 18 & $928 a$ & 3,386 & $3,69 c$ \\
\hline & 0 & & 3,29 & & & 88 & 1,91 & 7 & 80 & $0,10 / a$ & 17 & 0,368 & 0,398 \\
\hline 0 & $\mathrm{Na}$ & & & 9,38 & & 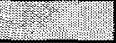 & $\sqrt{25}$ & 1.96 & 8. & $0,30 / 6$ & $281 / d$ & 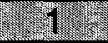 & $81,13 \mathrm{f}$ \\
\hline & $\mathrm{Cl}$ & & & & 8,34 & & 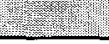 & & 1,92 & $0,27 / \mathrm{c}$ & $2,50 / 6$ & $0,88 / f$ & 1 \\
\hline
\end{tabular}

A partir das áreas sob os picos de ionização e da Eq. (74) foi determinada a quantidade relativa de um mesmo elemento entre as diferentes regiões. Porém, usando a Eq. (78) para determinar a quantidade relativa de diferentes elementos ( $i$ e $k$ ) em uma mesma região seria necessário determinar as constantes $c_{j}$ e $c_{k}$. Como o objetivo é apenas determinar as relações do tipo:

$$
\left(N_{i} / N_{k}\right)_{\text {regiăo u }} /\left(N_{i} / N_{k}\right)_{\text {regiăo } v}
$$

estas quantidades foram parametrizadas em função das relações determinadas na região A: 


$$
\begin{gathered}
N_{d} / N_{S i}=a \\
N_{N a} / N_{S i}=b \\
N_{C} / N_{S i}=c \\
N_{N a} / N_{O}=d \\
N_{C} / N_{o}=e \\
N_{C} / N_{N a}=f
\end{gathered}
$$

Substituindo as Eq. (87) a (92) e os valores das áreas sob os picos de ionização na Eq. (85), as quantidades relativas dos diferentes elementos nas demais regiões foram determinadas em função de $a, b, c, d$, e e $f$. 
4.3. Adsorção de PNIPAM - As Figuras 78 e 79 mostram imagens de campo claro de submonocamadas de partículas de sílica da dispersão $D$, obtidas a partir da secagem a $20^{\circ} \mathrm{C}$ das dispersões sem adição de adsorbatos e com a adição de diferentes concentrações de PNIPAM (90 Kg/Mol).
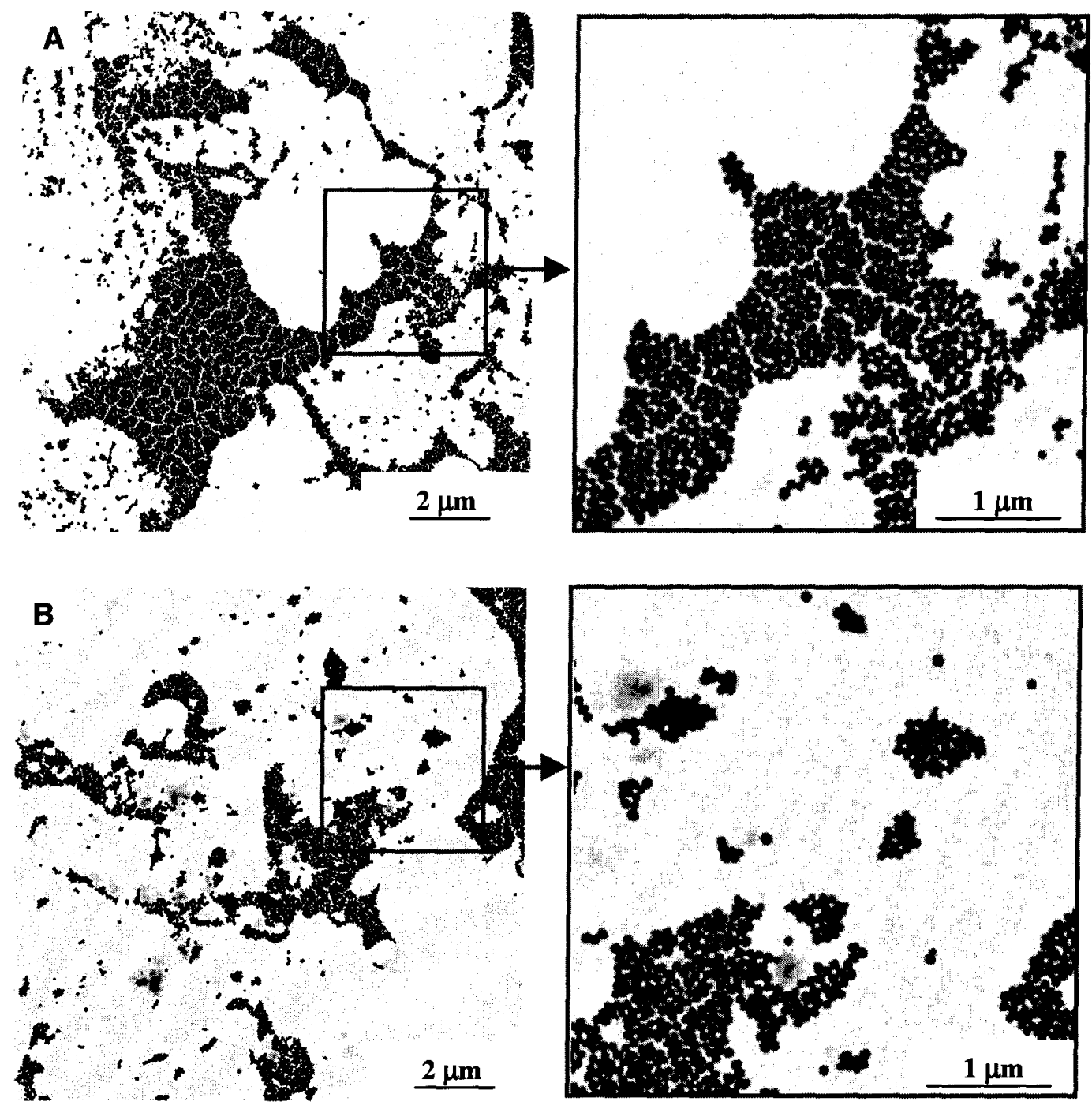

Figura 78. Imagens de campo claro de partículas de sílica da dispersão D, obtidas secando dispersões a $20^{\circ} \mathrm{C}$ : (A) após a diluição em água, e (B) após a diluição em PNIPAM $10^{-5} \mathrm{~g} / \mathrm{mL}$ seguida de uma nova diluição em água. As imagens da direita mostram as ampliações das regiōes indicadas. 
A
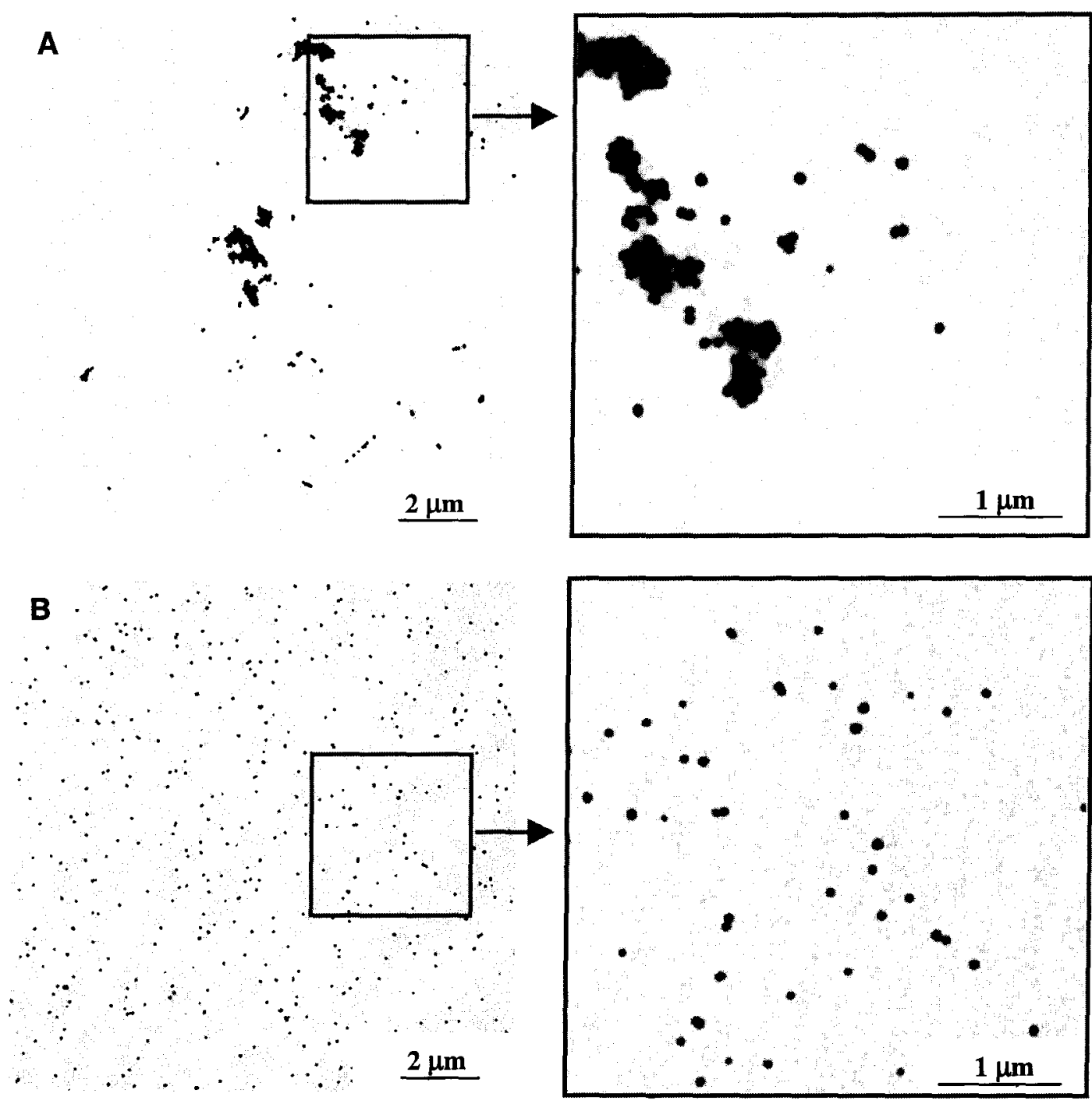

Figura 79. Imagens de campo claro de partículas de sílica da dispersão $D$, obtidas secando dispersões a $20^{\circ} \mathrm{C}$ preparadas após a diluição em (A) PNIPAM $10^{-4} \mathrm{~g} / \mathrm{mL}$ $\left(20^{\circ} \mathrm{C}\right)$ e (B) PNIPAM $10^{-3} \mathrm{~g} / \mathrm{mL}$, seguida de uma nova diluição em água. As imagens da direita mostram as ampliações das regiões indicadas.

$\mathrm{Na}$ ausência de polímero são formadas regiōes com agregados bidimensionais de partículas de sílica. Na presença de baixa concentração de polímero $\left(10^{-5} \mathrm{~g} / \mathrm{mL}\right)$, não é observado um efeito significante no ordenamento. Entretanto, com o aumento da concentração do polímero, é observado um decréscimo na extensão dos domínios ordenados e um aumento na dissociação das partículas. Na concentração de $10^{-3} \mathrm{~g} / \mathrm{mL}$, um arranjo aberto de partículas dispersas é formado na secagem da dispersão diluída. 
Como o PNIPAM possui quantidade significativa de carbono, e a amostra de sílica tem apenas traços, este elemento foi utilizado para o mapeamento elementar e a localização do polímero na amostra. A Figura 80 mostra os mapas elementares de carbono adquiridos com perda de energia de $284 \pm 8$ eV (ESI-TEM) de partículas de sílica secas a $20^{\circ} \mathrm{C}$ a partir de uma diluição em água, e em PNIPAM a $10^{-4} \mathrm{~g} / \mathrm{mL}$ e $10^{-3} \mathrm{~g} / \mathrm{mL}(90 \mathrm{Kg} / \mathrm{Mol})$, seguida de uma nova diluição em água.
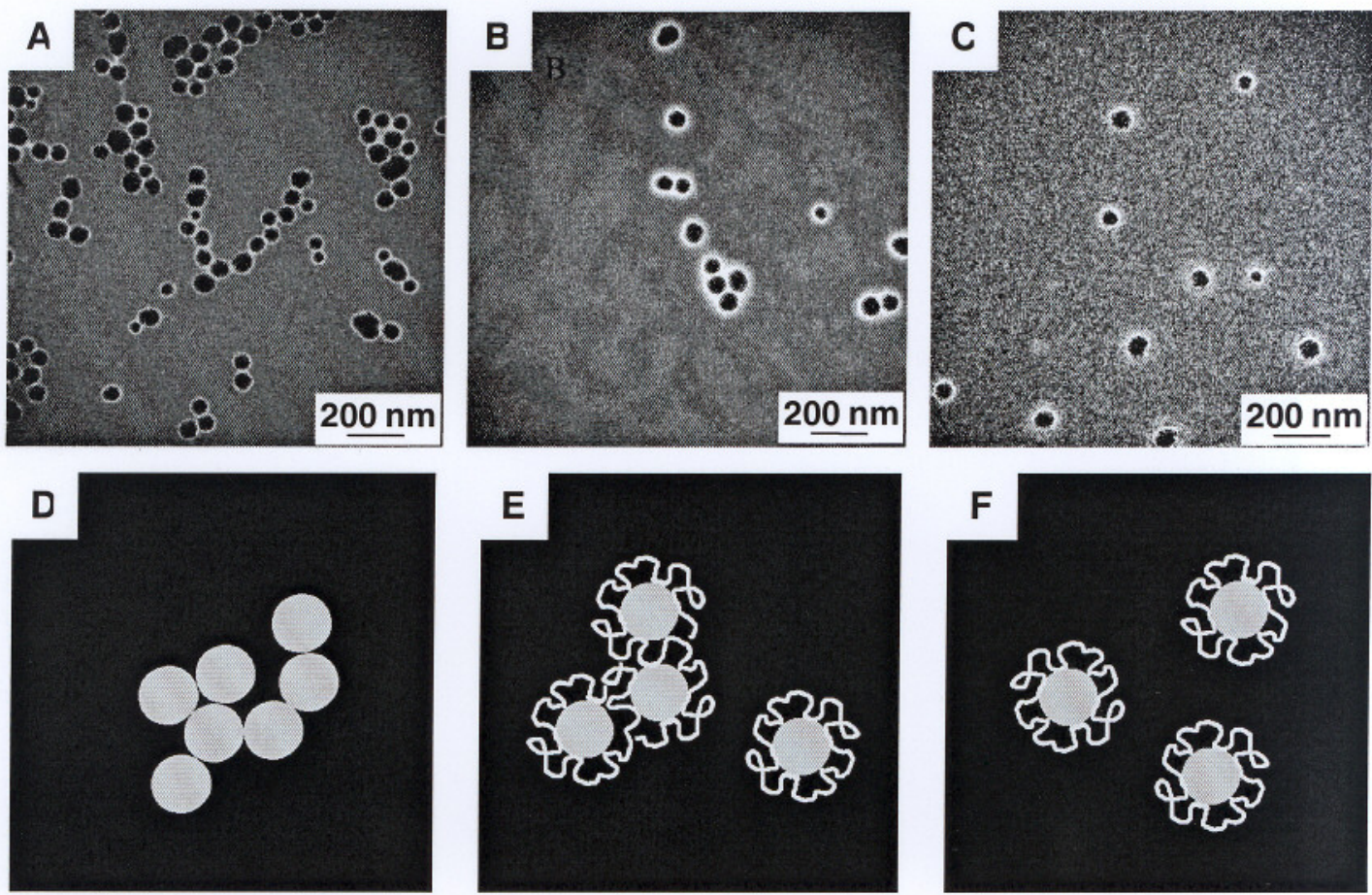

Figura 80. Mapas de carbono das partículas de sílica secas a $20^{\circ} \mathrm{C}$ a partir da diluição em (A) água, e em PNIPAM a (B) $10^{-4} \mathrm{~g} / \mathrm{mL}$ e (C) $10^{-3} \mathrm{~g} / \mathrm{mL}(90 \mathrm{Kg} / \mathrm{Mol})$, seguida de uma nova diluição em água. Os esquemas (D), (E) e (F) ilustram o respectivo recobrimento das partículas por cadeias de PNIPAM e a dissociação dos agregados.

A intensidade do brilho é proporcional à concentração de carbono. Em todas as imagens um anel brilhante pode ser visto ao redor das partículas de sílica, indicando uma maior concentração de carbono na superfície das partículas. $\mathrm{Na}$ ausência de polímero, o anel brilhante é devido ao carbono residual do TEOS, usado 
na síntese das partículas. Na presença de polímeros, os anéis são mais espessos e intensos. Entretanto, as espessuras dos anéis não são uniformes ao redor das partículas, e não variam muito com a concentração dos polímeros. Estes anéis intensos são atribuídos às cadeias de PNIPAM adsorvidas.

Da mesma forma, a espessura da camada adsorvida em função da massa molar do polímero pode ser determinada a partir do anel brilhante ao redor da partícula. A Figura 81 mostra os mapas elementares de carbono das submonocamadas de partículas de sílica, obtidas a partir da secagem a $20^{\circ} \mathrm{C}$ das dispersões diluídas em soluções de PNIPAM com três diferentes massas molares: 90, 190 e $1050 \mathrm{Kg} / \mathrm{Mol}$, na concentração de $10^{-3} \mathrm{~g} / \mathrm{mL}$, seguida de uma nova diluição em água.


Figura 81. Mapas de carbono das partículas de sílica secas a $20^{\circ} \mathrm{C}$ na presença de PNIPAM com diferentes massas molares (A) $90 \mathrm{Kg} / \mathrm{Mol}$, (B) $190 \mathrm{Kg} / \mathrm{Mol}$, (C) $1050 \mathrm{Kg} / \mathrm{Mol}$, na concentração de $10^{-3} \mathrm{~g} / \mathrm{mL}$, seguida de nova diluição em água.

A espessura da camada de polímero adsorvida foi calculada a partir de diferentes perfis de níveis de cinza entre mapas elementares e imagens de campo claro, como está exemplificado na Figura 82. Estes valores são apresentados na Tabela 10. Resultados obtidos de experimentos de PCS são também mostrados para comparação e confirmação da presença das camadas de polímeros adsorvidas nas partículas. 

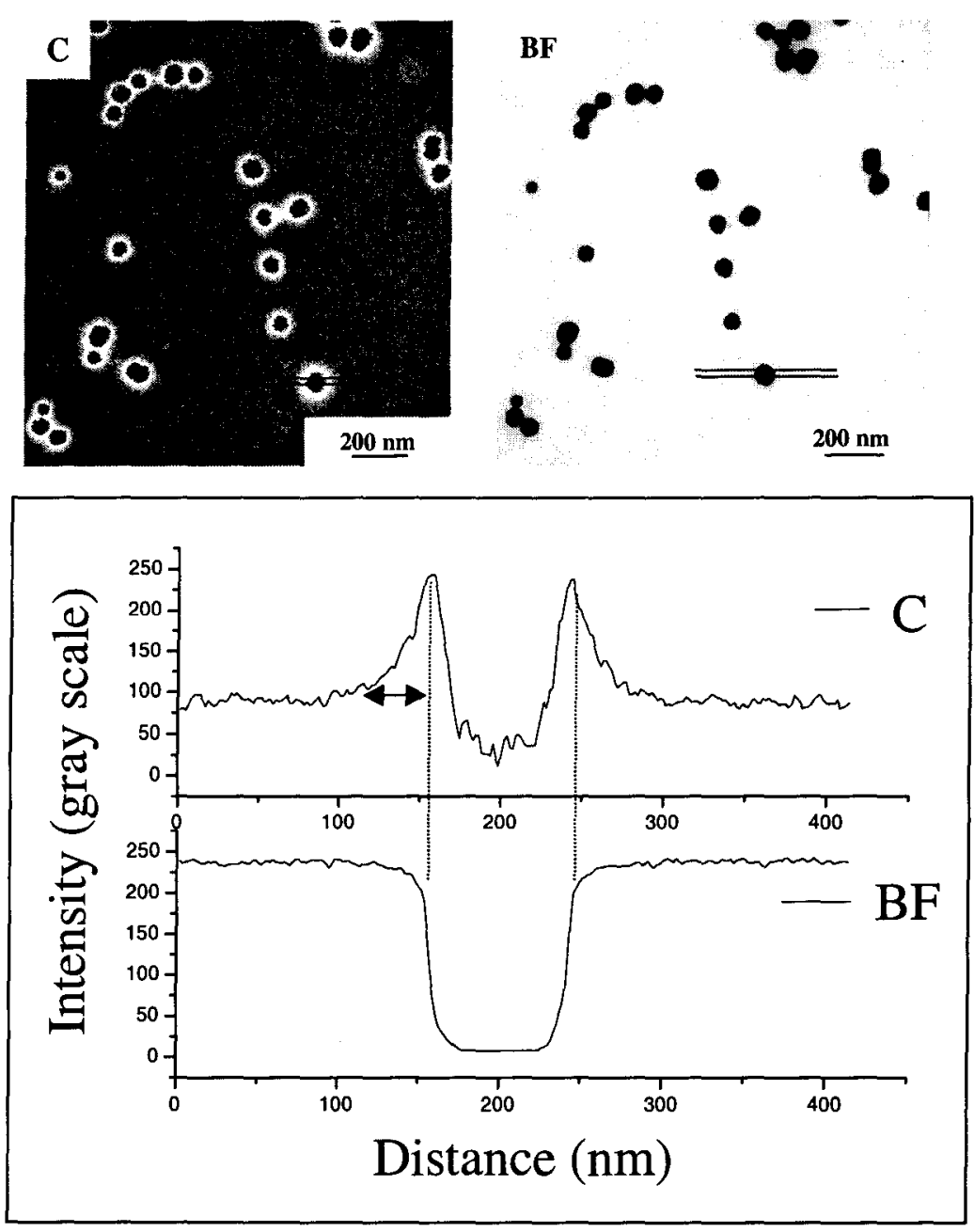

Figura 82. Perfis de níveis de cinza obtidos do mapa de $\mathrm{C}$ e da imagem de campo claro. A seta indica a espessura da camada de carbono adsorvida na partícula.

Tabela 10. Espessura da camada de polímero adsorvida determinada a partir de experimentos de TEM e PCS.

\begin{tabular}{|c|c|c|c|}
\cline { 2 - 4 } \multicolumn{1}{c|}{} & \multicolumn{3}{c|}{ MASSA MOLAR DO PNIPAM (Kg/Mol) } \\
\cline { 2 - 4 } \multicolumn{1}{c|}{} & 90 & 190 & 1050 \\
\hline $\begin{array}{c}\text { TEM - Espessura da camada } \\
\text { adsorvida }(\mathrm{nm}) \text { sob vácuo } 10^{-6} \mathrm{mbar}\end{array}$ & $10 \pm 5$ & $21 \pm 5$ & $38 \pm 5$ \\
\hline $\begin{array}{c}\mathrm{PCS}^{*} \text { - Espessura da camada } \\
\text { adsorvida }(\mathrm{nm}) \text { em água, a 25C }\end{array}$ & $10 \pm 2$ & $35 \pm 2$ & $129 \pm 3$ \\
\hline
\end{tabular}

* o valor da espessura da camada de PNIPAM foi calculado como a metade do valor do diâmetro efetivo das partículas para cada massa molar, subtraído o valor do diâmetro efetivo das partículas sem a adsorção de polímero.

Em ambos os casos a espessura da camada adsorvida aumenta com a massa molar. 
A Figura 83 mostra a comparação das partículas secas sob condições de solvatação de PNIPAM $(90 \mathrm{Kg} / \mathrm{Mol})$ boas $\left(20^{\circ} \mathrm{C}\right)$ e ruins $\left(40^{\circ} \mathrm{C}\right)$.
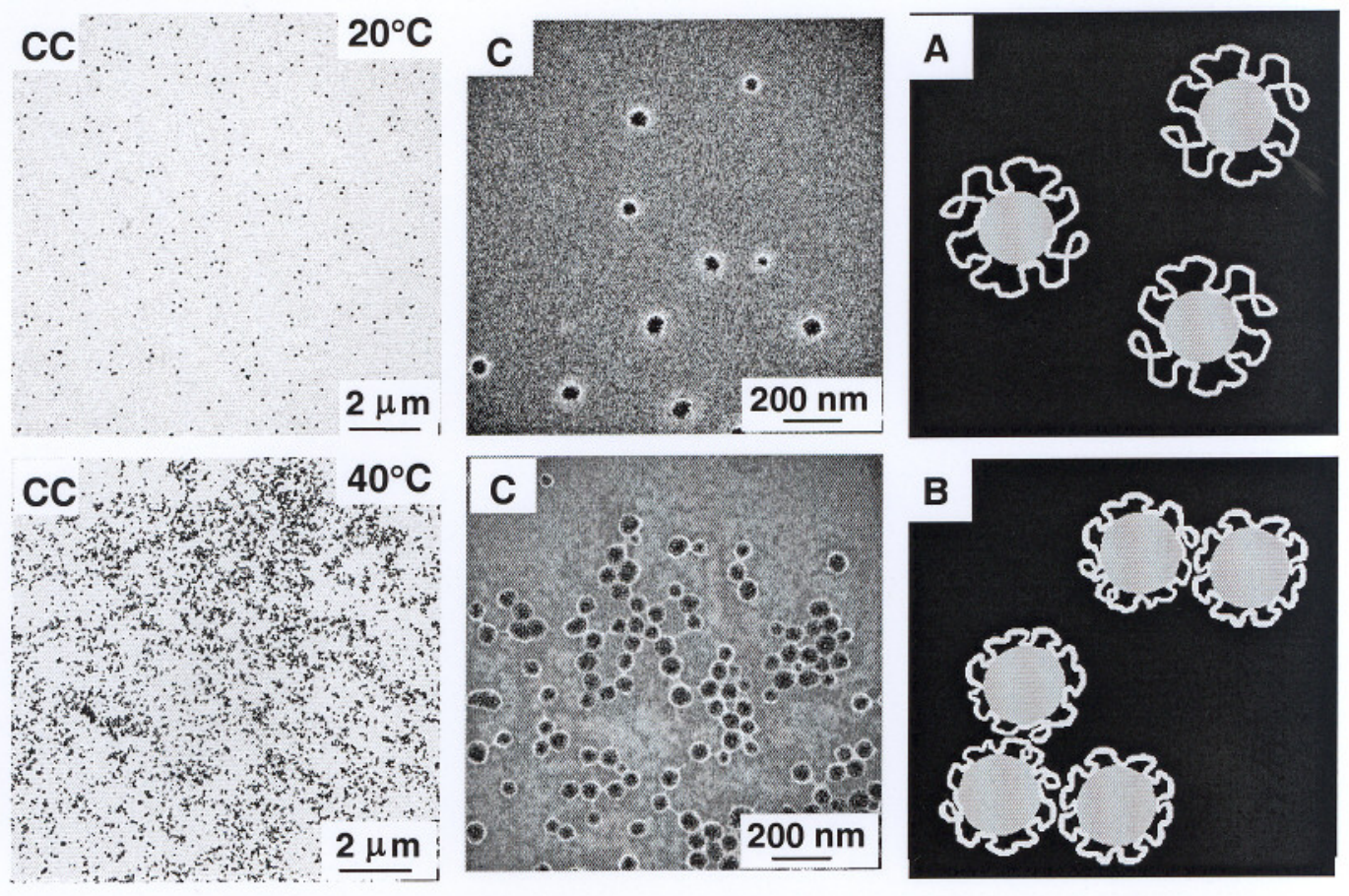

Figura 83. Imagens de campo claro (CC) e mapas elementares (C) de carbono de partículas de sílica secas a partir da diluição em PNIPAM $(90 \mathrm{Kg} / \mathrm{Mol})$ a $20^{\circ} \mathrm{C}$ e a $40{ }^{\circ} \mathrm{C}$, na concentração de $10^{-3} \mathrm{~g} / \mathrm{mL}$, seguida de uma nova diluição em água. Os esquemas $(A)$ e $(B)$ ilustram os respectivos recobrimentos das partículas por cadeias de PNIPAM e a dissociação dos aglomerados.

As Figuras 83 e 84 mostram uma clara transição de uma deposição de partículas de forma dispersa para uma forma agregada quando a temperatura de secagem é aumentada de $20^{\circ} \mathrm{C}$ para $40{ }^{\circ} \mathrm{C}$. Os mapas de carbono correspondentes mostram um decréscimo na espessura da camada de polímero adsorvida, confirmando a precipitação da camada de polímero adsorvido. Neste caso são formados agregados abertos, em contraste com os agregados compactos obtidos na ausência de polímero. 
A Figura 84 mostra as ampliações das imagens de campo claro das Figuras 78 e 83 das partículas de sílica secas em água, e em PNIPAM a $20^{\circ} \mathrm{C}$ e $40^{\circ} \mathrm{C}$.

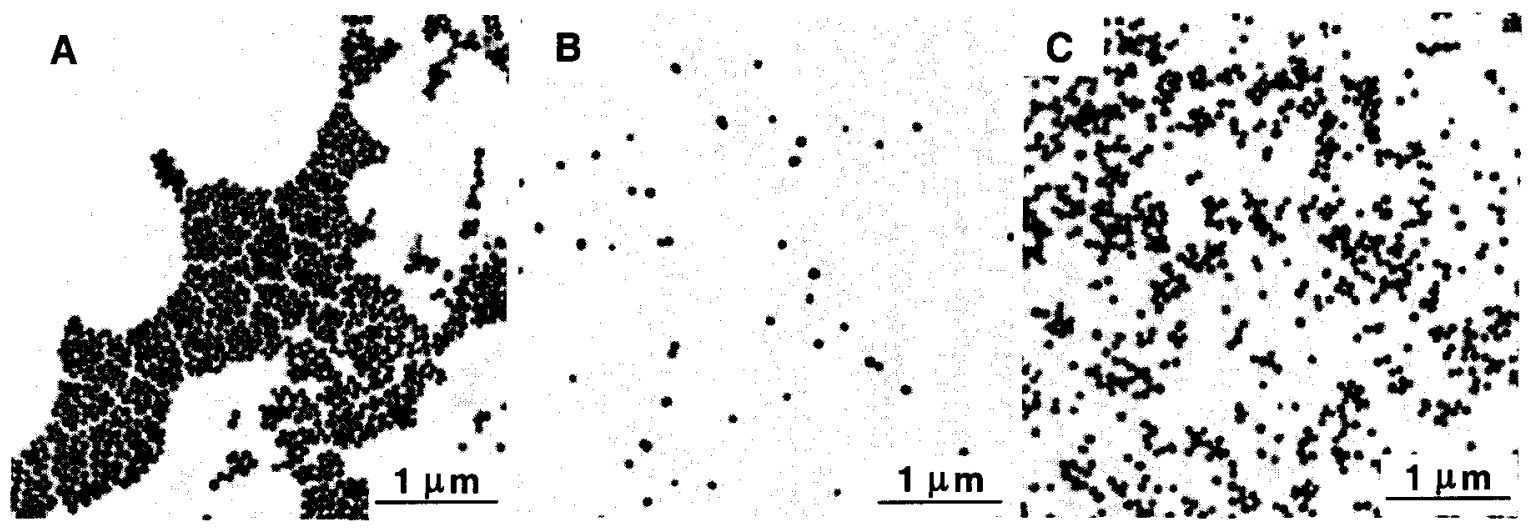

Figura 84. Ampliações das imagens de campo claro das Figuras 78 e 83 , das partículas de sílica secas após diluição em (A) água, e em PNIPAM (90 Kg/Mol) na concentração de $10^{-3} \mathrm{~g} / \mathrm{mL}$, seguida de uma nova diluição em água, a (B) $20^{\circ} \mathrm{C}$ e (C) $40^{\circ} \mathrm{C}$, respectivamente. 


\subsection{Adsorção de surfactantes}

4.4.1. Adsorção de SDS - As Figuras 85 e 86 mostram as imagens de campo claro de submonocamadas de partículas de sílica da dispersão $D$, obtidas secando sem adição de adsorbatos, e com a adição de diferentes concentrações de SDS $\left(1,0 \times 10^{-5} \mathrm{~mol} . \mathrm{L}^{-1}, 1,0 \times 10^{-3} \mathrm{~mol} . \mathrm{L}^{-1}\right.$ e $\left.1,0 \times 10^{-1} \mathrm{~mol}^{-L^{-1}}\right)$, seguida de nova diluição em água .


Figura 85. Imagens de campo claro de partículas de sílica da dispersão $D$, obtidas secando dispersões preparadas (A) após a diluição em água e (B) após a diluição em SDS $1,0 \times 10^{-5} \mathrm{~mol}^{-L^{-1}}$ seguida de nova diluição em água. As imagens da direita mostram as ampliações das regiões indicadas. 




Figura 86. Imagens de campo claro de partículas de sílica da dispersão D, obtidas secando dispersões preparadas após a diluição em (A) SDS $1,0 \times 10^{-3} \mathrm{~mol}^{-L^{-1}}$ e (B) SDS $1,0 \times 10^{-1}$ mol. $\mathrm{L}^{-1}$, seguida de uma nova diluição em água. As imagens da direita mostram as ampliações das regiões indicadas.

$\mathrm{Na}$ ausência de SDS (Figura 85A) as partículas de sílica se depositaram como agregados bidimensionais descontínuos. A Figura 85B mostra que mesmo na presença de baixa concentração de $\operatorname{SDS}\left(1,0 \times 10^{-5} \mathrm{~mol}^{-1} \mathrm{~L}^{-1}\right)$ é observado um efeito no ordenamento das partículas, formando-se um arranjo aberto de pequenos agregados ao lado de partículas dispersas, durante a secagem da dispersão. Com o aumento da concentração do surfactante, é verificada uma diminuição no grau de agregação das partículas depositadas (Figuras 86A e 86B). 
As Figuras 87, 89 e 91 mostram uma sequência de imagens de campo claro e perda de energia $(\Delta \mathrm{E}=20 \mathrm{eV})$, obtidas com maior resolução, das amostras secas após a diluição em SDS $\left(1,0 \times 10^{-5} \mathrm{~mol} \cdot \mathrm{L}^{-1}, 1,0 \times 10^{-3} \mathrm{~mol} \cdot \mathrm{L}^{-1}\right.$ e $\left.1,0 \times 10^{-1} \mathrm{~mol} \cdot \mathrm{L}^{-1}\right)$ seguida de nova diluição em água. Para analisar a adsorção do SDS, nas mesmas regiões foram obtidos os mapas elementares de carbono e de sódio, para a localização das moléculas de $\mathrm{CH}_{3}\left(\mathrm{CH}_{2}\right)_{11} \mathrm{SO}_{4}^{-}$e dos contra-íons $\mathrm{Na}^{+}$(Figuras 88, 90 e 92), respectivamente.

\section{SDS $1,0 \times 10^{-5} \mathrm{~mol} \cdot \mathrm{L}^{-1}$}


Figura 87. Imagens de campo claro (CC) e de perda de energia $(\Delta E=20 \mathrm{eV})$ na região de baixa perda, de uma mesma área de uma amostra das partículas de sílica 
preparada a partir da dispersão $D$, após a diluição em SDS $1,0 \times 10^{-5} \mathrm{~mol}^{-\mathrm{L}^{-1}}$ seguida de nova diluição em água. Os gráficos mostram as intensidades dos níveis de cinza dos perfis com $25 \mathrm{~nm}$ de largura indicados na imagem.

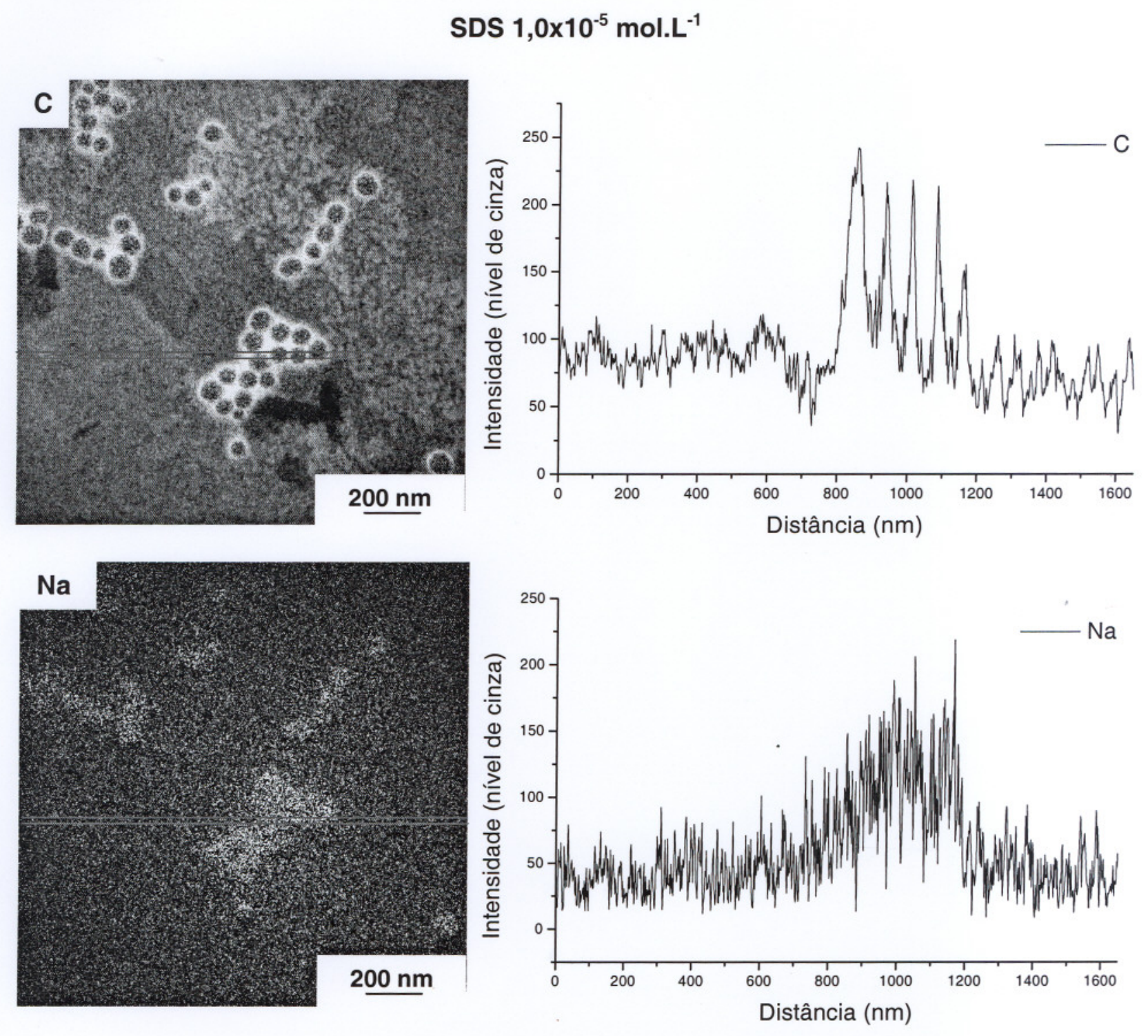

Figura 88. Mapas elementares de carbono e sódio obtidos na mesma área da amostra da Figura 87. Os gráficos mostram as intensidades dos níveis de cinza dos perfis com $25 \mathrm{~nm}$ de largura indicados nas imagens. 


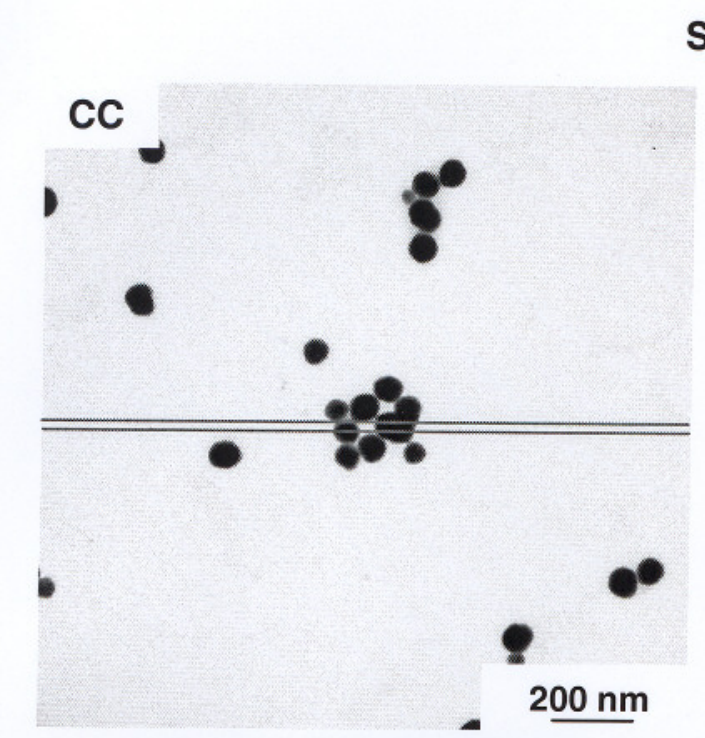

SDS $1,0 \times 10^{-3} \mathrm{~mol}^{-L^{-1}}$
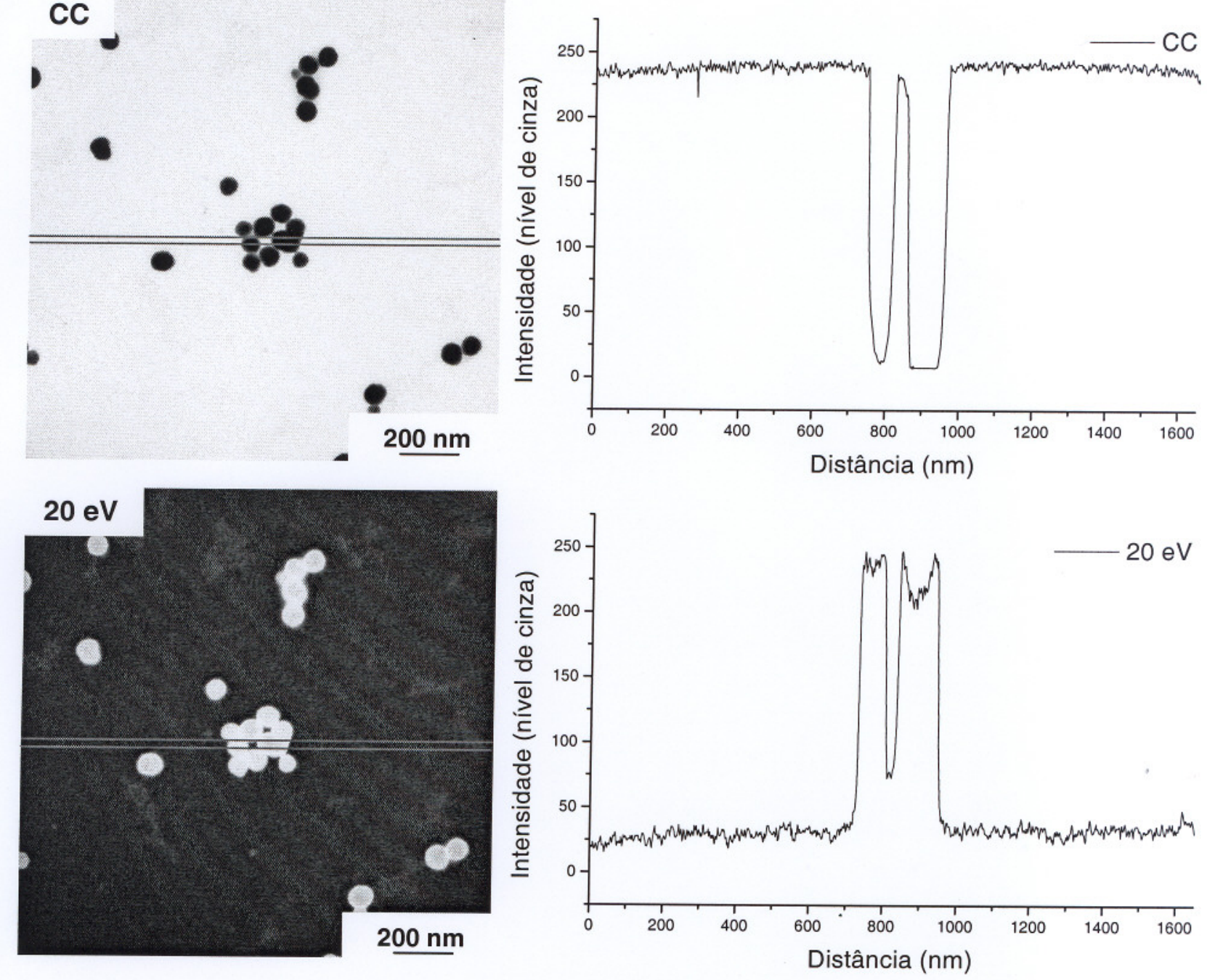

Figura 89. Imagens de campo claro $(C C)$ e de perda de energia $(\Delta E=20 \mathrm{eV})$ na região de baixa perda, de uma mesma área de uma amostra das partículas de sílica preparada a partir da dispersão $D$, após a diluição em SDS $1,0 \times 10^{-3} \mathrm{~mol}^{-L^{-1}}$ seguida de nova diluição em água. Os gráficos mostram as intensidades dos níveis de cinza dos perfis com $25 \mathrm{~nm}$ de largura indicados na imagem. 
SDS $1,0 \times 10^{-3} \mathrm{~mol}^{-L^{-1}}$
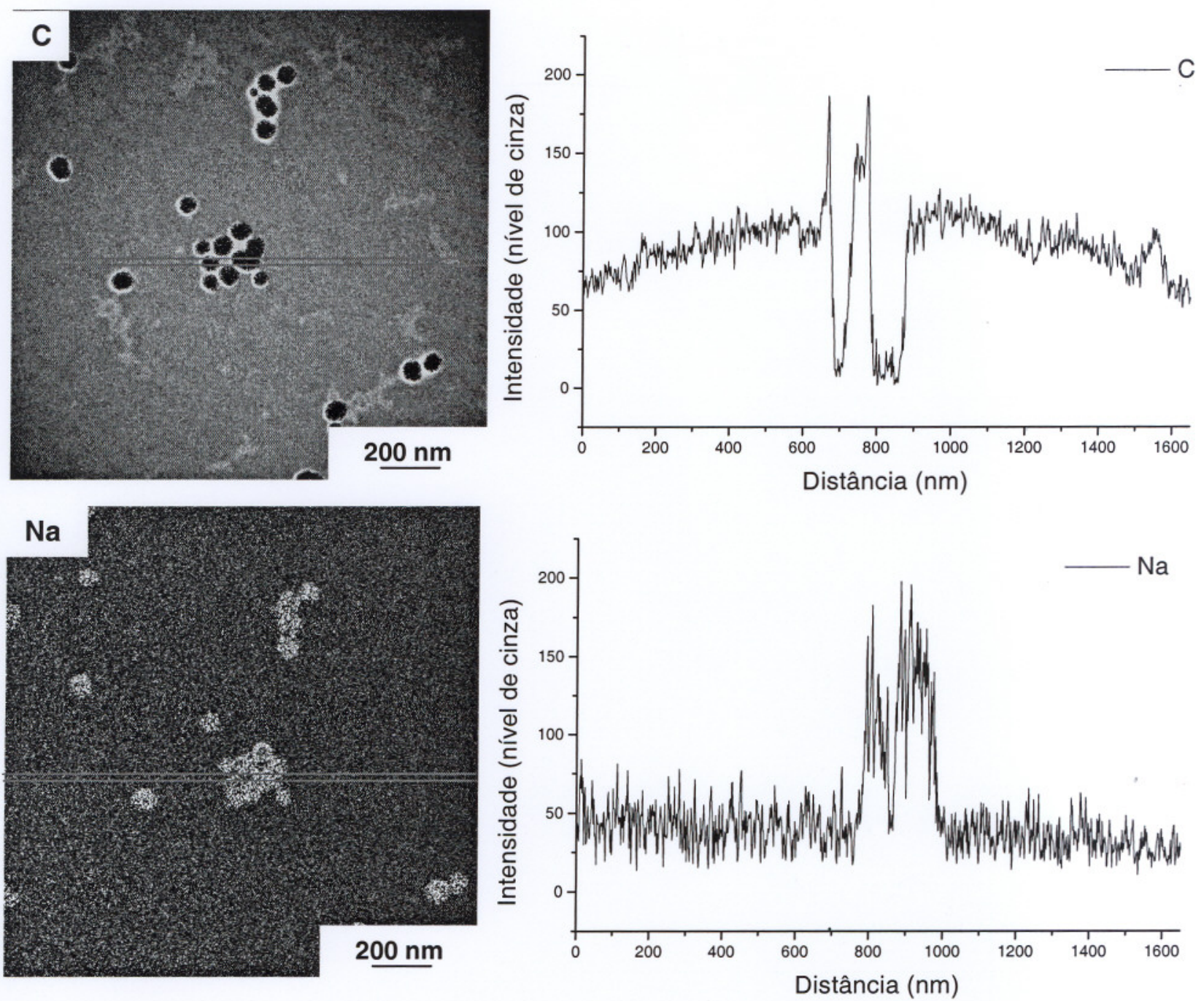

Figura 90. Mapas elementares de carbono e sódio obtidos na mesma área da amostra da Figura 89. Os gráficos mostram as intensidades dos níveis de cinza dos perfis com $25 \mathrm{~nm}$ de largura indicados nas imagens. 


\section{SDS $1,0 \times 10^{-1} \mathrm{~mol}^{-L^{-1}}$}
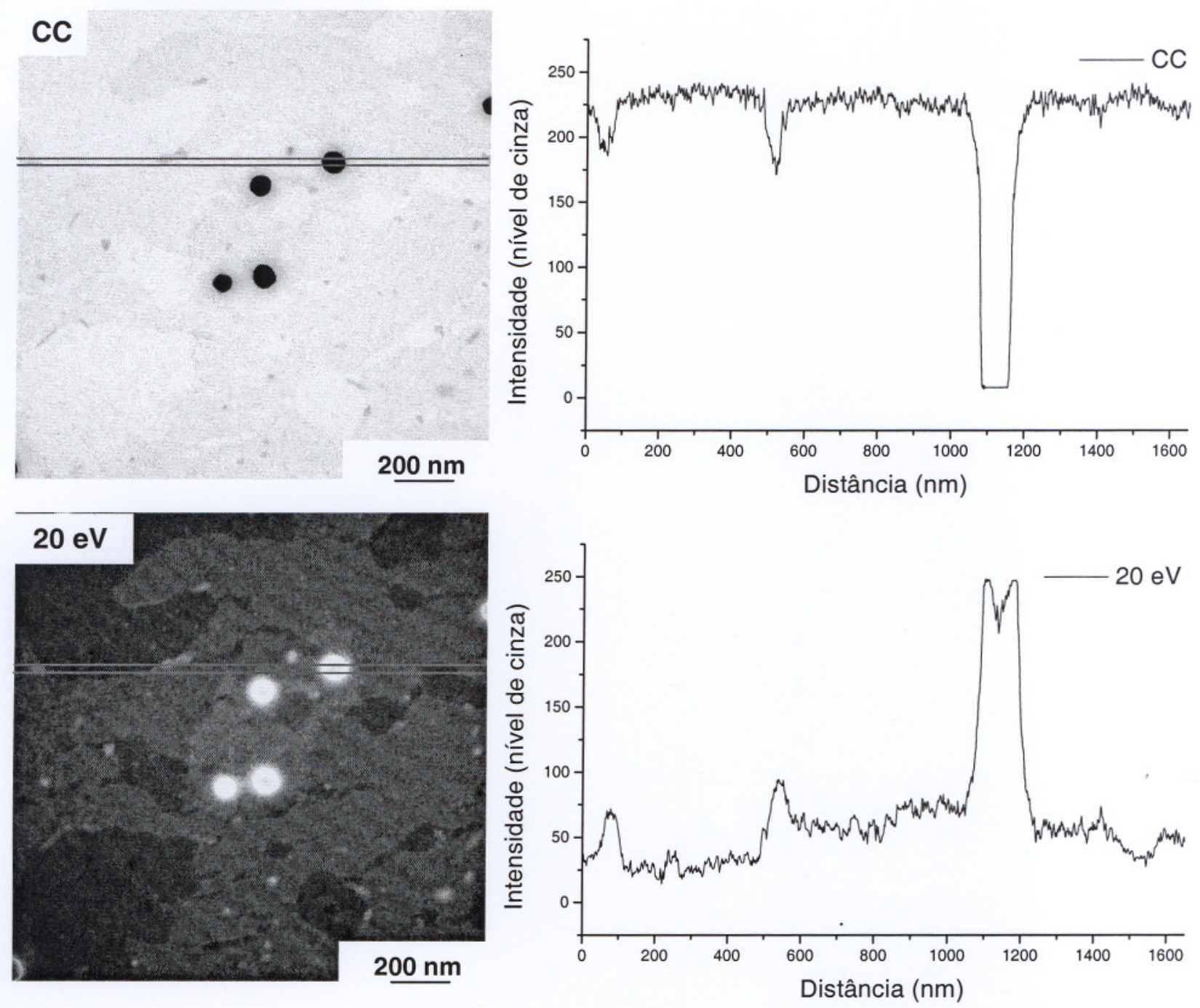

Figura 91. Imagens de campo claro $(C C)$ e de perda de energia $(\Delta E=20 \mathrm{eV})$ na região de baixa perda, de uma mesma área de uma amostra das partículas de sílica preparada a partir da dispersão $\mathrm{D}$, após a diluição em SDS $1,0 \times 10^{-1} \mathrm{~mol}^{-\mathrm{L}^{-1}}$ seguida de nova diluição em água. Os gráficos mostram as intensidades dos níveis de cinza dos perfis com $25 \mathrm{~nm}$ de largura indicados na imagem. 


\section{SDS $1,0 \times 10^{-1} \mathrm{~mol}^{-L^{-1}}$}
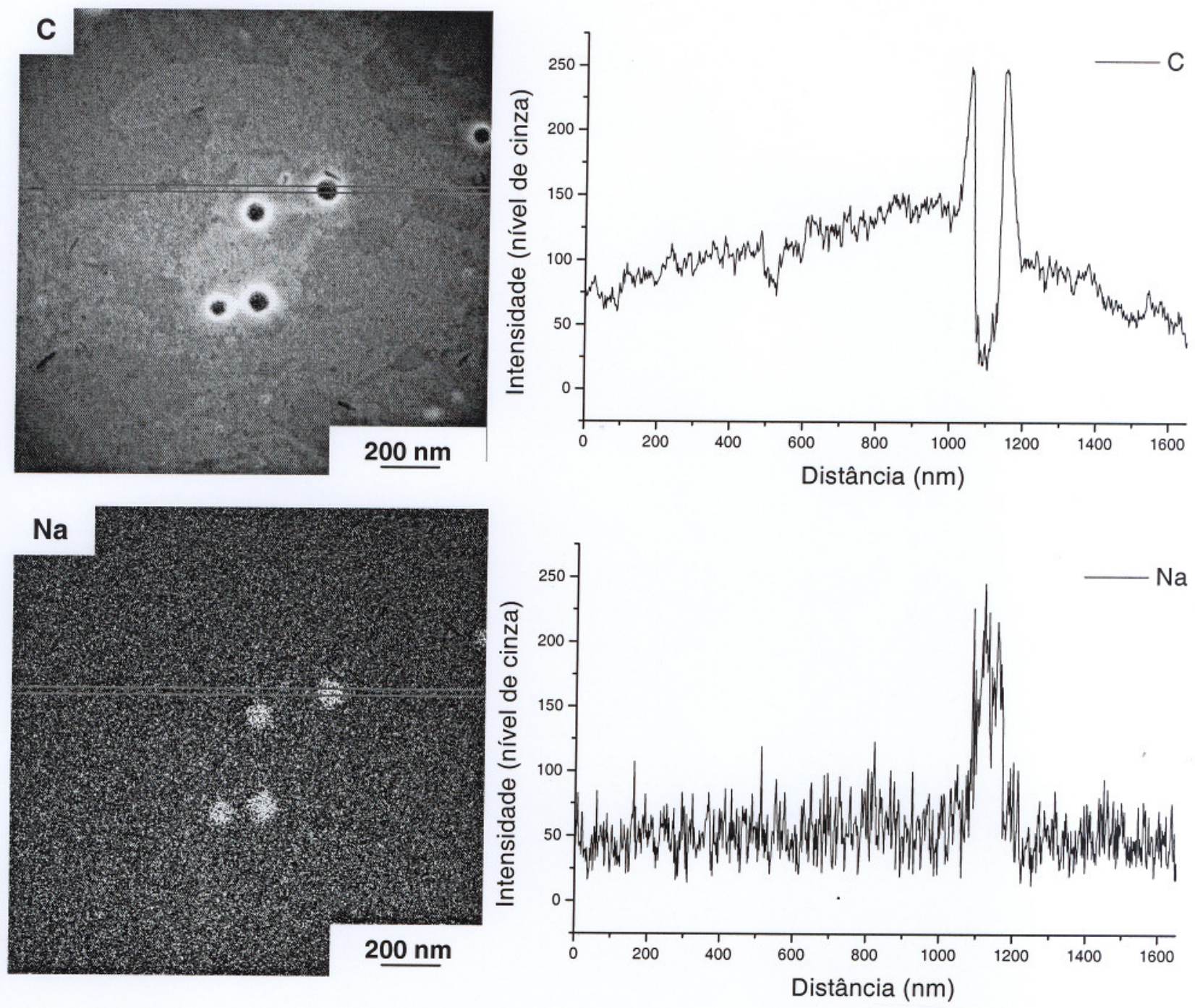

Figura 92. Mapas elementares de carbono e sódio obtidos na mesma área da amostra da Figura 91. Os gráficos mostram as intensidades dos níveis de cinza dos perfis com $25 \mathrm{~nm}$ de largura indicados nas imagens. 
A inversão do contraste entre as imagens de campo claro e de perda de energia das Figuras 87, 89, e 91 é suficiente para concluirmos que não há efeito importante de espalhamento múltiplo para perdas de energia de $20 \mathrm{eV}$. Nas imagens de perda de energia, o contraste entre a casca e o centro das partículas aumentou com o aumento da concentração de SDS.

Os mapas elementares de carbono das Figuras 88,90 e 92 mostram um anel brilhante ao redor das partículas de sílica, indicando uma maior concentração de carbono na superfície das partículas. Estes anéis são mais espessos e intensos na amostra preparada com maior concentração de SDS (Figura 92). Entretanto, as espessuras dos anéis não são uniformes ao redor das partículas. Estes anéis são atribuídos às moléculas de $\mathrm{CH}_{3}\left(\mathrm{CH}_{2}\right)_{11} \mathrm{SO}_{4}{ }^{\circ}$ adsorvidas. Também no substrato destas figuras são verificadas regiões mais brilhantes. Estas regiōes também apresentam maior brilho nas amostras preparadas com maior concentração de SDS.

Os mapas de sódio mostram que $\circ \mathrm{Na}^{+}$está presente no interior das partículas de sílica, distribuído de forma heterogênea, e sua concentração aumenta com o aumento da concentração de SDS. No substrato, a presença de $\mathrm{Na}^{+}$é pequena e a distribuição é bastante heterogênea e por toda a superfície. 
4.4.2. Adsorção de CTAB - As Figuras 93 e 94 mostram as imagens de campo claro de submonocamadas de partículas de sílica da dispersão $D$, obtidas secando sem adição de adsorbatos, e com a adição de diferentes concentrações de CTAB $\left(1,0 \times 10^{-5} \mathrm{~mol} . \mathrm{L}^{-1}, 1,0 \times 10^{-3} \mathrm{~mol} . \mathrm{L}^{-1}\right.$ e $\left.1,0 \times 10^{-1} \mathrm{~mol}^{-L^{-1}}\right)$, seguida de nova diluição em água .
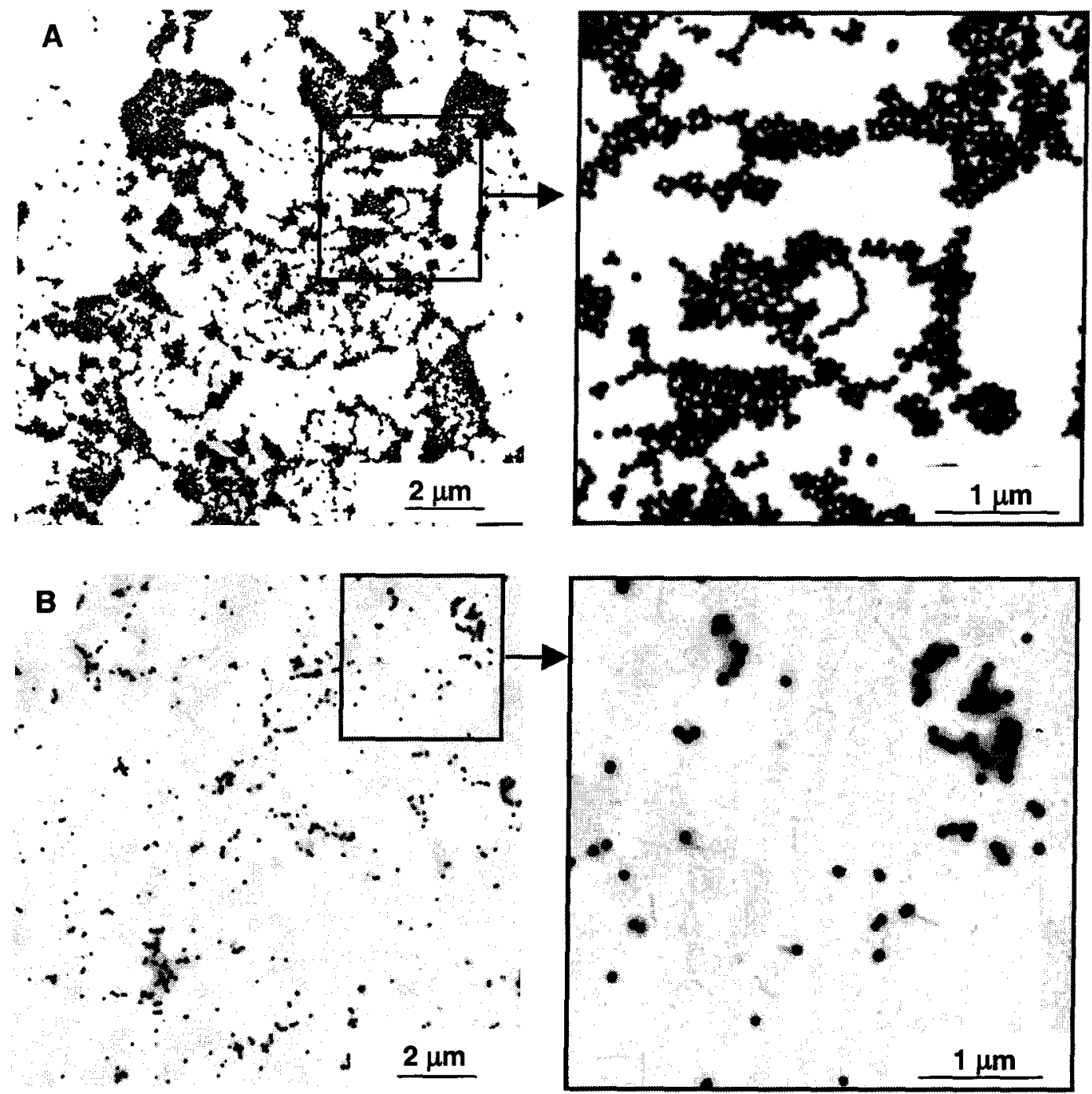

Figura 93. Imagens de campo claro de partículas de sílica da dispersão $D$, obtidas secando dispersões preparadas (A) após a diluição em água e $(B)$ após a diluição em CTAB $1,0 \times 10^{-5}$ mol. $L^{-1}$ seguida de nova diluição em água. As imagens da direita mostram as ampliações das regiões indicadas. 

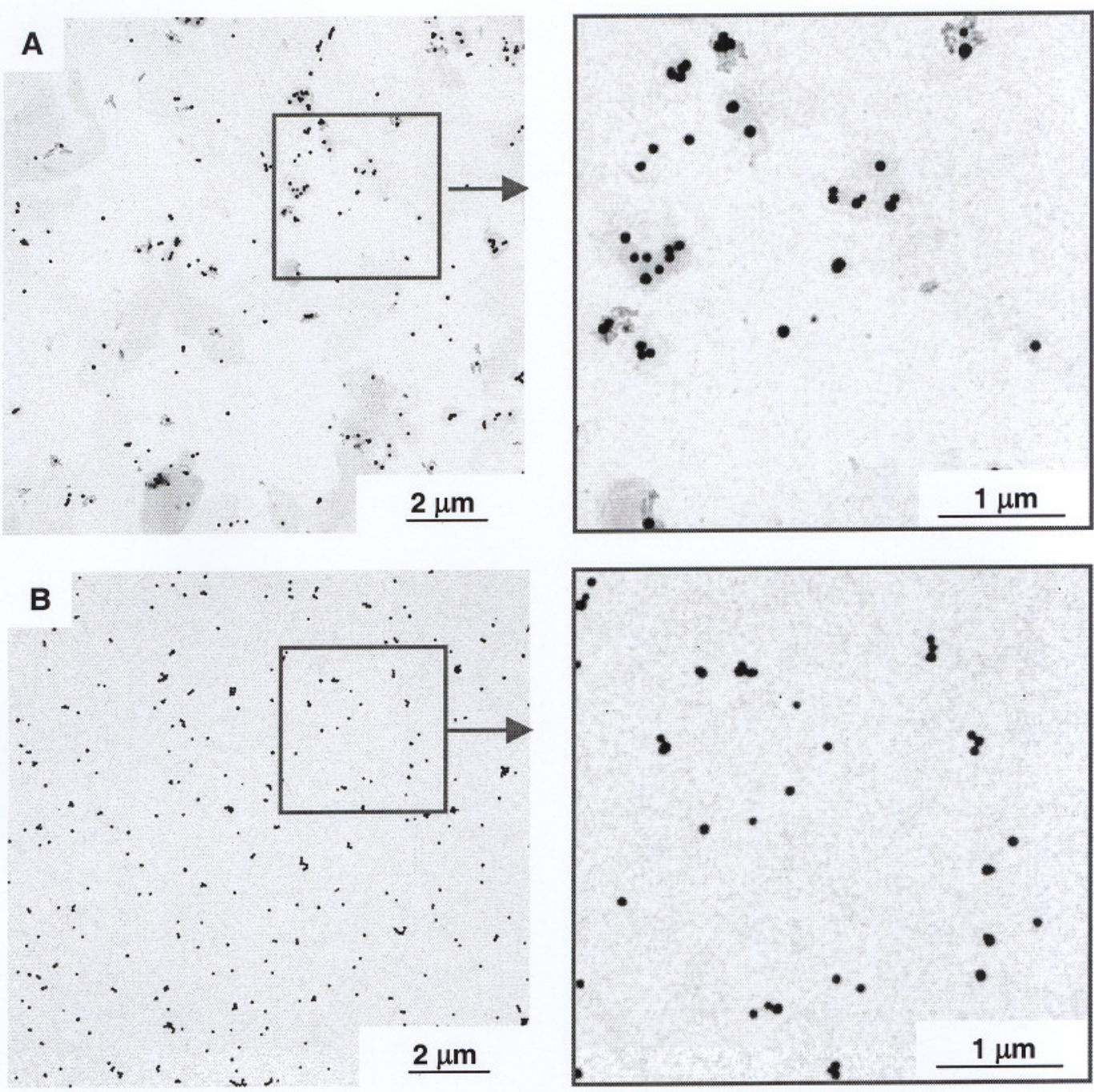

Figura 94. Imagens de campo claro de partículas de sílica da dispersão D, obtidas

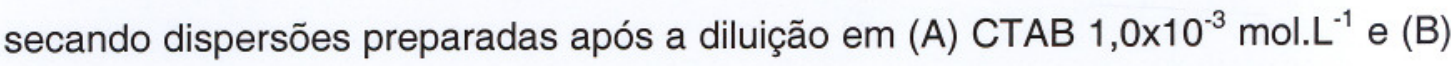
CTAB $1,0 \times 10^{-1}$ mol. $L^{-1}$, seguida de uma nova diluição em água. As imagens da direita mostram as ampliações das regiões indicadas.

Sem adição de CTAB (Figura 93A) as partículas se depositaram como agregados bidimensionais descontínuos e com diferentes quantidades de partículas. Mudanças significativas no ordenamento das partículas foram observadas durante o processo de secagem. Mesmo preparadas na presença de CTAB $1,0 \times 10^{-5}$ mol.L-1 (Figura 93B) os agregados de partículas dissociaram-se em agregados menores e partículas isoladas. Com o aumento da concentração do surfactante é observado uma maior dissociação dos agregados (Figura 94A e 94B). 
As Figuras 95, 97 e 99 mostram uma sequência de imagens de campo claro e perda de energia ( $\Delta \mathrm{E}=20 \mathrm{eV})$, obtidas com maior resolução, das amostras secas após a diluição em diferentes concentrações de CTAB, seguida de nova diluição em água. Para analisar a adsorção do $\mathrm{CTAB}$, nas mesmas regiões foram realizados mapeamentos elementares de carbono e bromo para a localização das moléculas de $\mathrm{CH}_{3}\left(\mathrm{CH}_{2}\right)_{15} \mathrm{~N}\left(\mathrm{CH}_{3}\right)_{3}{ }^{+}$, e do contra-íon $\mathrm{Br}^{-}$(Figuras 96, 98 e 100), respectivamente.
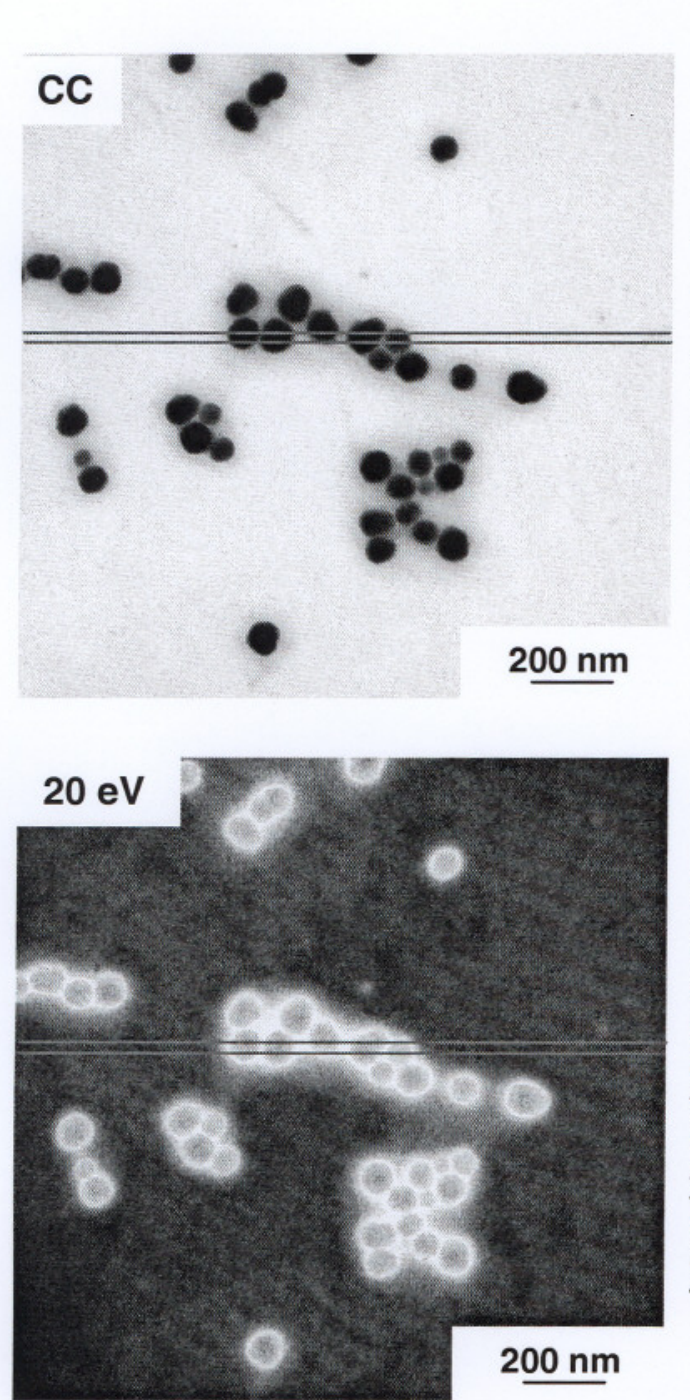

\section{CTAB $1,0 \times 10^{-5} \mathrm{~mol}^{-\mathrm{L}^{-1}}$}


Figura 95. Imagens de campo claro $(\mathrm{CC})$ e de perda de energia $(\Delta \mathrm{E}=20 \mathrm{eV})$, de uma mesma área de uma amostra das partículas de sílica preparada a partir da dispersão $D$, após a diluição em CTAB $1,0 \times 10^{-5} \mathrm{~mol}^{-L^{-1}}$ seguida de nova diluição em água. Os gráficos mostram as intensidades dos níveis de cinza dos perfis com 25 $\mathrm{nm}$ de largura indicados na imagem. 
CTAB $1,0 \times 10^{-5} \mathrm{~mol}^{-1} \mathrm{~L}^{-1}$
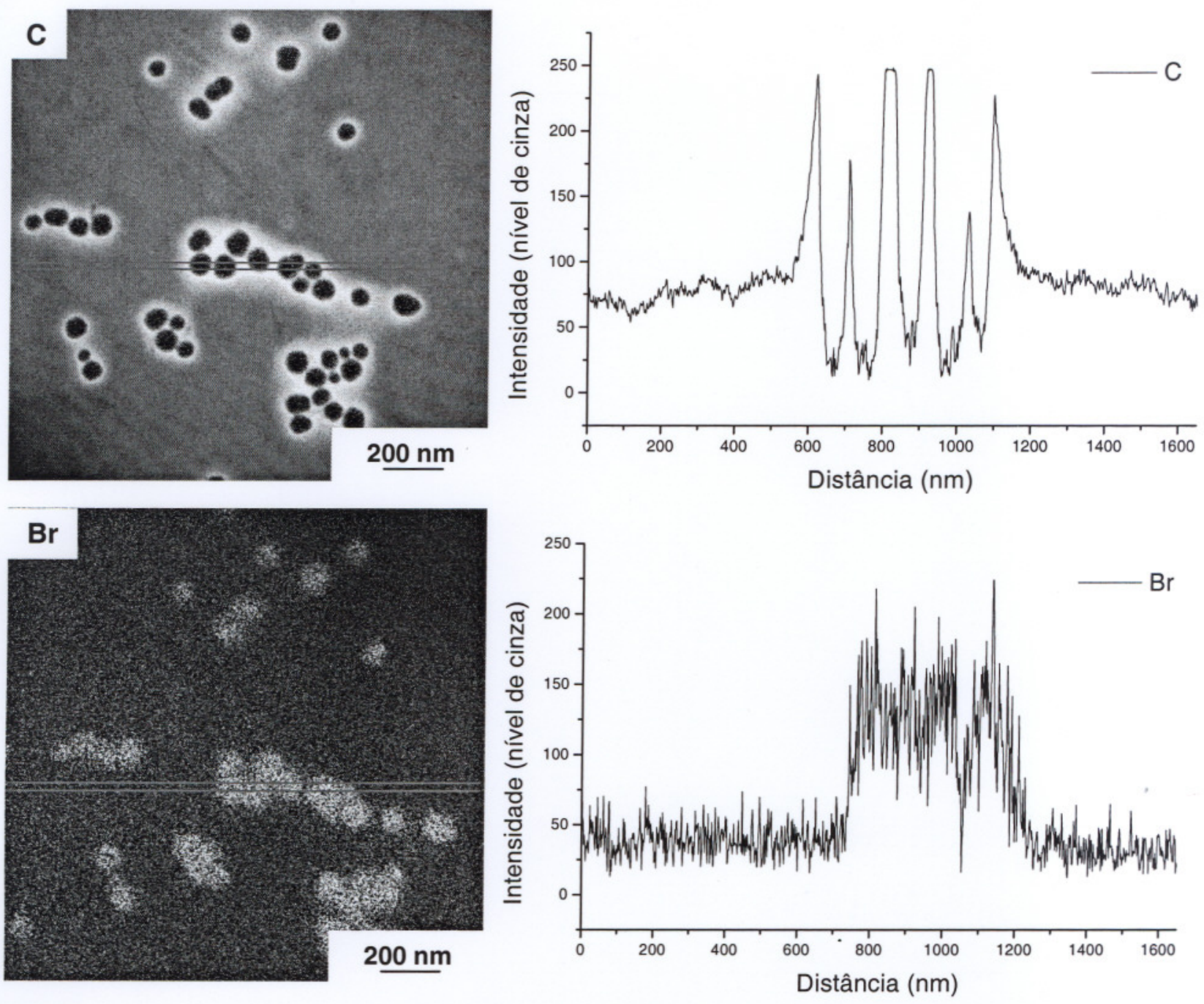

Figura 96. Mapas elementares de carbono e bromo obtidos na mesma área da amostra da Figura 95. Os gráficos mostram as intensidades dos níveis de cinza dos perfis com $25 \mathrm{~nm}$ de largura indicados nas imagens. 


\section{CTAB $1,0 \times 10^{-3} \mathrm{~mol}^{-\mathrm{L}^{-1}}$}
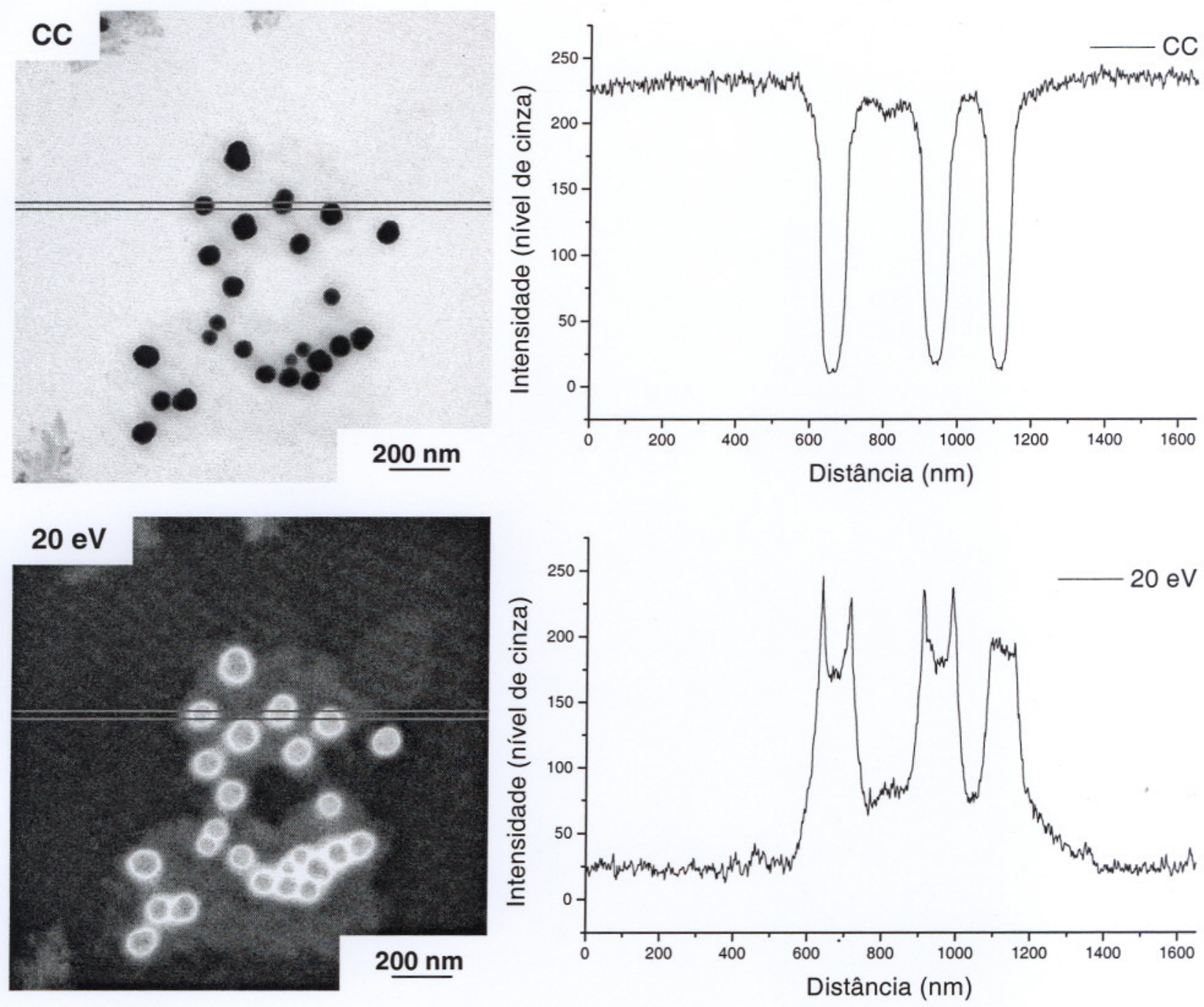

Figura 97. Imagens de campo claro $(\mathrm{CC})$ e de perda de energia $(\Delta \mathrm{E}=20 \mathrm{eV})$ na região de baixa perda, de uma mesma área de uma amostra das partículas de sílica preparada a partir da dispersão $D$, após a diluição em CTAB $1,0 \times 10^{-3} \mathrm{~mol}^{-\mathrm{L}^{-1}}$ seguida de nova diluição em água. Os gráficos mostram as intensidades dos níveis de cinza dos perfis com $25 \mathrm{~nm}$ de largura indicados na imagem. 


\section{CTAB $1,0 \times 10^{-3} \mathrm{~mol}^{-\mathrm{L}^{-1}}$}
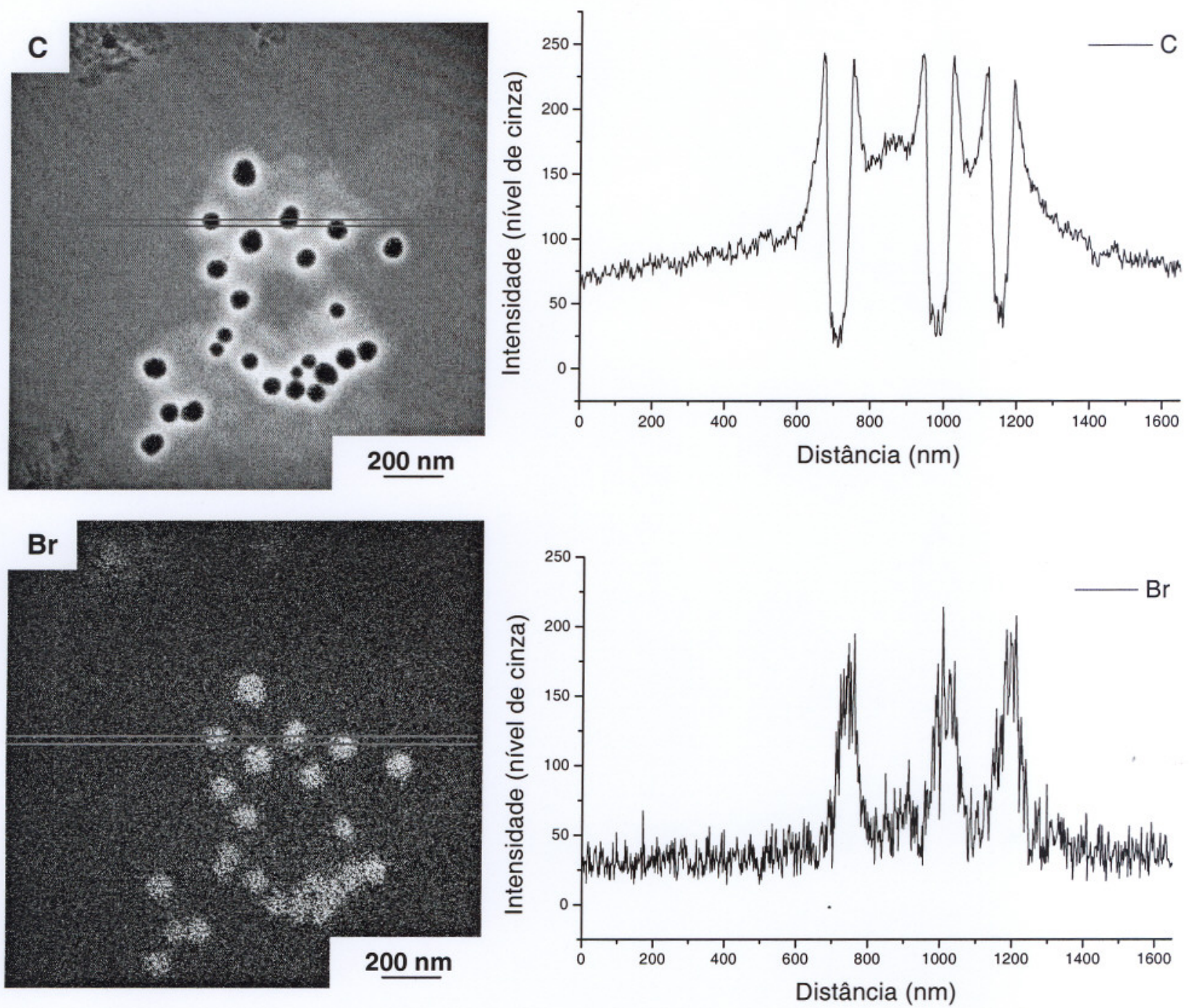

Figura 98. Mapas elementares de carbono e bromo obtidos na mesma área da amostra da Figura 97. Os gráficos mostram as intensidades dos níveis de cinza dos perfis com $25 \mathrm{~nm}$ de largura indicados nas imagens. 


\section{CTAB $1,0 \times 10^{-1} \mathrm{~mol}^{-\mathrm{L}^{-1}}$}
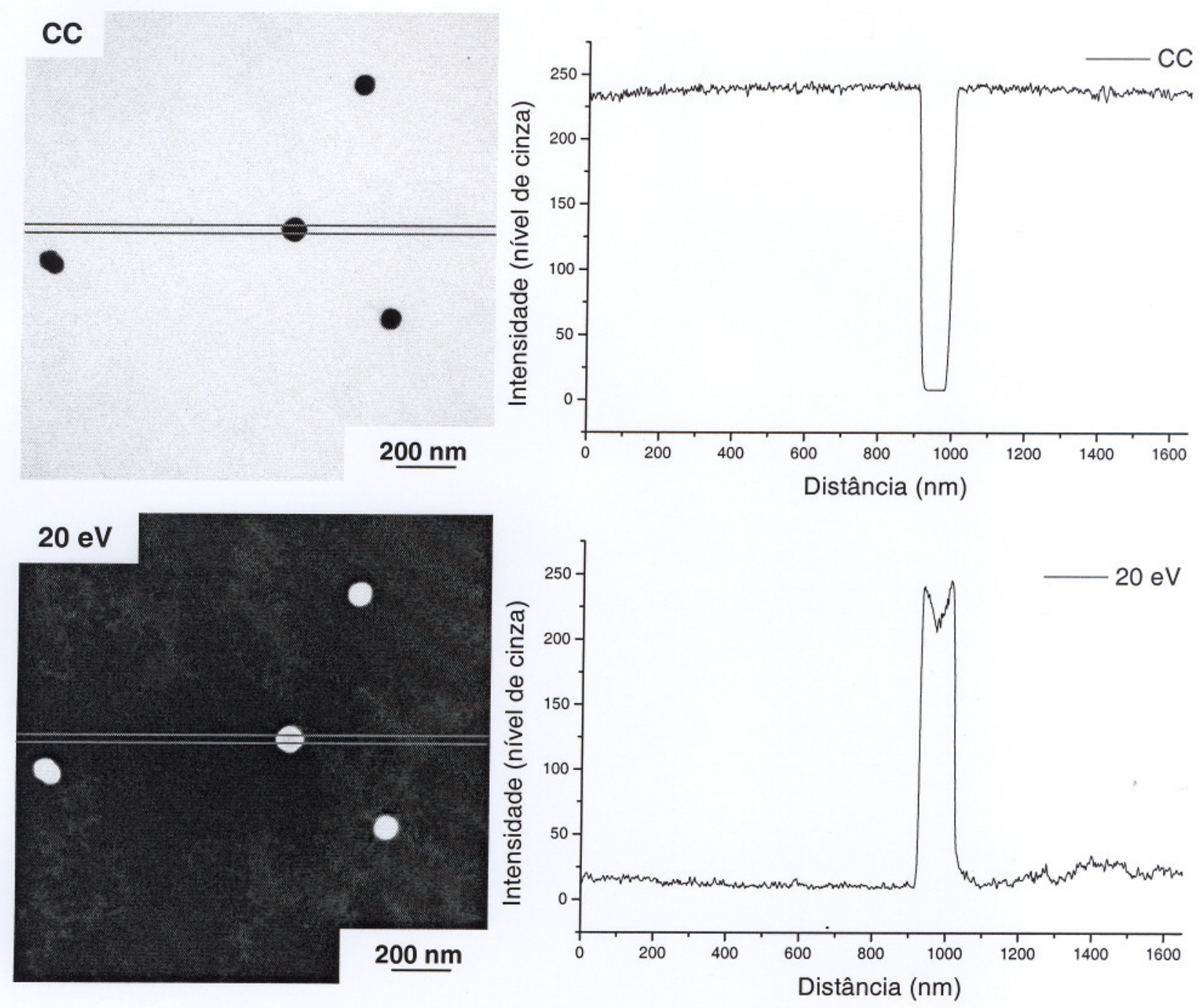

Figura 99. Imagens de campo claro $(C C)$ e de perda de energia $(\Delta E=20 \mathrm{eV})$ na região de baixa perda, de uma mesma área de uma amostra das partículas de sílica preparada a partir da dispersão $\mathrm{D}$, após a diluição em CTAB $1,0 \times 10^{-1} \mathrm{~mol} \cdot \mathrm{L}^{-1}$ seguida de nova diluição em água. Os gráficos mostram as intensidades dos níveis de cinza dos perfis com $25 \mathrm{~nm}$ de largura indicados na imagem. 


\section{CTAB $1,0 \times 10^{-1} \mathrm{~mol}^{-\mathrm{L}^{-1}}$}
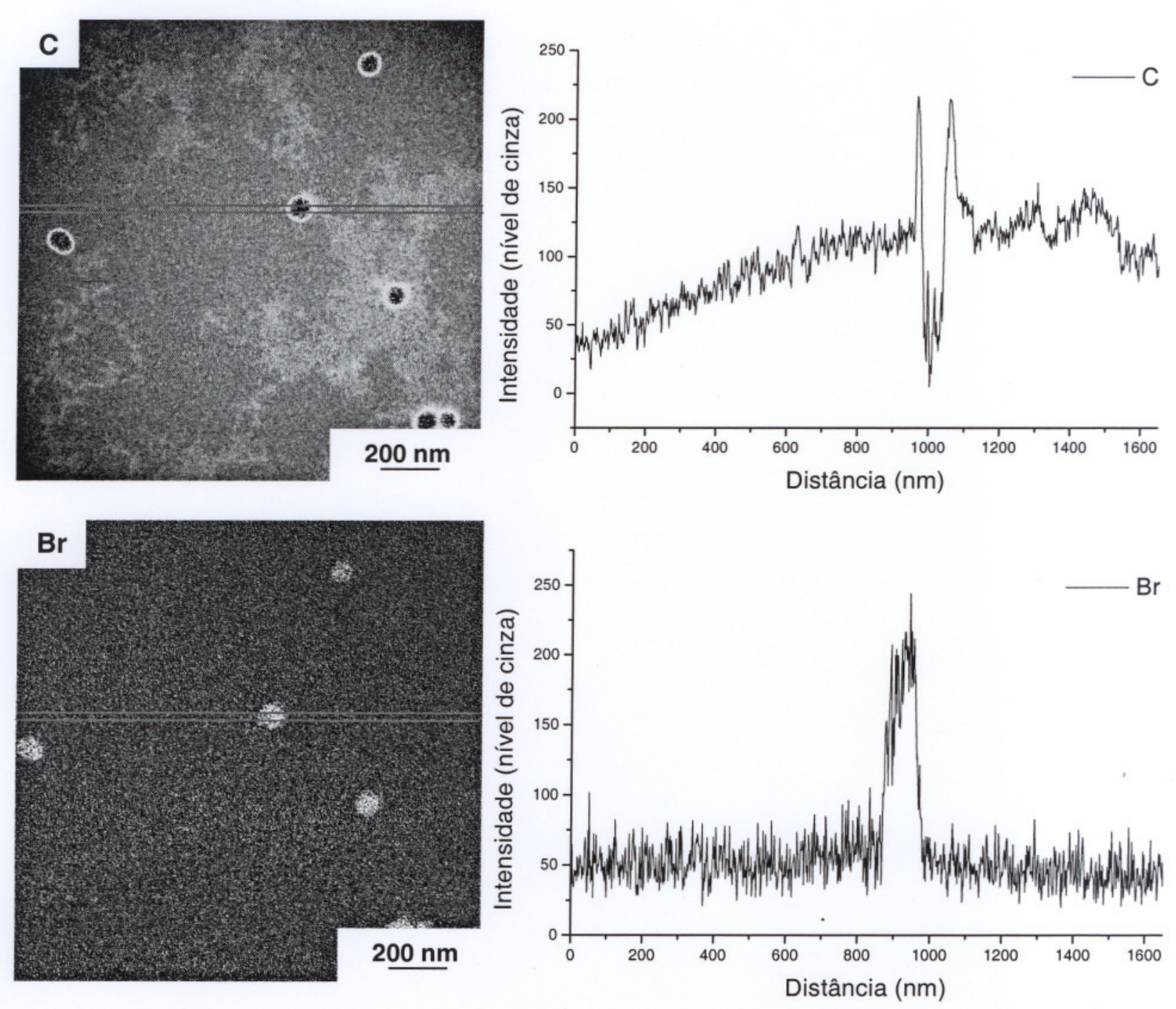

Figura 100. Mapas elementares de carbono e bromo obtidos na mesma área da amostra da Figura 99. Os gráficos mostram as intensidades dos níveis de cinza dos perfis com $25 \mathrm{~nm}$ de largura indicados nas imagens. 
As imagens de campo claro das Figuras 95 e 98 apresentam uma diminuição de sinal ao redor dos agregados de partículas e das partículas isoladas. Este sinal aumenta gradativamente até aproximadamente $75 \mathrm{~nm}$ das partículas, atingindo um valor constante sobre o substrato. As imagens de perda de energia mostram um aumento de sinal na mesma região. Isto indica que existe material depositado sobre o substrato ao redor das partículas, até aproximadamente $75 \mathrm{~nm}$ da superfície.

Os mapas elementares de carbono das Figuras 96 e 97 mostram um anel brilhante ao redor das partículas, com espessura não uniforme de aproximadamente $75 \mathrm{~nm}$. Estes anéis são atribuídos às moléculas de $\mathrm{CH}_{3}\left(\mathrm{CH}_{2}\right)_{15} \mathrm{~N}\left(\mathrm{CH}_{3}\right)_{3}{ }^{+}$adsorvidas. Na Figura 100 o substrato também apresenta regiões irregulares mais brilhantes.

Os mapas elementares de bromo mostram que o $\mathrm{Br}^{-}$está presente no interior das partículas de sílica, distribuídos de forma heterogênea, e sua concentração aumenta com a concentração do CTAB. No substrato a presença de $\mathrm{Br}^{-}$é pequena, e a distribuição é bastante heterogênea, por toda a superfície. 
4.4.3. Adsorção de RENEX 300 - As Figuras 101 e 102 mostram as imagens de campo claro de submonocamadas de partículas de sílica da dispersão D, obtidas secando sem adição de adsorbatos, e com a adição de diferentes concentrações de $\operatorname{RENEX}\left(1,0 \times 10^{-5} \mathrm{~mol} . \mathrm{L}^{-1}, 1,0 \times 10^{-3} \mathrm{~mol}^{-L^{-1}}\right.$ e $1,0 \times 10^{-1}$ mol.L $\left.\mathrm{L}^{-1}\right)$, seguida de nova diluição em água .


Figura 101. Imagens de campo claro de partículas de sílica da dispersão D, obtidas secando dispersões preparadas (A) após a diluição em água, e (B) após a diluição

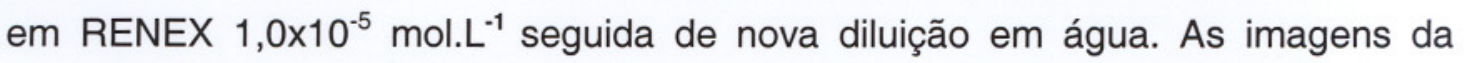
direita mostram as ampliações das regiões indicadas. 


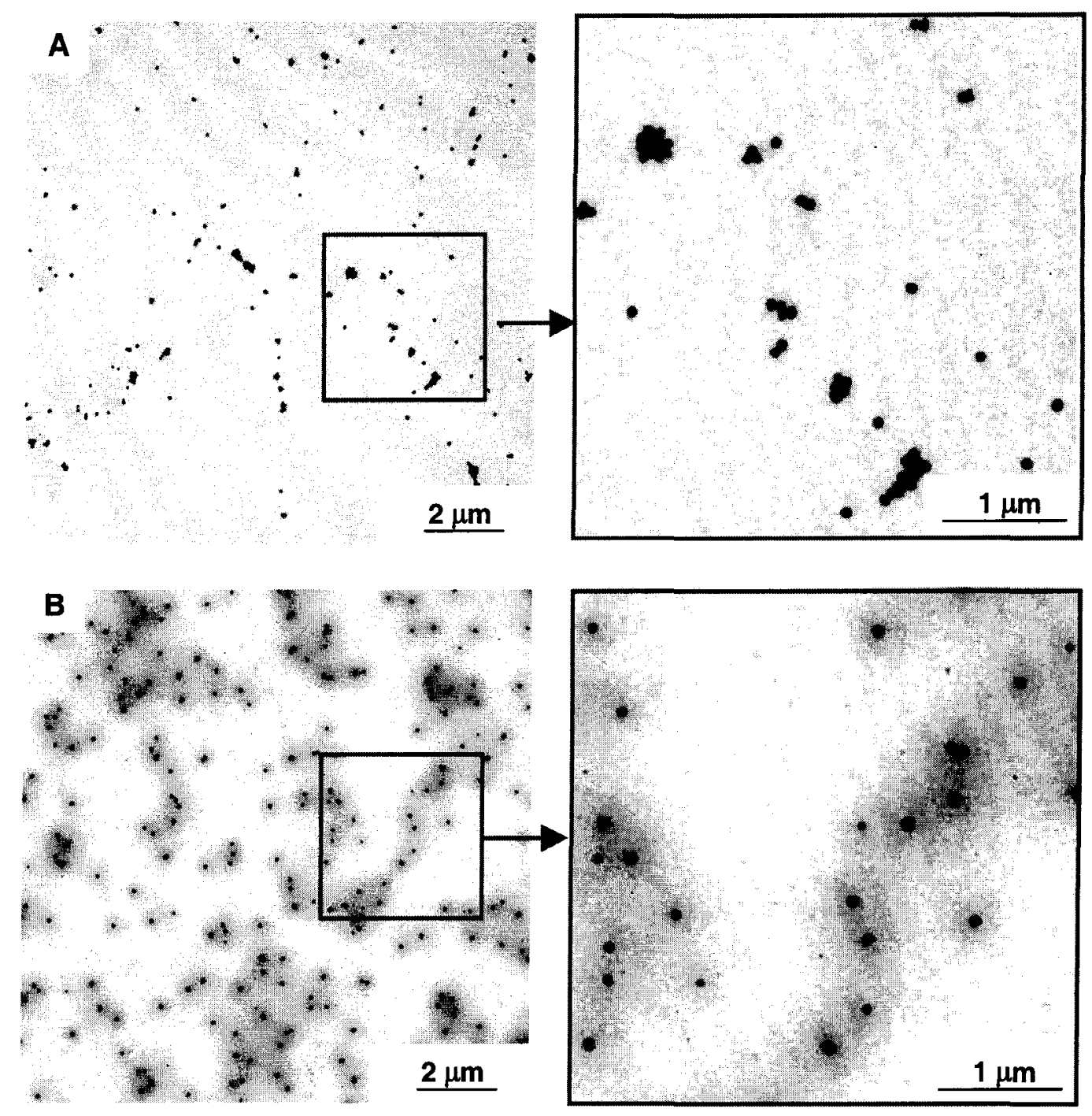

Figura 102. Imagens de campo claro de partículas de sílica da dispersão $D$, obtidas secando dispersões após a diluição em (A) CTAB $1,0 \times 10^{-3} \mathrm{~mol}^{-L^{-1}}$ e (B) RENEX $1,0 \times 10^{-1}$ mol. $L^{-1}$, seguida de uma nova diluição em água. As imagens da direita mostram as ampliações das regiões indicadas.

Baixas concentrações de RENEX (Figura 101B) provocam mudanças significativas na dissociação dos agregados de partículas. Esta dissociação aumenta com o aumento da concentração do RENEX (Figura 102A e 102B).

Para a localização das moléculas de $\mathrm{HO}\left(\mathrm{C}_{2} \mathrm{H}_{4} \mathrm{O}\right)_{30} \quad \mathrm{C}_{15} \mathrm{H}_{23} \mathrm{O}$, foram realizados mapeamentos elementares de carbono: as Figuras 103, 104 e 105 mostram as imagens de campo claro, perda de energia $(\Delta \mathrm{E}=20 \mathrm{eV})$ e mapas elementares de carbono de uma mesma região de cada amostra. 

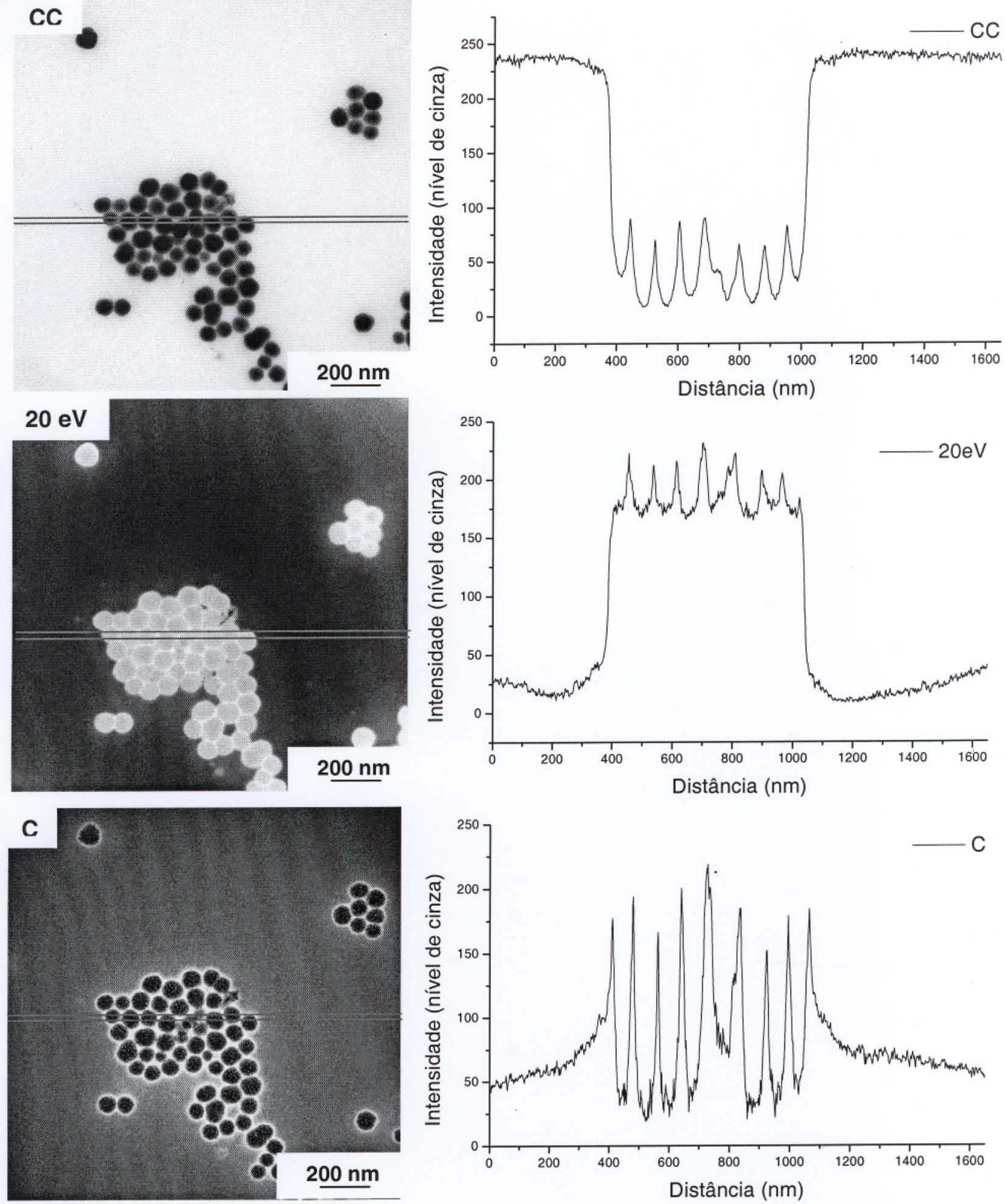

Figura 103. Imagens de campo claro (CC), perda de energia $(\Delta E=20 \mathrm{eV})$ e mapa elementar de carbono (C) de uma mesma área de uma amostra das partículas de sílica preparada a partir da dispersão $D$, após a diluição em RENEX $1,0 \times 10^{-5} \mathrm{~mol}^{-L^{-1}}$ seguida de nova diluição em água. Os gráficos mostram as intensidades dos níveis de cinza dos perfis com $25 \mathrm{~nm}$ de largura indicados nas imagens. 

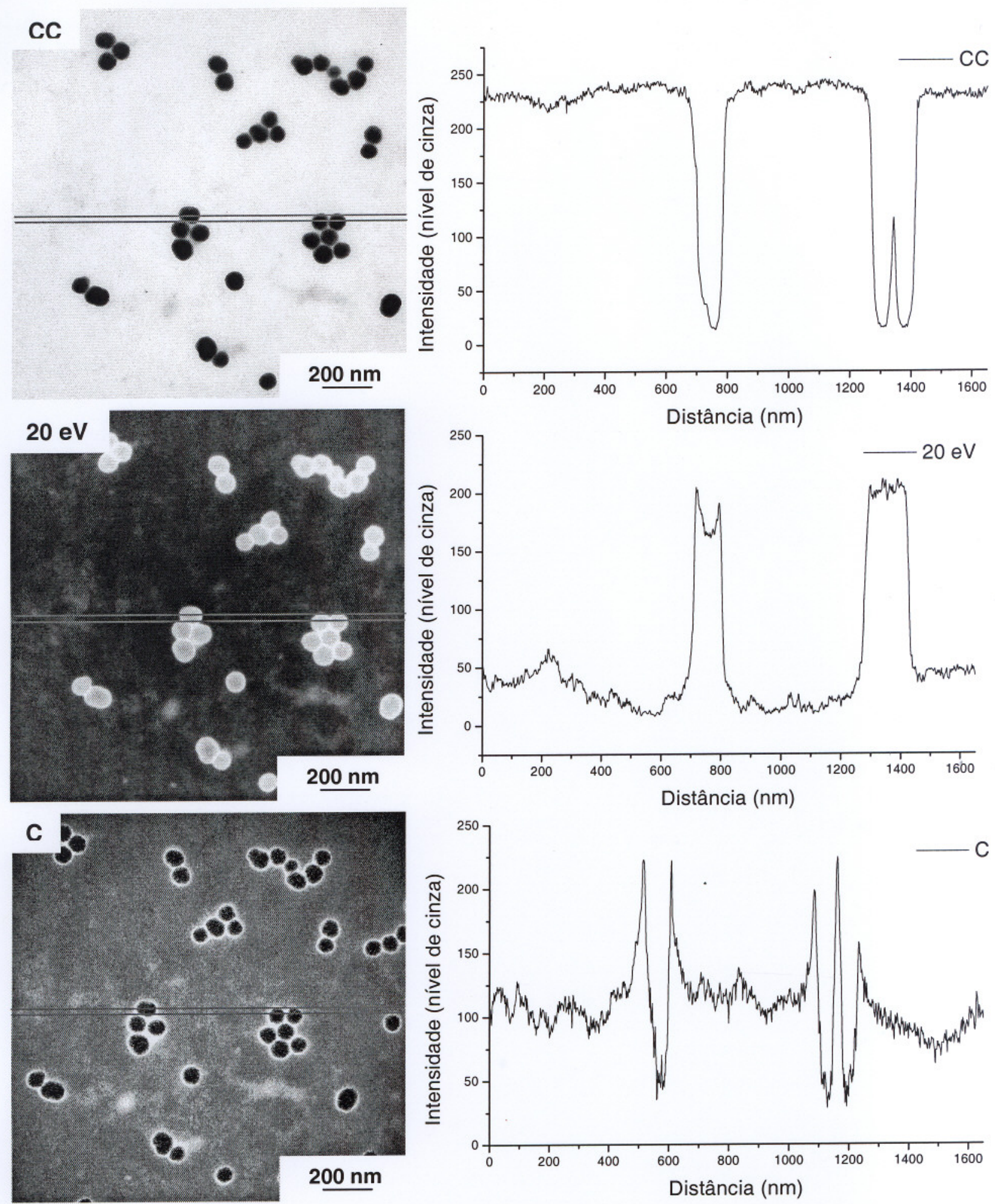

Figura 104. Imagens de campo claro (CC), perda de energia $(\Delta E=20 \mathrm{eV})$ e mapa elementar de carbono (C) de uma mesma área de uma amostra das partículas de

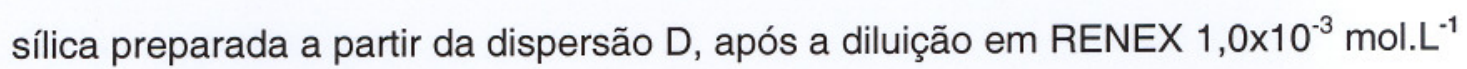
seguida de nova diluição em água. Os gráficos mostram as intensidades dos níveis de cinza dos perfis com $25 \mathrm{~nm}$ de largura indicados nas imagens. 

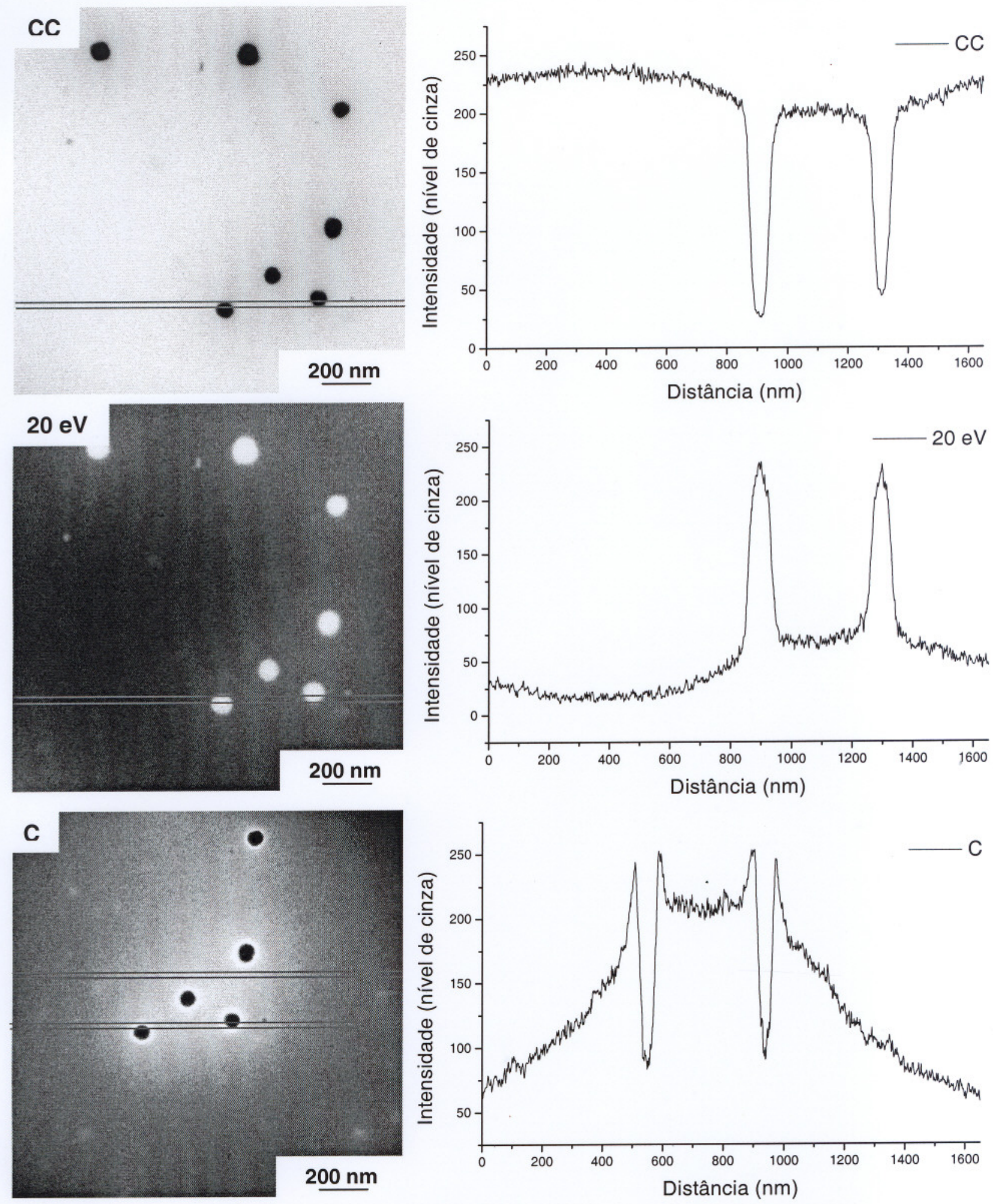

Figura 105. Imagens de campo claro (CC), perda de energia $(\Delta \mathrm{E}=20 \mathrm{eV})$ e mapa elementar de carbono $(C)$ de uma mesma área de uma amostra das partículas de sílica preparada a partir da dispersão $D$, após a diluição em RENEX $1,0 \times 10^{-1} \mathrm{~mol}^{-L^{-1}}$ seguida de nova diluição em água. Os gráficos mostram as intensidades dos níveis de cinza dos perfis com $25 \mathrm{~nm}$ de largura indicados nas imagens. 
As imagens de campo claro das Figuras 103 a 105 mostram uma diminuição de sinal ao redor dos agregados de partículas e das partículas isoladas, que aumentam gradativamente até atingir um valor constante sobre o substrato. Nas imagens de perda de energia ocorre um aumento de sinal na mesma região, isto indica que existe material depositado ao redor das partículas sobre o substrato. Este acúmulo diminui gradativamente com a distância da superfície das partículas. Nas imagens de baixa perda de energia $(\Delta E=20 \mathrm{eV})$ o contraste da casca para o centro diminui com o aumento da concentração de RENEX, chegando a inverter na Figura 105. O acúmulo de RENEX ao redor das partículas diminui a probabilidade de um elétron sofrer uma única colisão ao atravessar a amostra, o que diminui o sinal na imagem de perda de energia.

Os mapas elementares de carbono mostram um anel brilhante bastante intenso ao redor das partículas de sílica, indicando uma maior concentração de carbono nestas regiões, atribuídas a adsorção de moléculas de $\mathrm{HO}\left(\mathrm{C}_{2} \mathrm{H}_{4} \mathrm{O}\right)_{30} \mathrm{C}_{15} \mathrm{H}_{23} \mathrm{O}$. Estes anéis são mais espessos e intensos para a amostra preparada com maior concentração de RENEX. 


\section{DISCUSSÃO}

5.1. Partículas de sílica - As dispersões de sílica preparadas pelo método de Stöber apresentaram uma excelente estabilidade em meio etanólico: após 18 meses armazenadas nesse meio não apresentaram variações significativas de diâmetros médios. A dispersão $D\left(\phi_{\mathrm{TEM}}=77 \mathrm{~nm}\right)$ foi escolhida para o estudo da adsorção de co-solutos e análise por ESI-TEM. As partículas desta dispersão possuem diâmetro médio maior que as dispersões A, B e C. Assim, podem ser observadas no microscópio sob aumento menor que as partículas pequenas, gerando imagens de boa qualidade. Por outro lado, as partículas da dispersão $E$ possuem diâmetro maior que as partículas da dispersão D. Porém, nestas partículas ocorre espalhamento múltiplo de elétrons, com perda de energia $(\Delta E=$ $20 \mathrm{eV}$ ), em uma escala suficiente para dificultar os procedimentos de análises de imagens de ESI-TEM.

O intumescimento das partículas permite a sorção dos co-solutos. As partículas da dispersão D apresentam um elevado intumescimento: sorção (em volume) de $149 \%$ de água e $121 \%$ de etanol (Tabela 4). Portanto pode haver sorção de espécies de várias dimensões e características de ionicidade e polaridade. A partícula intumescida é um ambiente químico sobre o qual não há praticamente nenhuma informação na literatura. O exame microscópico do material sorvido permite que se conheça o efeito de características estruturais de um soluto sobre a sua sorptividade. 
5.2. Adsorção de $\mathrm{NaCl}$ - As imagens de campo claro das Figuras 63 e 64 mostraram que as partículas de sílica expostas a concentrações maiores de $\mathrm{NaCl}$ $\left(1,0 \times 10^{-5}\right.$ mol. $L^{-1}, 1,0 \times 10^{-3}$ mol. $L^{-1}$ e $0,5 \mathrm{~mol}^{-L^{-1}}$, respectivamente), seguidas de uma nova diluição em água, resultam após a secagem das dispersões na deposição de agregados de partículas mais densos e descontínuos.

A quantificação dos elementos por EELS foi realizada na amostra preparada com maior concentração inicial de $\mathrm{NaCl}\left(0,5 \mathrm{~mol} . \mathrm{L}^{-1}\right)$.

A partir dos resultados apresentados na Tabela 9, podemos verificar que apesar de não apresentarem partículas, as regiões B e C contêm $11 \%$ e $3 \%$ respectivamente da quantidade de Si existente em área identica da região A (Figura 106). Isto evidencia a presença de compostos de Si não-particulados.


Figura 106. (CC) Imagem de campo claro (Figura 71) identificando as regiões A, B e C onde foram obtidos os espectros de perda de energia e (Si) distribuição de Si nestas regiões. 
As quantidades de $\mathrm{Na}$ e $\mathrm{Cl}$ na região $\mathrm{B}$ são $21 \%$ e $23 \%$ da região $\mathrm{A}$, e na região C são $11 \%$ e $12 \%$ da região A respectivamente. Estas quantidades de $\mathrm{Na}$ e Cl nas partículas estão próximas da razão estequiométrica, mostrando que os dois íons são sorvidos em quantidades próximas (Figura 107). A razão $\mathrm{Na} / \mathrm{Cl}$ é $14 \%$ maior na região $A$ que na região $C$, e $3 \%$ maior na região $B$ em que na região $C . O$ excesso de $\mathrm{Na}^{+}$nas partículas, e na região que contém maior quantidade dos compostos de Si solúveis, pode ser entendido considerando que as partículas de sílica e os ácidos silícicos possuem um potencial zeta negativo.

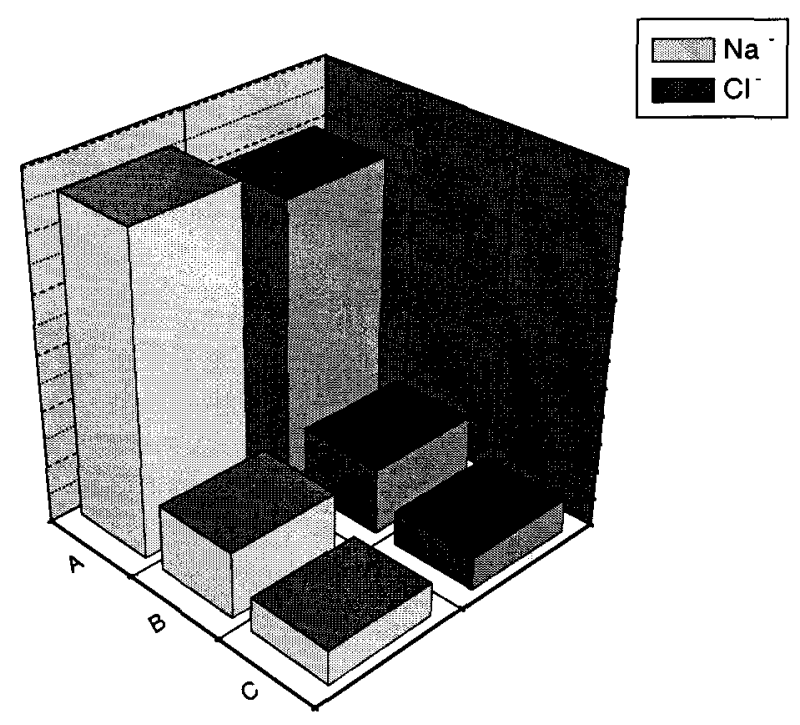

Figura 107. Distribuição de $\mathrm{Na}^{+}$e $\mathrm{Cl}^{-}$nas regiões $\mathrm{A}, \mathrm{B}$ e $\mathrm{C}$, considerando uma proporção com razão estequiométrica na região $C$. 
O oxigênio está presente tanto na sílica como na água de hidratação e no substrato de parlódio (que contém $\mathrm{O}$ ) recoberto com um filme de $\mathrm{C}$ (que pode estar em parte oxidado) (Figura 108). Subtraindo a quantidade de O presente no substrato, a variação na proporção entre $\mathrm{O}, \mathrm{Na}$ e $\mathrm{Cl}$ nas regiões $\mathrm{B}$ e $\mathrm{C}$ é menor que $4 \%$. Porém, a proporção destes elementos em relação ao silício é cerca de $78 \%$ maior na região C que na região $B$, e os valores absolutos das quantidades decrescem a metade. $A$ relação O/Si é 5,2 vezes maior na região $B$ do que na região $A$, e 9,2 vezes maior na região $\mathrm{C}$ do que na região $\mathrm{A}$. Isto indica que tanto $\circ \mathrm{Si}$ como $\circ \mathrm{Na}$ e $\mathrm{Cl}$ estão mais hidratados na região $C$ do que na região $B$, e que também estão mais hidratados em $B$ que na região $A$.

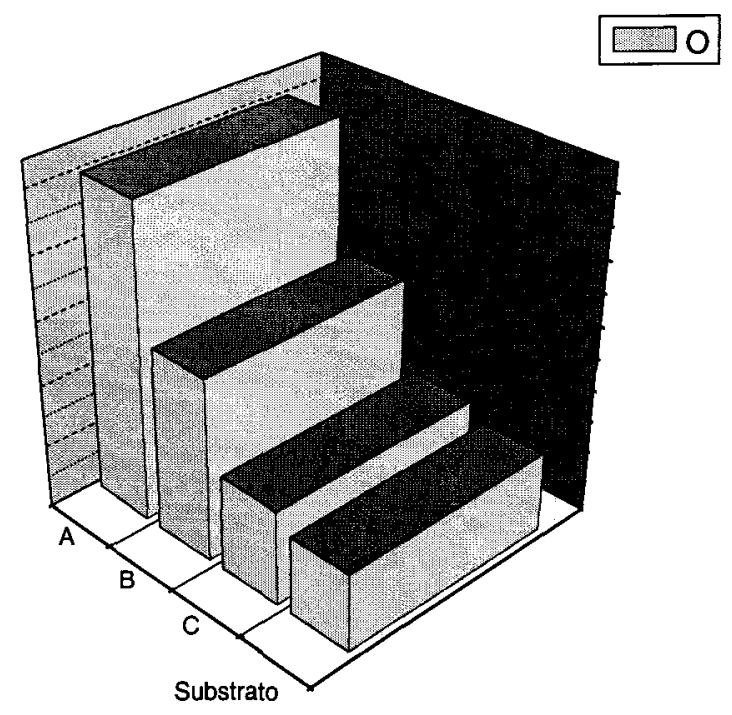

Figura 108. Distribuição de O nas regiões $A, B, C$ e no substrato. 
5.3. Adsorção de PNIPAM - As Figuras 78 e 79 mostraram que a organização das partículas de sílica sob secagem é significativamente modificada após a adição de polímeros. Foi observado um aumento na dispersão das partículas secas, com o aumento da concentração do polímero. Os mapas elementares de carbono da Figura 80 mostram que este efeito é diretamente relacionado com as camadas de polímero adsorvidas nas partículas de sílica.

Esta observação reflete os efeitos das camadas de polímeros adsorvidas na estabilidade das dispersões coloidais: acima de uma concentração polimérica crítica, onde é obtida uma completa cobertura da superfície das partículas pelo polímero adsorvido, a repulsão estérica das camadas adsorvidas opõe-se fortemente às interações atrativas de van der Waals entre as partículas. ${ }^{[107]}$ Esta estabilização é altamente sensivel a qualidade do solvente.

Em um bom solvente, como PNIPAM em água a $20^{\circ} \mathrm{C}$, o polímero adsorvido forma um novelo solúvel na camada estendida da superfície, e a superposição dos segmentos de polímero destas camadas é energeticamente desfavorável. A interação entre camadas adsorvidas é então repulsiva. Em um solvente ruim, ocorre o colapso das espiras, levando à precipitação das camadas adsorvidas. A interação atrativa resultante das camadas adsorvidas causa a desestabilização das partículas, afetando a organização durante a secagem. A $40^{\circ} \mathrm{C}$ (acima da LCST), a água é um solvente ruim para o PNIPAM, e a camada polimérica adsorvida colapsa.

A Tabela 10 mostra que os valores obtidos para a espessura da camada de polímero adsorvido são maiores em PCS (meio aquoso) do que em TEM (vácuo). Isto pode ser explicado pelo modelo de adsorção polimérico proposto por Scheutjens and Fleer. ${ }^{[108]}$ Neste modelo a conformação das cadeias adsorvidas foi calculada considerando o volume das cadeias poliméricas e a interação entre o solvente e as cadeias. Também são considerados o número e o comprimento 
médio das cadeias, e a distribuição de tamanho de trens, alças e caudas. Em meio aquoso, as moléculas poliméricas do PNIPAM adsorvidas possuem somente parte de seus segmentos na superfície das partículas de sílica formando os trens. Uma fração substancial dos segmentos está protuberante na solução, como alças e caudas.

Quando são submetidas ao vácuo, as estruturas poliméricas colapsam sobre a superfície das partículas de sílica. $O$ maior efeito foi verificado para o PNIPAM com maior massa molar, $1050 \mathrm{Kg} / \mathrm{Mol}$ (Figura 81). Com maior número de segmentos na sua cadeia, a redução na espessura foi de $91 \mathrm{~nm}$, ou seja $70 \%$. Para o PNIPAM com massa molar de $190 \mathrm{Kg} / \mathrm{Mol}$ a redução de espessura foi de $14 \mathrm{~nm}$, $40 \%$. O PNIPAM com $90 \mathrm{Kg} / \mathrm{Mol}$ não apresentou uma redução de espessura dentro do erro experimental.

\subsection{Adsorção de surfactantes}

5.4.1. Adsorção de SDS - Os mapas elementares de carbono das Figuras 88,90 e 92 mostraram que as cadeias $\mathrm{CH}_{3}\left(\mathrm{CH}_{2}\right)_{11} \mathrm{SO}_{4}^{-}$são adsorvidas na superfície das partículas de sílica, não sendo detectadas no seu interior. O aumento da concentração de SDS aumenta a presença das destas cadeias depositadas ao redor das partículas após a secagem. Os mapas de sódio destas figuras mostraram que $\circ \mathrm{Na}^{+}$foi sorvido no interior das partículas de sílica, distribuído de forma heterogênea, e sua concentração também aumenta com o aumento da concentração de SDS.

Em todas as concentrações de SDS utilizadas foram observados depósitos, com formato irregular, distribuídos em algumas regiões sobre o substrato. Os mapas elementares mostram que estes depósitos possuem considerável quantidade de carbono, devido a presença das cadeias $\mathrm{CH}_{3}\left(\mathrm{CH}_{2}\right)_{11} \mathrm{SO}_{4}{ }^{-}$, porém não possuem quantidades de sódio significativamente superiores às do fundo. 
5.4.2. Adsorção de CTAB - Os mapas elementares de carbono das Figuras 95,97 e 99 mostraram que as cadeias $\mathrm{CH}_{3}\left(\mathrm{CH}_{2}\right)_{15} \mathrm{~N}\left(\mathrm{CH}_{3}\right)_{3}{ }^{+}$são adsorvidas na superfície das partículas de sílica, não sendo detectadas no seu interior. Mesmo as partículas de sílica sendo negativas, os mapas de $\mathrm{Br}^{-}$destas figuras mostraram que o $\mathrm{Br}^{-}$foi sorvido no interior das partículas, distribuído de forma heterogênea, e sua concentração aumenta com o aumento da concentração de CTAB, de forma análoga ao que foi observado no SDS. Isto pode ser atribuído aos seguintes fatores: 1) imiscibilidade das cadeias hidrofóbicas na partícula intumescida; 2) exclusão das cadeias do interior dos poros intumescidos, devido às suas dimensões.

Em todas as concentrações de CTAB utilizadas também foram observados depósitos sobre o substrato, localizados preferencialmente ao redor dos agregados das partículas. Os mapas elementares mostraram que estes depósitos possuem considerável quantidade de carbono, devido a presença das cadeias $\mathrm{CH}_{3}\left(\mathrm{CH}_{2}\right)_{15} \mathrm{~N}\left(\mathrm{CH}_{3}\right)_{3}{ }^{+}$, porém não possuem quantidades significativas de bromo.

5.4.3. Adsorção de RENEX 300 - Os mapas elementares de carbono das Figuras 103 a 105 mostraram que as cadeias de $\mathrm{HO}\left(\mathrm{C}_{2} \mathrm{H}_{4} \mathrm{O}\right)_{30} \mathrm{C}_{15} \mathrm{H}_{23} \mathrm{O}$ são adsorvidas na superfície das partículas de sílica, não sendo detectadas no seu interior. O aumento da concentração de RENEX aumenta a presença destas cadeias depositadas ao redor das partículas após a secagem. A concentração de depósitos de $\mathrm{HO}\left(\mathrm{C}_{2} \mathrm{H}_{4} \mathrm{O}\right)_{30} \quad \mathrm{C}_{15} \mathrm{H}_{23} \mathrm{O}$ no substrato, ao redor dos aglomerados de partículas aumenta com a concentração de RENEX. 


\section{CONCLUSÕES}

Sorção de ions: a partir das soluções de $\mathrm{NaCl}$ os íons $\mathrm{Na}^{+}$e $\mathrm{Cl}^{-}$, independentemente do sinal de sua carga elétrica, foram sorvidos no interior das partículas negativas de sílica $(\zeta=-46 \mathrm{mV})$. $\mathrm{O}$ aumento da concentração de $\mathrm{NaCl}$ resulta, após a secagem das dispersões, na deposição de agregados de partículas mais densos e descontínuos, com superposição de partículas em algumas regiões.

Sorção de PNIPAM: O aumento da concentração de PNIPAM, abaixo da temperatura crítica, resulta na deposição de partículas de forma cada vez menos associada. A organização das partículas durante a secagem depende da repulsão das cadeias poliméricas adsorvidas. Acima da temperatura crítica o polímero se precipitou nas superfícies das partículas, permitindo uma maior aproximação entre elas. Nas amostras preparadas usando PNIPAM com diferentes massas molares, os mapas elementares de carbono mostraram um significativo aumento da espessura dos polímeros adsorvidos com o número de segmentos das cadeias. Com a remoção do solvente foi observado o colapso da estrutura do polímero adsorvido.

Sorção de surfactantes: Os surfactantes iônicos SDS e CTAB, como o não-iônico RENEX $300{ }^{\circledR}$, foram adsorvidos somente na superfície das partículas, não sendo detectados no seu interior. As amostras preparadas na presença de concentrações 
maiores de surfactantes apresentaram uma maior quantidade de surfactante ao redor das partículas e se depositaram de forma menos associada. No caso dos surfactantes iônicos, as micelas depositadas no substrato não acumulam contraíons, que independentemente do sinal da carga elétrica, são encontrados no interior das partículas.

Os resultados de sorção de íons e adsorção de polímeros e surfactantes mostraram a potencialidade das nanopartículas de sílica serem utilizadas como transportadoras de co-solutos em diferentes aplicações. A alta estabilidade coloidal destas partículas de sílica permite que sejam estabilizados, e assim transportados, co-solutos pouco solúveis, como certos medicamentos injetáveis, fertilizantes e reagentes insolúveis para reação em dispersão. 


\section{CONSIDERAÇÕES FINAIS}

A manufatura de materiais cerâmicos e vítreos baseados em silica já era realizada de modo empírico há milhares de anos. Hoje, por causa de sua vasta utilização tecnológica, ${ }^{[109,110,111,112,113]}$ a sílica está sujeita a um contínuo e detalhado escrutínio que revela novas propriedades e aspectos. Isto tem ocorrido principalmente na escala nanométrica, onde a interação entre nanopartículas e moléculas do meio é diferente de corpos em escala macroscópica, sendo causado pela alta razão superfície-volume das nanopartículas e materiais nanoporosos. A sílica, como outros materiais nanoparticulados, apresenta propriedades ópticas, magnéticas, elétricas e químicas diferenciadas das propriedades do mesmo material na forma macroscópica.

Nesta tese foi mostrado que monolitos de sílica nanoparticulada, formados a partir da secagem de dispersões em umidade e temperatura ambiente, apresentam variação na sua dureza e tenacidade à fratura que mostram valores interessantes para algumas aplicações. Revestimentos vítreos e monolitos de sílica nanopartículada podem ser preparados sem necessidade de temperaturas elevadas, sendo provável que as nanopartículas possam também ser moldáveis por compressão a frio.

Outra aplicação de nanopartículas que tem sido largamente investigada é a fabricação de supra-partículas incluindo mais que um componente coloidal, ou introduzindo modificações nas interações partícula-partícula, produzindo compósitos funcionalizados. Em diferentes campos de aplicações, como biologia, 
medicina, farmacologia, eletrônica e outros, ${ }^{[114,115,116,117]}$ é observado o interesse na fabricação e caracterização de nanopartículas com estrutura casca-caroço ${ }^{[18,119}$, 120,121] e compósitos com partículas coloidais. ${ }^{[122,123,124,125,126,127]}$ Por outro lado, ainda são poucos os trabalhos na literatura usando técnicas para a observação direta dos produtos de sorção em nanopartículas, com resolução espacial nanométrica. Atualmente o número de trabalhos na Web of Science com as palavras de busca "EELS" e "particles" é menor que 100, e há apenas 50 com as palavras "ESI" e "particles". Incluindo a palavra "sílica" são apenas 3 trabalhos, ${ }^{[128,129,130]}$ sendo que dois são contribuições deste grupo.

Nesta tese, foi realizada a observação direta dos produtos de sorção, utilizando-se um modelo para a quantificação relativa dos elementos. Essa perspectiva abre caminho para a análise quantitativa absoluta, a partir da determinação das características dos elementos analisados, como seção de choque do elemento em função da energia do elétrons do feixe incidente, e dos parâmetros de aquisição, como intensidade do feixe, ângulo de incidência e outros. 


\section{REFERÊNCIAS BIBLIOGRÁFICAS}

1 - BJELOPAVLIC, M.; SINGH, P.K.; EL-SHALL, H.; MOUDGIL, B.M. Role of surface molecular architecture and energetics of hydrogen bonding sites in adsorption of polymers and surfactants. J. Coll. Interface Sci., v.226, p.159-65, 2000.

2 - KETELSON, H.A.; PELTON, R.; BROOK, M.A. Colloidal stability of Stöber silica in acetone-water mixtures. J. Coll. Interface Sci., v.179, p.600-7, 1996.

3 - KIM, K.S.; KIM, J.K.; KIM, W.S. J. Mater Res., v.16, n.2, p.545, 2001.

4 - DONG. P. Advances in preparation and application of monodisperse colloidal silica particles. Prog. Nat. Sci., v.10, n.8, p.575-84, 2000.

5 - CHANG C.L.; FOGLER H.S. Kinetics of silica particle formation in nonionic W/O microemulsions from TEOS. AlChE J., v.42, n.11, p.3153-63, 1996.

6 - BOGUSH G.H.; ZUKOSKI C.F. Uniform silica particle precipitation - An aggregative growth model. J. Coll. Interface Sci., v.142, n.1, p.19-34, 1991.

7 - JONES L.N. Controlling silica particle-size using sedimentation technique. Adhes. Age, v.24, n.12, p.43-6, 1981.

8 - STÖBER, W.; FINK, A.; BOHN, E. Controlled growth of monodisperse silica spheres in micron size range. J. Coll. Interface Sci., v.26, p.62. 1968.

9 - MATIJEVIC, E. Preparation and properties of uniform size colloids. Chem. Mater, v.5, p.412-26, 1993.

10 - COSTA, C.A.R.; LEITE, C.A.P.; SOUZA, E.F.; GALEMBECK, F. Size effects on the microchemistry and plasticity of Stöber silica particle: A study using EFTEM, FESEM and AFM-SEPM microscopies. Langmuir, v.17, p.189-94, 2001.

11 - LEITE, C.A.P.; SOUZA, E.F.; GALEMBECK, F. Core-and-shell nature of Stöber silica particles. J. Braz. Chem. Soc., v.12, n.4, p.519-25, 2001.

12 - DESPAS, C.; WALCARIUS, A; BESSIERE, J. In situ investigation of the ionization of silica in aqueous ammonia by using a high frequency dielectric method. Talanta, v.45, p.357-69, 1997.

13 - CHEN, SHENG-LI; DONG, P.; YANG, GUANG-HUA; YANG, JIU-JIN. Kinetics of formation of monodisperse colloidal silica particles through the hydrolysis and condensation of tetraethylorthosilicate. Industrial \& Engineering Chemistry Research, v.35, p.4487-93, 1996.

14 - LEE, K.; SATHYAGAL, A.N.; McCORMICK, A.V. A closer look at an aggregation model of Stöber process. Colloids and Surfaces A: Physicochemical and Engineering Aspects, v.144, p.115-25, 1998.

15 - JELINEK, L.; DONG, P.; ROJASPAZOS, C.; TAIBI, H.; KOVATS, E.S. Study of the Stöber reaction. Properties of colloidal silica spheres prepared via alkoxide hydrolysis. Langmuir, v.8, p.2152-64, 1992.

16 - BRINKER, C.J.; SCHERER, G.W. Sol-Gel Science, Academic Press, 1990.

17 - AVNIR, D.; KAUFMAN, V.R. Alcohol is an unnecessary additive in the silicon alkoxide sol-gel process. J. Non Cristalline Solids, v.192, p.180-2, 1987. 
18 - ASSINK, R.A.; KAY, B.D. Sol-gel kinetics. Functional-group kinetics. J. Non Cristalline Solids, v.99, p.359-70, 1988.

19 - ASSINK, R.A.; KAY, B.D. J. Non Cristalline Solids, Sol-gel kinetics. Test of the statistical reaction model. J. Non Cristalline Solids, v.107, p.35-40, 1988.

20 - ILER, R.K. The Chemistry of Silica, Wiley, New York, 1979.

21 - FREUNDLICH, H. Some recent work on gels. J. Phys. Chem., v.41, p.901-10, 1937.

22 - HURD, C.B. Chem. Revs., v.22, p.403-22, 1938.

23 - HURD, C.B.; SMITH, M.D.; WITZEL, F.; GLAMM Jr., A.C. J. Phys. Chem., v.57, p.70, 1952.

24 - BUCKLEY, A.M.; GREENBLATT, M. The sol-gel preparation of silica-gels. J. Chem. Educ., v.71, p.599-602, 1994.

25 - EGERTON, R. F. Electron energy-loss spectroscopy in the electron microscope, ed. Plenum Press, New York, 1986.

26 - JOY, D.C., Principles of analytical electron microscopy, ed. Plenum Press, New York, 1986.

27 - LEITE, C.A.P. Transformações térmicas de argilominerais haloisíticos na faixa de temperatura de $400^{\circ}$ a $1300^{\circ} \mathrm{C}$. Estudo por microscopia e difração de elétrons. São Paulo, 1986. Dissertação (Mestrado) - Instituto de Física, Universidade de São Paulo.

28 - LEITE, CAP; GALEMBECK, F. Nanocrystalline domain identification in gold films, by backscattered electron imaging and energy-filtered transmission electron microscopy, J. Coll. Interf. Sci., v.1, p.235, 2001.

29 - HILLIER, J.; BAKER, R. F. Further developments on the electron microanalyzer. J. Appl. Phys., v.16, p.266, 1945.

30 - COLLIEX, C.; COSSLET, V.E.; LEAPMAN, R. D.; TREBBIA, P. Contribution of electron-energy loss spectroscopy to development of analytical electronmicroscopy. Ultramicroscopy, v.1, p.301-15, 1976.

31 - COLLIEX, C; MANOUBI, T.; KRIVANEK, O. L. EELS in the electronmicroscope - a review of present trends. J. Electron Microsc., v.35, p.307, 1986.

32 - HEYDENREICH, J.; RECHNER, W. Analytical electron-microscopy of materials. Mikrochim. Acta, v.1, p.93-113, 1987.

33 - GERTHSEN, D.; HAHN, E.; ROSENAUER, A.; SCHON, O.; HEUKEN, M.; $\mathrm{RIZZI}$, A. Composition fluctuations in InGaN analyzed by transmission electron microscopy. Phys. Status Solidi A, v.177, p.145-55, 2000.

34 - CASTAING, R.; HENNENQUIN, J.F.; HENRY, L.; SLODZIAN, G. The magnetic prism as an optical system. In Focussing of Charged Particles. Ed. A, Septier, Academic Press, New York, p.265-293, 1967.

35 - HOWIE, A. Proc. $39^{\text {th }}$ Annl. Mtg., ed. G. W. Bailey, Claitor's Publishing, Baton Rouge, Louisiana, p.186, 1981.

36 - SHUMAN, H.; KRUIT, P.; SOMLYO, A.P. Trace-element quantification in ELS. In Analytical Electron Microscopy. Ed. D.B. Williams and D.C. Joy, San Francisco Press, San Francisco, p.77, 1984.

37 - SHUMAN, H.; SOMLYO, A.V.; SOMLYO, A.P. Quantitative electron-probe microanalysis of biological thin-sections. Methods and validity. Ultramicroscopy, v.1, p.317-39, 1976.

38 - JOY, D.; MAHER, D.M. Scanning Electron Microscopy, v.1, p.325-34, 1977.

39 - DEXPERT, H.; LYNCH, J.P.; FREUND, E. Developments in Electron Microscopy and Analysis, Inst. Phys. Conf. Ser., v.61, p.171-4, 1982.

40 - BAZETTJONES, D.P.; OTTENSMEYER, F.P. Phosphorus distribution in the nucleosome Science, v.211, p.169-70, 1981.

41 - JOY, D.C. High spatial resolution ELS microanalysis. Proc. Microsc. Soc. Can., v.9, p.13, 1982. 
42 - ISAACSON, M.S.; UTLAUT, M. On the chemical identification of individual atoms. Ann. Proc. Electron Microsc. Soc. Am., ed. G. W. Bailey, Claitor's Publishing, Baton Rouge, Louisiana, p.524-5, 1979.

43 - EGERTON, R. F. Electron energy-loss spectroscopy for elemental analysis, Phil. Trans. R. Soc. Lond. A, v.305, p.521, 1982.

44 - JEANGUILAUME, C.; TREBBIA, P.; COLLIEX, C. About the use of electron energy-loss spectroscopy for chemical mapping of thin foils with high spatial resolution, Ultramicroscopy, v.3, p.237, 1978.

45 - GOLDSTEIN, J.I.; NEWBURY, D.E.; ECHLIN, P.; JOY, D.C.; ROMIG JR. A.D.; LYMAN, C.E.; FIORI, C.; LIFSHIN, E. Scanning Electron Microscopy and X-Ray Microanalysis, Plenum Press, New York, p.76., 1992.

46 - BINNING, G.; QUATE, C.F.; GERBER, C. Atomic force microscopy. Phys. Ver. Lett., v.56, p.930-3, 1986.

47 - WEAVER, J.M.R.; ABRAHAM, D.W. High-resolution atomic force microscopy potentiometry. J. Vac. Sci. Technol., v.9, p.1559-61, 1991.

48 - TERRRIS, B.D.; STERN, J.E.; RUGAR, D.; MAMIN, H.J. Localized charge force microscopy. J. Vac. Sci. Technol. A, v.8, n.1, p.374, 1990.

49 - BELAIDI, S.; GIRARD, P.; LEVEQUE, G. Electrostatic forces acting on tip in atomic force microscopy: modelization and comparison with analytic expressions. J. Appl. Phys., v.81, n.3, p.1023-30. 1997.

50 - NONNENMACHER, M.; O'BOYLE, M.P.; WICKRAMASINGHE, H.K. Kelvin probe force microscopy. Appl. Phys. Lett., v.58, n.25, p.2921-3, 1991.

51 - SMITH, W.F. Principios de ciência e engenharia dos materiais, McGraw-Hill, Lisboa, 1996.

52 - ASKELAND, D.R. The Science and Engineering of Material. PWS Publishing Company, Boston, 1994.

53 - CALLISTER JR., W.R. Materials science and engineering. An introdution. John Wiley \& Sons, Inc, New York, 1996.

54 - SHACKELFORD, J.F. Introduction to materials science for engineers. PrenticeHall, Inc, New Jersey, 1996.

55 - PARMQVIST, S. Occurrence of crack formation during Vickers indentation as a measure of the tougness of hard metals. Arch. Eisenhuttenwes, v. 33, p. 629-33, 1962 apud ROSENSTIEL, S.F.; PORTER, S.S. Apparent fracture tougness of dental porcelain with a metal substructure. Dent. Mat. v.4, p.187-90, 1988.

56 - LIMA, M.M.; GODOY, C.; AVELAR-BATISTA, J.C.; MODENESI, P.J. Toughness evaluation of HVOF WC-Co coatings using non-linear regression analysis. Materials Science and Engineering, v.357, p.337-45, 2003.

57 - LICHTENBERGER, O.; NEUMANN, D. A study of Si-L and O-K Elnes in plant material: $\mathrm{SiO}_{2}, \mathrm{Ca}$ and $\mathrm{Zn}$ silicate in Minuarti. J. Microscopy, v.183, p.45-52, 1996.

58 - SCHNEIDER, R.; WOLTERSDORF, J.; RÖDER, A. EELS nanoanalysis for investigating both chemical composition and bonding of interlayers in composites. Mikrochimica Acta, v.125, p.361-5, 1997.

59 - DIMONIE, V.L.; EL-AASSER, M.S.; VANDERHOFF, J.W. Polym. Mat. Sci. Eng., v.58, p.821, 1988.

60 - KHOKHLOV, A.R.; KRAMARENKO, E.Y. Weakly charged polyelectrolytes: collapse induced by extra ionization. Macromolecules, v.29, p.681-685, 1996.

61 - GALEMBECK, F.; LIMA, E.C.O.; MASSON, N.C.; MONTEIRO, V.A.R.; SOUZA, E.F. In Fine Particles Sciences and Technology: From Micro to Nanoparticles, Pelizzetti, E., Ed.,Kluwer: Dordrecht, 1996.

62 - TICIANELLI, E.A.; GONZALEZ, E.R. Eletroquímica, Ed. EdUSP, São Paulo, 1998.

63 - WELLS, J.D.; KOOPAL, L.K.; KEIZER, A. Monodisperse, nonporous, spherical silica particles. Colloids Surf., v.166, p.171-6, 2000. 
64 - FLEER, G.J., Thesis, Agricultural University, Wageningen, Netherlands; Meded. Landbouwhogeschool Wageningen, v.71, p.20, 1971.

65 - KOOPAL, L.K., Interference of polymer adsorption from electrical double layer measurements. Wageningen, The Netherlands. 1978. Tese (Doutorado) Agricultural University.

66 - MIYAJIMA, T.; MORI, M.; ISHIGURO, S.; CHUNG, K.H.; MOON, C.H. On the complexation of $\mathrm{Cd}(\mathrm{II})$ ions with polyacrylic acid. J. Colloi. Interf. Sci., v.184, p.27988, 1996.

67 - KITCHENER, J.A.; MUSSELWHITE, P.R. Emulsion Science, P. Sherman Ed., Academic Press, London, 1968.

68 - LANKVELD, J.M.G. Polymer adsorption and its effect on colloidal stability.

Wageningen, The Netherlands1970. Tese (Doutorado) - Agricultural University.

69 - KUZKIN, S.K.; NEBERA, V.P. Synthetic Flocculants in De-watering Processes, Moscow 1963 ( Trans. Nat. Lending Library, Boston, G.B., 1966).

70 - TAJOMA, S. Technol. Reports Kyushu Univ., 30, 2, 1957.

71 - LA MER,V.K.; HEALY, T.W. Adsorption-flocculation reactions of macromolecules at solid-liquid interface. Rev. Pure Appl. Chem, 13, 112, 1963.

72 - SCHEUTJENS, J.M.H.M.; FLEER, M.A.; STUART, M.A.C. End effects in polymer adsorption - a tale of tails. Colloids Surf., v.21, p.285-306, 1986.

73 - TAKAHASHI, A.; KAWAGUCHI, M. The structure of macromolecules adsorbed on interfaces. Adv. Polym. Sci., v.46, p.1-65, 1982.

74 - COSGROVE, T.; CROWLEY, T.L.; RYAN, K.; WEBSTER, J.R.P. The effects of solvency on the structure of an adsorbed polymer layer and dispersion stability. Colloids Surf., v.51, p.255-69, 1990.

75 - LEE, E.M.; THOMAS, R.K.; RENNIE, A.R. Reflection of neutrons from a polymer layer adsorbed at the quartz-water interface. Eurphys. Lett., v.13, p.135$41,1990$.

76 - COHEN STUART, M.A.; WAAJEN, F.H.W.H.; COSGROVE, T.; VINCENT, B.; CROWLEY, T.L. Hydrodynamic thickness of adsorbed polymer layers. Macromolecules, 17, 1825-30, 1984.

77 - FLEER, G.J.; COHEN STUART, M.A.; SCHEUTJENS, J.M.H.M.; COSGROVE, T.; VINCENT, B. Polymers at Interfaces, London, Chapman Hall, p.234-6, 1992.

78 - SCHILD, H.G. Poly(N-isopropylacrylamide) - Experiment, theory and application. Prog. Polym. Sci., v.17, p.163-249, 1992.

79 - HU, T.J.; GAO, J.; WU, C. Temperature induced hydrophobic adsorption and desorption of linear polymer chains on surfactant-free latex nanoparticles. J. Phys. Chem. B, v.106, n.38, p.9815-9, 2002.

80 - ZHANG, J.; PELTON, R. The dynamic behavior of poly( $\mathrm{N}$-isopropylacrylamide) at the air/water interface. Colloids and Surf. A: Physicochem. Eng. Aspects, v.156, p.111-2, 1999.

81 - ZHOU, S.; SHIYAN, F.; AU-YEUNG, S.C.F.; WU, C. Light-scattering-studies of poly( $\mathrm{N}$-isopropylacrylamide) in tetrahydrofuran and aqueous-solution. Polymer, v.36, n.7, p.1341-6, 1995.

82 - ZHU, P.W.; NAPPER, D.H. Volume phase transitions of poly $(\mathrm{N}$ isopropylacrylamide) latex particles in mixed water- $\mathrm{N}, \mathrm{N}$-dimethylformamide solutions. Chem. Phys. Lett., v.256, p.51-6, 1996.

83 - CHEN, G.H.; HOFFMAN, A.H. Bioconjugate Chem., 4, 509, 1993.

84 - YOSHIDA, R.; UCHIDA, K.; KANEKO, Y.; SAKAI, K.; KIKUCHI, A.; SAKURAI, Y.; OKANO, T. Comb-type grafted hydrogels with rapid de-swelling response to temperature-changes. Nature, v.374, p.240-2, 1995.

85 - CHU, L.Y.; PARK, S.H.; YAMAGUCHI, T.; NAKAO, S.I. J. Membrane Sci., v.192, p.27-39, 2001. 
86 - PARK, T.G.; HOFFMAN, A.S. Effect of temperature cycling on the activity and productivity of immobilized beta-galactosidase in a thermally reversible hydrogel bead reactor. Apply. Biochem. Biotech., v.19, p.1-9, 1988.

87 - SCHILD H.G.; TIRRELL D.A. Interaction of poly(N-isopropylacrylamide) with sodium n-alkyl sulfates in aqueous solution. Langmuir, v.7, p.665-71, 1991.

88 - LEE L.T.; Jean B.; Menelle A. Effect of temperature on the adsorption of poly(Nisopropylacrylamide) at the air-solution interface. Langmuir, v.15, p.3267-72, 1999. 89 - HUNTER, R.J. Fundations of collloid science, Clarendon Press, Oxford, 1989.

90 - FUERSTENAU, D.W. The chemistry of biosurfaces, (ed. Hair, M.L.), Marcel

Dekker, New York, v.1, p.143, 1971.

91 - OTTEWILL, R.H. Nonionic Surfactants, ed. Martin J. Schick, Marcel Dekker, New York, 1967.

92 - FURLONG, D.N; ASTON, J.R. Adsorption of polyoxyethylated nonyl phenols at

silica aqueous-solution interfaces. Colloid. Surface., v.4, p.121-9, 1982.

93 - GRAY, G.W.; WINSOR, P.A. Liquid crystals and plastic crystals, Ellis Horwood,

Chichester, UK, and Wiley, New York, v.1 e 2, 1974.

94 - GALEMBECK, F. "O Estado Coloidal",

http://planeta.terra.com.br/educacao/fernagal/pdocumentos3.htm

95 - BOONAMNUAYVITAYA, V.; CHAIYA, C.; TANTHAPANICHAKOON, W.; JARUDILOKKUL, S. Removal of heavy metals by adsorbed prepared from pyrolyzed coffe residues and clay. Separation and Purification Technology, v.35, p.11-2, 2004.

96 - KISLENKO, V.N.; BERLIN, A.A.; MOLDOVANOV, M.A. Mathematical model of kinetics of polymer adsorption onto a solid surface in the diffusional field. Journal of Colloid and Interface Science, v.173, p.128-34, 1995.

97 - GUN'KO, V.M. et al. Aqueous suspensions of fumed silica and adsorption of proteins. Journal of Colloid and Interface Science, v.192, p.166-78, 1997.

98 - MEAR, A.M.; LE SAINT, J.; PRIVAT, M. Asorption mechanisms of carbofuran on silica: structure, kinetics, and solubility influence. Ecotoxicology and enviromental safety, v.35, p.163-73, 1996.

99 - CHU, B.S. et al. Separation of vitamin $\mathrm{E}$ from pal fatty acid distillate using silica. Batch desorption study. Journal of Food Engineering, v.64, p.1-7, 2004.

100 - BAUER, D.; BUCHHAMMER, H.; FUCHS, A.; JAEGER, W.; KILLMANN, E.; LUNKWITZ, K.; REHMET, R.; SCHWARZ, S. Stability of colloidal silica, sikron and polystyrene latex influenced by the adsorption of polycations of different charge density. Colloids Surf., v.156, p.291-305, 1999.

101 - PROBST, W. (LEO-Zeiss Elektronenmikroskopie Gmbh), Comunicação pessoal, 2001.

102 - REIMER, L.; ZEPKE, U.; MOESCH, J.; SCHULZE-HILLERT, St.; ROSSMESSEMER, M.; PROBST, W.; WEIMER, E. A Reference Handbook of Standard Data for Identification and Interpretation of Electron Energy Loss Spectra and for Generation os Electron Spectroscopic Images, Carl Zeiss, Oberkochen, 1992.

103 - NAJI, A.; THOMAS, P.; GHANBAJA, J.; BILLAUD, D. Identification by TEM and EELS of the products formed at the surface of a carbon electrode during its reduction in $\mathrm{MClO}_{4}-\mathrm{EC}$ and $\mathrm{MBF}_{4}-\mathrm{EC}$ electrolytes $(\mathrm{M}=\mathrm{Li}, \mathrm{Na})$. Micron, v.31, p.401-9, 2000.

104 - NAJI, A.; GHANBAJA, J.; WILLMANN, P.; BILLAUD, D. TEM characterization of the passivating layer formed during the reduction of graphite electrodes in selected electrolytes. Journal of Power Sources, v.81, p.207-11, 1999.

105 - SCHNEIDER, R.; WOLTERSDORF, J.; RÖDER, A. EELS nanoanalysis for investigating both chemical composition and bonding of interlayers in composites. Mikrochimica Acta, v. 125, p.361-5, 1997. 
106 - LICHTENBERGER, O.; NEUMANN, D. A study of Si-L and O-K ELNES in plant material: $\mathrm{SiO}_{2}, \mathrm{Ca}-\mathrm{e} \mathrm{Zn}$-silicate in Minuartia. Journal of Microscopy, v.183, p.45-52, 1996.

107 - LUCKHAM, P.F. Interaction between polymer-bearing surfaces, in Polymer Surfaces and Interfaces, W.J. Feast and H.S. Munro, John Wiley, 1987.

108 - SCHEUTJENS, J.M.H.M.; FLEER, G.J., Statistical theory of the adsorption of interacting chain molecules. Train, loop, and tail size distribution. J. Phys. Chem., v.84, p.178-90, 1980.

109 - FLOCH, H. et al. Process for the production of thin films having optical properties. Commissariat a l'Energie Atomique, FR, U.S. Patent 5.639.517, 1997.

110 - VAN ROMPUY, L. et al. Heat sensitive imaging elemental and a method for producing lithographic plates therewith. AGFA-Gevaert, NV, U.S. Patent 5.985.515, 1999.

111 - HARRIS, M.T. et al. Silica powders for powder evacuated thermal insulating panel and method. The United States of America, U.S. Patent 5.480.696, 1996.

112 - VERMEERSCH, J. et al. Method for making a lithographic printing plate involving on press development. AGFA-Gevarert, NV, U.S. Patent 6.110.644, 2000.

113 - GOER, U. et al. Modified rubber powders comprising silicatic fillers prepared from precipitation suspensions, process for their preparation and their use. PKU Pulverkautschuk Union GmbH, U.S. Patent 6.720.369, 2004.

114 - MATIJEVIC, E. Preparation and properties of uniform size colloids. Chem. Mater, v.5, p.412-426, 1993.

115 - DUBOIS, Z.G. et al. Spray compositions. The Procter \& Gamble Company, U.S. Patent 5.843.881, 1998.

116 - FURUSAWA, K.; NAGASHIMA, K.; ANZAI, C. Synthetic process to control the total size and component distribuition of multilayer magnetic composite-particles. Colloid. Polym. Sci., v.272, p.1104-10, 1994.

117 - KO, H.; LEE, H.W.; MOON, J. Fabrication of colloidal self-assembled monolayer (SAM) using monodisperse silica and its use as a lithographic mask. Thin Solid Films, v.447, p.638-44, 2004.

118 - OLDENBURG, S.J. et al. Metal nanoshell. William Marsh Rice University, TX, U.S. Patent 6.685.986, 2004.

119 - OTSUBO, Y.; KAZUYA, E. Electrorheological properties of suspensions of inorganic shell organic core composite-particles. J. Colloid Interf. Sci., v.168, p.230, 1994.

120 - FURUSAWA, K.; KIMURA, Y.; TAGAWA, T. Syntheses of composite polystyrene lattices with silica particles in the core. J. Colloid Interf. Sci., v.109, p.69-76, 1986.

121 - HALLAS, N.J. et al. Partial coverage metal nanoshells and method of making same. William Marsh Rice University, TX, U.S. Patent 6.660.381, 2003.

122 - CHENG, C.M.; MICALE, F.J.; VANDERHOFF, M.S.; EL-AASSER, M.S. Pore structural studies of monodisperse porous polymer particles. J. Colloid. Interf. Sci., v.150, p.549-58, 1992.

123 - FURUSAWA, K.; ANZAI, C. Heterocoagulation behavior of polymer lattices with spherical silica. Colloids Surf., v.63, p.103-11, 1992.

124 - HARDING, R.D. Heterocoagulation in mixed dispersions effect of particle-size, size ratio, relative concentration, and surface potential of colloidal components. $J$. Colloid Interf. Sci., v.40, p.164, 1972.

125 - KAWAHASHI, N.; MATIJEVIC, E. Preparation and properties of uniform coated aolloidal particles. Yttrium basic carbonate on polystyrene latex. J. Colloid Interf. Sci., v.138, p.534-42, 1990. 
126 - BLEIER, A.; MATIJEVIC, E. Heterocoagulation. Interactions of polyvinylchloride latex with ludox HS silica. J. Chem. Soc. Faraday Trans., v.1, n.74, p.1346, 1978.

127 - ZHAO, D.; QIN, W.; WU, C.; QIN, G.; ZHANG, J.; LÜ, S. Laser selective spectroscopy of europium complex embedded in colloidal silica spheres. Chemical Physics Letters, v.388, p.400-5, 2004.

128 - COSTA, C.A.R.; LEITE C.A.P.; GALEMBECK, F. Size dependence of Stober silica nanoparticle microchemistry. Journal of Physycal Chemistry B, v.107, p.4747-55, 2003.

129 - GALEMBECK, F.; DA SILVA, M.D.V.M.; LEITE C.A.P.; COSTA, C.A.R.; GALEMBECK, A. Particle and polymer microchemistry and electric domain mapping. Molecular crystals and liquid crystals, v.374, p.159-66, 2002.

130 - EHRMAN, S.H.; FRIEDLANDER, S.K.; ZACHARIAH, M.R. Characteristics of $\mathrm{SiO}_{2} / \mathrm{TiO}_{2}$ nanocomposite particles formed in a premixed flat flame. J. Aerosol Sci., v.29, p.687-706, 1998. 